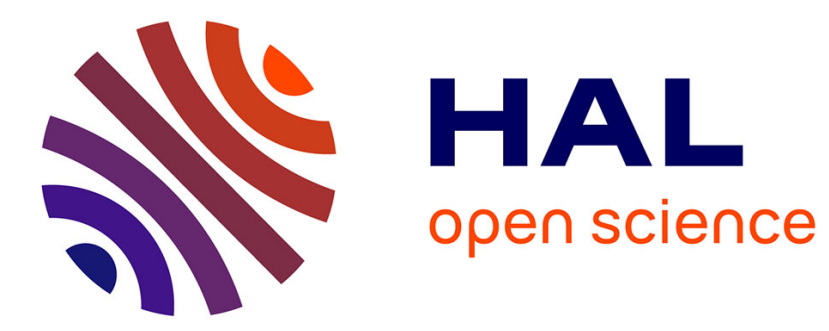

\title{
Effect of early age drying shrinkage on the seismic response of RC Structures
}

\author{
Chaimaa Jaafari
}

\section{To cite this version:}

Chaimaa Jaafari. Effect of early age drying shrinkage on the seismic response of RC Structures. Civil Engineering. Université de Lyon, 2020. English. NNT : 2020LYSEI113 . tel-03208861

\section{HAL Id: tel-03208861 https://theses.hal.science/tel-03208861}

Submitted on 26 Apr 2021

HAL is a multi-disciplinary open access archive for the deposit and dissemination of scientific research documents, whether they are published or not. The documents may come from teaching and research institutions in France or abroad, or from public or private research centers.
L'archive ouverte pluridisciplinaire HAL, est destinée au dépôt et à la diffusion de documents scientifiques de niveau recherche, publiés ou non, émanant des établissements d'enseignement et de recherche français ou étrangers, des laboratoires publics ou privés. 


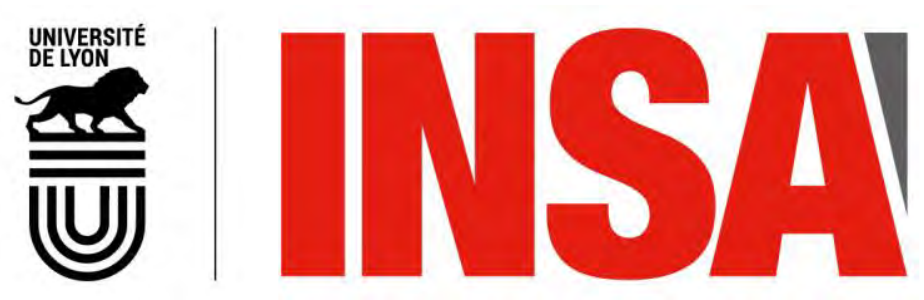

$\mathrm{N}^{\circ} \mathrm{d}^{\prime}$ ordre NNT : 2020LYSEI 113

THESE de DOCTORAT DE L'UNIVERSITE DE LYON opérée au sein de

( I NSA Lyon)

Ecole Doctorale $\mathrm{N}^{\circ} 162$

( MÉCANI QUE, ENERGÉTI QUE, GÉNI E CI VI L, ACOUSTI QUE DE LYON)

\section{Génie Civil}

Soutenue publiquement le 27/11/2020, par :

Chaimaa J aafari

\section{Effect of early age drying shrinkage on the seismic response of RC Structures}

Devant le jury composé de :

$\begin{array}{llll}\text { DARQUENNE Aveline } & \text { Professeur des Universités } & \text { INSA Rennes } & \text { Présidente } \\ \text { DAVENNE Luc } & \text { Professeur des Universités } & \text { Université Paris Nanterre } & \text { Rapporteur } \\ \text { CANDIA Gabriel } & \text { Associate Professor } & \text { Universidad Del Desarollo } & \text { Rapporteur } \\ \text { RICHARD Benjamin } & \text { HDR Ingénieur } & \text { IRSN } & \text { Examinateur } \\ \text { DJERAN MAIGRE Irini } & \text { Professeur des Universités } & \text { INSA Lyon } & \text { Examinatrice } \\ \text { GRANGE Stéphane } & \text { Professeur des Universités } & \text { INSA Lyon } & \text { Directeur de thèse } \\ \text { BERTRAND David } & \text { Maître de Conférences } & \text { INSA Lyon } & \text { Encadrant } \\ \text { DELHOMME, Fabien } & \text { Maître de Conférences } & \text { INSA Lyon } & \text { Encadrant }\end{array}$




\section{Département FEDORA - INSA Lyon - Ecoles Doctorales - Quinquennal 2016-2020}

\begin{tabular}{|c|c|c|}
\hline SIGLE & ECOLE DOCTORALE & NOM ET COORDONNEES DU RESPONSABLE \\
\hline CHIMIE & $\begin{array}{l}\text { CHIMIE DE LYON } \\
\text { http://www.edchimie-lyon.fr } \\
\text { Sec. : Renée EL MELHEM } \\
\text { Bât. Blaise PASCAL, 3e étage } \\
\text { secretariat@edchimie-lyon.fr } \\
\text { INSA : R. GOURDON }\end{array}$ & $\begin{array}{l}\text { M. Stéphane DANIELE } \\
\text { Institut de recherches sur la catalyse et l'environnement de Lyon } \\
\text { IRCELYON-UMR } 5256 \\
\text { Équipe CDFA } \\
2 \text { Avenue Albert EINSTEIN } \\
69626 \text { Villeurbanne CEDEX } \\
\text { directeur@edchimie-lyon.fr }\end{array}$ \\
\hline E.E.A. & $\begin{array}{l}\text { ÉLECTRONIQUE, } \\
\text { ÉLECTROTECHNIQUE, } \\
\text { AUTOMATIQUE } \\
\text { http://edeea.ec-lyon.fr } \\
\text { Sec. : M.C. HAVGOUDOUKIAN } \\
\text { ecole-doctorale.eea@ec-lyon.fr }\end{array}$ & $\begin{array}{l}\text { M. Gérard SCORLETTI } \\
\text { École Centrale de Lyon } \\
\text { 36 Avenue Guy DE COLLONGUE } \\
\text { 69 134 Écully } \\
\text { Tél : 04.72.18.60.97 Fax 04.78.43.37.17 } \\
\text { gerard.scorletti@ec-lyon.fr }\end{array}$ \\
\hline E2M2 & $\begin{array}{l}\text { ÉVOLUTION, ÉCOSYSTÈME, } \\
\text { MICROBIOLOGIE, MODÉLISATION } \\
\text { http://e2m2.universite-lyon.fr } \\
\text { Sec. : Sylvie ROBERJOT } \\
\text { Bât. Atrium, UCB Lyon } 1 \\
\text { Tél : 04.72.44.83.62 } \\
\text { INSA : H. CHARLES } \\
\text { secretariat.e2m2@univ-lyon1.fr }\end{array}$ & $\begin{array}{l}\text { M. Philippe NORMAND } \\
\text { UMR } 5557 \text { Lab. d'Ecologie Microbienne } \\
\text { Université Claude Bernard Lyon } 1 \\
\text { Bâtiment Mendel } \\
\text { 43, boulevard du } 11 \text { Novembre } 1918 \\
\text { 69 } 622 \text { Villeurbanne CEDEX } \\
\text { philippe.normand@univ-lyon1.fr }\end{array}$ \\
\hline EDISS & $\begin{array}{l}\text { INTERDISCIPLINAIRE } \\
\text { SCIENCES-SANTÉ } \\
\text { http://www.ediss-lyon.fr } \\
\text { Sec. : Sylvie ROBERJOT } \\
\text { Bât. Atrium, UCB Lyon } 1 \\
\text { Tél : 04.72.44.83.62 } \\
\text { INSA : M. LAGARDE } \\
\text { secretariat.ediss@univ-lyon1.fr }\end{array}$ & $\begin{array}{l}\text { Mme Sylvie RICARD-BLUM } \\
\text { Institut de Chimie et Biochimie Moléculaires et Supramoléculaires } \\
\text { (ICBMS) - UMR 5246 CNRS - Université Lyon } 1 \\
\text { Bâtiment Curien - 3ème étage Nord } \\
\text { 43 Boulevard du } 11 \text { novembre } 1918 \\
\text { 69622 Villeurbanne Cedex } \\
\text { Tel : +33(0)4 } 72448232 \\
\text { sylvie.ricard-blum@univ-lyon1.fr }\end{array}$ \\
\hline INFOMATHS & $\begin{array}{l}\text { INFORMATIQUE ET } \\
\text { MATHÉMATIQUES } \\
\text { http://edinfomaths.universite-lyon.fr } \\
\text { Sec. : Renée EL MELHEM } \\
\text { Bât. Blaise PASCAL, 3e étage } \\
\text { Tél : 04.72.43.80.46 } \\
\text { infomaths@univ-lyon1.fr }\end{array}$ & $\begin{array}{l}\text { M. Hamamache KHEDDOUCI } \\
\text { Bât. Nautibus } \\
\text { 43, Boulevard du } 11 \text { novembre } 1918 \\
\text { 69 622 Villeurbanne Cedex France } \\
\text { Tel : 04.72.44.83.69 } \\
\text { hamamache.kheddouci@univ-lyon1.fr }\end{array}$ \\
\hline Matériaux & $\begin{array}{l}\text { MATÉRIAUX DE LYON } \\
\text { http://ed34.universite-lyon.fr } \\
\text { Sec. : Stéphanie CAUVIN } \\
\text { Tél : 04.72.43.71.70 } \\
\text { Bât. Direction } \\
\text { ed.materiaux@insa-lyon.fr }\end{array}$ & $\begin{array}{l}\text { M. Jean-Yves BUFFIÈRE } \\
\text { INSA de Lyon } \\
\text { MATEIS - Bât. Saint-Exupéry } \\
7 \text { Avenue Jean CAPELLE } \\
69621 \text { Villeurbanne CEDEX } \\
\text { Tél : 04.72.43.71.70 Fax : 04.72.43.85.28 } \\
\text { jean-yves.buffiere@insa-lyon.fr }\end{array}$ \\
\hline MEGA & \begin{tabular}{|l} 
MÉCANIQUE, ÉNERGÉTIQUE, \\
GÉNIE CIVIL, ACOUSTIQUE \\
http://edmega.universite-lyon.fr \\
Sec. : Stéphanie CAUVIN \\
Tél : 04.72.43.71.70 \\
Bât. Direction \\
mega@insa-lyon.fr
\end{tabular} & $\begin{array}{l}\text { M. Jocelyn BONJOUR } \\
\text { INSA de Lyon } \\
\text { Laboratoire CETHIL } \\
\text { Bâtiment Sadi-Carnot } \\
\text { 9, rue de la Physique } \\
\text { 69 621 Villeurbanne CEDEX } \\
\text { jocelyn.bonjour@insa-lyon.fr }\end{array}$ \\
\hline ScSo & $\begin{array}{l}\text { ScSo* } \\
\text { http://ed483.univ-lyon2.fr } \\
\text { Sec. : Véronique GUICHARD } \\
\text { INSA : J.Y. TOUSSAINT } \\
\text { Tél : 04.78.69.72.76 } \\
\text { veronique.cervantes@univ-lyon2.fr }\end{array}$ & $\begin{array}{l}\text { M. Christian MONTES } \\
\text { Université Lyon } 2 \\
\text { 86 Rue Pasteur } \\
69 \text { 365 Lyon CEDEX } 07 \\
\text { christian.montes@univ-lyon2.fr }\end{array}$ \\
\hline
\end{tabular}




\section{Remerciements}

Plusieurs personnes ont joué un rôle phare dans l'aboutissement de ce travail de thèse considérable qui a duré trois années. Je voudrai saisir l'occasion pour les remercier.

Tout d'abord, je tiens à remercier mes encadrants de thèse: Stéphane Grange, David Bertrand et Fabien Delhomme. Leur encadrement exemplaire et continu le long de ces trois années a eu un rôle important dans la réussite de ce projet. Ils étaient toujours présents pour répondre à mes questions et interrogations, me conseiller et m'encourager. Ils m'ont également fait confiance dans mes choix.

Ensuite, un grand merci à Jean François Georgin, Tina Guillot et Elodie Prudhomme qui m'ont été d'une aide précieuse sur la partie THC et matériau.

Un grand merci également à Nicolas Tardif du Laboratoire LAMCOS de l'INSA de Lyon et à ses doctorants Nicolas Jacquet et Thomas Jailin ainsi qu'à Philippe Chaudet, pour le temps qu'ils m'ont accordé et pour leurs réponses à mes diverses interrogations concernant la corrélation d'image 2D.

Un grand merci à Emeric Bruyere et Romain Trunfio avec qui j'ai eu l'occasion de travailler pendant une grande partie de ma thèse pour le développement des essais pseudodynamiques et leur validation sur la dalle d'essai Eiffel du laboratoire. Merci du temps que vous m'avez accordé, de votre confiance et de votre aide.

Je tiens également à remercier Eric Augeard, Nouredinne Chateur et mes étudiants de Pirds Alexandre Granet, Sarah Bareigts, Linon Dubedat, Sara Ballesteros et Dingcheng Xie.

Un grand merci à Laurent Baillet et Philippe Gueguen d'ISTERRE (Institut des Sciences de la Terre de Grenoble) qui ont accepté de se déplacer à plusieurs reprises à Lyon pour la réalisation de mesures de bruit de fond.

Je remercie également Jean Philippe Maheraut, Luis Gonzales Garcia et Thierry Guerrero de la société Quadric qui nous ont permis d'instrumenter les portiques par fibre optique. Je vous remercie pour votre aide et disponibilité.

Par ailleurs, j'ai eu l'occasion d'échanger lors des étapes de développement de mon projet de thèse avec des experts nationaux et internationaux en dynamique non-linéaire des structures (Pr. Jacky Mazars (3SR, Grenoble), Pr. Patrick Paultre (Université de Sherbrooke), Dr. Pierre Pegon (ISPRA, Italie)) qui nous ont rendu visite au laboratoire. Je tiens à les remercier pour avoir bien voulu nous apporter aides et conseils de grande qualité.

Je remercie par ailleurs l'ensemble du personnel du laboratoire GEOMAS ainsi que les différents doctorants et collègues de bureau, avec qui j'ai pu passer des moments très 
agréables, toujours dans la bonne humeur et la convivialité. Janet, Nour, Thomas, Adnane, Atefeh, Rosie, Nicole, José, un grand merci !

Un grand merci à l'ensemble des enseignants du département Génie Civil et Urbanisme de l'INSA de Lyon et à leur tête Madame Sylvie Barraud.

Enfin, mille merci à mes parents et frères. Je pense que des remerciements ne sauraient exprimer à quel point je suis reconnaissante pour tout ce que vous avez fait pour moi. Vous m'avez toujours accompagné, écouté et aidé. Un grand merci pour tous vos sacrifices. Je ne vous dédie pas cette thèse car elle vous appartient déjà, je nous félicite plutôt pour notre nouvel accomplissement. 


\section{Résumé}

Les structures en béton armé s'endommagent au cours de leur vie à cause de plusieurs facteurs : conditions thermiques, attaques chimiques, retrait, fluage, carbonatation, corrosion, etc. Ce processus d'endommagement débute dès les premiers jours de la vie de l'ouvrage et continue lors de son vieillissement. L'endommagement au jeune âge peut influencer significativement le comportement dynamique des structures en béton armé. En effet, la fréquence propre d'une structure, qui constitue un paramètre de dimensionnement, peut être fortement réduite à cause de cet endommagement. Afin de déterminer l'influence de l'endommagement dû aux effets du jeûne âge (0 à 28 jours) sur la réponse sismique d'une structure en béton armé, ce travail de thèse a combiné à la fois modélisations numériques et essais pseudo-dynamiques sur deux groupes de portiques en béton armé. Le premier groupe a été gardé en conditions endogènes (échanges hydriques avec l'extérieur empêchés) durant le jeune âge afin de limiter les effets du retrait de séchage (fissuration). Le second groupe a quant à lui été gardé en conditions non-endogènes (échange d'eau avec le milieu extérieur possible) similaires aux conditions de chantier, ce qui a induit un endommagement initial (fissurations) dû notamment à un retrait de séchage plus important. Les deux types de portiques ont été soumis à la fin de leur jeune âge au même chargement sismique au moyen d'essais pseudo-dynamiques. D'une part, ce manuscrit présente les résultats expérimentaux obtenus à travers la réalisation d'essais pseudodynamiques afin d'évaluer le comportement dynamique des portiques face à un séisme d'intensité modérée. Les structures ont été instrumentées en utilisant de la fibre optique, des capteurs de déplacement et de force ainsi que des vélocimètres et de la corrélation d'image. D'autre part, le modèle numérique en poutres multifibres qui a été développé pour les portiques et qui permet de suivre l'évolution de leur endommagement au jeune âge et de déterminer leur réponse lorsqu'ils sont soumis à un accident sismique est présenté. Dans ce modèle numérique, le retrait et les déformations thermiques du béton sont calculés avant d'être réinjectés dans un modèle d'endommagement couplé permettant de tenir compte des effets de fluage et de déformations mécaniques. Le modèle numérique a été validé en comparant ses résultats à ceux obtenus expérimentalement, ce qui a permis d'évaluer l'évolution de fréquences propres des deux types de structures au jeune âge ainsi que de quantifier leur différence de comportement dans le domaine non-linéaire. Les travaux menés dans le cadre de cette thèse ont donc permis de proposer un modèle complet pour les structures en béton armé qui peut être utilisé afin de suivre l'évolution de leur endommagement allant de leur réalisation à l'application d'un accident sismique et de quantifier leur vulnérabilité sismique.

\section{Mots-clés}

Jeûne Age, Retrait de séchage, Essais Pseudo-dynamiques, Béton Armé, Réponse sismique, Modélisation en Elements Finis Multifibres, Monitoring, Vulnérabilité sismique. 


\section{Abstract}

Reinforced Concrete (RC) structures get damaged over time due to many factors: thermal conditions, chemical attacks, shrinkage, creep, carbonation, corrosion, etc. This damaging process starts at early-age and continues with structure aging. Early age damage can have a significant impact on the dynamic behavior of reinforced concrete structures. In fact, the natural frequency of a structure, which is a design parameter can be highly reduced due to this damage. In order to quantify the impact of early-age damage (0 to 28 days) on the seismic response of a reinforced concrete structure, this thesis combined both numerical modeling and pseudo-dynamic tests on two types of RC portal frames. The first one was kept in endogenous conditions (water exchange with the surrounding environment was prevented) during its early age period in a way to limit drying effects leading to cracks. As for the second one, it was kept in non-endogenous conditions (possibility of water exchange with the surrounding environment) similar to construction site conditions, which induced an initial damage (cracks apparition) due to a more important drying shrinkage. Both types of RC portal frames were subjected after their early age period to the same seismic loading using pseudodynamic tests. On the one hand, this manuscript presents the experimental results obtained through the use of pseudodynamic tests in order to evaluate the behavior of the two types of RC structures under a moderate intensity earthquake. The structures were instrumented using optical fiber sensors, displacement and load sensors, velocimeters and monitored using Digital Image Correlation. On the other hand, the enhanced multifiber beam model that was developed for the portal frames in order to follow their early age damage and to determine their static and dynamic behavior while accounting for their early age effects is presented. In this numerical model, shrinkage and concrete thermal deformations are calculated and then introduced as inputs of a coupled damage model accounting for creep and mechanical deformations. Such model was validated by comparing its results to the ones obtained experimentally, which made it possible to evaluate the evolution of frequency content of the two types of structures during early age and to quantify their difference of behavior in the non-linear domain. Work conducted within this thesis thus allowed proposing a complete model for reinforced concrete structures that can be used in order to follow their damage evolution from casting until being subjected to a seismic load and to quantify their seismic vulnerability.

\section{Keywords}

Early age, Drying Shrinkage, Pseudo-Dynamic testing, Reinforced Concrete, Seismic Response, Multifiber Finite Element modeling, Monitoring, Seismic vulnerability. 


\section{Résumé étendu en Français}

\section{Contexte}

L'année 2018 a été marquée par l'effondrement du pont Morandi (en béton armé) en Italie causant plusieurs morts. Cet évènement dramatique nous rappelle que lors de leur vieillissement, les structures en béton armé s'endommagent et deviennent plus vulnérables. Cet endommagement commence dès le jeune âge et continue au cours de la vie de l'ouvrage. Il peut être causé par plusieurs facteurs [1]: le fluage, le retrait, la corrosion les déformations thermiques et la carbonatation. Il a pour conséquence de rendre la structure plus vulnérable vis à vis des chargements permanents ou d'exploitation qu'elle doit supporter ou encore vis à vis de certains chargements accidentels tels que les séismes et impacts. Cette thèse traite plus particulièrement de l'effet de l'endommagement initial qui a lieu lors du jeune âge (0 à 28 jours) sur la réponse sismique des structures en béton armé. En effet, les codes de dimensionnement des structures en béton armé vis à vis du risque sismique [2] [3] actuellement en vigueur ne traitent pas de ce sujet. Ainsi, les effets du jeune âge sur les performances dynamiques des structures en béton armé doivent être quantifiés. Plus particulièrement, l'effet du retrait de séchage sur la réponse dynamique des structures en béton armé est étudié dans cette thèse.

\section{Objectifs et Méthodologie}

Les objectifs de cette thèse sont de quantifier expérimentalement les effets du retrait de séchage au jeune âge sur la réponse sismique de structures en Béton Armé (BA), de proposer et de valider un modèle numérique (en le confrontant aux résultats expérimentaux) capable de reproduire leur comportement statique et dynamique sous séisme tout en prenant en compte l'évolution de leur endommagement au jeune âge.

Tout d'abord, une campagne expérimentale a été menée sur portiques en BA qui ont été coulés et durci dans des conditions différentes au jeune âge avec un groupe de référence dit "endogène" dans lequel le retrait de séchage est freiné et un groupe dit "non-endogène" dans lequel le retrait de séchage n'est pas freiné. A la fin de la phase de jeune âge, les différents portiques ont été soumis à des essais statiques cycliques et des essais Pseudo-Dynamiques (PsD) [4, permettant d'obtenir leur réponse dynamique sous sollicitation sismique, afin de quantifier leur différence de comportement. Ensuite, un modèle enrichi de type multifibres a été développé pour chaque groupe. Ce modèle permet de suivre l'évolution de l'endommagement au jeune âge due au retrait, aux déformations thermiques et au fluage, et d'évaluer leur réponse vis-à-vis de sollicitations statiques ou dynamiques.

Le modèle repose sur une approche Thermo-Hygro Chimique (THC) développée au sein du laboratoire GEOMAS de l'INSA de Lyon [5] et basée sur les travaux de Buffo Lacarrière [6], Mainguy [7] et Coussy [8]. En outre, ce modèle utilise 3 modules viscoélastiques de type Kelvin Voigt afin de simuler le fluage ([9] [10]) ainsi que le $\mu$ modèle pour tenir compte de l'endommagement du béton [11]. Les résultats expérimentaux issus des essais cycliques et PsD ont été comparés aux résultats numériques afin de valider le modèle 
proposé.

Cette thèse est constituée de quatre chapitres:

- Dans le chapitre 1, un état de l'art sur l'endommagement des structures en béton armé est proposé: les causes de l'endommagement, les modèles existants permettant de simuler cet endommagement (modèle THC, modèle de fluage, modèle mécanique d'endommagement de type Mazars, etc.) ainsi que les recherches antérieures menées sur le sujet. Une revue bibliographique des techniques numériques qui sont utilisées afin de simuler le comportement des portiques en béton armé étudiés est présentée (Principe de résolution de la méthode des Eléments finis, les éléments multifibres de type Timoshenko avec enrichissement de la loi de comportement, analyses pushover, analyse modale, analyse spectrale et analyse non-linéaire dynamique). De plus, un état de l'art sur la technique pseudo-dynamique est également proposé. Par ailleurs, le principe des techniques d'instrumentation employées est explicité (Capteurs de force et de déplacement, corrélation d'image, mesures de bruits de fond et mesures par fibre optique).

- Le chapitre 2 présente le protocole expérimental, ainsi que les résultats associés, qui a été adopté afin d'étudier les effets du retrait de séchage sur l'évolution de l'endommagement au jeune âge ainsi que la réponse statique et dynamique des deux couples de portiques. Un premier groupe a été conservé en conditions endogènes lors du jeune âge (les échanges hydriques avec l'environnement extérieur ont été limités en recouvrant les portiques de cellophane de manière à réduire le retrait de séchage). Un second groupe de portiques (composé de deux portiques) a été gardé en conditions non-endogènes (portiques non protégés et donc échanges hydriques possibles). A la fin du jeune âge (28 jours) un portique de chaque groupe a été soumis à un essai statique cyclique afin de déterminer sa réponse statique non-linéaire. Durant les essais statiques cycliques, les portiques ont été instrumentés en utilisant des capteurs de déplacement (LVDT) et de force (type galette). Les deux autres portiques (un de chaque groupe) ont été suivi durant leur jeune âge en utilisant des vélocimètres (bruits de fond) et de la fibre optique (afin de suivre leur évolution de fréquence propre et d'endommagement). Ensuite, à la fin de leur jeune âge, ils ont été testés en utilisant la technique pseudo-dynamique afin de comparer leur réponse dynamique non-linéaire sous séisme modéré. Durant les essais pseudo-dynamiques, les portiques ont été instrumentés en utilisant des vélocimètres, capteurs de déplacement et capteurs de force. Un suivi par corrélation d'image des champs de déplacement à la surface des portiques a en outre été réalisé [12] [13].

Les essais ont montré une différence de raideur entre les deux structures (la raideur initiale du portique endogène obtenue expérimentalement est quatre fois plus importante que celle du portique non-endogène). Par ailleurs, les essais pseudo-dynamiques qui ont été réalisés sur les deux types de portiques ont également montré une différence de comportement en terme de déplacement et d'efforts au cours du temps. La courbe force en fonction du déplacement révèle que le déplacement maximum 
atteint par le portique non-endogène est $33 \%$ plus élevé que celui atteint par le portique endogène (Figure 11). La corrélation d'image a permis de suivre les distributions de fissures lors du chargement dynamique et a montré que les fissures se sont principalement manifestées au niveau des noeuds d'ossature pour les deux types de portiques. Par ailleurs, les mesures de bruits de fond ont montré une chute de fréquence plus importante dans le portique non-endogène par rapport au portique endogène.

- Dans le chapitre 3, le modèle numérique basé sur des éléments finis poutres multifibres couplés à une loi de comportement enrichie (prise en compte du retrait, fluage, déformations thermiques et de l'endommagement mécanique) est présenté et ses résultats sont comparés aux résultats expérimentaux pour validation. Le modèle permet de décrire l'évolution de l'endommagement des portiques et de simuler leur réponse mécanique statique et dynamique à la fin de la phase de jeune âge. Le modèle numérique multifibres qui a été développé pour les portiques a permis de suivre leur endommagement au jeune âge et de reproduire leur comportement expérimental statique et dynamique. Un modèle 3D mais utilisé en 2D sous des conditions de contraintes planes $2 \mathrm{D}$ utilisant une loi de comportement enrichie similaire a également été développée afin d'amélorer la description des motifs d'endommagement pour une meilleure prise en compte de la cinématique des noeuds d'ossatures (non-capturée par des éléments poutres).

\section{Conclusions}

Tout d'abord, les résultats expérimentaux qui ont été obtenus ont permis de montrer une différence de comportement entre les deux types de portiques (endogènes et nonendogènes). Les résultats cycliques ont montré une différence de raideur entre les deux structures tandis que les essais PsD ont montré une différence de réponse en effort et en déplacement. Une comparaison des résultats obtenus expérimentalement et numériquement a permis de valider le modèle numérique (Figure 1). La différence de comportement observée à l'issue des essais cycliques et PsD suggère que des structures en BA sont sensibles aux conditions dans lesquelles la maturation du béton au jeune age est effectuée. Même si pour des séismes majeurs, la différence de comportement entre 2 groupes de portiques sera moins importante, la différence de raideur constatée dans le domaine élastique peut conduire à une mauvaise évaluation de la vulnérabilité sismique dans les zones de sismicité modérée (comme la France métropolitaine).

\section{Perspectives}

Les portiques étudiés sont de dimensions réduites. Du fait de leur faible section, les effets de fluage et de déformations thermiques sont supposés négligeables (gradient de température faible sur leur épaisseur). Une extension du travail pourrait être l'étude de structures à échelle 1 (poutre avec retrait gêné, noeuds d'ossature 


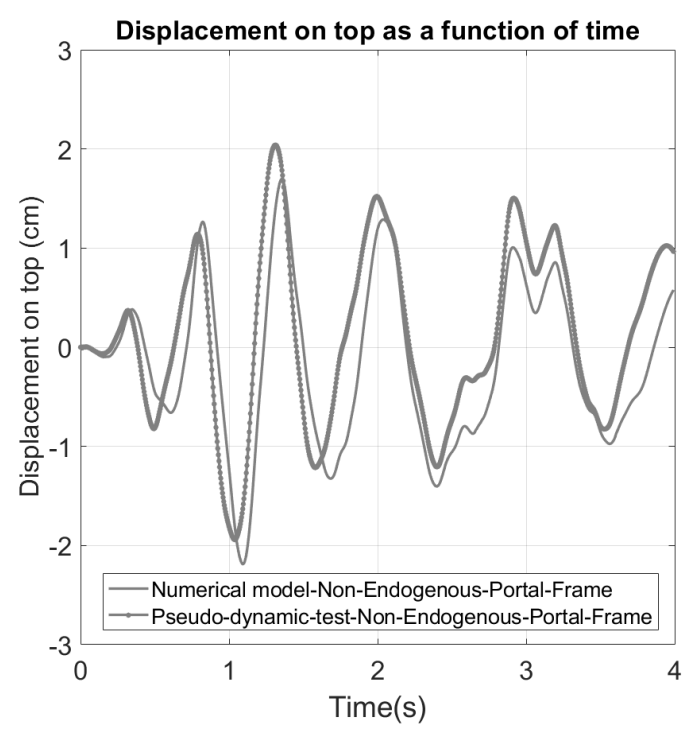

(a)

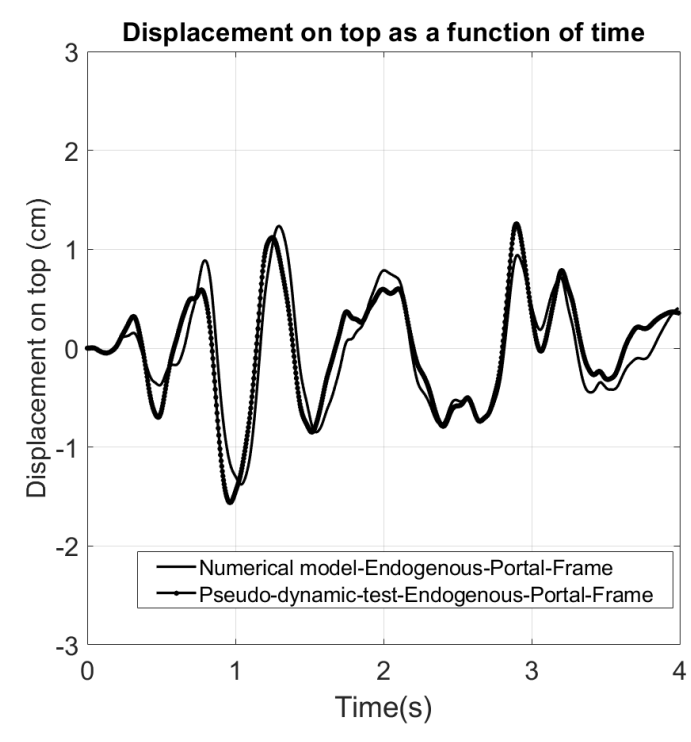

(b)

Figure 1: Déplacements en fonction du temps et comparaison entre résultats issus des essais PsD et ceux issus du modèle multifibres (a) Non-Endogène (b) Endogène

de portiques, etc.) En considérant des structures de dimensions réelles, il serait possible d'étudier des structures massives en béton dans lesquelles le fluage et les déformations thermiques sont plus importantes. En menant de nouvelles campagnes expérimentales à échelle réelle, il sera en fait certainement possible de valider ou d'améliorer le modèle actuel. Par ailleurs, il serait envisageable d'enrichir d'avantage le modèle actuel afin de tenir compte d'autres sources d'endommagement (effets de corrosion ou encore des Réactions Alcali-Granulat). 


\section{Contents}

$\begin{array}{ll}\text { General Introduction } & 1\end{array}$

1 State of the art 5

1.1 Early age damage effect on the seismic response of RC structures . . . . 5

1.2 Early age damage physical origins $\ldots \ldots \ldots \ldots \ldots$

1.3 RC early age damage modeling $\ldots \ldots \ldots \ldots . \ldots . \ldots$

1.3 .1 THC model . . . . . . . . . . . . . . . . . 8

1.3.1.1 Mass Transfer . . . . . . . . . . . . . . . . . . 9

1.3.1.2 Hydration reaction . . . . . . . . . . . . . . 12

1.3 .1 .3 Heat Transfer . . . . . . . . . . . . . . . . . 15

1.3.1.4 Fluid-solid interaction . . . . . . . . . . . . . 15

1.3.1.5 THC model summary . . . . . . . . . . . . . 17

1.3 .2 Creep model . . . . . . . . . . . . . . . . . 19

1.3 .3 Mechanical models . . . . . . . . . . . . . . . . 20

1.3.3.1 Concrete mechanical model . . . . . . . . . . . . . . 20

1.3.3.2 Steel mechanical model . . . . . . . . . . . . . . 22

1.4 Finite Element (FE) modeling for earthquake engineering . . . . . . . . . . 23

1.4.1 Non-linear Dynamic Analysis . . . . . . . . . . . . . 23

1.4 .2 Seismic analysis of structures $\ldots \ldots \ldots . \ldots 26$

1.4.2.1 Static Pushover . . . . . . . . . . . . . . . 26

1.4.2.2 Modal and spectral analysis . . . . . . . . . . . 27

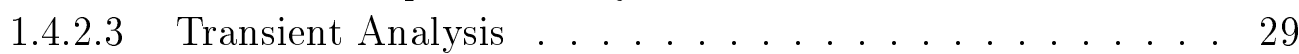

1.4 .3 3D Timoshenko beam FE . . . . . . . . . . . . . . 30

1.4 .4 Multi fiber beam FE . . . . . . . . . . . . . . . . . 35

1.4 .5 Enhanced multifiber beam FE . . . . . . . . . . . . . 37

1.5 Experimental techniques for RC structures monitoring $\ldots \ldots \ldots$. . . 38

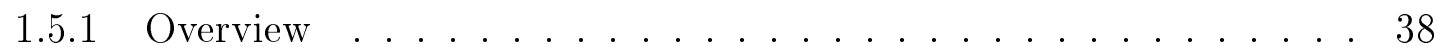

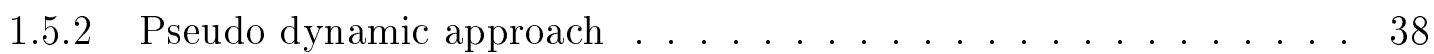

1.5 .2 .1 History $\ldots \ldots \ldots \ldots . \ldots \ldots$

1.5.2.2 Principle and limitations . . . . . . . . . . . . . . . 39

1.5.3 Measurement techniques . . . . . . . . . . . . . . . 41

1.5.3.1 Digital Image Correlation . . . . . . . . . . . . . . . . . . . . . . . .

1.5.3.2 Ambient vibration measurements . . . . . . . . . . . . 42

1.5.3.3 Optical fiber measurements . . . . . . . . . . . . . 44

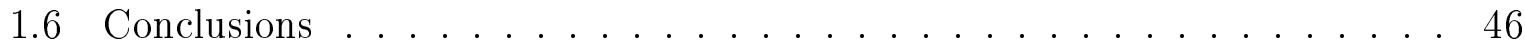


2 Experimental damage evolution of two RC portal frames during their early age period and their response when being submitted to static or seismic inputs

2.1 Experimental Protocol . . . . . . . . . . . . . . . . . . . . . . 48

2.2 Portal frames characterization . . . . . . . . . . . . . . . . . . . . 48

2.2.1 Geometry and mortar formulation . . . . . . . . . . . . . . 48

2.2.2 Material Properties . . . . . . . . . . . . . . . . 49

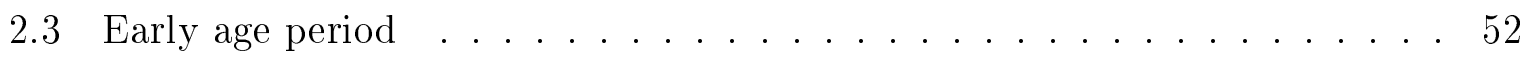

$2.3 .1 \quad$ Strain and crack evolutions using optical fiber . . . . . . . . . . . . 52

$2.3 .2 \quad$ Frequency content evolution using ambient vibrations . . . . . . . . . 56

2.3 .3 Temperature and humidity evolutions at early age . . . . . . . . . 57

2.4 Static response after early age $\ldots \ldots \ldots \ldots \ldots \ldots$

$2.5 \quad$ Dynamic response of the portal frames after early age . . . . . . . . . . 63

2.5 .1 Spectral Analysis . . . . . . . . . . . . . . . 63

2.5 .2 Pseudo-dynamic tests . . . . . . . . . . . . . . . 66

2.5.2.1 $\quad$ PsD procedure and validation . . . . . . . . . . . 66

2.5.2.1.1 Procedure of resolution . . . . . . . . . . . 66

2.5.2.1.2 $\quad$ PsD application on a linear steel spring. . . . . . 67

2.5.2.2 RC portal frames results . . . . . . . . . 70

2.6 Damage evolution during earthquake . . . . . . . . . . . . . . 74

2.6 .1 Crack pattern evolution over concrete surface . . . . . . . . . . . 74

2.6 .2 Frequency content evolution . . . . . . . . . . . . . . . . 76

2.6 .3 Discussion . . . . . . . . . . . . . . . . . . . . . . . . . . . . . . . . . . . 77

2.7 Effect of boundary conditions $\ldots \ldots \ldots \ldots \ldots \ldots$

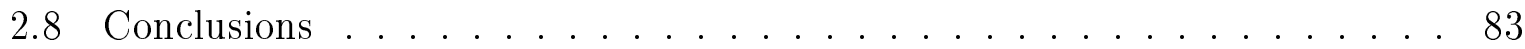

3 Numerical simulation of the early age damage evolution of two RC portal frames and its effect on their static and dynamic behavior under $\begin{array}{ll}\text { a seismic load } & 87\end{array}$

3.1 Methodology of resolution . . . . . . . . . . . . . . . . 88

3.1.1 Step 1: Shrinkage and temperature time evolutions (THC 3D model) 88

3.1.2 Step 2 : Early age damage evolution (multifiber beam model cou-

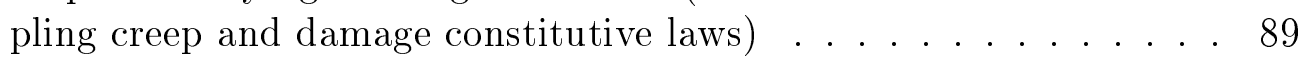

3.1 .3 Step 3: Static and dynamic response . . . . . . . . . . . . . . . . 91

3.2 THC Model . . . . . . . . . . . . . . . . . . . . . . 91

3.2 .1 Resolution process on COMSOL . . . . . . . . . . . . . . . 91

3.2.1.1 $\quad$ Hydration . . . . . . . . . . . . . . . . . . . . . . 92

3.2 .1 .2 Porosity . . . . . . . . . . . . . . . . . . 92

3.2.1.3 Mass transfer of liquid water and water vapor . . . . . . . 93

3.2.1.4 Dry air equilibrium . . . . . . . . . . . . . . 95

3.2.1.5 Heat transfer . . . . . . . . . . . . . . . . 95

3.2 .2 Calibration of the THC model . . . . . . . . . . . . . . . . . . 96

3.2 .3 Inputs and outputs of the THC model . . . . . . . . . . . . . . . . 98

3.3 Multifiber beam model with an enhanced constitutive law. . . . . . . . . 100

$3.3 .1 \quad$ Multifiber approach . . . . . . . . . . . . . . 100 
3.3 .2 Concrete fibers enhanced constitutive law . . . . . . . . . . . . 101

3.3.2.1 Internal elements constitutive laws . . . . . . . . . . 102

3.3.2.1.1 Viscoelastic constitutive law . . . . . . . . . . 102

3.3.2.1.2 Mazars Concrete law . . . . . . . . . . . 103

3.3.2.2 Internal equilibrium . . . . . . . . . . . . . 106

3.3 .2 .3 Static condensation . . . . . . . . . . . . . . . . . 110

3.3.2.4 Global Newton-Raphson Algorithm . . . . . . . . . . . . . 110

3.3 .3 Steel fibers enhanced constitutive law . . . . . . . . . . . . . . . . 110

3.4 Description of the numerical model of the portal frames . . . . . . . . . . . 111

3.4 .1 Mesh and boundary conditions . . . . . . . . . . . . . . . . . . . . . . . 111

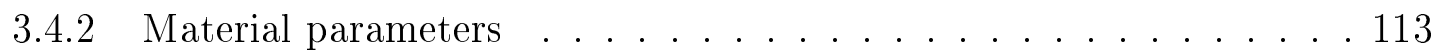

3.4 .3 Constitutive laws parameters . . . . . . . . . . . . . . . . . 115

3.4.4 Inputs data from THC model . . . . . . . . . . . . . . . 116

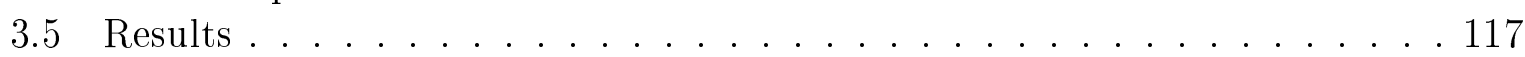

3.5.1 Early Age Damage Evolution . . . . . . . . . . . . . . 118

3.5 .2 Static Pushover . . . . . . . . . . . . . . . . . . . . 121

3.5.2.1 Mesh sensitivity analysis . . . . . . . . . . . . . . 121

3.5 .3 Pushover results . . . . . . . . . . . . . . . . . . . . . . 123

3.5 .4 Modal Analysis . . . . . . . . . . . . . . . . . . . . 124

3.5 .5 Spectral Analysis . . . . . . . . . . . . . . . . . . . . . . . . . . . . . . . . . . . . . . . . .

3.5 .6 Dynamic Analysis . . . . . . . . . . . . . . . . . . 128

3.6 Comparison between multifiber model and 2D model results . . . . . . 128

3.6 .1 Mesh discretization . . . . . . . . . . . . . . . . . . 129

3.6 .2 Constitutive laws . . . . . . . . . . . . . . . . . . 131

3.6 .3 Early age damage $\ldots \ldots \ldots \ldots . \ldots \ldots . \ldots \ldots$

3.6 .4 Modal Analysis . . . . . . . . . . . . . . . . . . . . . . . . . . . . . . . . . . . . . . . . . . . . . . . . . . . .

3.6 .5 Pushover Analysis . . . . . . . . . . . . . . . . . . . . . . . . . . . . . . . . . . . . . . . . . . . .

3.6 .6 Dynamic Analysis . . . . . . . . . . . . . . . . . . 136

3.7 Conclusions . . . . . . . . . . . . . . . . . . . . 137

\begin{tabular}{lll}
\hline & General conclusions & 143
\end{tabular}

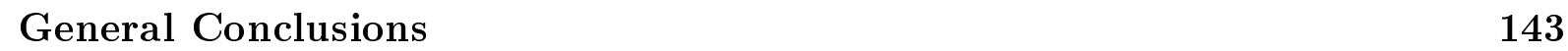




\section{List of Figures}

\begin{tabular}{|c|c|}
\hline 1 & Déplacements en fonction du temps et comparaison entre résultats issus \\
\hline & des essais PsD et ceux issus du modèle multifibres (a) Non-Endogène (b) \\
\hline & 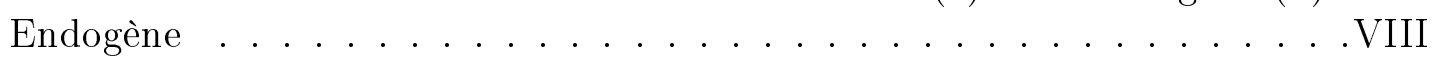 \\
\hline & Reinforced concrete damage over time. \\
\hline
\end{tabular}

1.1 Equivalent humidity at the miniscus interface between liquid and vapor water 12

1.2 (a) Finite element types (b) the beam theory (c) Timoshenko beam kine-

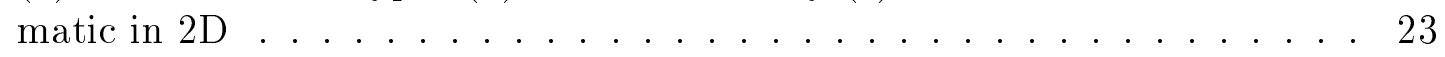

1.3 Generalized displacements and rotations and nodal displacements and rotations in a Timoshenko beam . . . . . . . . . . . . . . . 31

$1.4 \quad$ Multifiber beam element (a) Cross section with Gauss Integration positions

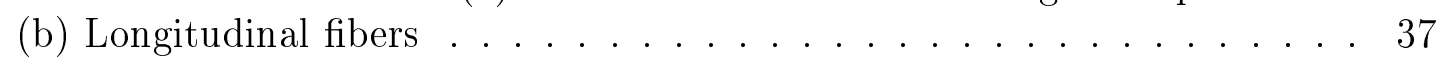

1.5 Iterative PsD procedure [4] . . . . . . . . . . . . . . . . . . . 40

1.6 Ambient vibration recorder City Shark II . . . . . . . . . . . . . . . 45

$2.1 \quad$ Experimental protocol $\ldots \ldots \ldots \ldots$. . . . . . . . . . . . 49

2.2 Early age conditions (a) Endogenous (b) Non-Endogenous (c) Crack Apparitions in the Non-Endogenous Portal Frame at the end of the 28 days . 50

2.3 Geometry of the RC portal frames (a) Front View (b) Cross Section . . . . 51

2.4 Mass loss evolutions of Non-Endogenous (Non-Endo) and Endogenous (Endo) $4 \mathrm{~cm}$ by $4 \mathrm{~cm}$ by $16 \mathrm{~cm}$ prismatic specimens . . . . . . . . . . 53

2.5 (a) Location of the optical fiber along the reinforcements and (b) mapping

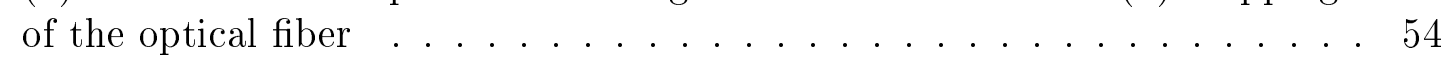

2.6 Strain at the end of 8 days (a) Non-Endogenous Frame (b) Endogenous

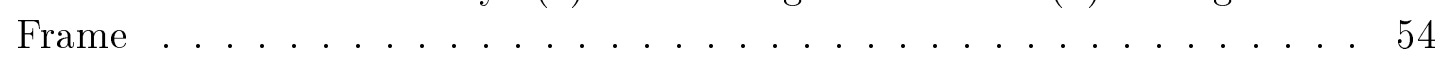

2.7 Strain Evolution (a) Non-Endogenous OP Segment (b) Endogenous OP Segment (c) Non-Endogenous UV Segment (D) Endogenous UV Segment . 55

2.8 (a) First mode of vibration and velocimeters position during early age (a) scheme and (b) Experiment $\ldots \ldots \ldots \ldots \ldots 6$

2.9 First natural frequency evolution in the (xy) plane during the early age period. The period between 437 hours and 521 hours correspond to 'No

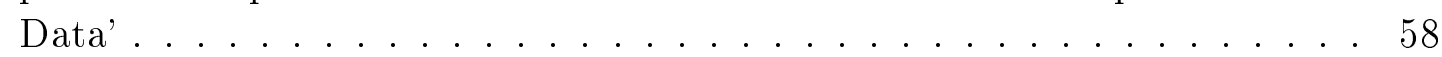

2.10 External ambient temperature and humidity evolutions during the early

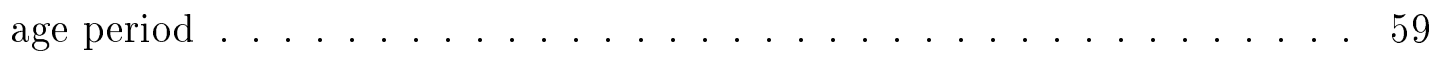

2.11 (a) Cyclic displacement Time-History and (b) Experimental set-up. . . . . 60

2.12 Experimental response to the cyclic loading . . . . . . . . . . 60 
2.13 Envelope of the experimental response of the portal frames to the cyclic loading and Spectral Analysis curves . . . . . . . . . . . . . . . 61

2.14 Evolution of displacements measured using LVDT1, LVDT2, LVDT3 and LVDT4 during the cyclic displacement static tests performed on the Endogenous and Non-Endogenous portal frames. LVDT sensors were positioned as shown in Figure 2.11b: LVDT1 measured the lateral drift of the second floor of the portal frames, whereas LVDT2 measured the lateral drift of the first floor and LVDT3 the horizontal displacement at the bottom of the left column of the portal frames and LVDT4 measured out of plane

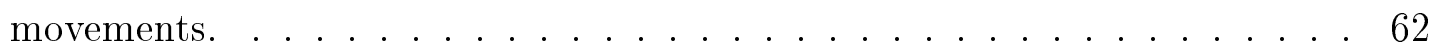

2.15 (a) Boundary conditions and simulated concentrated masses (b) Equivalent Single Degree of freedom System $\ldots \ldots \ldots . \ldots . \ldots 64$

2.16 Spectral Analysis (a) 0.3 g Accelerogram, (b) Pseudo-acceleration response spectrum, (c) Spectral analysis results $\ldots \ldots . \ldots . \ldots 65$

2.17 Numerical and experimental interaction during the PsD tests. F is the force value and $\mathrm{d}$ the displacement value. . . . . . . . . . . . . . 66

2.18 Psd test experimental set up used to test a linear steel spring . . . . . . . . 67

2.19 Linear steel spring under a sinusoidal signal . . . . . . . . . . . . . 68

2.20 Eurocode input data for PsD tests on the linear steel spring . . . . . . . 69

2.21 Linear Steel Spring under a Non-Linear Time History . . . . . . . . . . . . 69

2.22 Video Tracking (a) Followed black circles during the video tracking (b) Comparison between the displacement determined using PsD and the measured displacement using video-tracking. . . . . . . . . . . . . . 70

2.23 Position of Velocimeters during PsD testings (a) Scheme (b) Experiment . 71

2.24 Pseudo-dynamic test results (a) Displacement-time Evolution and (b) ForceDisplacement Evolution $\ldots \ldots \ldots \ldots 72$

2.25 Correlation (a) Speckle (b) grid (c) Experimental set-up . . . . . . . . . 73

2.26 Position of points to define by the user in order to generate the meshing of

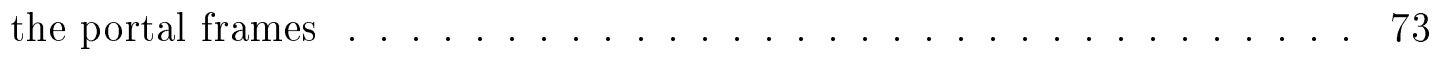

2.27 Displacement as a function time results using LVDT1 sensor and digital Image correlation (a) Non-Endogenous portal frame (b) Endogenous portal

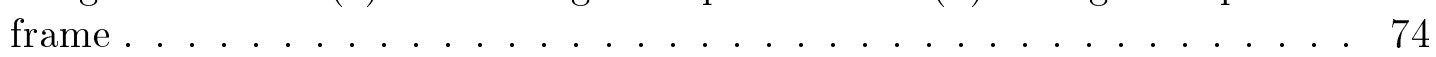

2.28 Evolution of displacements measured using LVDT1, LVDT2, LVDT3 and LVDT4 during the pseudo-dynamic test performed on the Endogenous and Non-Endogenous portal frames. LVDT sensors were positioned as shown in Figure 2.11b: LVDT1 measured the lateral drift of the second floor of the portal frames, whereas LVDT2 measured the lateral drift of the first floor and LVDT3 the horizontal displacement at the bottom of the left column of the portal frames and LVDT4 measured out of plane movements. . . . . 75

2.29 (a) Crack pattern correlation points and (b) Zones of cracks apparition . . 76

2.30 Non-Endogenous Portal frame crack evolution using Ufreckles [13] . . . . . 77

2.31 Endogenous Portal frame crack evolution using Ufreckles [13] . . . . . . . . 78

2.32 Strain increase and cracks apparition using Ufreckles [13] . . . . . . . . . 79 
2.33 Frequency and displacement evolutions during PsD tests: (a) Endogenous and (b) Non-Endogenous. Red dotted lines indicate maximum local negative displacements where a drop of frequency occured . . . . . . . . . . 80

2.34 Vertical displacements (Y direction) at the bottom of the three columns of the first group of portal fames (endogenous and non-endogenous) tested experimentally with PsD tests . . . . . . . . . . . . . 81

2.35 Evolutions of vertical displacement (following the Y direction), velocity and acceleration at the bottom of the right column of the NE-portal frame (of the first portal group of portal frames tested with PsD tests) $\ldots . . . .81$

2.36 Evolutions of vertical displacement (following the Y direction), velocity and acceleration at the bottom of the right column of the E-portal frame (of the first portal group of portal frames tested with PsD tests)

2.37 Results obtained with the second group of portal frames tested using PsD tests: Displacement as a function time results using LVDT1 sensor and digital image correlation (a) Non-Endogenous portal frame (b) Endogenous

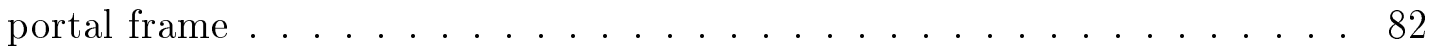

2.38 Vertical displacements (Y direction) at the bottom of the three columns of the second group of portal fames (endogenous and non-endogenous) tested experimentally with $\mathrm{PsD}$ tests $\ldots \ldots \ldots \ldots . \ldots . \ldots . \ldots 33$

2.39 Evolution of displacements measured using LVDT1, LVDT2, LVDT3 and LVDT4 during the pseudo-dynamic tests performed on a second group of Endogenous and Non-Endogenous portal frames. LVDT sensors were positioned as shown in Figure 2.11b: LVDT1 measured the lateral drift of the second floor of the portal frames, whereas LVDT2 measured the lateral drift of the first floor and LVDT3 the horizontal displacement at the bottom of the left column of the portal frames and LVDT4 measured out of plane

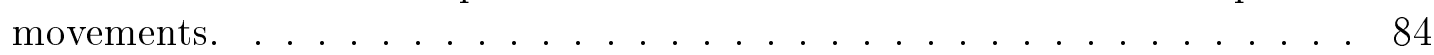

3.1 Resolution steps and softwares used. Step 1 : Resolution of the THC problem on COMSOL to get the internal temperature and strain shrinkage fields. Step 2: Simulation (ALT4S) of the EA damage by integrating COMSOL outputs (temperature and strain shrinkage fields). Step 3: Simulation of the mechanical response of the structures to an external excitation (pushover or earthquake). $T_{\text {ext }}$ and hygro $_{\text {ext }}$ are the external temperature and humidity measured during the early age period using sensors. $T_{\text {int }}$ and $\epsilon_{\text {shrinkage }}$ are the temperature and shrinkage evolutions within the cross-sections of the portal frames calculated using COMSOL. $\sigma_{\text {Final }}, \epsilon_{\text {Final }}$, $P_{\text {Final }}$ and $d_{\text {Final }}$ are stress, strain, internal force and displacement values of the different fibers of the model at the end of resolution step 2 . . . . . 88

3.2 (a) Multifiber cross-section and (b) Finite element mesh and concentrated

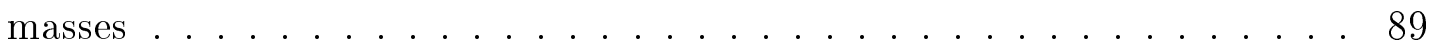

3.3 Enhanced multifiber beam element with internal degrees of freedom. $u_{k_{i}}$ are deformations, $v_{k_{i}}$ are derivatives of deformations and $a_{k_{i}}$ are second derivatives of deformations and $p_{k_{i}}$ are stresses. . . . . . . . . . . 90

3.4 Calibration of the THC Model by fitting temperature evolution curve . . . 97 
3.5 Prismatic beam elements used for the calibration of the THC model (a) Manufacturing process (b) 24 hours coverage using a plastic sheet after casting (c) Endogenous goup conservation conditions $\ldots \ldots . \ldots 98$

3.6 Calibration of the THC Model (a) Percentage of Mass Loss as a function of time (b) Shrinkage as a function of time . . . . . . . . . . . . . 99

3.7 Shrinkage and temperature evolutions (at the concrete fibers of all the elements of the portal frames) calculated through an interpolation of the data provided by the THC model on COMSOL. The evolutions of temperature of the different fibers are almost similar. The portal frames have a small cross-section, thus the gradient of temperature is negligible. . . . . . . . . 100

3.8 Principle of the multifiber beam model $([78][79]) K=$ Stiffness Matrix; $a_{s}=$ Section compatibility Matrix; $B=$ Gradient Metric; $L=$ Length of the beam element $; U=$ Nodal displacement $\sigma=$ Stress Matrix; $P=$ Load Vector, $\epsilon=$ Strain Matrix, $H$ is the damaged Young moduls . . . . . . . . . . . . . . 101

3.9 Strain calculation within a concrete fiber element [14] [10] . . . . . . . . . 102

3.10 Shrinkage evolution at an intermediate cross section of the portal frames interpolated at the Gauss points of a multifiber cross-section at 28 days (Non-Endogenous Case). Since all cross sections of the portal frames except for the sections located at the joints are subjected to similar temperature and humidiy outside conditions, their shrinkage and temperature evolutions are similar. The additional shrinkage occuring at the corners of the joints was not accounted for in the multifiber model. . . . . . . . . . . . . . . 112

3.11 (a) Pinned connection realization process and (b) Corrections applied to the numerical model based on experimental observations: (1) Excentricity of the pinned connections accounted for by adding rigid elements at the bottom of the portal frames and (2) Vertical displacement, velocity and acceleration determined using Digital Image correlation at the bottom of the right column implemented into the model when conducting the dynamic

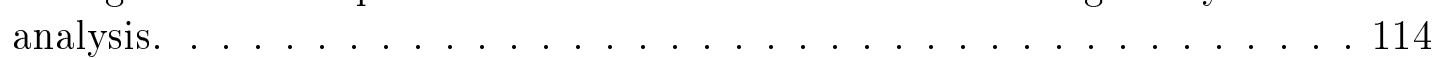

3.12 Material constitutive laws . . . . . . . . . . . . . . . . 116

3.13 Numerical pushover analysis using the multifiber beam model: Position of the imposed displacement (3.13a), displacement time history (Figure 3.13b) and multifiber beam model pushover results and comparison with experimental pushovers (positive envelope of cylic test results) and spectral analysis (Figure $3.13 \mathrm{c}$ ) for Endogenous (E) and Non-Endogenous (NE) portal frames . . . . . . . . . . . . . . . . 117

3.14 Pushover curves obtained for different discretizations to study mesh sensibility. "Initial" corresponds to the initial meshing given in Figure 3.15 , while "Initial + p1" is the refined mesh presented in Figure 3.16 , ,Initial + p2" corresponds to the discretization of Figure $\mid 3.17$ and "Initial $+\mathrm{p} 3$ " to the discretization of Figure 3.18 . . . . . . . . . . . . . . . . 118

3.15 Initial Mesh "Initial" (a) Elements numbers (b) Node numbers . . . . . . . 119

3.16 First refinement of the initial mesh by adding elements around the joints of the beam of the first floor "Initial + p1" (a) Elements numbers (b) Node

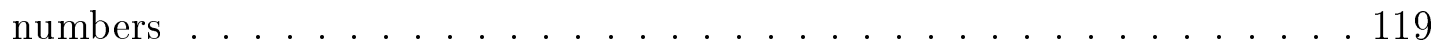


3.17 Second refinement of the initial mesh by adding elements around the joints of the beams of the first and second floor "Initial + p2" (a) Elements numbers (b) Node numbers . . . . . . . . . . . . . . . . . . . 120

3.18 Third refinement consisting in dividing the initial mesh by 3 "Initial + p3" (a) Elements numbers (b) Node numbers . . . . . . . . . . . . . . . . 121

3.19 Damage and normal stress $\left(\sigma_{x x}\right)$ evolutions at early age in all portal frame concrete fibers (many fibers get damaged at early age in the non-endogenous

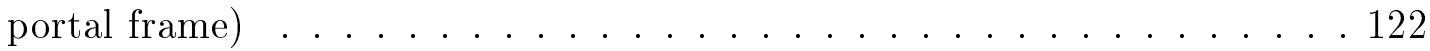

3.20 Non-Endogenous Portal frame: Damage layers at the end of the early age

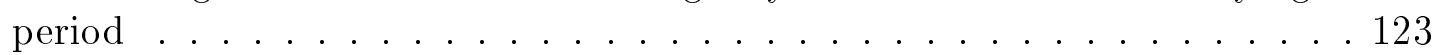

3.21 Non-Endogenous portal frame evolving parameters during early age: (a) Evolution of the hydration coefficient $\xi$ (b) Evolution tensile Strength $R_{t}$ and (c) Evolution of tensile strength as a function of $\xi \ldots . . . . .124$

3.22 Variability of tensile strength in the numerical model: (a) Evolution tensile Strength $R_{t_{i}}$ of the different fibers and (c) Evolution of tensile strength $R_{t_{i}}$ as a function of $\xi$ (degree of hydration) $\ldots \ldots \ldots \ldots . \ldots \ldots 125$

3.23 Displacements as a function of time comparison between PsD results and multifiber model in the first group (a) Non-Endogenous (b) Endogenous . 129

3.24 Force as a function of displacement comparison between PsD results and multifiber model in the first group (a) Non-Endogenous (b) Endogenous . 130

3.25 Displacements as a function of time comparison between PsD results and multifiber model in the second group (a) Non-Endogenous (b) Endogenous 131

3.26 Force as a function of displacement comparison between PsD results and multifiber model in the second group (a) Non-Endogenous (b) Endogenous 132

3.27 2D Mesh on CAST3M . . . . . . . . . . . . . . . . . . . . . . . . . . . . . . . . . 132

3.28 2D Mesh discretization . . . . . . . . . . . . . . . . . . . . . 133

3.29 Concrete laws used in the 2D model and in the multifiber model. Tensile and compressive strength of concrete used in the 2D model are slightly heigher than the ones used in the multifiber model (4 MPa versus $2.5 \mathrm{MPa}$ for tensile strength and $38 \mathrm{MPa}$ versus $35 \mathrm{MPa}$ for compressive strength) .134

3.30 2D damage pattern at the end of the early age period (a) Endogenous (b)

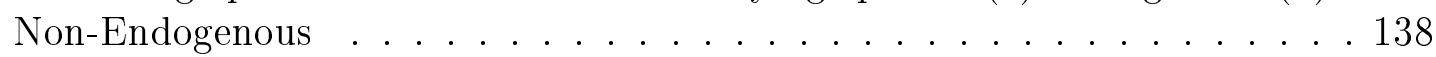

3.31 2D mode shapes determined using a modal analysis . . . . . . . . . . 139

3.32 2D more refined mesh . . . . . . . . . . . . . . . . . . . 139

3.33 Pushover results obtained: experimentally and numerically (using 2D and multifiber models). Spectral analysis curves obtained experimentally are also plotted. . . . . . . . . . . . . . . 140

3.34 Comparison of the diplacement as a function of time curve obtained using PsD tests, multifiber and 2D simulations (a) Non-Endogenous (b) Endoge-

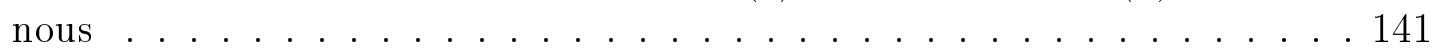

3.35 Comparison of the load as a function of diplacement curve obtained using PsD tests, multifiber and 2D simulations (a) Non-Endogenous (b) Endoge-

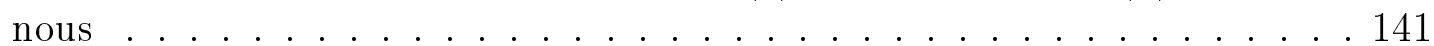




\section{List of Tables}

1.1 THC Equations and unknowns . . . . . . . . . . . . . . . . 18

2.1 Mortar properties at the end of Early Age $\left(R_{t}=\right.$ Tensile Strength, $R_{c}=$ Compressive Strength and $E=$ Young modulus, NE=Non-Endogenous, $\mathrm{E}=$ Endogenous $)] . \quad 52$

2.2 Boundary conditions and masses: $\mathrm{AV}=$ Ambiant Vibrations, $\mathrm{EA}=$ EarlyAge, $\mathrm{SA}=$ Spectral Analysis, $\mathrm{PsD}=$ Pseudo-Dynamic, $\mathrm{BC}=$ Boundary Con-

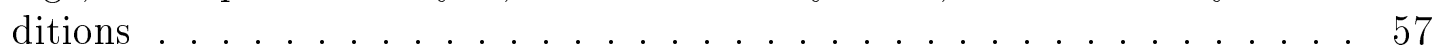

2.3 Maximum capacity detemined by performing pushovers on the tested portal frames: Group 1 corresponds to the portal frames that were tested using static loadings, Group 2 corresponds to the first series of portal frames tested using PsD tests and Group 3 corresponds to the second series of portal frames tested using PsD tests . . . . . . . . . . . . 63

2.4 Stiffness $k$, frequency $f$ and maximum base shear $V$ at the end of the early

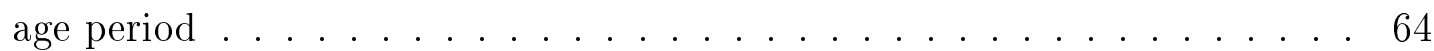

3.1 THC model coefficients and determination method . . . . . . . . . . . . . 99

3.2 Concrete and steel reinforcements model parameters. $E=$ Elastic modulus; $\nu=$ Poisson ratio; $f_{t}$ is the law parameter accounting for tensile strength; $f_{c}$ is the law parameter accounting for compressive strength; $A_{t}=1$ st parameter govering the evolution of damage (traction); $A_{c}=1$ st parameter govering the evolution of damage (compression); $B_{t}=2$ nd parameter governing the evolution of damge (traction); $B_{c}=2$ nd parameter governing the evolution of damage (compression); $\beta_{1}$ and $\beta_{2}$ are related to damping, respectively with and without damage and $F_{y}=$ Steel yield stress. . . . . . . . . . 116

3.3 Time required to conduct a pushover analysis of the not initially damaged portal frame using different meshes . . . . . . . . . . . . 126

3.4 Portal frame mode shapes . . . . . . . . . . . . . . . . 126

3.5 Natural frequency values at the end of 28 days . . . . . . . . . . . . 126

3.6 Concrete parameters used in the 2D model. $E=$ Elastic modulus; $\nu=$ Poisson ratio; $f_{t}$ is the law parameter accounting for tensile strength; $f_{c}$ is the law parameter accounting for compressive strength; $A_{t}=1$ st parameter govering the evolution of damage (traction); $A_{c}=1$ st parameter govering the evolution of damage (compression); $B_{t}=2$ nd parameter governing the evolution of damge (traction); $B_{c}=2$ nd parameter governing the evolution of

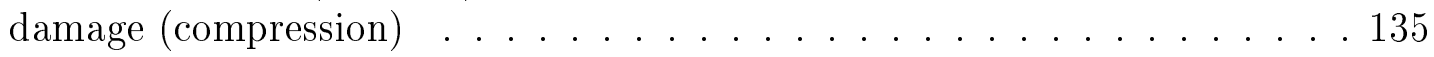


3.7 Comparison of stiffness and natural frequency values at the end of 28 days between the Endogenous and Non-Endogenous Portal frames (results obtained experimentally and numerically using 2D and multifiber beam sim-

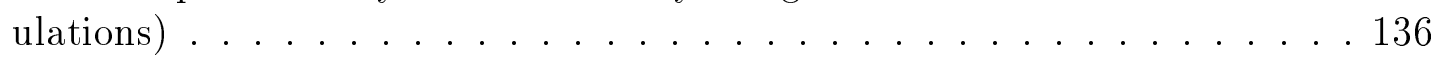


XX 


\section{General Introduction}

\section{Context}

In 2018, the Morandi Bridge collapsed in Italy causing many deaths. Such dramatic event reminds us that during their aging process reinforced concrete structures get damaged and become more vulnerable. This damage starts at early age and continues during the life time of the structure (Figure 21). It can be caused by creep, shrinkage, corrosion, thermal deformation, carbonation and so on [1]. As a consequence of this damage, the structure becomes more vulnerable and can collapse either due to its self weight and live loads or due to hazards such as earthquakes or impacts. This thesis focuses on the effect of the initial damage that takes place during the early age period (0-28 first days) on the seismic response of reinforced concrete structures. Current Reinforced Concrete (RC) seismic design codes ([2] [3]) do not deal with this aspect. Thus, early age effects on the dynamic performances of RC structures need to be quantified. More particularely, the effect of drying shrinkage on the dynamic behavior of concrete structures is focused on in this thesis.

\section{Objectives and Methodology}

The objectives are to experimentally quantify the effects of early age drying shrinkage on the seismic response of Reinforced Concrete Structures (RC) and to propose a numerical model able to simulate the static and dynamic behavior of RC structures under an earthquake while taking into account their early age damage evolution.

On the one hand, an experimental framework was conducted on $\mathrm{RC}$ portal frames that were casted an kept in different conditions during early age with a reference group "endogenous group" where drying shrinkage was limited and a "non-endogenous" group where shrinkage was not prevented. At the end of the early age period, the different portal frames were subjected to cyclic and Pseudo-dynamic (PsD) tests [4], allowing to obtain their dynamic response in order to quantify their difference in behavior. On the other hand, an enhanced multifiber beam model was developed for each group. Such model allows following the evolution of damage at early age due to shrinkage, thermal 


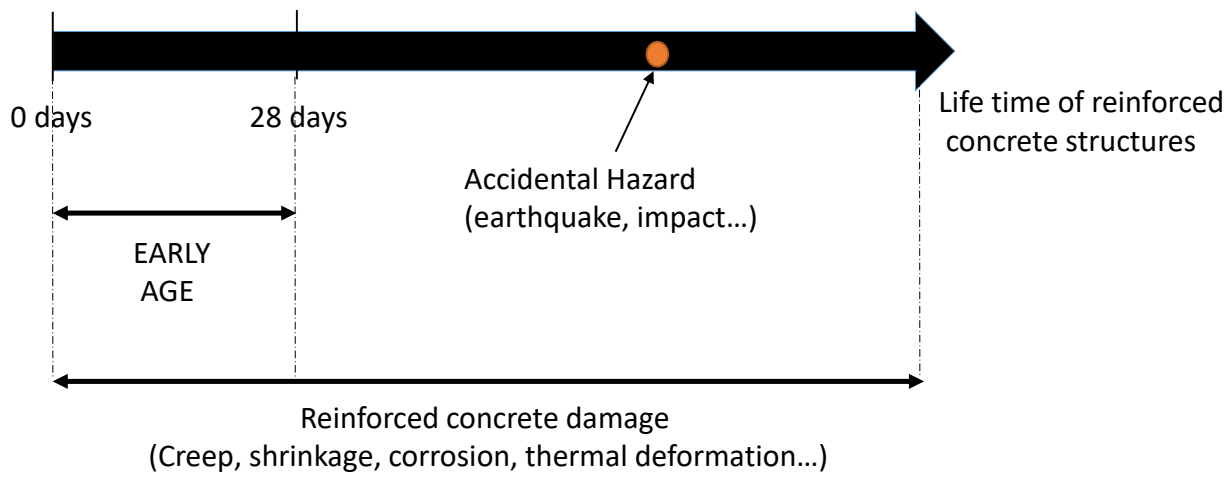

Figure 2: Reinforced concrete damage over time

deformations and creep, and to evaluate their response under static and dynamic loadings.

The numerical model uses a Thermo-Hygro-Chemical (THC) approach developed within the GEOMAS lab of INSA Lyon [5] based on the work of Buffo Lacarriere [6], Mainguy [7] and Coussy [8]. In addition, it uses 3 viscoelastic Kelvin Voigt models to simulate creep ([9] [10]) as well as the $\mu$ damage model to simulate concrete damage [11]. Experimental results obtained with cyclic and PsD tests were compared to numerical results to validate the proposed model.

This thesis is composed of four main chapters.

- Chapter 1 presents literature related research dealing with the effects of concrete damage on the dynamic properties of RC structures to show the gap in knowledge. A review of RC structures early age damage causes and models (THC model, Creep models, concrete damage laws, etc.) is also provided. Furthermore, this Chapter presents a review of some effective numerical modeling techniques used in the literature to simulate the behavior of RC structures (FEM principle of resolution, multifiber Timoshenko beam elements with an enhancement of the constitutive law, pushover analysis, modal analysis, spectral analysis and Non-linear dynamic analysis). In addition, a state of the art on the pseudodynamic technique that can be used to experimentally test the dynamic response of civil enginering structures is presented. Last, a review of existing monitoring techniques (Digital Image Correlation, ambient vibration, optical fiber, displacement and load sensor measurements) is provided. 
- Chapter 2 presents the experimental protocol that was used to underline the effects of EA drying shrinkage on damage evolution, static and dynamic response of two groups of RC portal frames. A first group (composed of two portal frames) was kept in endogenous conditions during early age (The portal frames of this first group were covered using a plastic sheet in a way to stop water exchange with the surrounding environment from occuring and thus to limit early age drying shrinkage from happening). A second group of portal frames (composed of two portal frames) was kept in non-endogenous conditions (No imposed covering during early age). At the end of the early age period (28 days) one portal frame of each group was subjected to a static cyclic loading to determine its non-linear static response. During the static cyclic tests, the portal frames were instrumented using displacement (LVDT) and load sensors. The two remaining portal frames (one of each group) were followed during their early age period using velocimeters and optical fibers and then tested at the end of their early age period using the pseudo-dynamic technique in order to compare their non-linear dynamic response under a low intensity accelerogram. During the pseudo-dynamic tests, the portal frames were instrumented using velocimeters, displacement and load sensors and monitored using 2D Digital Image Correlation [12] [13].

- In Chapter 3 the numerical multifiber beam model with an enhanced constitutive law to account for shrinkage, creep, thermal deformations and mechanical strains developed for the portal frames is presented and its results are compared to the experimental ones for validation. The model allows to describe the early age damage evolution of the portal frames as well as to predict their mechanical response under static or dynamic loads at the end of their EA period. A 2D model with a similar enhanced constitutive law (generalized to a 3D in plane configuration) was also developed in order to capture the damage patterns observed experimentally and to account for the effects of the kinematic of the nodes of the portal frames (not captured using beam elements).

- Conclusions and perspectives are presented in Chapter 4. 


\section{CHAPTER 1 \\ State of the art}

This chapter is a state of the art where the main tools and concepts used in the rest of the manuscript are explained. Concepts presented in this state of the art were divided into 5 main sections. In the first section, an overview of literature references dealing with the evaluation of early age damage effects on the seismic response of $\mathrm{RC}$ structures is presented. In the second section, an explanation of the physical origins of early age damage that takes place in concrete structures is given. The third section presents some popular and efficient models used in the literature to simulate early age damage of RC structures: THC models, creep models, as well as mechanical models for concrete and steel. The fourth section deals with the principle of some classical and more advanced techniques used by structural engineers in order to quantify the seismic response of structures: Finite element analysis, pushover analysis, modal and spectral analysis as well as transient analysis, 3D Timoshenko beam finite elements and multifiber beam elements. Then, the fifth section presents the principle of different testing and monitoring techniques such as the pseudodynamic technique, digital image correlation, ambient vibration measurements and optical fiber measurements. Conclusions of the Chapter are provided in Section 6 .

\subsection{Early age damage effect on the seismic response of RC structures}

Current RC seismic design codes [2] [3] do not deal with Early Age (EA) effects on the seismic response of RC structures. Thus, Early age effets on the dynamic performances of RC structures need to be quantified. Many research programs were conducted or are still undergoing in order to quantify and model the effect of early age damage. Such research initiatives will allow improving current applied codes and standards. The CEOS.fr National program for instance showed that the natural frequency of a RC beam subjected to early-age restrained shrinkage is highly affected [14].

In the last decade, many research articles providing numerical models used to simulate the effects of early age drying shrinkage on the mechanical behavior of concrete structures were published [15]. However, such models were not fully validated. [16] pointed out that 
the stiffness of RC structures decreases during their aging process due to cracking which is shown through a 2D numerical simulation based on a proposed Thermo-Hygral Analysis. Unfortunately, no experimental work was conducted to validate the numerical simulations. In [17], numerical simulations using a Thermo-Hygral model were performed on RC structures of different dimensions in order to show that the decrease of natural frequency due to early age effects is more important in structures having a small thickness. In [18] authors modeled the dynamic behavior of a 28 story building of real size kept in either endogenous or non-endogenous conditions using a FEM approach. Only the non-endogenous building was both experimentally tested and simulated numerically, whereas the endogenous one (sealed one) was only modeled numerically. Moreover, additional strain and damage sources were significant (thermal deformations, corrosion) and drying shrinkage effects were not exclusively quantified. In [19, the effects of drying shrinkage on the mechanical performances of shear walls were underlined from an experimental and a numerical point of view under quasi-static cyclic loadings. The authors of [20],[21] and [22], also studied the effects of shrinkage using static loadings on beams. In addition, two types of finite element models (one with shrinkage) to simulate the envelope of the response of beam columns under monotonic and cyclic loading are provided in [23], whereas [24] shows how adding steel fibers to concrete specimens helps reducing shrinkage greatly.

In this thesis, the effects of early age drying shrinkage on the dynamic behavior of $\mathrm{RC}$ structures were determined numerically and experimentally by testing two RC portal frames (kept respectively in Endogenous and Non-Endogenous conditions) at the end of their early age period using the Pseudo-dynamic technique. The size of the structures, their small cross section and casting conditions allowed studying the effects of early age drying shrinkage while other sources of damage (thermal shrinkage, creep, mechanical deformations, etc.) were limited. Moreover, from a measurement point of view, the experimental setup was composed of many accurate and complementary monitoring techniques (LVDT sensors, velocimeters, optical fibers, 2D Digital Image correlation, humidity sensors, temperature sensors, etc.)

\subsection{Early age damage physical origins}

During their early age period, concrete structures get damaged due to shrinkage, thermal deformations, and creep. Shrinkage and thermal deformations are independent of mechanical deformations whereas creep causes mechanical deformations even if the structure is unloaded. 
Concrete is made of cement, water, fine aggregates, and coarse aggregates [25]. To those components can be added admixtures or additives to improve certain properties (retarders, accelerators, etc.) The total amount of water in concrete is the water absorbed by the aggregates, the water necessary for the hydration of cement and the water needed for workability. Aggregates absorb water till reaching a saturated surface dry condition (SSD). Part of the water present in concrete is used in the hydration process of the cement. Hydration is an exothermic reaction occurring between cement and water, consuming water in order to form hydration products, and allowing concrete getting its final strength. The remaining water present in concrete allows having enough workability. Concrete structures can be subjected to 5 types of shrinkage [25] [26] [27] [28] [29]:

- Plastic Shrinkage that takes place while concrete is still fresh (while cement paste is still plastic) and has not yet hardened (usually during the first hours after concrete has been cast in place). That type of shrinkage is due to the evaporation of free water from concrete in the surrounding environment which induces tensile stresses on the surface layers restrained by the non-shrinking inner concrete. Concrete is very weak in tension, therefore, those tensile stresses induce cracking.

- Autogenous Shrinkage: During the hydration of concrete, the chemical reaction that occurs consumes water which generates a depression within concrete pores leading to a contraction of the material (Contraction of le Châtelier). As stated in [30], its value remains small in comparison with the other types of shrinkage (50 to $100 \frac{\mathrm{\mu m}}{\mathrm{m}}$ ). However such type of shrinkage increases when the water/cement ratio decreases (less than 0.42). Indeed, in concrete having a low water to cement ratio, all the water is used in the hydration process and the demand for more water creates very fine capillaries. The surface tension within the capillaries causes autogenous shrinkage.

- Drying shrinkage happens after concrete has hardened (when a good portion of the chemical hydration has been done). It is due to the evaporation of water in the surrounding environment as for plastic shrinkage (which induces a depression in the pores and thus a contraction of concrete) [31]. As shown in [30], drying shrinkage is directly proportional to water content in concrete. The more water is present in concrete, the more drying shrinkage will occur.

- Thermal Shrinkage: During the hydration process, an increase in the core temperature of the structures occurs. The gradient of temperature between the core of 
the section and its outer part causes strain deformations. Such deformation type is less important for structures having a small cross-section. Indeed, in this case, the gradient of temperature is less important.

- Carbonation Shrinkage: It is due to the reaction of $\mathrm{CO}_{2}$ in the environment with hydration products [31] that causes concrete to contract. Carbonation shrinkage induces an increase in concrete strength. However, it also neutralizes the alkaline nature of the hydrated cement paste, reducing therefore the protection of steel from corrosion [30]. This type of shrinkage increases during the aging process of concrete structures and can be neglected at early age.

Literature provides several models that can be used to simulate early age damage due mainly to shrinkage, thermal deformations, creep and mechanical deformations in RC structures. Such models will be explained in the following section. Thermo-Hygo-Chemical models (THC) allow accounting for concrete shrinkage and thermal deformations whereas creep can be determined using Kelvin-Voigt rehological models in series. During the past decades, several models were developed to accurately simulate the mechanical behavior of RC concrete structures under static and dynamic loadings.

\subsection{RC early age damage modeling}

\subsubsection{THC model}

Shrinkage due to the hydration process (Chemical Shrinkage) and due to liquid water evaporation in the environment (Drying Shrinkage) and also thermal deformations can be calculated using a THC (Thermo-hygro-chemo) model. Many models exist in the litterature [6], the one that was chosen to be described here was developed in the GEOMAS lab [5]. It is based on the work of Buffo-Lacarrière [6], Mainguy [7] and Coussy [8]. In such model, the degree of saturation of the mortar is calculated by solving three sets of differential equations based on conservation laws: liquid water, water vapour and wet air equilibrium equations. The evolution of the total porosity as well as the distribution of pores are taken into account when solving the equilibrium equations to account for early age effects. Using the equivalent pore pressure of cement based materials concept as explained by Coussy [8] shrinkage evolution is then calculated. As for thermal deformation, it is calculated by solving a heat transfer thermal conduction differential equation. All differential equations can be solved using a FEM software (COMSOL software for instance was used in this thesis) and model parameters have to be calibrated to account for the 
properties of concrete used in the structure under study. In the following paragraphs, the different equations that are envolved in the resolution of the THC model are presented.

\subsubsection{Mass Transfer}

Concrete can be defined as a porous material [8] made of a solid skeleton (cement matrix) (anhydrates and hydrates) and pores composed of liquid water, vapor water and wet air. Pores have a volume $\phi . S$ being the degree of saturation of the cement based material, the volume of $\phi$ occupied by liquid water is equal to $\phi S$ whereas the volume occupied by gas (vapor water and wet air) is equal to $\phi(S-1)$. Knowing that liquid water has a density $\rho_{l}$ whereas vapor water has a density $\rho_{v}$ and wet air a density $\rho_{a}$, it is possible to calculate the mass of the liquid water $m_{l}$, the mass of the vapor water $m_{v}$ and the mass of the dry air $m_{a}$ in the porous concrete medium using equations $1.1,1.2$ and 1.3 .

$$
\begin{gathered}
m_{l}=\rho_{l} \phi S \\
m_{v}=\rho_{v} \phi(1-S) \\
m_{a}=\rho_{a} \phi(1-S)
\end{gathered}
$$

During concrete hydration, chemical reactions that take place consume liquid water. The mass of liquid water consumed during such reactions is $m_{l \rightarrow \xi}$. Cement based materials are open thermodynamic systems allowing water exchange with the surrounding environment. Thus, part of the liquid water present in the cement based material evaporates in the surrounding environment if concrete structures are not covered with protective sheets (i.e non endogenous conditions). $m_{l} \rightarrow v$ is the mass of liquid water that evaporates.

Liquid water, vapor water and dry air are governed by the following equilibrium equations.

$$
\begin{gathered}
\frac{\partial m_{l}}{\partial t}+\operatorname{div}\left(w_{l}\right)=-\frac{\partial m_{l \rightarrow v}}{\partial t}-\frac{\partial m_{l \rightarrow \xi}}{\partial t} \\
\frac{\partial m_{v}}{\partial t}+\operatorname{div}\left(w_{v}\right)=\frac{\partial m_{l} \rightarrow v}{\partial t}
\end{gathered}
$$




$$
\frac{\partial m_{a}}{\partial t}+\operatorname{div}\left(w_{a}\right)=0
$$

In the previous equations, $w_{l}$ refers to the flux of liquid water, $w_{v}$ is the flux of vapor water and $w_{a}$ is the flux of dry air within the porous material. In fact, within the porous material, there are liquid water, vapor water and dry air movements that occur, their value depends on the permeability and diffusivity of the material that can be determined experimentally. Liquid water flux $w_{l}$ can be determined using the Darcy law given in equation 1.7.

$$
w_{l}=-\rho_{l} \frac{K_{l}^{e f f}}{\eta_{l}} \operatorname{grad}\left(p_{l}\right)
$$

In equation 1.7, $K_{l}^{e f f}$ is the effective permeability of liquid water in the concrete porous medium, $\eta_{l}$ is water viscosity and $p_{l}$ is liquid water pressure.

$$
\begin{gathered}
K_{l}^{e f f}=K \times K_{r l}\left(S_{l}\right) \\
K=K_{0} \frac{\phi}{\phi_{0}}
\end{gathered}
$$

Where $K$ is the permeability of the porous medium.

$$
K_{r l}\left(S_{l}\right)=S_{l}^{1 / 2}\left[1-\left(1-S_{l}^{2.27}\right)^{1 / 2.27}\right]^{2 / 2.27}
$$

Vapor water flux $w_{l}$ can be determined using a combination of Fick and Darcy law as shown in equation 1.11 .

$$
w_{v}=-D_{e f f} \operatorname{grad}\left(\rho_{v}\right)-\rho_{v} \frac{K_{v}^{e f f}}{\eta_{g}} \operatorname{grad}\left(p_{g}\right)
$$

Where $\eta_{g}$ is the viscosity of gas and $p_{g}$ is the pressure of the gas mix, whereas $D_{\text {eff }}$ is the coefficient of the effective diffusion of water vapor in wet air.

$$
D_{e f f}=D \frac{\phi}{\tau}
$$

Where $\tau$ is the tortuosity and $D$ the coefficient of diffusion of water vapor in wet air 
whereas $K_{v}^{e f f}$ is the effective permeability relative of the air in the porous medium.

$$
\begin{gathered}
K_{v}^{e f f}=K \times K_{r g}\left(S_{l}\right) \\
K_{r g}\left(S_{l}\right)=\left(1-S_{l}\right)^{1 / 2}\left[1-S_{l}^{2.27}\right]^{2 / 2.27}
\end{gathered}
$$

$w_{a}$ which is the flux of dry air within the porous material can be calculated using equation 1.15

$$
w_{a}=-D_{e f f} \operatorname{grad}\left(\rho_{a}\right)-\rho_{a} \frac{K_{v}^{e f f}}{\eta_{g}} \operatorname{grad}\left(p_{g}\right)
$$

In order to calculate gas pressure value needed in the previous equation, there is a need to apply the Ideal-gas law as given in equation 1.16 .

$$
\rho_{i}=\frac{M_{i}}{R T} p_{i}
$$

Where $M_{i}$ is the molar mass of a given gas, $R$ is the ideal gas constant, $T$ is the temperature of the mix and $p_{i}$ is the pressure of gas and $\rho_{i}$ the density of gas. The liquid water pressure can be determined knowing the gas pressure (sum of water vapor and dry air) using the equation of Kelvin-Laplace (equation 1.17 )

$$
p_{g}-p_{l}=-\rho_{l} \frac{R T}{M_{l}} \ln (h)
$$

Where:

$$
p_{g}=p_{v}+p_{a}
$$

Equation 1.18 is the Dalton's law of partial pressures. It states that the total pressure exerted is equal to the sum of the partial pressures of the individual gases.

$$
h=\frac{p_{v}}{p_{v s a t}}
$$

Where $p_{\text {vsat }}$ is the saturated vapor pressure and $h_{e q}$ is the equivalent humidity. At the miniscus surface between liquid water phase and vapor water phase (figure 1.1), if the equivalent humidity is reached, liquid vapor can evaporate. $h$ is the relative humidity. It can be defined as the ratio of the water vapor pressure and the saturated pressure vapor of water. It is also assumed that the rate of change between the liquid phase and the vapor 
phase is proportional to the difference between the vapor pressure and the saturation vapor pressure.

$$
\frac{\partial m_{l \rightarrow v}}{\partial t}=k_{l \rightarrow v}\left(h_{e q}-h\right)
$$

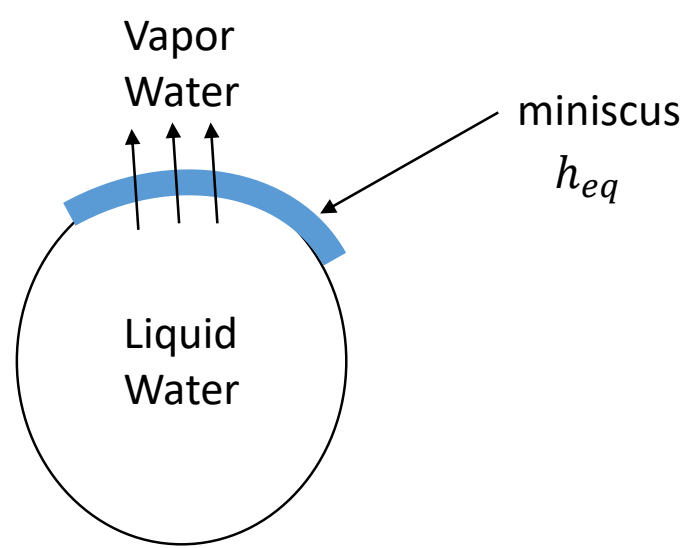

Figure 1.1: Equivalent humidity at the miniscus interface between liquid and vapor water

In order to determine $h_{e q}$, the desorption curve needs to be drawn. Indeed as shown in equation 1.21 , the degree of saturation $S$ and the humidity $h$ are linked.

$$
S(\alpha, T, h)=\left(1-\exp \left[-m \frac{2 \gamma M_{e}^{n \alpha}}{\rho_{l} R T \ln (h)}\right]\right)^{p}
$$

In equation 1.21, $M_{e}$ is the molar mass of water whereas $m, n$ and $p$ are constants that need to be determined using calibration. $k_{l} \rightarrow v\left(h_{e q}-h\right)$ is a coefficient chosen to initiate numerical calculations.

\subsubsection{Hydration reaction}

The degree of hydration $\alpha$ is defined as the ratio between the mass of cement that reacted during the hydration reaction and the mass of the initial anhydrous $m_{c}$ cement before hydration starts:

$$
m_{c}^{\text {dissolved }}=\alpha m_{c}
$$

At each hydration time step, it is possible to use the value of $\alpha$ the degree of hydration in order to calculate: the volume of dissolved cement that reacted which is $V_{d i s}$, the volume 
of the remaining cement that didn't react defined as $V_{a n h}$ and the volume of cement paste which is made of anhydrous cement and dissolved cement and defined as $V_{\text {paste }}$.

$$
V_{\text {dis }}=\alpha \frac{m_{c}}{V_{\text {paste }} d_{c}}
$$

The volume of anhydrous cement at each time step can be calculated using the following expression:

$$
V_{a n h}=(1-\alpha) \frac{m_{c}}{V_{\text {paste }} d_{c}}
$$

The dissolved cement reacts with the available free water that becomes a bound water of volume $V_{e c}$ in order to form hydrates. The volumic fraction of hydrates per unity of paste volume can be calculated using the contraction of Le Chatelier parameter $\beta_{\text {chat }}$ :

$$
V_{\text {hyd }}=\beta_{\text {chat }}\left(V_{\text {dis }}+V_{e c}\right)
$$

$\gamma$ is the stoichiometric ratio of the hydration reaction of cement: It is defined as the mass of water $m_{e c}$ needed so that all the initial anhydrous cement $m_{c}$ reacts (equation 1.26 ).

$$
\gamma=\frac{m_{e c}}{m_{c}}
$$

Using $\gamma$ it is possible to determine the volume of bound water.

$$
V_{e c}=\gamma \alpha \frac{m_{c}}{V_{\text {past }} d_{e}}
$$

Thus $m_{l \rightarrow \xi}$ defined previously as the mass of water consumed during the reaction of hydraction can be written as:

$$
m_{l \rightarrow \xi}=\gamma \alpha \frac{m_{c}}{V_{\text {past }}}
$$

The model that governs the hydration kinematic was developed by Laurie Buffo-Lacarriere as part of her PhD thesis work [6]. The rate of the reaction is induced by two antagonist mechanisms. Chemical activation promotes the chemical reaction whereas the loss of accessibility of cement to the water is a slowing down factor of the reaction. The rate of the hydration chemical reaction depends on the temperature of the system. Such dependence is expressed by the Arrhenius equation (equation 1.29 ). 


$$
\dot{\alpha}=A e^{-\frac{-E_{a}}{R T}}
$$

Where $A$ is the coefficient of Chemical Affinity (usually taken as a polynomial sum function of the degree of hydration with constant paramters that need to be calibrated) [10], $T$ the temperature, $E_{a}$ is the activation energy (constant) and $R$ is the universal gas constant. Thus, the Arrhenius equation relates the heat equilibrium reaction (which allows determining the temperature of the system) to the hydration reaction. The two equilibriums are therefore interdependent. In the model proposed by Buffo-Lacarriere such expression is enhanced using two terms $k$ and $\pi$ as shown in equation 1.30 .

$$
\dot{\alpha}=k \pi A e^{-\frac{-E_{a}}{T}}
$$

Where $\pi$ is the coefficient of accessibility to water.

$$
\pi=e^{\left[-B\left(\frac{r_{m}}{r_{k}}\right)^{n}\right]}
$$

Where $r_{m}$ is the radius of accessibility given by:

$$
r_{m}=\frac{V_{h y d}}{S \phi_{p} V_{a n h}}
$$

Where $\phi_{p}$ is the porosity of the paste. In the hydration model of Buffo-Lacarrière, the coefficient of chemical activation $A$ is calculated as follow:

$$
A=\frac{\alpha m_{c}}{V_{\text {paste }} S d_{c}}
$$

$d_{c}$ being the density of cement and $d_{e}$ the density of water. The volume of hydrates can be determined using the following expression:

$$
V_{\text {hyd }}=\beta_{\text {chat }}\left(1+\gamma \frac{d_{c}}{d_{e}}\right) V_{d i s}
$$

The total porosity $\phi$ is defined as:

$$
\phi=1-\left(V_{\text {hyd }}+V_{\text {anh }}\right) V_{\text {paste }}
$$

$\phi$ can be calculated using the following differential equation that relates it to the rate of 
hydration $\dot{\alpha}$ :

$$
\dot{\phi}=\dot{\alpha}\left[1-\beta_{\text {chat }}\left(1+\gamma \frac{d_{c}}{d_{e}}\right)\right] \frac{m_{c}}{d_{c}}
$$

Which allows determining the chemical shrinkage $\epsilon_{\text {chemical }}$ using equation 1.37 :

$$
\epsilon_{\text {chemical }}=\alpha\left(\beta_{\text {chat }}-1\right)\left(1+\gamma \frac{d_{c}}{d_{e}}\right) \frac{m_{c}}{d_{c}}
$$

\subsubsection{Heat Transfer}

The heat equilibrium equation is the following:

$$
\rho C_{p} \frac{\partial T}{\partial t}+\operatorname{div}\left(-\lambda_{T} \operatorname{grad}(T)\right)=\frac{\partial Q_{1}}{\partial t}+\frac{\partial Q_{2}}{\partial t}
$$

Where: $\lambda_{T}$ is the coefficient of thermal conductivity and $\rho$ is the density of the porous material and $C_{p}$ is the specific heat capacity. The rate of the heat of hydration is given as :

$$
\frac{\partial Q_{1}}{\partial t}=\dot{\alpha} m_{c} Q_{\epsilon}
$$

Where $Q_{\epsilon}$ is the ultimate heat of hydration, $\alpha$ the hydration coefficient and $m_{c}$ the mass of anhydrous cement before hydration starts. Thus, heat transfer is directly related to hydration.

The Heat of vaporization can be calculated using:

$$
\frac{\partial Q_{2}}{\partial t}=-\frac{\partial m_{l} \rightarrow v}{\partial t} L_{l \rightarrow v}
$$

Where $L_{l \rightarrow v}$ is the latent heat of vaporization.

\subsubsection{Fluid-solid interaction}

According to the theory of porous medium developed by Coussy [8], the fluid that occupies the porous space interacts with the solid skeleton. Such interaction can be accounted for by defining an effective stress:

$$
\dot{\sigma}^{\prime}=k \dot{\epsilon}=\dot{\sigma}+b \dot{\pi}
$$


Where $k$ is the modulus of compressibility of the porous medium, $\epsilon$ the mechanical deformation, $b$ the Biot coefficient calculated following the expression [32]:

$$
b=\frac{\phi}{[1-0.5(1-\phi)]}
$$

Where $\phi$ is the material porosity and $\pi$ the equivalent pore pressure. The modulus of compressibility $k$ can be determined as follow:

$$
k=\frac{E}{3(1-2 \nu)}
$$

Where $E$ is the Young modulus of the mortar and $\nu$ the Poisson ratio.

The decrease of the degree of saturation induces a meniscus to form at the liquid-vapor interface which allows the equilibrium of surface forces below saturation vapor pressure.

$$
\pi=p^{*}-U
$$

Where $p^{*}$ is the average pressure in the fluid and $U$ is the sum of interfacial energies (liquid-gas interface, liquid-solid and solid-gas interface). The average pressure in the fluid is given by the Dalton Law (equation 1.45):

$$
p^{*}=S p_{l}+(1-S) p_{g}
$$

The sum of surface energies is defined as the surface air under the capillary pressure curve $p_{c}(S)$ as:

$$
U(S)=\int_{S}^{1} p_{c}(S) \mathrm{d} S
$$

Thus, it can be deduced that:

$$
d \pi=-S d p_{c}+d p_{g}
$$

Drying shrinkage $\left(\epsilon_{r}\right)$ can be determined knowing that: $\dot{\sigma}^{\prime}=k \dot{\epsilon}=\dot{\sigma}+b \dot{\pi}$

$$
\dot{\epsilon_{r}}=-\frac{b S}{k} \dot{p_{c}}+\frac{1}{k} \dot{p_{g}}
$$

The equation of Kelvin Laplace allows accounting for the physico-chemical equilibrium: 


$$
p_{c}=-\rho_{l} \frac{R T}{M_{l}} \ln (h)
$$

$p_{c}$ being the difference between the gas pressure and the liquid pressure it is possible to write:

$$
p_{g}-p_{l}=p_{c}(S)
$$

The capillary pressure $p_{c}$ can be written as a function of $S$ the degree of saturation as follow:

$$
p_{c}(S)=a\left(S^{-b}-1\right)^{1-1 / b}
$$

Where $a$ and $b$ are constants that depend on the type of material used.

Which gives the expression of the differential equation that allows getting the evolution of the drying shrinkage:

$$
\dot{\epsilon_{r}}=-\rho_{l} \frac{b S R T}{h k M_{l}} \dot{h}+\rho_{l} \frac{b S R \ln (h)}{k M_{l}} \dot{T}+\frac{1}{k} \dot{p_{g}}
$$

Then it is possible to deduce the total shrinkage $\epsilon_{\text {shrinkage }}$ by summing up the contributions of drying shrinkage $\epsilon_{r}$ and chemical shrinkage $\epsilon_{\text {chemical }}$.

$$
\epsilon_{\text {shrinkage }}=\epsilon_{r}+\epsilon_{\text {chemical }}
$$

\subsubsection{THC model summary}

In summary, in the considered THC model mass equilibrium equations, are related to the hydration reaction, itself related to the heat transfer equilibrium and to the fluid solid interactions that occur within the porous medium defined by the cement based material. In total, it is possile to define 21 main unknown variables of the problem (from which it is possible to determine sub variables). The model also allows writing 21 main equations which allows solving the problem in order to get the 21 variables evolutions over time using the COMSOL software. Among the variables that can be determined using the model: there is the evolution of the temperature within the structure $T$, the hydration rate evolution $\dot{\alpha}$, the Saturation evolution $S$, the porosity evolution $\phi$, the mass loss evolution and so on. A summary of the equations and unknowns of the model are presented in table 
1.1. It should also be pointed out that in the THC model there are many constants that

\begin{tabular}{|c|c|c|}
\hline Equation number & Equation & Number of unknonws \\
\hline 1 & $\frac{\partial m_{l}}{\partial t}+\operatorname{div}\left(w_{l}\right)=-\frac{\partial m_{l} \rightarrow v}{\partial t}-\frac{\partial m_{l} \rightarrow \xi}{\partial t}$ & 7 \\
\hline 2 & $\frac{\partial m_{v}}{\partial t}+\operatorname{div}\left(w_{v}\right)=\frac{\partial m_{l} \rightarrow v}{\partial t}$ & $m_{l}, m_{v}, m_{a}$ \\
\hline 3 & $\frac{\partial m_{a}}{\partial t}+\operatorname{div}\left(w_{a}\right)=0$ & $w_{l}, w_{v}, w_{a}, \dot{m}_{l \rightarrow v}$ \\
\hline 4 & $\rho_{\text {wet-air }}=\frac{M_{i}}{R T} p_{\text {wet-air }}$ & 4 \\
\hline 5 & $\rho_{\text {vapor-water }}=\frac{M_{i}}{R T} p_{\text {vapor-water }}$ & $\rho_{\text {wet-air }}, \rho_{\text {vapor-water }}$ \\
\hline & & $p_{\text {wet-air }}, p_{\text {vapor-water }}$ \\
\hline 6 & $p_{g}-p_{l}=-\rho_{l} \frac{R T}{M_{l}} \ln (h)$ & 1 \\
\hline & & $p_{l}$ \\
\hline 7 & $w_{l}=-\rho_{l} \frac{K_{l}^{e f f}}{\eta_{l}} \operatorname{grad}\left(p_{l}\right)$ & 0 \\
\hline 8 & $w_{v}=-D_{e f f} \operatorname{grad}\left(\rho_{v}\right)-\rho_{v} \frac{K_{v}^{e f f}}{\eta_{g}} \operatorname{grad}\left(p_{g}\right)$ & 1 \\
\hline 9 & $w_{a}=-D_{\text {eff }} \operatorname{grad}\left(\rho_{a}\right)-\rho_{a} \frac{K_{v}^{e f f}}{\eta_{g}} \operatorname{grad}\left(\rho_{g}\right)$ & $p_{g}$ \\
\hline 10 & $p_{g}-p_{l}=p_{c}(S)$ & 1 \\
\hline & & $p_{c}(S)$ \\
\hline 11 & $p_{c}(S)=a\left(S^{-b}-1\right)^{1-1 / b}$ & 1 \\
\hline & & $S$ \\
\hline 12 & $S(\alpha, T, h)=\left(1-\exp \left[-m \frac{2 \gamma M_{e}^{n \alpha}}{\rho_{1} R T \ln (h)}\right]\right)^{p}$ & 1 \\
\hline & & $h$ \\
\hline 13 & $m_{l}=\rho_{l} \phi S$ & 1 \\
\hline 14 & $m_{v}=\rho_{v} \phi(1-S)$ & $\phi$ \\
\hline 15 & $m_{a}=\rho_{a} \phi(1-S)$ & \\
\hline 16 & $p_{g}=p_{v}+p_{a}$ & \\
\hline 17 & $\dot{\alpha}=k \pi A e^{-\frac{-E_{a}}{T}}$ & 2 \\
\hline & & $\alpha, T$ \\
\hline 18 & $\dot{\phi}=\dot{\alpha}\left[1-\beta_{\text {chat }}\left(1+\gamma \frac{d_{c}}{d_{e}}\right)\right] \frac{m_{c}}{d_{c}}$ & \\
\hline 19 & $\rho C_{p} \frac{\partial T}{\partial t}+\operatorname{div}\left(-\lambda_{T} \operatorname{grad}(T)\right)=\frac{\partial Q_{1}}{\partial t}+\frac{\partial Q_{2}}{\partial t}$ & 0 \\
\hline 20 & $\epsilon_{\text {chemical }}=\alpha\left(\beta_{\text {chat }}-1\right)\left(1+\gamma \frac{d_{c}}{d_{e}}\right) \frac{m_{c}}{d_{c}}$ & 1 \\
\hline & & $\epsilon_{\text {chemical }}$ \\
\hline 21 & $\dot{\epsilon_{r}}=-\rho_{l} \frac{b S R T}{h k M_{l}} \dot{h}+\rho_{l} \frac{b S R \ln (h)}{k M_{l}} \dot{T}+\frac{1}{k} \dot{p_{g}}$ & 1 \\
\hline & & $\epsilon_{r}$ \\
\hline
\end{tabular}

Table 1.1: THC Equations and unknowns

need to be determined through experimental calibration of the model as will be explained in Chapter 3. 


\subsubsection{Creep model}

Creep induces an increase of strain in concrete structures. It is possible to divide creep into two main categories [33]: basic creep due to the movements of water within the structure and drying creep caused by movements of water between the structure and the surrounding environment. In basic creep, it is possible to distinguish short term creep caused by the redistribution of water within the capillarities of the structure and long term creep induced by the displacement of gel particles under a loading. Basic creep can be measured experimentally using a ring test [10]. Drying creep is not yet a fully understood phenomenon due according to some theories to microcracking in concrete skin or to stressinduced shrinkage [34]. It is common to only model basic creep which is independent from shrinkage. Basic creep evolution of concrete structures at early age is function of the evolution of the degree of hydration $\xi[35]$. In order to model basic creep evolution at early age, certain authors suggested the use of a chain of Kelvin Voigt models put in series where each model has constant parameters that are added together in order to best approximate creep behavior [35]. Indeed, it was experimentally and mathematically proven that such rheological model allows to approach well creep evolution observed experimentally. De Schutter [35], suggested to replace the multiple Kelvin Voigt models with an original single Kelvin Voigt model that has varying parameters over time. Kelvin Voigt model parameters are calculated at each time step knowing the value of the rate of the hydration reaction. That later can be determined by solving a THC model for instance. The differential equation governing the Kelvin Voigt model is the following [10]:

$$
\tau_{b c} \ddot{\epsilon_{b c}}+\left(\tau_{b c} \frac{\dot{k}_{b c}(\xi)}{k_{b c}(\xi)}+1\right) \dot{\epsilon_{b c}}=\frac{\dot{\sigma}}{k_{b c}(\xi)}
$$

Where $\tau_{b c}$ is the characteristic time (contant), $k_{b c}$ is the spring stiffness (increasing with the degree hydration ), $\sigma$ the effective stress and $\xi$ the degree of hydration. $b c$ stands for basic creep.

$$
k_{b c}(\xi)=k_{b c \infty} \frac{0.473}{2.081-1.608 \xi} \xi^{0.62}
$$

Where $k_{b c \infty}$ is the final stiffness (at the end of the early age period). The Dashpot viscosity of the model is given by equation 1.56 .

$$
\eta_{b c}=k_{b c}(\xi) \tau_{b c}
$$


The Kelvin Voigt model presented by De Shutter has proven its efficiency in accurately reproducing the early age creep behavior of concrete structures. In order to have even finer results, authors of the article [10] proposed the use of three Kelvin Voigt viscoelastic models in series where each creep model has varying parameters: $k_{b c 1}, k_{b c 2}, k_{b c 3}, \eta_{b c 1}, \eta_{b c 2}$ and $\eta_{b c 3}$ that depend on the hydration evolution $\xi$ and constant parameters: $\tau_{b c 1}, \tau_{b c 2}$, $\tau_{b c 3}: k_{b c 1 \infty}, k_{b c 2 \infty}$ and $k_{b c 3 \infty}$. Each Kelvin Voigt model follows the differential equation given in equation 1.54 .

In order to better approximate the creep behavior of concrete during the early age period (0-28 days) it was proposed in [14] to choose time constants as follow: $\tau_{b c 1}=0.1$ day $; \tau_{b c}=1$ day and $\tau_{b c 3}=10$ days in a way to have a good coverage of all the period. As for $k_{b c 1 \infty}, k_{b c 2 \infty}$ and $k_{b c 3 \infty}$ they are determined through calibration (by fitting experimental and numerical creep data). In this thesis, a similar 3 Viscoelastic Kelvin Voigt model was implemented in an enhanced multifiber beam constitutive law in order to simulate the early age creep evolution of the portal frames as will be explained in Chapter 3.

\subsubsection{Mechanical models}

\subsubsection{Concrete mechanical model}

Over the years, Professor Jacky Mazars contributed to the development of many models that allow simulating the behavior of concrete structures.

The first model developed in 1984 known as the "Basic Model" [36] allowed characterizing the isotropic behavior of concrete structures under monotonic and static loadings in elasticity. Such model was based on a continuum mechanics approach and consisted in calculating 2 damage variables " $D_{c}$ " to account for concrete behavior in compression and " $D_{t}$ " for concrete behavior in traction. It was also based on the calculation of an equivalent deformation. In its $3 \mathrm{D}$ formulation, compression and traction damage parameters were combined to calculate a global damage variable " $\mathrm{D}$ ".

This first model was then enhanced later on to simulate the cyclic behavior of concrete structures. Between 1995 and 2001 the PRM model (standing for Pontiroli, Rouquand and Mazars) was developed [37. Such model accounts for permanent deformations and cracks openings and closings during the loading.

The PMR model was improved in order to reproduce the hysteretic behavior of concrete and to account for the effect of the velocity of the external applied loading (by 
multiplying the damage threshold with an amplification factor "R"). Taking into account the effect of the velocity of the external applied loading allows reproducing the behavior of concrete structures subjected to impact loadings (to simulate the behavior of rockfall protection galleries for instance). Such model was used for example in the thesis of Berthet Rambaud in 2004 under the Abaqus software [38].

Later on, the $\mu$ damage model was developed in 2013 [11]. It uses a simplified formalism and allows taking into account the cyclic and dynamic behavior of concrete structures. It consists in calculating two types of equivalent deformations in compression and traction from which two damage thresholds in compression and traction are calculated. They are then combined to define a global damage threshold. In its 1D formalism, the $\mu$ model also accounts for permanent deformations, hysteretic dissipation of energy and cracks openings and closings.

In conclusion, it can be said that while first attempts to model concrete behavior didn't account for permanent deformations and were not compatible with cyclic behavior [36], more recent models were able to reproduce the cyclic and dynamic behavior of concrete structures ( $\mu$ model of 2013) [11]. In this thesis, strain to stress relationship of concrete fibers was determined using the non-linear Mazars $\mu$ model [11]. It relates strain to stress using a damage variable $D$ calculated using a thermodynamics framework based on two variables $Y_{t}$ and $Y_{c}$ for concrete cracking and crushing.

$$
\begin{gathered}
\sigma=\Delta_{0}(1-D): \epsilon \\
Y=r Y_{t}+(1-r) Y_{c} \\
D=1-(1-A) \frac{Y_{0}}{Y}-A e^{-B\left(Y-Y_{0}\right)}
\end{gathered}
$$

Where $\Delta_{0}$ is the Stiffness Matrix, $\epsilon$ the Strain Matrix, $\sigma$ the Stress Matrix, $D$ the Damage variable, $r$ the Triaxiality factor, $A$ and $B$ are constant parameters, whereas $Y_{0}$ is the initial elastic threshold (takes into account compression and traction contributions).

Such model has proven its efficiency in accurately reproducing the cyclic behavior of concrete structures under static or dynamic loadings [11]. 


\subsubsection{Steel mechanical model}

The 1D non-linear Menegotto [39] cyclic model with strain hardening [40] is widely used in the literature as it accurately reproduces the behavior of steel rebars under dynamic and cyclic loadings. This model allows determining the normal stress $\sigma_{x x}$ within a steel reinforcement knowing as an input the axial deformation $\epsilon_{x x}$ of the steel fiber. The model is based on the following equation:

$$
\sigma_{x x}=b \epsilon_{x x}+\frac{(1-b) \epsilon_{x x}}{\left(1+\epsilon_{x x}^{R}\right)^{\frac{1}{R}}}
$$

In this equation $b$ is a constant corresponding to the hardening ratio, whereas $R$ evolves during time as follow:

$$
R=R_{0}-\frac{c_{R 1} \xi}{c_{R 2}+\xi}
$$

Where $R_{0}, c_{R 1}$ and $c_{R 2}$ are constants determined through calibration, whereas $\xi$ is calculated at each iteration step and is function of stress and strain values.

Such law will be used in order to simulate the behavior of the longitudinal steel reinforcements of the portal frames under study. It should be pointed out that in order to account for early age thermal deformation of steel rebars such model was slightly modified as will be explained in Chapter 3 .

To study the vulnerability of structures under earthquakes, civil engineers make use of numerical tools to approach the dynamic behavior of structures. Among popular methods used worldwide, we can find the Finite Element method. Such method is intuitive and easy to implement in numerical softwares. It also allows performing non-linear dynamic analysis of structures by solving the equation of motion of the considered system. Based on the Finite element method, civil engineers can perform different types of analysis such as the static pushover analysis, a modal analysis, the linear dynamic spectral analysis and the dynamic transient analysis. 3D Finite element analysis simulations, while being accurate are often hard to implement and are time consuming. Simplified methods such as the multifiber beam finite element approach have raised as an alternative method to model structures. Next section will present the main equations and steps involved when performing a non-linear dynamic analysis using the finite element approach. An explanation of the principle of the pushover analysis, the spectral and modal analysis as well as the transient analysis will be given in addition to an explanation of the multifiber 
beam finite element approach.

\subsection{Finite Element (FE) modeling for earthquake engi- neering}

\subsubsection{Non-linear Dynamic Analysis}

The dynamic behavior of a structure can be determined using a non-linear finite element (FEM) approach [41]. In such technique, the studied structure is devided into elements (1D beam elements, 2D elements, 3D elements, etc.) as shown in figure $1.2 \mathrm{a}$. Each element is composed of nodes at its ends where displacement values are unknown. The displacement at any position of the structure can be determined starting from the nodal displacements (once determined) through interpolation using shape functions. Thus, the FEM allows going from a continuous problem to a descritized problem.

When being subjected to a loading, the structure has to satisfy the equation of motion at each time step (equation 1.62 ) in the global coordinate system (coordinate system of the structure).

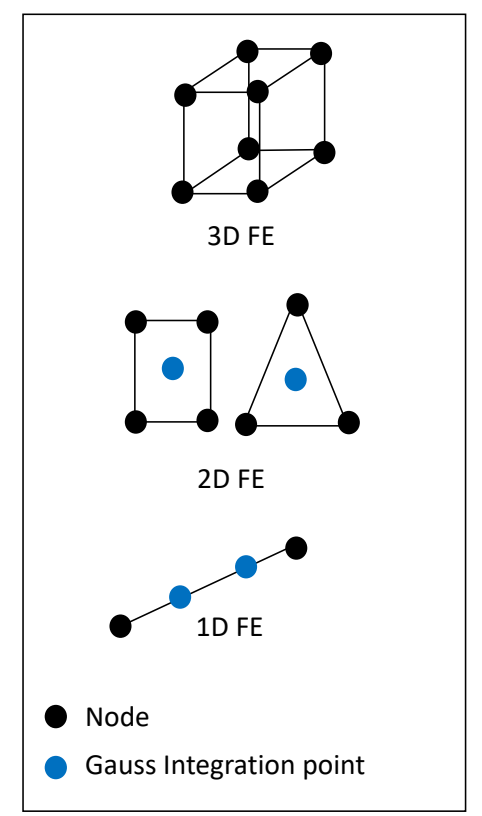

(a)

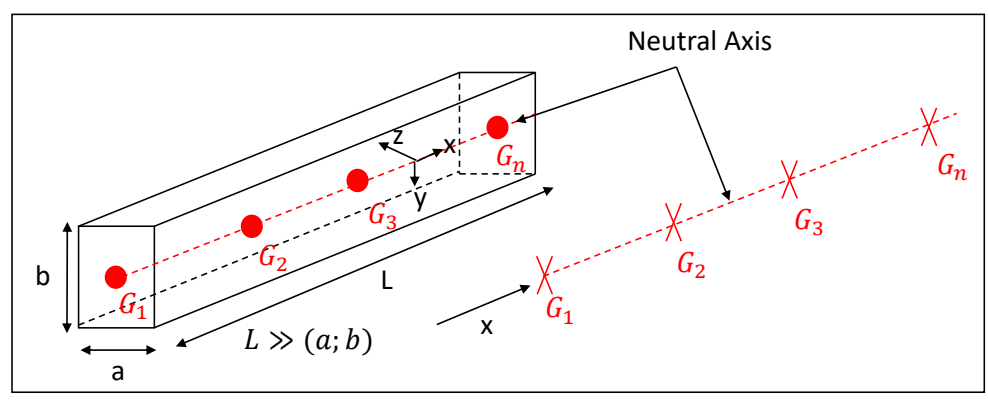

(b)

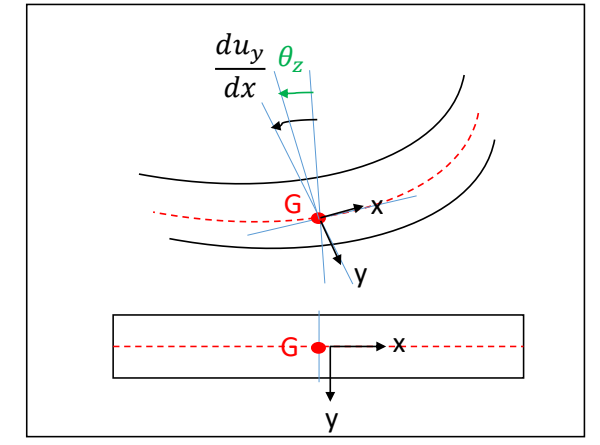

(c)

Figure 1.2: (a) Finite element types (b) the beam theory (c) Timoshenko beam kinematic in $2 \mathrm{D}$ 


$$
M \ddot{U}_{i}+C \dot{U}_{i}+P\left(U_{i}, \dot{U}_{i}, \ddot{U}_{i}\right)=F_{i}
$$

Where $i$ is the time step, $M$ is the Mass matrix , $C$ is the Damping matrix, $P\left(U_{i}, \dot{U}_{i}, \ddot{U}_{i}\right)$ is the Restoring force, $F$ is the External load vector, $U$ is the Nodal displacement vector, $\dot{U}$ is the Nodal velocity vector and $\ddot{U}$ is the Nodal acceleration vector.

Knowing the displacement, velocity and acceleration vectors at time step $i$, the objective is to determine those variables at the following time step $i+1$. By writing the equation of motion at time step $i+1$, we come up with the following equation 1.63

$$
M \ddot{U}_{i+1}+C \dot{U}_{i+1}+P\left(U_{i+1}, \dot{U}_{i+1}, \ddot{U}_{i+1}\right)=F_{i+1}
$$

In the previous equation displacement, velocity and acceleration values are unknown. To solve the problem, there is a need to use 2 additional equations that relate velocity and acceleration to diplacement. Among temporal existing integration schemes, the Newmark equations involving $\beta$ and $\gamma$ parameters are often used in the literature [42]. Written at time step $i+1$, Newmark equations are expressed as follow:

$$
\begin{gathered}
\dot{U}_{i+1}=\dot{U}_{i}+(1-\gamma) \Delta t \ddot{U}_{i}+\frac{\gamma}{\beta \Delta t}\left[U_{i+1}-U_{i}-\Delta t \dot{U}_{i}-\left(\frac{1}{2}-\beta\right) \Delta t^{2} \ddot{U}_{i}\right] \\
\ddot{U}_{i+1}=\frac{1}{\beta(\Delta t)^{2}}\left[U_{i+1}-U_{i}-\Delta t \dot{U}_{i}-\left(\frac{1}{2}-\beta\right) \Delta t^{2} \ddot{U}_{i}\right]
\end{gathered}
$$

$\gamma$ and $\beta$ values are chosen depending on the temporal integration scheme wanted. In our case: $\gamma$ was chosen equal to $\frac{1}{2}$ and $\beta$ to $\frac{1}{4}$. Choosing such constants allows having an implicit scheme free of numerical dissipation of energy and unconditionally stable. Using such relations, the equation of motion becomes:

$$
\left(\frac{1}{\beta(\Delta t)^{2}} M+\frac{\gamma}{\beta \Delta t} C\right) U_{i+1}+P\left(U_{i}, \dot{U}_{i}, \ddot{U}_{i}\right)=F_{i+1}+\left[\frac{C \gamma}{\beta \Delta t}+\frac{M}{\beta(\Delta t)^{2}}\right] U_{i}+\left[C\left(\frac{\gamma}{\beta}-1\right)+\frac{M}{\beta \Delta t}\right] \dot{U}_{i}+\left[C \Delta t\left(\frac{\gamma}{\beta}\left(\frac{1}{2}-\beta\right)-(1-\gamma)\right)+\frac{M\left(\frac{1}{2}-\beta\right)}{\beta}\right] \dot{U}_{i}
$$

In the previous equation, the right side is known. It is composed of the external loading and of constants. On the left side, the mass matrix and the damping matrix are known constants whereas the internal force vector $P\left(U_{i}, \dot{U}_{i}, \ddot{U}_{i}\right)$ and the displacement vector $U_{i+1}$ are unknowns. If the material behaves linearly the term $P\left(U_{i}, \dot{U}_{i}, \ddot{U}_{i}\right)=P\left(U_{i+1}\right)=K U_{i+1}=$ $F_{i+1}$ and the system can be solved directly. However, if the material has a non-linear 
behavior then, the internal force $P$ is a non linear function of the kinematic variables $(U$, $\dot{U}$ and $\ddot{U})$ and its expression depends on the material constitutive law. Thus, the equation of motion is solved directly using an iterative procedure (Newton-Raphson algorithm). The resolution process of the Newton procedure can be divided into 5 main steps:

1. The displacement vector at time step $i+1$ is at first assumed to be equal to the displacement vector at time step $i$ and $k$ which is the counter for the Newton loop is set equal to 1 .

2. From the assumed displacement vector value, strain vector is determined (the relation between displacement and strain depends on the chosen kinematic: Timsohenko, Navier-Bernoulli, etc.) More generally, the relation between displacements and strains depends on the shape functions of the finite elements used (QUA4, TRI3, etc.)

3. Knowing the material constitutive law, stress vector is calculated and from it the internal force vector $P$ is determined (by assembling the contributions of the different elements).

4. A residual parameter $R_{i+1}$ is definied at time step $i+1$ as equal to the difference between the right side and the left side of the equation of motion (equation 1.67). If its value is more important than an $\epsilon$ threshold chosen value, the Newton loop starts.

$$
R_{i+1}=-P\left(U_{i}, \dot{U}_{i}, \ddot{U}_{i}\right)+F_{i+1}=-P_{i+1}+F_{i+1}
$$

5. Newton loop

The displacement vector at time step $i+1$ is corrected by adding and additional term $\delta U_{i+1}^{k}$ and $k$ is set equal to $k+1 . \delta U_{i+1}^{k}=\frac{-R_{i+1}^{k}}{\left(\frac{\partial R}{\partial U}\right)_{i+1}^{(k)}}$.

Where:

$$
\left(\frac{\partial R}{\partial U}\right)_{i+1}^{(k)}=\frac{1}{\beta(\Delta t)^{2}} M+\frac{\gamma}{\beta \Delta t} C+K
$$

$\left(\frac{\partial R}{\partial U}\right)_{i+1}^{(k)}$ is the tangent operator and the value of $\delta U_{i+1}^{k}$ is determined through a linearization of $R_{i+1}^{k}$.

Knowing the material constitutive law, stress vector is calculated and from it the internal force vector $P$ is determined. 
The residual parameter of iteration $i+1$ which equals to the difference between the right side and the left side of the equation of motion is calculated. If its value is more important than the $\epsilon$ threshold chosen value, the Newton loop continues. Otherwise, the Newton loop ends.

Thus, the displacement vector assumed at one Newton iteration step $k$ is corrected by adding and additional term $\delta U_{i+1}^{k}$ until converging towards a null residual value.

It should be pointed out that all the equations that were expressed were given in a global coordinate system $(\mathrm{X}, \mathrm{Y}, \mathrm{Z})$. Which means that if the considered structure is composed of many finite elements then there is a need to define a global stiffness matrix starting from the individual stiffness matrices of the elements (depending on the element type) as well as global displacement and internal load vectors. In this thesis, the portal frames were devided into Timoshenko beam finite elements with 3 degrees of freedom per node (plane problem).

\subsubsection{Seismic analysis of structures}

In order to quantify the seismic behavior of structures, civil engineers perform different types of analysis [43]. Static pushover analysis allows determining the initial stiffness of structures and their strength capacity, modal analysis allows determining the numerical signature of a structure and its natural frequencies that are needed to conduct a spectral analysis. Transient analysis is a more advanced and complex type of analysis that allows simulating the non-linear dynamic behavior of structures. A brief explanation of the principle of the pushover analysis, the modal and spectral analysis as well as the transient analysis will be given next.

\subsubsection{Static Pushover}

A pushover analysis is a non-linear static analysis [44. It allows evaluating the inelastic response of a building without performing a full dynamic non-linear analysis. In a force based approach, it consists in imposing on a structure monotonically increasing lateral loads applied at the center of mass of the floors that push the building (which explains the term pushover analysis) until its displacement reaches some predetermined limits (maximum allowable storey drift or ductility limit) or until the structure reaches an unstable state or experiences collapse. In such analysis, the structure is subjected to a modal inertia force distribution [43]. In a displacement based approach, a pushover consists in applying a monotonically increasing displacement Time History on a structure until reaching its ultimate capacity. A pushover analysis allows drawing a capacity curve which is the curve 
giving the evolution of base shear as a function of the displacement on top of a structure. Such curve gives interesting information such as the initial elastic stiffness or the ultimate strength of a structure [44].

In order to conduct a pushover analysis using a finite element software with a displacement based approach, the idea is to solve a simplified version of the equation of motion (equation 1.62 presented previously, where velocity and acceleration terms are removed and where a static displacement time history is imposed at the nodes positioned at the center of masses of the floors of the structure (following a modal inertia displacement distribution accounting for the effective mass participation of the different modes). The known displacements are removed from the equation and then that later is solved.

\subsubsection{Modal and Spectral analysis}

Modal analysis allows getting the natural frequencies and mode shapes of a structure. When performing a modal analysis, the equation of motion becomes:

$$
M \ddot{U}_{i}+K U_{i}=0
$$

Where $M$ is the Mass matrix , $U$ is the Nodal displacement vector, $\ddot{U}$ is the Nodal acceleration vector and $K$ is the stiffness matrix. In fact, when performing a modal analysis, we are solving the equation of motion knowing the intial displacement and velocity. The idea is to suppose that displacement can be written as : $U=u e^{i \omega t}$ where $\omega$ is the angular frequency of the system and $u$ the mode shape. The equation 1.69 becomes then :

$$
\left[-\omega^{2} M+K\right] u e^{i \omega t}=0
$$

The determinant of $\left[-\omega^{2} M+K\right]$ gives the frequencies, from which it is possible to determine the mode shapes $u$. Mode shapes give the proportions of how much one mass displaces in comparison to the others, the value of displacement being time dependent. In a finite element approach, a modal analysis can be performed by inverting the global stiffness $K$ of the finite element structure. In fact, the eigenvalues of $K^{-1} M$ are the $\frac{1}{\omega_{i}^{2}}$ values.

Based on the modal frequencies or periods obtained using a modal analysis, it is possible to perform a spectral analysis which is a dynamic linear analysis very commonly used in the practice for the design of structures. In order to conduct a spectral analysis, there is a need to know on the one hand the natural frequencies of a structure (that characterize the behavior of the structure) and on the other hand to have a response 
spectrum (given by seismologists or by design codes) that characterizes the effect of an earthquake on a single degree of freedom system.

A response spectrum can be constructed as follow: A linear single degree of freedom system is characterized by its mass and stiffness. Such system has a period (or frequency) that is function of its mass and stiffness. If we impose to that system an accelerogram, and that we write its equation of motion in terms of acceleration (by writing displacement and velocity values in terms of acceleration using for example Newmark equations), it is possible to directly determine its response in terms of acceleration. The maximum acceleration response of such system when being subjected to the accelerogram gives one point of the response spectrum curve. By choosing another combination of mass and stiffness leading to another period, we come up with another single degree of freedom system. If we apply to that new system the same accelerogram, we will get another maximum acceleration response (which gives a second point of the response spectrum). By repeating the same procedure, it is possible to construct the reponse spectrum of a single degree of freedom system to an earthquake. Such curve gives the pick acceleration response of a single degree of freedom system as a function of its period (or frequency).

However, such response spectrum is deduced using only one Time History accelerogram that is relative to one earthquake. Seismologists repeat the same procedure and draw other response spectrum curves for different earthquakes (time histories). Then the response under the worst scenario earthquake gives them the design response spectrum.

For each natural frequency of the structure (modal analysis), it is possible to determine using the response spectrum, the pick acceleration of the structure for the specific mode considered. From that value, the base shear $F_{i}^{\max }$ of the structure for the mode $i$ under consideration can be calculated (equation 1.71).

$$
F_{i}^{\max }=\frac{S_{p a} \times \phi_{i}^{T} M \delta}{\phi_{i}^{T} M \phi_{i}} M \phi_{i}
$$

Where: $S_{p a}$ is the spectral acceleration of mode $i ; \phi_{i}$ is the mode shape value at mode $i$; $M$ is the structure mass Matrix and $\delta$ is the projection vector.

In practice, only the modes that have an important effective mass $m_{\text {eff }}$ (equation 1.72 and participation factor (equation 1.73) are taken into account (the sum of mass participation of the considered modes should equal at least $90 \%$ of the total mass of the structure). 


$$
\begin{gathered}
m_{e f f_{i}}=\frac{\left(\phi_{i}^{T} M \delta\right)^{2}}{\phi_{i}^{T} M \phi_{i}} \\
p_{i}=\frac{\phi_{i}^{T} M \delta}{\phi_{i}^{T} M \phi_{i}}
\end{gathered}
$$

Where: $\phi_{i}$ is the mode shape value at mode $i$; $M$ is the structure mass matrix and $\delta$ is the projection vector.

Ultimately, the maximum base shear of the structure under the given response spectrum can be calculated by summing up base shear values $F_{i}^{\max }$ at each mode $i$.

In order to account for the non-linear behavior of structures using a spectral analysis it is possible to introduce ductility factors.

The spectral analysis method is very commonly used in the practice by civil engineers. Existing seismic codes provide a more simplified method known as the lateral force procedure [2]. In such method, only the fundamental period of the structure is considered in the analysis, and a procedure is provided for the users to account for higher mode effects.

\subsubsection{Transient Analysis}

A dynamic analysis can be performed numerically by applying an accelerogram (recorded) to studied structures. To achieve that, the equation of motion (equation 1.62 is solved as previously explained. The only difference is that due to the acceleration imposed to the structure an additional term is added on the right side of the equation and the external force term is removed since no external loading is imposed to the structure in addition to the accelerogram. The equation of motion that is solved becomes then:

$$
M \ddot{U}_{i}+C \dot{U}_{i}+P\left(U_{i}, \dot{U}_{i}, \ddot{U}_{i}\right)=-M \Delta A_{a c c}
$$

Where $M$ is the Mass matrix , $C$ is the Damping matrix, $P(U)$ is the Restoring force, $A_{a c c}$ is the accelerogram Time History, $U$ is the Nodal displacement vector, $\dot{U}$ is the Nodal velocity vector and $\ddot{U}$ is the Nodal acceleration vector.

In order to perform a non-linear dynamic analysis, there is a need to define a damping matrix. The damping matrix $C$ commonly chosen in the equation of motion is a Rayleigh 
damping matrix [43]. Such matrix is a combination of the mass matrix and stiffness matrix.

$$
[C]=\alpha M+\beta K
$$

By defining the damping this way, we come up with a diagonal matrix in the space of mode shapes. If the damping matrix is not diagonal in the space of mode shapes the different modes will be coupled due to damping.

$$
\begin{gathered}
\alpha=\frac{2 \times \xi \times \omega_{1} \omega_{2}}{\omega_{1}+\omega_{2}} \\
\beta=\frac{2 \times \xi}{\omega_{1}+\omega_{2}}
\end{gathered}
$$

Where $\omega_{1}$ and $\omega_{2}$ are the angular natural first natural frequencies and $\xi$ is the damping ratio.

\subsubsection{D Timoshenko beam FE}

Beam theory deals with structures having a cross-section very small in comparison to their length (Figure 1.2b). Such element types can be represented by a line (neutral axis). The different points of the line represent the position of the neutral axis of the cross section $\left(G_{1}, G_{2}, G_{3}\right.$, etc.) The Timoshenko beam theory considers that the section of the beam element remains straight but not necessarily perpendicular to its neutral axis (A distorsion of the cross-section is allowable).

As shown in figure 1.3, along the beam neutral axis, the displacement at a position $x$ of the axis is given by $U_{x}(x)$ following the $x$ direction $U_{y}(x)$, following the $y$ direction and $U_{z}(x)$ following the $z$ direction. The rotation at a position $x$ of the axis is given by $\theta_{x}(x)$ following the $x$ direction $\theta_{y}(x)$, following the $y$ direction and $\theta_{z}(x)$ following the $z$ direction. Such displacements and rotations are calculated through an interpolation using the nodal displacement and rotation values $U_{1 x}, U_{2 x}, U_{1 y}, U_{2 y}, U_{1 z}, U_{2 z}, \theta_{1 x}, \theta_{2 x}, \theta_{1 y}, \theta_{2 y}, \theta_{1 z}$ and $\theta_{2 z}$ as illustrated in Figure 3.8). From the displacement of the beam along the neutral axis, Timoshenko theory proposes to determine the displacement at any point of the cross section along the beam defined by its coordinates $(x, y, z)$ using equations 1.78, 1.79, and 1.80. Such equations account for the possible distorsion of the section, which is defined as a possible rotation between the cross section and the bending line (induced by shear deformation). Thus, the displacement following the $x$ direction of a point of the crosssection $u_{x}(x, y, z)$ depends on the displacement following the $x$ direction $U_{x}(x)$ of a point 


$$
\left[U_{x}(x) ; U_{y}(x) ; U_{z}(x) ; \theta_{x}(x) ; \theta_{y}(x) ; \theta_{z}(x)\right]
$$

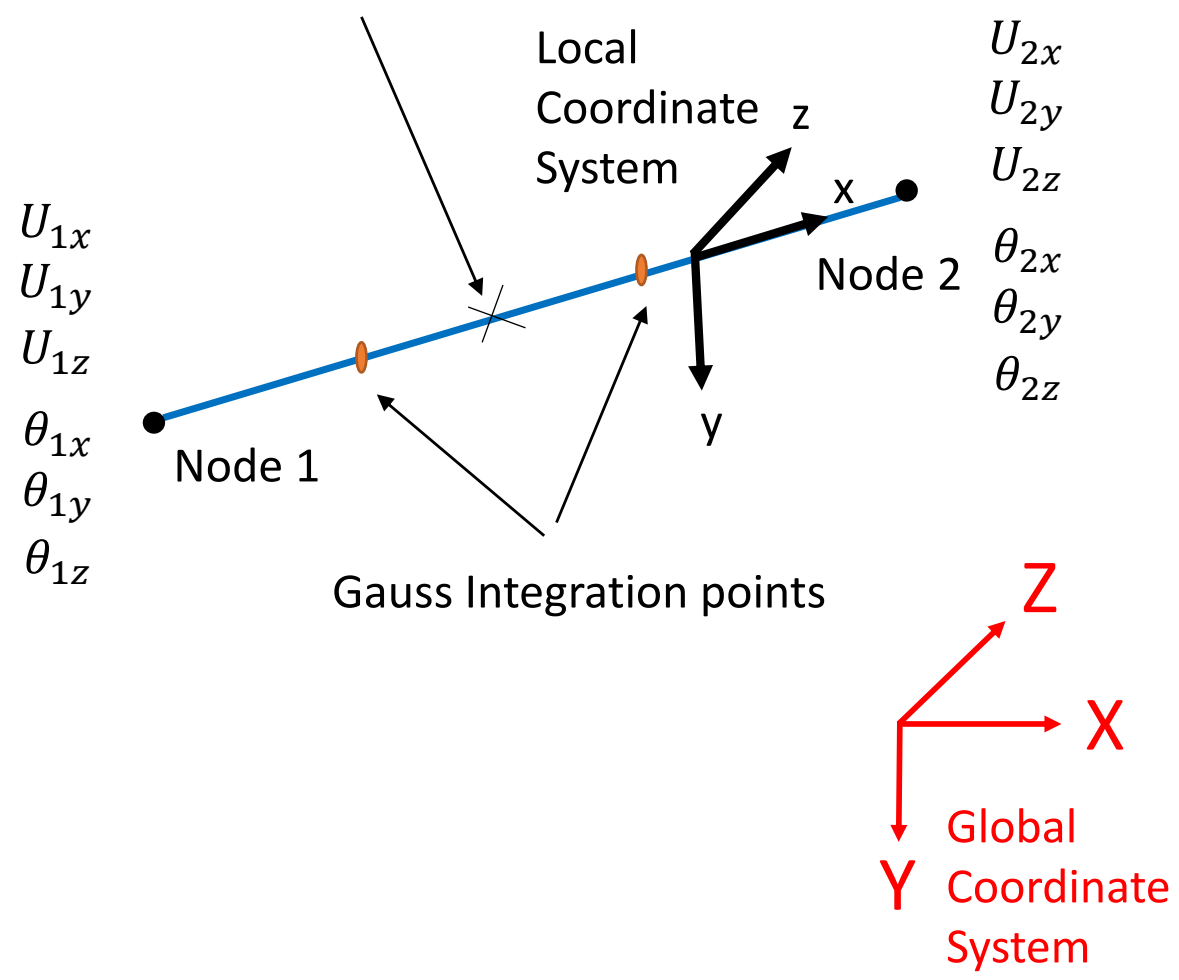

Figure 1.3: Generalized displacements and rotations and nodal displacements and rotations in a Timoshenko beam

at a position $x$ of the neutral axis, and the rotation $y$ and $z$ at a position $x$ of the neutral axis [45].

$$
\begin{gathered}
u_{x}(x, y, z)=U_{x}(x)-y \theta_{z}(x)+z \theta_{y}(x) \\
u_{y}(x, y, z)=U_{y}(x)-z \theta_{x}(x) \\
u_{z}(x, y, z)=U_{z}(x)+y \theta_{x}(x)
\end{gathered}
$$

If the considered problem is $2 \mathrm{D}, \theta_{x}$ and $\theta_{y}$ need to be removed from the previous expressions. In the $3 \mathrm{D}$ case, the deformation value at a given position ( $\mathrm{x}, \mathrm{y}, \mathrm{z})$ of the cross section can be determined by deriving the displacement expressions given previously [45]. 
Deformation expressions are given in equations 1.81 , 1.82 and 1.83 .

$$
\begin{gathered}
\epsilon_{x}(x, y, z)=\frac{\partial u_{x}}{\partial x}=U_{x}^{\prime}(x)-y \theta_{z}^{\prime}(x)+z \theta_{z}^{\prime}(x) \\
2 \epsilon_{x y}(x, y, z)=\frac{\partial u_{x}}{\partial y}+\frac{\partial u_{y}}{\partial x}=U_{y}^{\prime}(x)-\theta_{z}(x)-z \theta_{x}^{\prime}(x) \\
2 \epsilon_{x z}(x, y, z)=\frac{\partial u_{x}}{\partial z}+\frac{\partial u_{z}}{\partial x}=U_{z}^{\prime}(x)+\theta_{y}(x)+y \theta_{x}^{\prime}(x)
\end{gathered}
$$

In the Timoshenko finite element approach, a structure will be divided into Timoshenko beam elements. Each beam element will be characterized by its element stiffness, restoring force nodal vector and displacement nodal vector. By taking into account the contribution of all the finite elements, it is then possible to assemble the stiffness matrix as well as the displacement and load vectors of the structure in the global axis coordinate system to solve the equation of motion given previously. In order to determine the expression of the stiffness matrix and internal force vector of the different elements in the finite element approach, there is first a need to choose shape functions that allow determining the expression of the displacements along the elements as a function of the nodal displacements. $\{U(x)\}=[N]\{U\}$ where $\{U(x)\}$ is the generalized displacement vector at a positions $x$ of the beam element whereas $\{U\}$ is the nodal displacement vector and $[N]$ is the shape function matrix. At each node there are 3 unknown displacements and 3 unknown rotations. In our case, we chose the shape functions given in the matrix of equation 1.84 that can be found in Kotronis et.al [45]. Cubic shape functions were used for transverse displacements and quadratic for rotations. High order shape functions were used in order to overcome shear locking phenomenon. Such numerical phenomenon corresponds to the apparition of parasite stiffnesses in slender elements [45]. Using high order shape functions also allows for one element to reproduce the real displacement of a punctual and distributed loading under different boundary conditions. It should be pointed out that interpolation functions are determined once using the Elastic Young modulus 
and Elastic Shear stiffness and then assumed constants for the next steps [45].

$$
[N]=\left[\begin{array}{cccccccccccc}
N_{1} & 0 & 0 & 0 & 0 & 0 & N_{2} & 0 & 0 & 0 & 0 & 0 \\
0 & N_{3} & 0 & 0 & 0 & N_{4} & 0 & N_{5} & 0 & 0 & 0 & N_{6} \\
0 & 0 & N_{3}^{*} & 0 & -N_{4}^{*} & 0 & 0 & 0 & N_{5}^{*} & 0 & -N_{6}^{*} & 0 \\
0 & 0 & 0 & N_{1} & 0 & 0 & 0 & 0 & 0 & N_{2} & 0 & 0 \\
0 & 0 & -N_{7}^{*} & 0 & N_{8}^{*} & 0 & 0 & 0 & -N_{9}^{*} & 0 & N_{10}^{*} & 0 \\
0 & N_{7} & 0 & 0 & 0 & N_{8} & 0 & N_{9} & 0 & 0 & 0 & N_{10}
\end{array}\right]
$$

Where: $N_{1}=1-\frac{x}{L} ; N_{2}=\frac{x}{L}$;

$$
\begin{aligned}
& N_{3}=\frac{1}{1+\phi}\left\{2\left(\frac{x}{L}\right)^{3}-3\left(\frac{x}{L}\right)^{3}-\phi\left(\frac{x}{L}\right)+1+\phi\right\} \\
& N_{4}=\frac{L}{1+\phi}\left\{\left(\frac{x}{L}\right)^{3}-\left(2+\frac{\phi}{2}\right)\left(\frac{x}{L}\right)^{2}+\left(1+\frac{\phi}{2}\right)\left(\frac{x}{L}\right)\right\} \\
& N_{5}=\frac{1}{1+\phi}\left\{2\left(\frac{x}{L}\right)^{3}-3\left(\frac{x}{L}\right)^{2}-\phi\left(\frac{x}{L}\right)\right\} \\
& \left.N_{6}=\frac{L}{1+\phi}\left\{\left(\frac{x}{L}\right)^{3}-\left(1-\frac{\phi}{2}\right)\left(\frac{x}{L}\right)^{2}-\frac{\phi}{2}\right)\left(\frac{x}{L}\right)\right\} \\
& N_{7}=\frac{6}{(1+\phi) L}\left\{\left(\frac{x}{L}\right)^{2}-\left(\frac{x}{L}\right)\right\} \\
& N_{8}=\frac{1}{(1+\phi) L}\left\{3\left(\frac{x}{L}\right)^{2}-(4+\phi)\left(\frac{x}{L}\right)+(1+\phi)\right\} \\
& N_{9}=-\frac{6}{(1+\phi) L}\left\{\left(\frac{x}{L}\right)^{2}-\left(\frac{x}{L}\right)\right\} \\
& N_{10}=\frac{1}{(1+\phi)}\left\{3\left(\frac{x}{L}\right)^{2}-(2-\phi)\left(\frac{x}{L}\right)\right\} \\
& N_{i}^{*}=N_{i}\left(\phi^{*}\right) \phi=\frac{12 \int_{S} E_{y}^{2} d S}{L^{2} k_{y} \int_{S} G d S}=\frac{12 E I_{z}}{L^{2} k_{y} G A} \text { and } \phi^{*}=\frac{12 \int_{S} E_{z}^{2} d S}{L^{2} k_{z} \int_{S} G d S}=\frac{12 E I_{y}}{L^{2} k_{z} G A}
\end{aligned}
$$

Where $G$ is the shear modulus, $E$ the Young modulus, $L$ is the length of the beam element, $k_{y}$ and $k_{z}$ are shear correction factors (their value is function of the material and cross-section geometry) [46], $I_{z}$ and $I_{y}$ are the sections's moment of Inertia and $A$ is the area of the cross-section. As previously stated, the Timoshenko kinematic then allows linking the generalized displacements to the generalized deformations. $\{\epsilon(x, y, z)\}=$ $[B]\{U\}$. Again, $\epsilon$ is the generalized deformation vector at a position of coordinate (x,y,z) in the beam element that can be deduced knowing the nodal displacements $\{U\}$ and the chosen kinematic (here Timsohenko kinematic using the $[B]$ matrix given in equation 1.85. Knowing that, it is possible to write the equation of motion in its weak form [41] and using the theorem of virtual work it is possible to determine the expression of the Timoshenko element stiffness as well as the restoring force vector [45]. Such expressions are given in equations 1.88 and 1.89 


$$
[B]=\left[\begin{array}{cccccccccccc}
N_{1}^{\prime} & 0 & 0 & 0 & 0 & 0 & N_{2}^{\prime} & 0 & 0 & 0 & 0 & 0 \\
0 & N_{3}^{\prime}-N_{7} & 0 & 0 & 0 & N_{4}^{\prime}-N_{8} & 0 & N_{5}^{\prime \prime}-N_{9} & 0 & 0 & 0 & N_{6}^{\prime}-N_{10} \\
0 & 0 & N_{3}^{\prime *}-N_{7}^{\prime *} & 0 & -N_{4}^{\prime *}+N_{8}^{\prime *} & 0 & 0 & 0 & N_{5}^{\prime *}-N_{9}^{\prime *} & 0 & -N_{6}^{*}+N_{10}^{\prime *} & 0 \\
0 & 0 & 0 & N_{1}^{\prime} & 0 & 0 & 0 & 0 & 0 & N_{2}^{\prime} & 0 & 0 \\
0 & 0 & -N_{7}^{\prime *} & 0 & N_{8}^{\prime *} & 0 & 0 & 0 & -N_{9}^{\prime *} & 0 & N_{10}^{\prime *} & 0 \\
0 & N_{7}^{\prime} & 0 & 0 & 0 & N_{8}^{\prime} & 0 & N_{9}^{\prime} & 0 & 0 & 0 & N_{10}^{\prime}
\end{array}\right]
$$

In equation 1.85, the ' sign stands for the derivative operation with respect to $x$. Each beam element will return the internal force vector $P_{\text {nod }}$ giving force values at the nodes of the beam element. Such vector can be calculated using the expression of the sectional force vector $P_{s}$ (equation 1.86):

$$
P_{s}=\left[N ; T_{y} ; T_{z} ; M_{x} ; M_{y} ; M_{z}\right]^{T}
$$

$N=\int_{S} \sigma_{x x} \mathrm{~d} S ; T_{y}=\int_{S} \sigma_{x y} \mathrm{~d} S ; T_{z}=\int_{S} \sigma_{x z} \mathrm{~d} S ; M_{z}=-\int_{S} y \sigma_{x x} \mathrm{~d} S ; M_{y}=\int_{S} z \sigma_{x x} \mathrm{~d} S ;$ $M_{x}=\int_{S}\left(-z \sigma_{x y}+y \sigma_{x z}\right) \mathrm{d} S$

Each beam element also returns an element stiffness matrix $\left[K_{\text {elem }}\right]$ that can be calculated by first determining the expression of the sectional stiffness matrix $\left[K_{s}\right]$ (equation 1.87 .

$$
\begin{gathered}
{\left[K_{s}\right]=\left[\begin{array}{cccccc}
k_{s 11} & 0 & 0 & 0 & k_{s 15} & k_{s 16} \\
0 & k_{s 22} & 0 & k_{s 24} & 0 & 0 \\
0 & 0 & k_{s 33} & k_{s 34} & 0 & 0 \\
0 & k_{s 24} & k_{s 34} & k_{s 44} & 0 & 0 \\
k_{s 15} & 0 & 0 & 0 & k_{s 55} & k_{s 56} \\
k_{s 16} & 0 & 0 & 0 & k_{s 56} & k_{s 66}
\end{array}\right]} \\
{\left[K_{\text {elem }}\right]=\int_{0}^{L}[B]^{T}\left[K_{s}\right][B] \mathrm{d} x} \\
{\left[P_{\text {nod }}\right]=\int_{0}^{L}[B]^{T}\left[P_{s}\right] \mathrm{d} x}
\end{gathered}
$$

$k_{s 11}=\int_{S} E \mathrm{~d} S, k_{s 15}=\int_{S} E z \mathrm{~d} S, k_{s 16}=-\int_{S} E y \mathrm{~d} S, k_{s 22}=k_{y} \int_{S} G \mathrm{~d} S, k_{s 24}=-k_{y} \int_{S} G z \mathrm{~d} S$, $k_{s 33}=k_{z} \int_{S} G \mathrm{~d} S, k_{s 34}=k_{z} \int_{S} G y \mathrm{~d} S, k_{s 44}=\int_{S} G\left(k_{z} y^{2}+k_{y} z^{2}\right) \mathrm{d} S, k_{s 55}=\int_{S} E z^{2} \mathrm{~d} S$, $k_{s 56}=-\int_{S} E y z \mathrm{~d} S, k_{s 66}=\int_{S} E y^{2} \mathrm{~d} S$ 


\subsubsection{Multi fiber beam FE}

The Multifiber beam concept was first introduced by Owen and Hilton [47], then it was largely adapted by many authors and proved its efficiency in accurately reproducing the Non-linear behavior of structures. Multifiber beam elements were then gradually enhanced to account for transverse reinforcements, shear, torsion, warping, etc. [46] [48] [49]. In the multifiber approach, the beam is divided into longitudinal fibers (Figure 1.4). Each fiber behaves independently and constributes to the global behavior of the beam element. This approach is an intermediate approach (The structure is not modeled in 3D nor in 1D) and allows accounting for material non-linearity of behavior (for example concrete material). Also, multifiber beams allow modeling non-homogenous (composite) cross-sections as each fiber can be made of a different material type (In RC structures for example we will have concrete fibers and steel fibers). In the expression of the sectional stiffness matrix given in equation 1.87 and of the sectional force vector (equation 1.86) there is a need to integrate over the cross section the expressions of young modulus and stresses which is easy to achieve using the multifiber beam approach. Indeed, in a multifiber beam the cross-section is divided into fibers and strain is calculated at the positions $\left(x_{i}, y_{i}, z_{i}\right)$ of the fibers independently, then stress (or young modulus) contributions of the different fibers are added to give the contribution of the whole cross-section. Fibers can be positioned by equally discretizing the cross section. In this thesis, and in order to further simplify numerical integrations, fibers are chosen to be positioned at the Gauss points of the crosssections.

To illustrate this concept, we can give the example of a beam element having a cross section made of concrete and steel (Figure1.4a). We assume that the cross-section is made of $n_{y f i b}=3$ concrete fibers in the y direction and of $n_{z f i b}=4$ concrete fibers in the z direction as well as of $n_{s}=4$ steel fibers of section $A_{s t}$ (it is possible to choose different values for $n_{y f i b}, n_{z f i b}$ and $n_{s}$, the same procedure will still apply). The RC cross-section is a rectangular cross-section of height $h$ and width $b$. The concrete fibers represented by lines (Figure $1.4 \mathrm{~b}$ ) are chosen to be localized at the Gauss points of the cross section as in the rest of the thesis.

In order to solve the problem there is a need to consider three scales of resolution (the element scale, the section scale and the material scale).

1. The scale of the Timoshenko beam element: The generalized displacement evolution along the beam element neutral axis is calculated using the nodal displacements through shape functions.

2. The section scale: The strain value at a fiber positioned at coordinates $(x, y, z)$ is 
determined using the Timoshenko kinematic.

3. The material scale: The stress value of the fibers is determined using different constitutive laws that depend on the type of material used (concrete, steel...). Knowing stress values at each fiber, section internal forces or sectional stiffness can be determined using the Gauss quadrature approach. Concrete contribution to the normal internal force $N$, shear forces $T_{y}, T_{z}$ and moments $M_{z}, M_{y}$ and $M_{x}$ can be determined as follow:

$$
\begin{gathered}
N=\int_{S} \sigma_{x x} \mathrm{~d} S=\int_{-b / 2}^{+b / 2} \int_{-h / 2}^{+h / 2} \sigma_{x x}(x, y, z) d y d z=\sum_{i=1}^{3} w_{i} \sigma_{x x}\left(x, y_{i}, z\right) \frac{b}{2} \sum_{j=1}^{4} w_{j} \sigma_{x x}\left(x, y, z_{j}\right) \frac{h}{2} \\
T_{y}=\int_{S} \sigma_{x y} \mathrm{~d} S=\int_{-b / 2}^{+b / 2+h / 2} \int_{-h / 2}^{+2} \sigma_{x y}(x, y, z) d y d z=\sum_{i=1}^{3} w_{i} \sigma_{x y}\left(x, y_{i}, z\right) \frac{b}{2} \sum_{j=1}^{4} w_{j} \sigma_{x y}\left(x, y, z_{j}\right) \frac{h}{2} \\
T_{z}=\int_{S} \sigma_{x z} \mathrm{~d} S=\int_{-b / 2-h / 2}^{+b / 2+h / 2} \int_{x z}(x, y, z) d y d z=\sum_{i=1}^{3} w_{i} \sigma_{x z}\left(x, y_{i}, z\right) \frac{b}{2} \sum_{j=1}^{4} w_{j} \sigma_{x z}\left(x, y, z_{j}\right) \frac{h}{2} \\
M_{z}=-\int_{S} y \sigma_{x x} \mathrm{~d} S=\sum_{i=1}^{3} w_{i} \sigma_{x x}\left(x, y_{i}, z\right) y_{i} \sum_{j=1}^{4} w_{j} \sigma_{x x}\left(x, y, z_{j}\right) \frac{h}{2} \\
M_{y}=\int_{S} z \sigma_{x x} \mathrm{~d} S=\sum_{i=1}^{3} w_{i} \sigma_{x x}\left(x, y_{i}, z\right) \frac{b}{2} \sum_{j=1}^{4} w_{j} \sigma_{x x}\left(x, y, z_{j}\right) z_{i} \\
M_{x}=-\sum_{i=1}^{3} w_{i} \sigma_{x z}\left(x, y_{i}, z\right) \frac{b}{2} \sum_{j=1}^{4} w_{j} \sigma_{x z}\left(x, y, z_{j}\right) z_{i}+\sum_{i=1}^{3} w_{i} \sigma_{x y}\left(x, y_{i}, z\right) y_{i} \sum_{j=1}^{4} w_{j} \sigma_{x y}\left(x, y, z_{j}\right) \frac{h}{2}
\end{gathered}
$$

$w_{i}$ and $w_{j}$ being the weight functions of the Gauss Integration quadrature, whereas $y_{i}$ and $z_{j}$ are the coordinates of the Gauss points. Such values are known in the literature and depend on the number of Gauss points chosen. In this example: for 


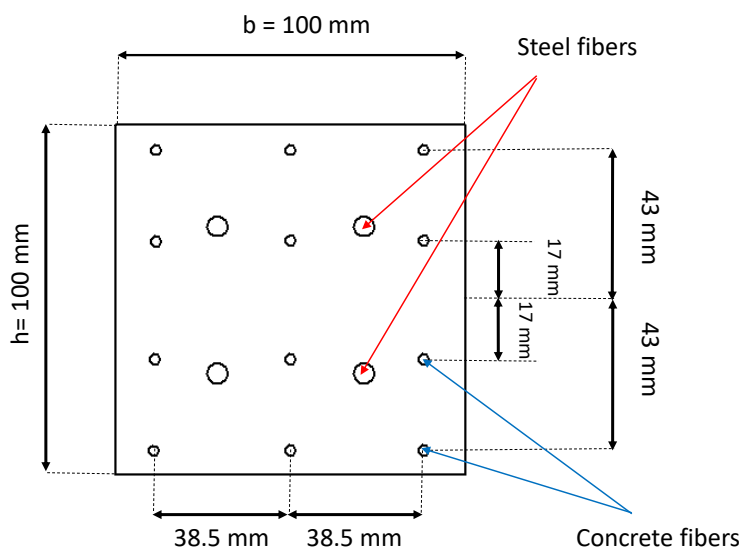

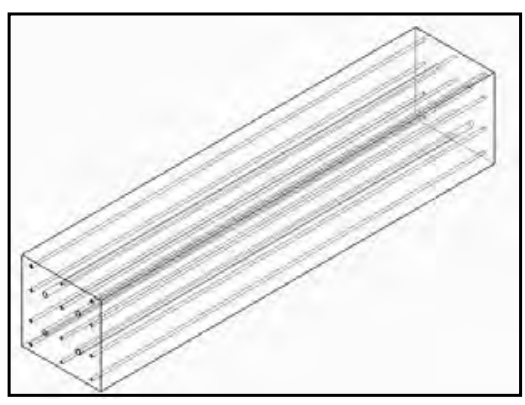

(b)

\section{(a)}

Figure 1.4: Multifiber beam element (a) Cross section with Gauss Integration positions (b) Longitudinal fibers

$i=1, w_{i}=\frac{8}{9}, y_{i}=0$. For $i=2, w_{i}=\frac{5}{9}, y_{i}=\sqrt{\frac{3}{5}}$ and for $i=3, w_{i}=\frac{5}{9}, y_{i}=-\sqrt{\frac{3}{5}}$. For $j=1, w_{j}=0.65, z_{j}=0.34$, for $j=2, w_{j}=0.65, z_{j}=-0.34$, for $j=3$, $w_{j}=0.35, z_{j}=0.86$, for $j=4, w_{j}=0.35, z_{j}=-0.86$. Figure 1.4 gives the position of the different Gauss points of this example. For the contribution of the steel rebars, stress values are determined at the position of each steel fiber, then this stress value is multiplied by the area $A_{s t}$ of the steel longitudinal rebars, which gives the contribution to the normal internal force of each steel fiber. Then the different contributions are added to the one coming from concrete. The same approach can be used to determine the different sectional forces and the sectional stiffness while accounting for the contribution of the different fibers.

Multifiber elements are suitable for implementation in home made finite element softwares (Filippou [50], Grange [51], etc.) The ATL4S finite element code developed on Matlab by Stéphane Grange [51] was used.

\subsubsection{Enhanced multifiber beam FE}

As previously stated, with multifiber beam elements, it is necessary to consider three scales of resolution: the element scale, the section scale and the material properties scale. Each of 
these scales can be enhanced by adding internal degrees of freedoms. At the element scale: Internal degrees of freedom can be added to the Timoshenko beam elements in order to account for embedded discontinuities [52] (to take into account the development of cracks within the element or plastic hinges). At the section scale, internal degrees of freedom can be added to account for warping, shear and lateral confinements due to stirrups [53], thus by enhancing the section kinematic. At the material scale, internal degrees of freedom can also be used in order to enhance the non-linear material law [54]. In our case, internal degrees of freedom were used in order to enhance the non-linear constitutive law, thus accounting for creep, shrinkage, thermal and mechanical deformations. The Algorithm used for the resolution will be explained in Chapter 3 of this thesis.

\subsection{Experimental techniques for RC structures moni- toring}

\subsubsection{Overview}

In order to study the dynamic behavior of structures, many experimental techniques exist: quasi-static tests, force-vibration tests, shaking table tests or pseudodynamic tests [55]. That later has proven in the recent decades its efficiency in accurately determining the seismic behavior of structures while being less costly than some popular techniques such as the shaking table test. In order to monitor structures that are being experimentally tested, many measurement techniques exist: Digital image correlation, optical fiber, ambient vibration measurements and so on. The dynamic behavior of the two types of portal frames studied in this thesis was determined using the Pseudo-dynamic technique. A review of this technique will be presented next. Then, the principle of different measurement techniques that were used as well during the testing process will be explained.

\subsubsection{Pseudo dynamic approach}

\subsubsection{History}

The Pseudo-dynamic technique was first developed in the 70s in Japan by Hakuro. The work conducted by Hakuro was summarized later by Takanashi and Nakashima [56]. In 1984, Shing and Mahin of the University of Berkeley (Seismic Engineering Research Center) have published an article [57] where they have explained the advantages of the pseudo-dynamic technique in overcoming some of the limitations of the shaking table technique. In fact, constructing shaking tables is usually very expensive which explains 
why shaking tables that are constructed are usually of small dimensions. Thus, they don't allow testing structures of important dimensions (real size structures). Tested structures are usually of reduced scales which induces dynamic and material similitud issues. Also, due to the small dimensions of the shaking tables, weight of tested structures has to be limited and for heavy samples structure interaction issues arise. Pseudodynamic technique is less costly since it requires the use of a reaction wall rather than a supporting table and allows testing structures of real dimensions. Also, substructuring is a very interesting feature of pseudodynamic tests that can be used in order to test part of a structure which behavior needs to be quantified while the rest of the structure is modeled numerically (In reference [58] substructuring test results were presented). First pseudodynamic test attempts were performed using the explicit Newmark method that presents the disadvantage of being conditionally stable [57. Then, a new implicit integration technique was proposed allowing overcoming stability, error propagation and high frequency noise issues [59] [60]. The $\alpha$ Operator Splitting algoritthm technique was developed later on at the ELSA Lab in Italy. It is a linearization of the $\alpha$ Method and presents the advantage of being non iterative and easy to integrate [4]. Such technique has proven its efficiency and is widely used today. Also, real time hybrid experiments that allow to dynamically test structures have been developed worldwide [61].

\subsubsection{Principle and limitations}

The pseudo-dynamic technique allows solving the equation of motion.

$$
M \ddot{U}+C \dot{U}+P(U)=F_{e x t}
$$

Where $M$ is the Mass matrix (Modeled), $C$ is the Damping matrix (Modeled), $P(U)$ is the Restoring force (Measured), $F_{\text {ext }}$ is the External load vector (Modeled), $U$ is the Nodal displacement vector, $\dot{U}$ is the Nodal velocity vector and $\ddot{U}$ is the Nodal acceleration vector. Thus, the mass of the system as well as the external load are numerically simulated while the restoring force of the system is measured experimentally.

The $\alpha$ OS Splitting algorithm adapted by Combesure and Pegon [4] was used in this thesis. It consists in predicting a displacement that is imposed to the structure using a jack. The real displacement of the structure is measured using a displacement sensor while the restoring force is measured using a load sensor. Then, a new displacement to be imposed in the next step is calculated. Using this iterative procedure (Figure 1.5), it is possible to determine the non-linear response of structures subjected to a seismic 


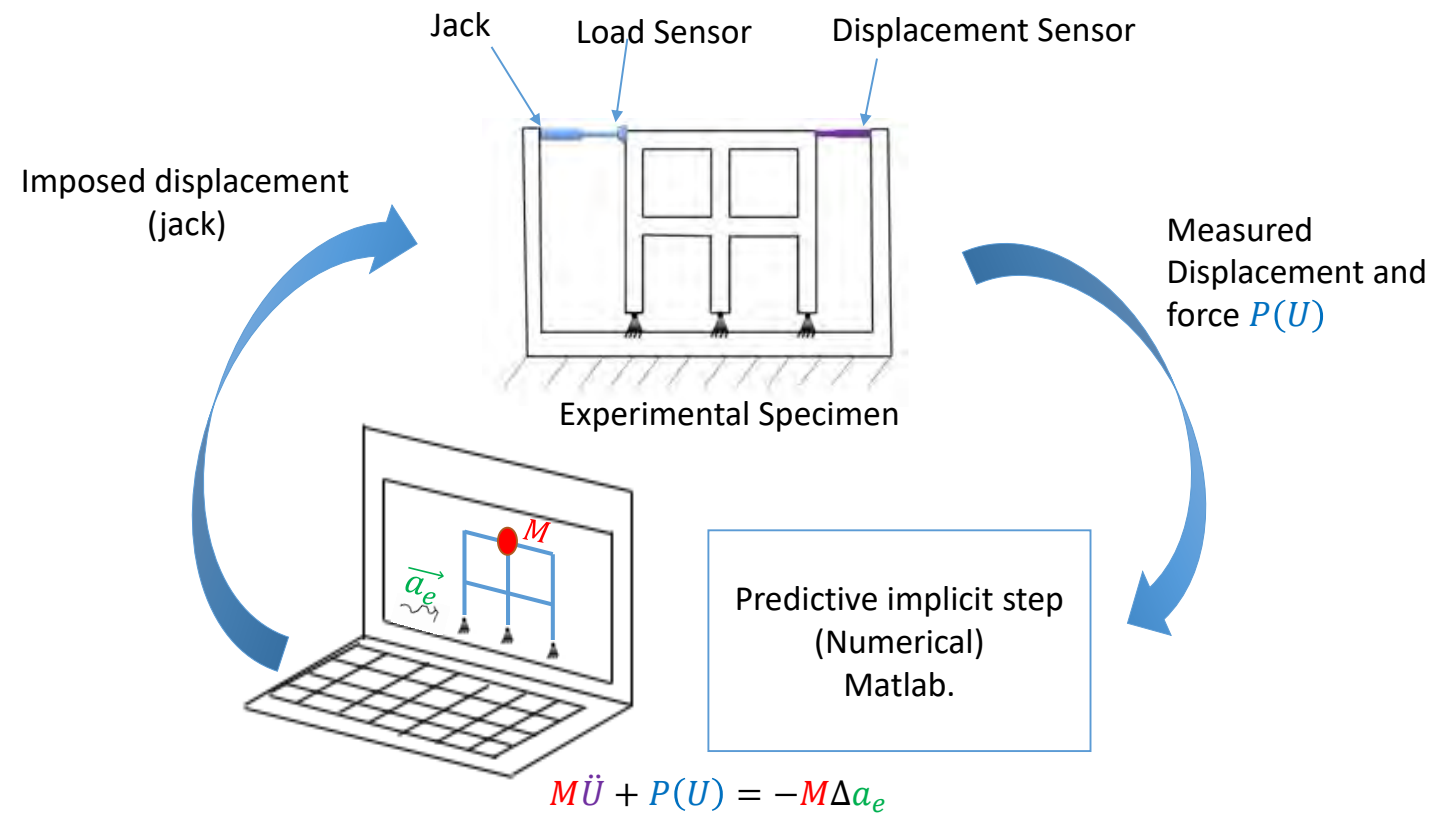

Figure 1.5: Iterative PsD procedure [4]

accelerogram.

The PsD technique presents limitations and cannot be used to accurately study the dynamic behavior of any structure. In fact, tested structures need to be lumped mass structures and their behavior doesn't have to be dependent on the rate of the loading (velocity dependence) since the test is a static test. Also, in order to use the $\alpha$ Splitting algorithm tested structures don't have to deform a lot (very important stiffness loss) [4]. The PsD technique can be used to accurately determine the seismic behavior of reinforced concrete structures. The response of such structures depends on the velocity of the imposed loading. However, if the velocity of the loading is low, the response of reinforced concrete structures remains similar under even lower velocity loadings. Seismic loading velocity is small enough and therefore the pseudodynamic method can be used [61]. The ELSA Laboratory in Italy for instance has performed many pseudo-dynamic tests on RC structures [62]. 


\subsubsection{Measurement techniques}

In order to monitor the dynamic behavior of structures, many measurement techniques exist. Among them, displacement sensors (LVDT), load sensors (pancake load cells), Digital Image correlation, ambient vibration and optical fibers were used in this thesis in order to follow damage and cracks apparition patterns of the tested portal frames. LVDT and pancake load cells are classical measurement techniques widely used in the practice for punctual measurements. LVDT sensors (standing for Linear Variable Differential Transformers) associate a position to an electrical signal, whereas pancake load cells associate a force to an electrical signal. The principle of digital image correlation, ambient vibration and optical fiber measurements will be explained next.

\subsubsection{Digital Image Correlation}

2D Digital Image correlation [63] 64 [64 65 [66] allows following diplacements and cracks apparitions in structures subjected to a mechanical loading. Displacement and strain values are determined by tracking changes between a reference image and subsequent images. Digital image correlation gives information on a local level as well as on a global level.

It requires the use of a camera as well as applying a grey level speckle pattern on the area to be tracked. The camera captures images of the Region of Interest (ROI) at a given interval of time. In our case the ROI is the whole portal frame. A speckle has to be applied on the ROI using for instance a white lime undercoating over which black dots are applied (using a painting). The dots have to be of different sizes and shapes in order to have a random texture. The original image is divided into numerical grids. Each grid is supposed to have a specific pattern different from the other grids. And it is assumed that from one image to the other the grid gray level remains constant.

$$
f(X)=g(\phi(X))
$$

In equation 1.97, $f$ is the reference image gray level expressed as a function of pixel coordinates whereas $g$ is the deformed image gray level expressed as a function of pixel coordinates. $X$ being the pixel coordinate in the initial state and $U$ the displacement of the pixel from the original configuration to the deformed image configuration, $f$ and $g$ need to satisfy equation 1.97 .

$$
\phi(X)=X+U(X)
$$

Equation 1.98 is the optical flow equation. The objective of image correlation is to 
find the $U$ displacement that best approximates that equation. The problem to be solved being a non linear ill posed problem, solving it necessitates using an iterative procedure and writing the displacement field as a combinaison of shape functions (On a similar way as in classical finite element problems). Thus, the original image has to be devided into finite elements for interpolation (four noded quadrilateral finite elements, triangular finite elements, etc.)

$$
U(X)=\bar{U}(X)+d U(X)
$$

Where $\bar{U}(X)$ is known. $d U(X)$ is the correction imposed to gradually correct the displacement value. Such expression can be written as a Taylor expansion for linearlization purposes.

$$
g(X+\bar{U}(X)+d U)=g(X+\bar{U}(X))+\nabla g \cdot d U(X)
$$

In order to determine the displacement value, the gradient of $g(\nabla g)$ should be non null in all the directions. To achieve this condition, there is a need to apply a random texture on the area of interest (different size of dots). Also, since the dots are of circular shapes, the gradient is defined in all the directions.

$$
C_{\text {err }}=(f(X)-g(X+U)) / f(X)
$$

Digital image correlation error allows following cracks apparition. Correlation error $C_{\text {err }}$ is calculated as shown in equation 1.101. It corresponds to the difference of gray level of a pixel of coordinate $X$ in the initial image $(f(X))$ and the gray level of the same pixel positioned at coordinate $X+U(X)$ in the deformed image devided by $(f(X))$. An important correlation error implies that the algorithm is not able to accurately find the corresponding pixels between the initial image and the deformed ones. It can be due to a lighting issue, a painting degradation or a crack apparition. Such data was used in this project in order to characterize cracks apparition [67]. Image correlation was performed using the UFreckles software [13].

\subsubsection{Ambient vibration measurements}

In order to determine the dynamic characteristics of a structure (frequency content, damping, etc.) it is possible to impose an excitation to the structure (impulse loading, sinusoidal loading, etc.) and to measure its response. An interesting alternative to this destructive process is to use the ambient vibration technique. It consists on using vibrations due to wind, oceans, transport, human activity, etc., to determine the dynamic properties of a structure such as its frequency content (at low frequencies $(<1 \mathrm{~Hz})$ using ocean ambient 
noise and at high frequencies using wind ambient noise (about $0.5 \mathrm{~Hz}$ up to about 15 to 60 $\mathrm{Hz}$ ) and anthropological noise (traffic, industries, $>2-4 \mathrm{~Hz})$ ), damping and modal shapes [68].

Once the vibrations of the structure under ambient vibrations are measured (using an accelerometer, a velocimeter, etc.), it is possible to use a Fast Fourier Transform in order to get the natural frequencies of the structure. The damping ratio of the structure can be determined using the half bandwith power technique. The Random Decrement Technique (RDT) is a more accurate technique used in order to extract the dynamic characteristics of the structure (frequency and damping ratio). Such technique was first introduced by Cole in the 70s [69]. It is based on the observation that under a loading the response of a given structure can be expressed as [70]:

$$
\begin{gathered}
x_{k r}(t)=x_{0 k r} D(t)+\dot{x}_{0 k r} V(t)+\phi_{k r} \int_{0}^{t} \phi_{r}^{T} h_{r}(t-\tau) f(\tau) d \tau \\
D(t)=e^{-\xi_{r} \omega_{r} t}\left(\cos \left(\omega_{d r}\right) t+\frac{\xi_{r} \omega_{r}}{\omega_{d r}} \sin \left(\omega_{d r}\right) t\right) \\
V(t)=\frac{1}{\omega_{d r}} \sin \omega_{d r} t
\end{gathered}
$$

In the previous equations $h_{r}(t)$ is the $r^{\text {th }}$ component of unit impulse response function of a viscously damped single-degree-of-freedom system; $x_{0 k r}$ and $x_{0 k r}$ is the initial displacement and velocity at the $k^{\text {th }}$ DOF; $\xi_{r}$ is the damping ration, $\phi_{r}$ is the rth mode shape; $\omega_{r}$ and $\omega_{d r}$ are the natural frequency and damped frequency. In equation 1.102 giving the response of the structure (displacement as a function of time ), the two first terms represent the response of the structure under a free vibration (under an initial displacement and veclocity) whereas the third term represents the response of the structure under a loading $f(t)$. By averaging the response of the structure the two last terms can be canceled and only the first term which has the shape of an exponential decay remains. Indeed, $f(t)$ follows a white noise Gaussian process and $\dot{v}$ is a zero mean Gaussian process and can thus be removed by averaging the data. Then, by fitting an exponential decay it is possible to determine the dynamic characteristics of the structure (which explains the name of the technique). Indeed $\xi$ is the damping ratio and $\omega$ the angular frequency that we are trying to determine. Practically speaking, for a multiple degree of freedom system, 
a first step consists on using a Fast Fourier transform on the response of the structure in order to roughly determine the natural frequencies of the structure. Once such values are known, if we want to determine more precisely the frequency and damping ratio of the $k^{t h}$ mode of the structure, then the measured response signal of the structure needs to be filtered around the needed mode. The filtered response is then divided into windows of the same size (having the same intial conditions: displacement and velocity). By taking the average of the different windows, it is possible to come up with the RD signal (a sinusoidal decreasing signal). An exponential decay can then be fitted to the decreasing signal. In order to measure the vibrations of the structure (via acceleromers or veocimeters for example) a recorder is needed to perform microtremor measurements. Many instrument types exist in the practice, the one chosen in this project is CityShark II [71. Such device is user friendly since it is portable and light-weight, it doesn't require the user to enter many paramaters (the amplifier gain, the sampling frequency and the time period of recording ar the main input parameters needed). Furthermore, such recorder has an interactive screen and doesn't require the use of an external computer in order to perform measurements. It is stored in a protective box that allows to transport it and to protect it from environmental harsh conditions (Figure 1.6). Moreover it has an internal battery for power supply, which allows it having an autonomy in case of power outage. Data is recorded in a memory card for later treatment.

\subsubsection{Optical fiber measurements}

Monomode optical fibers with a Rayleigh scattering were used (LUNA Brand) in this thesis. Such sensors are made of a silica glass core of small diameter covered by a Polyurethane cladding. The small core diameter $(2.8 \mathrm{~mm})$ allows transmitting only one mode of light. The advantage of this type of sensors is that it is not prone to dispersion and is accurate for long distance measurements. The core reflecting index is chosen to be very high in a way to have a total internal reflection. This technology allows conducting continous distributed strain measurements (384 measurements per meter) with a very high accuracy, which is very useful in the detection of crack openings [72]. The precision of the strain measurements is equal to $1 \mu \epsilon$. Along the optical fiber local imperfections are distributed and their position is known. An input light is imposed in the optical fiber and its reflections by back scattering are measured. When no strain or temperature is being imposed to the system, light propagates and gets reflected throughout the imperefections with a given signature. When strain or temperature values vary the frequency of the back scattered light is shifted. Strain value is related to the frequency shift. 


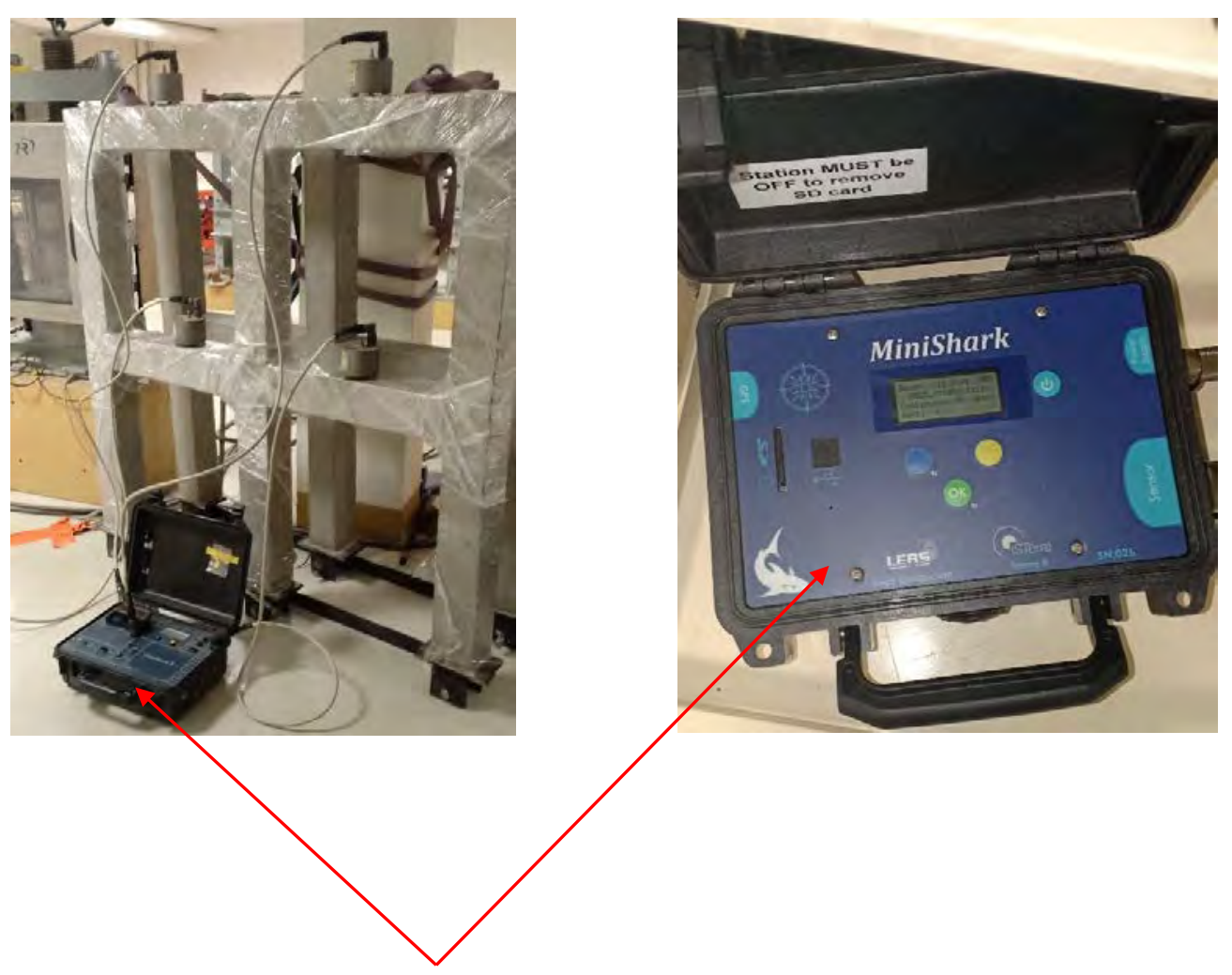

\section{City Shark II Recorder}

Figure 1.6: Ambient vibration recorder City Shark II 


\subsection{Conclusions}

In this Chapter, an explanation of the main concepts and techniques that were used in this thesis to quantify the effects of early age damage on the seismic response of RC structures both experimentally and numerically was given.

The principle of the pseudo-dynamic technique was explained. Such technique was used in order to experimentally study the dynamic behavior of two groups of portal frames that evolded respectively in endogenous and non-endogenous conditions during early as will be explained in details in Chapter 2. In order to monitor such structures during experiment, load and displacement sensors were used as well as Digital Image Correlation, ambient vibration measurements and optical fiber measurements. The principle of such measurements techniques was provided in this state of the art (section 1.5).

The portal frames tested in Chapter 2, were modeled using the finite element multifiber Timoshenko beam approach presented in this state of the art (section 1.4) as will be explained in Chapter 3. The constitutive law of the elements forming the portal frames was enhanced in order to account for early age damage (creep, shrinkage,thermal deformations and mechanical deformations). Creep was modeled using 3 Kelvin Voigt viscoelastic models in series as explained in section 1.3.2, whereas the $\mu$ damage model was used to model concrete bahavior and the Menegetto Pinto model was used to model steel rebars (subsection 1.3.3). In addition, shrinkage and thermal deformations were calculated by solving the equations of the THC model presented in subsection 1.3.1 using the COMSOL software. In order to quantify numerically the seismic behavior of the portal frames a pushover anlysis, a modal and spectral analysis as well as a transient analysis were performed (Chapter 3). The principle of such techniques was explained in subsection 1.4.2. 


\section{Experimental damage evolution of two $\mathrm{RC}$ portal frames during their early age period and their response when being submitted to static or seismic inputs}

In this Chapter, the difference of behavior between two types of portal frames that evolved in different conditions during their early age period (endogenous and non-endogenous conditions) is determined experimentally. Damage is followed during the early age period of the two types of structures that are then tested either using static cyclic tests or pseudodynamic tests. This Chapter is divided into 8 main sections. The first section presents the experimental protocol followed, while the second section describes the geometry and material properties of the studied portal frames. In section 3, a comparison of the early age damage evolution of the two types of structures determined using optical fiber and ambient vibration measurements is given as well as the evolution of ambient humidity and temperature. In section 4 , the non-linear static response of the two types of portal frames is determined, whereas in section 5 their linear and non-linear dynamic response that was obtained using pseudo-dynamic tests is presented. Prior to using such technique, that later was first validated by testing it on a linear steel spring. During PsD tests, damage evolution of the two types of portal frames was followed using ambient vibration measurements in addition to digital image correlation as will be presented in section 6 . A study of the effects of boundary conditions on the dynamic behavior of the portal frames is then conducted in section 7 by considering another group of portal frames having different boundary conditions that was tested experimentally with the same accelerogram used to test the first group. Last, conclusions of this chapter are provided in section 8 . 


\subsection{Experimental Protocol}

Two groups of portal frames are considered (Figure 2.1] [15]. One group is kept during its early age period in endogenous conditions (which means that it was coverered using a plastic sheet). The dimensions of the structures are given in section 2 of this Chapter. Their small cross-section allows reducing thermal deformations. Creep and mechanical deformations are also very small during early age. In order to make sure to get similar casting conditions and a homogenous material for both structures, two formworks were built and portal frames were casted the same day. The cement paste was blended (about 15 minutes) to get a homogeneous material. Then, after pouring, vibrators were used to remove air bubbles. Both portal frames were casted in place horizontally in a way to mitigate bleeding and segregation. Then, they were covered during 48 hours using wood formworks in a way to limit plastic shrinkage. After 48 hours from casting, the structures were put vertically using a lifting device. Mortar used in order to make the structures has a water to cement ratio of $50 \%$ which allows preventing autogenous shrinkage. Furthermore, carbonatation shrinkage is negligible at early age. The first portal frame was kept during its early age period in endogenous conditions. Which means that after 48 hours it was covered using a plastic film in a way to limit drying effects leading to cracks and avoid drying shrinkage. It is supposed to be a reference group where damage is limited.

The second portal frame was kept in non-endogenous conditions. In other words, no covering was imposed after 48 hours from casting, thus allowing water exchange with the surrounding environment during the hydration process. Such conditions are similar to the ones found in construction sites inducing cracks apparition.

\subsection{Portal frames characterization}

\subsubsection{Geometry and mortar formulation}

The portal frames are $1.4 \mathrm{~m}$ by $1.3 \mathrm{~m}$ structures (Figure $2.3 \mathrm{a}$ ). They are made of a square cross section of $11 \mathrm{~cm}$ by $11 \mathrm{~cm}$. Longitudinal reinforcements have a diameter of $8 \mathrm{~mm}$ whereas transverse reinforcements have a diameter of $6 \mathrm{~mm}$ (Figure 2.3 $\mathrm{a}$ ). The small dimensions of the cross sections allow reducing thermal deformations, whereas the geometry of the structures induces an important restrained shrinkage towards the nodes leading to an important drying shrinkage of the portal frame kept in non-endogenous conditions. The cement material used in order to make the portal frames has the following composition for $1 \mathrm{~m}^{3}: 1534 \mathrm{~kg}$ of sand $(0 / 5 \mathrm{~mm}), 511 \mathrm{~kg}$ of cement (CEM I $52.5 \mathrm{R}$ of VICAT), $1.53 \mathrm{~kg}$ of superplasticizer (Dynamon NRG 1040 of MAPEI) and $256 \mathrm{~kg}$ of water. 


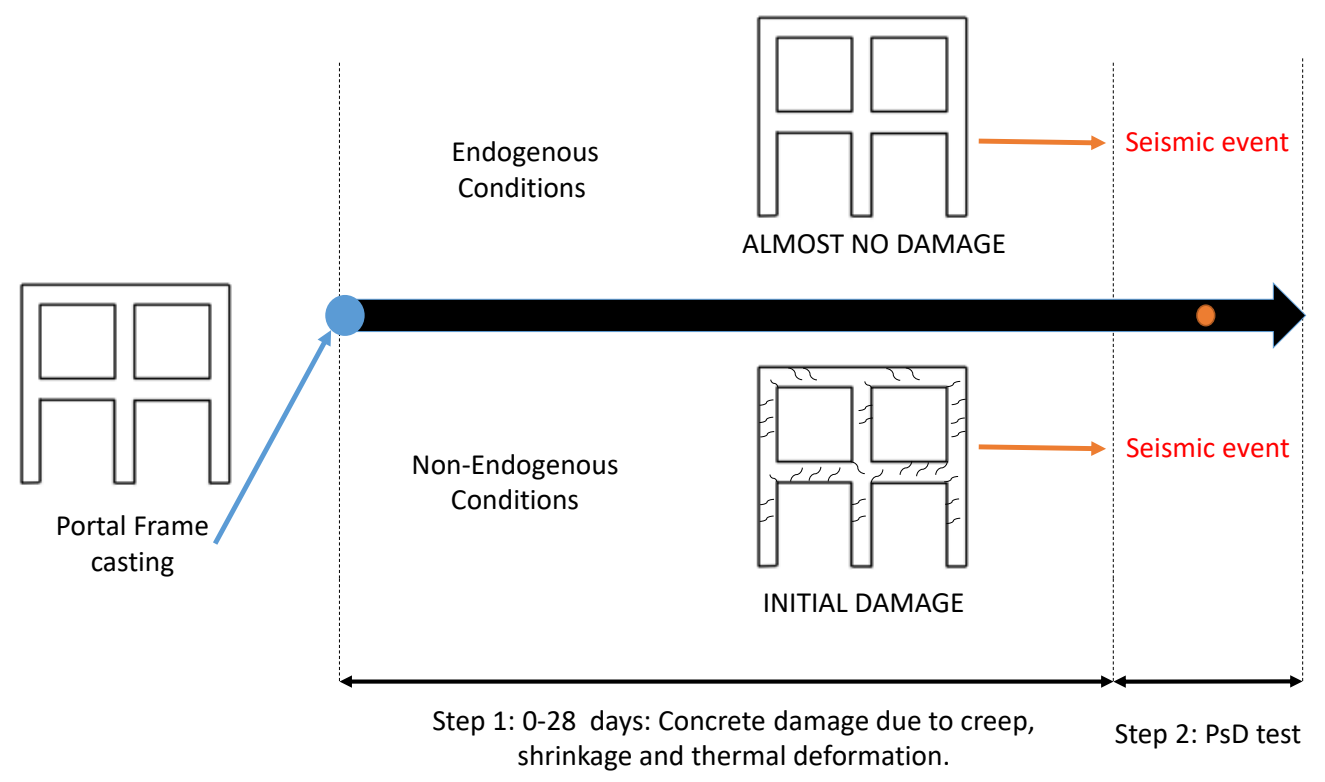

Figure 2.1: Experimental protocol

Mix proportions are 1:3 for cement to sand ratio, 1:2 for water to cement ratio and the dosage of the superplastifiant is $0.3 \%$ of the cement.

\subsubsection{Material Properties}

In order to determine the compressive and tensile strength of the mortar used in the portal frames as well as its Young modulus at the end of the early age period a series of experimental tests were performed on cylindrical samples $(11 \mathrm{~cm}$ diameter and $22 \mathrm{~cm}$ length). Two types of cylindrical samples were considered: One group that was kept in endogenous (EN) conditions at early age (Framework removal after 48 hours from casting and converage using a plastic sheet) and a second group kept in non-endogenous conditions at early age which means that no protection was used after framework removal [15]. Split cylinder test was used to determine the tensile strength of the samples and a compressiontesting machine was used to determine their compressive strength. Young modulus was determined by instrumenting the cylindrical samples with strain gauges and testing them under compression. Experimental results obtained for the different samples are given in Table 2.1 for the Endogenous and Non-Endogenous cases. On average, mortar used in the portal frames has a compressive strength of $56 \mathrm{MPa}$ and a tensile strength of $3 \mathrm{MPa}$, whereas its Young modulus is equal on average to $27 \mathrm{GPa}$. Steel reinforcements have a 


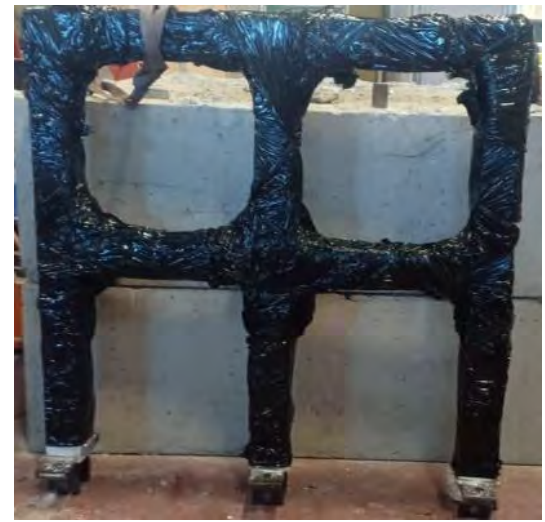

(a)

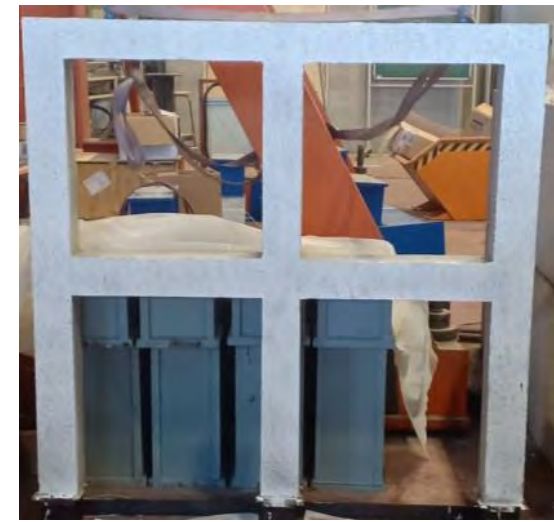

(b)
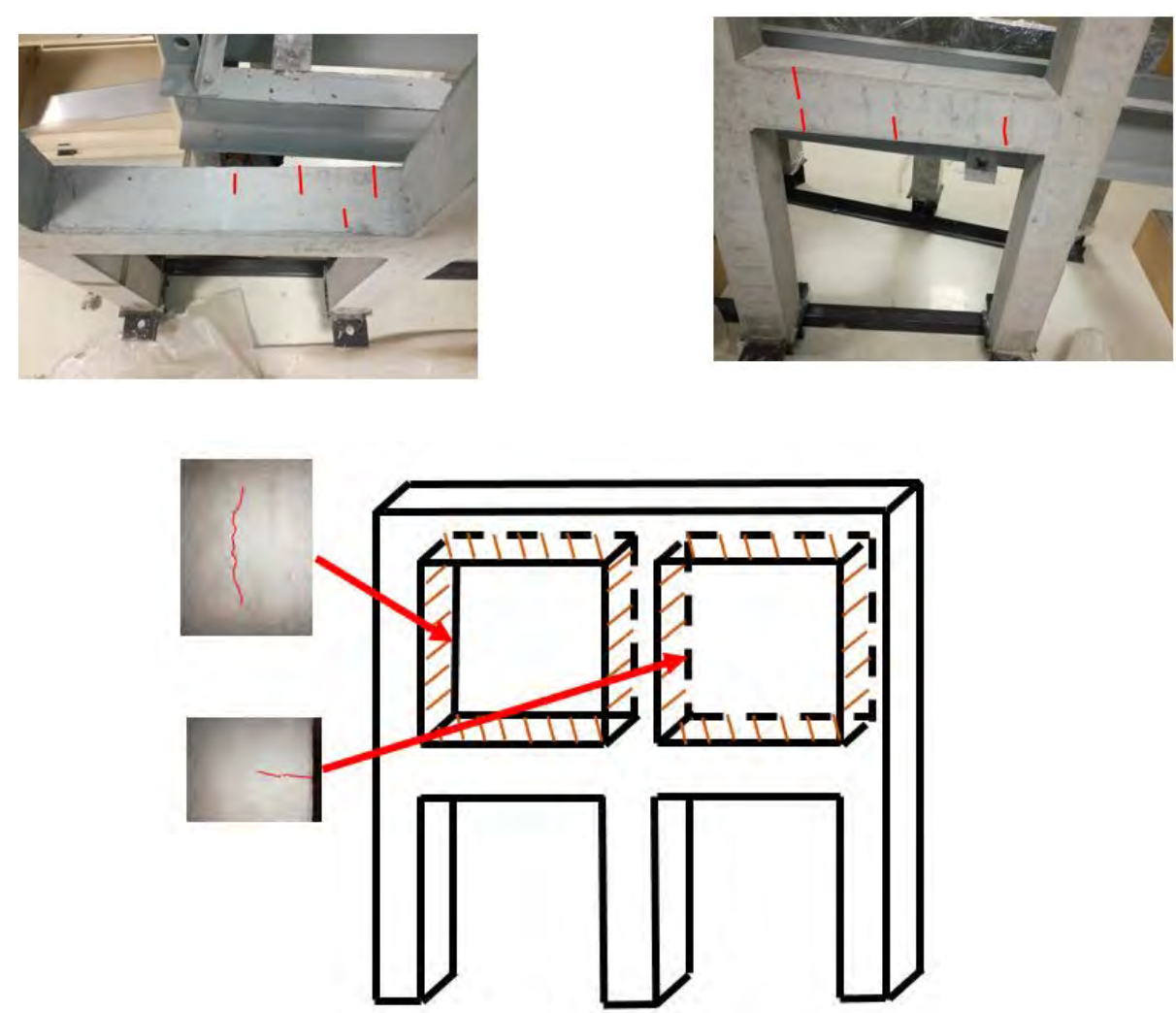

(c)

Figure 2.2: Early age conditions (a) Endogenous (b) Non-Endogenous (c) Crack Apparitions in the Non-Endogenous Portal Frame at the end of the 28 days 


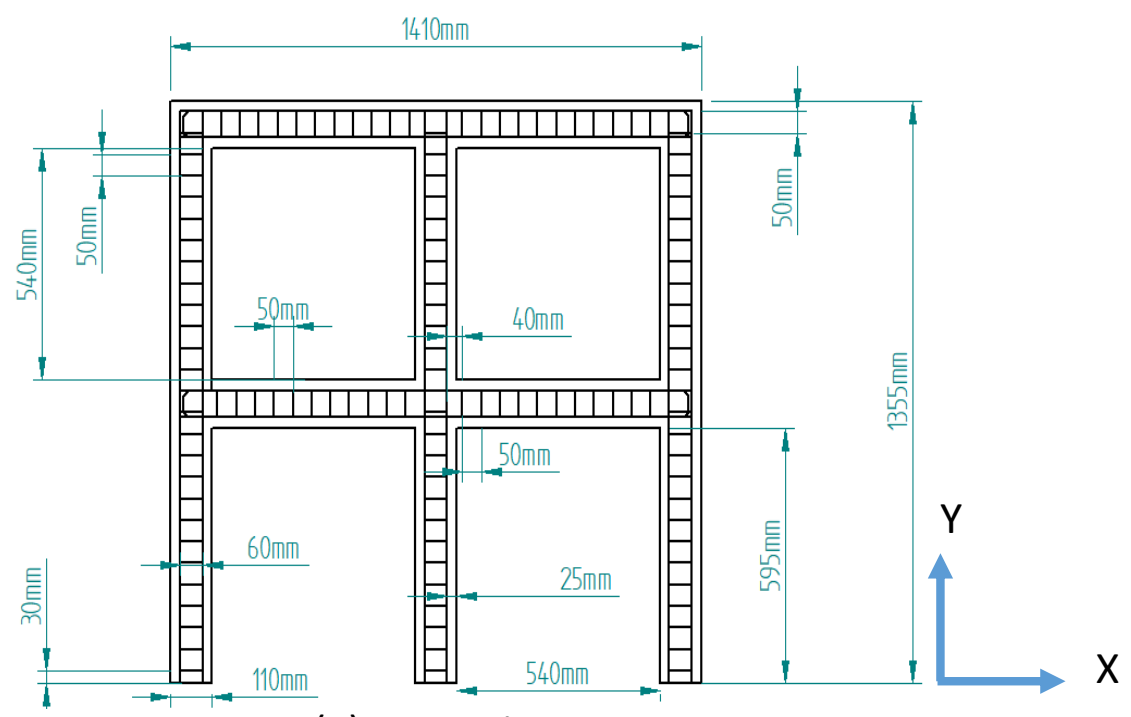

(a) Front view

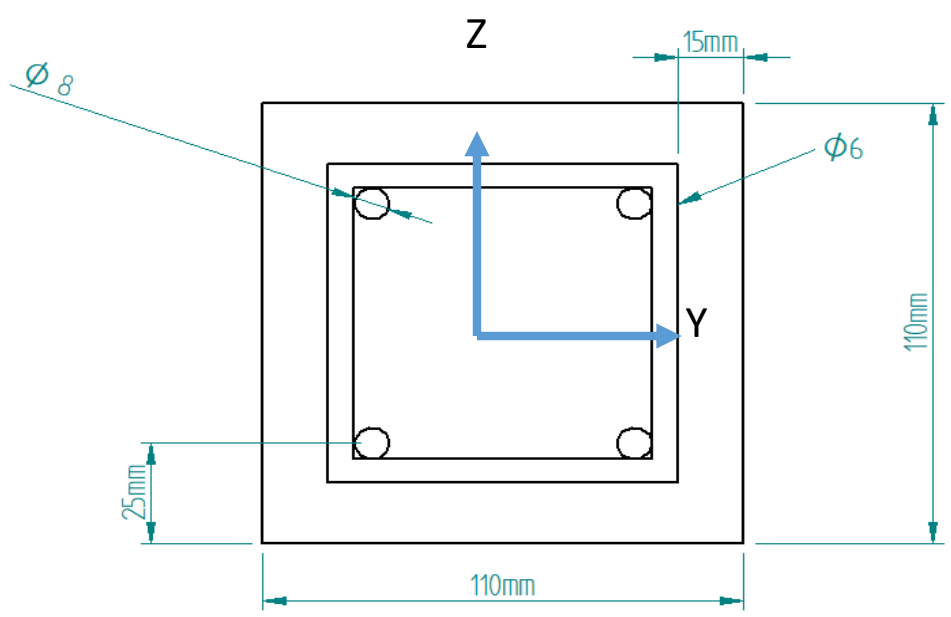

(b) Cross-section

Figure 2.3: Geometry of the RC portal frames (a) Front View (b) Cross Section 
yield stress of $500 \mathrm{MPa}$.

\begin{tabular}{c|c|c|c|c|c||c}
\hline Sample Number & \multicolumn{2}{|c|}{$R_{t}(\mathrm{MPa})$} & \multicolumn{2}{c|}{$R_{c}(\mathrm{MPa})$} & \multicolumn{2}{c}{$E(\mathrm{MPa})$} \\
\cline { 2 - 7 } & $\mathrm{NE}$ & $\mathrm{E}$ & $\mathrm{NE}$ & $\mathrm{E}$ & $\mathrm{NE}$ & $\mathrm{E}$ \\
\hline 1 & 3.1 & 4 & 47.4 & 57.2 & 26045 & 28659 \\
2 & & 2.8 & 58.2 & 60.9 & 26199 & 25267 \\
3 & 2.9 & 2.6 & 56.7 & 58 & 28471 & 27453 \\
4 & 3.3 & 3.4 & 55.2 & 57.9 & 25892 & 27190 \\
5 & 2.7 & 2.8 & 57.4 & 55 & 28249 & 28456 \\
Average & 3.0 & 3.12 & 55 & 57.8 & 26971 & 27405 \\
Standard deviation & 0.26 & 0.58 & 4.38 & 2.11 & 1275 & 1351 \\
\hline
\end{tabular}

Table 2.1: Mortar properties at the end of Early Age $\left(R_{t}=\right.$ Tensile Strength, $R_{c}=$ Compressive Strength and $E=$ Young modulus, NE=Non-Endogenous, $\mathrm{E}=$ Endogenous)

The evolutions of mass loss of $4 \mathrm{~cm}$ by $4 \mathrm{~cm}$ by $16 \mathrm{~cm}$ prismatic specimens, kept in the same endogenous and non-endogenous conditions as the 2 portal frames, were measured during the early age period (Figure 2.4). It showed that there is almost no mass loss in the endogenous specimens where water is not allowed to leave the specimens due to their protective cover. On the opposite, mass loss was significant in the non-endogenous specimens (up to $3 \%$ mass loss at the end of the early age period). The objective of measuring mass loss during early age, was to make sure that the protective sheet used in order to stop water transfer with the surrounding environment is efficient.

\subsection{Early age period}

During their early age period (0 to 28 days) the two portal frames were instrumented using optical fibers to monitor their strain evolution and detect cracks apparitions [15]. They were also instrumented with velocimeters to follow their frequency content evolution. The instrumentation using optical fibers and the monitoring have been performed with the help of the Quadric company in the framework of the EarlyQuake project [73].

\subsubsection{Strain and crack evolutions using optical fiber}

At the end of the 28 days, the portal frame that was kept in non-endogenous conditions had visible cracks on its surface (Figure 2.2.) whereas no apparent cracks were visible on the portal frame kept in endogenous conditions. In order to monitor cracks apparition during the early age period both groups were instrumented using optical fiber sensors at 


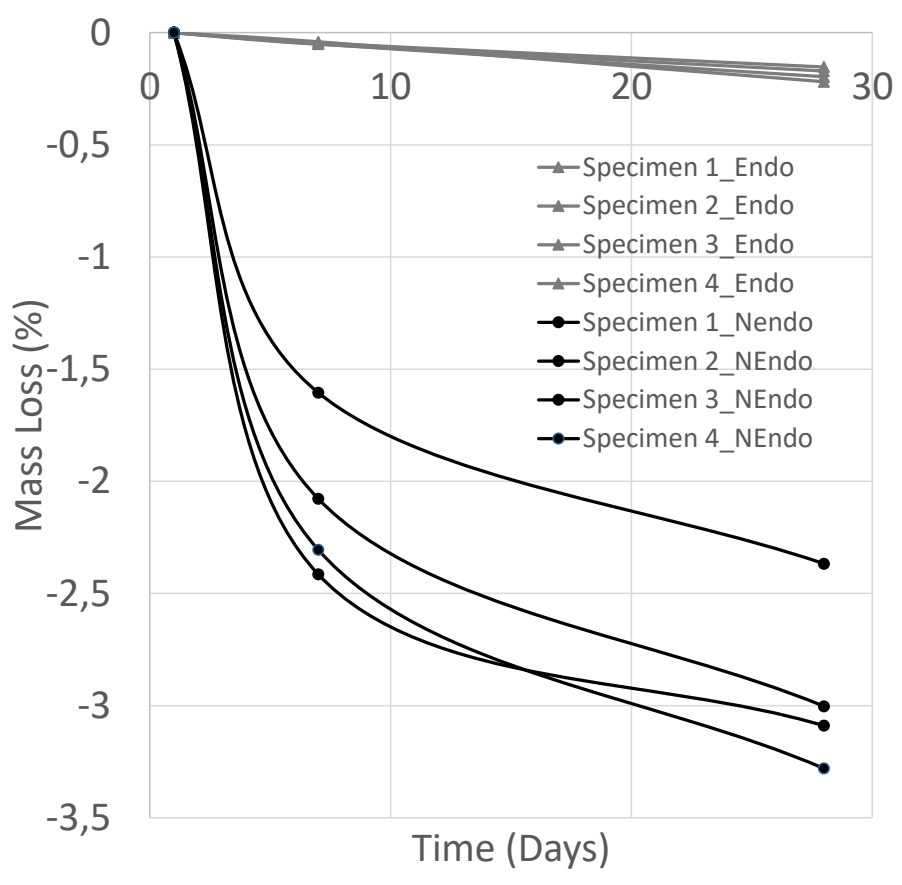

Figure 2.4: Mass loss evolutions of Non-Endogenous (Non-Endo) and Endogenous (Endo) $4 \mathrm{~cm}$ by $4 \mathrm{~cm}$ by $16 \mathrm{~cm}$ prismatic specimens

casting. Monomode optical fibers with a Rayleigh scattering were used (LUNA Brand). This technology allows conducting continous distributed strain measurements (384 measurements per meter) with a very high accuracy, which is very useful in the detection of cracks [72]. The precision of the strain measurements is equal to $1 \mu \epsilon$. Figure 2.5 a shows how the portal frames were instrumented with optical fiber for strain monitoring and Figure 2.5b gives the fiber mapping used. Figure 2.6 shows the strain spatial distribution towards the end of the 8th day $(184 \mathrm{~h})$ of the early age period in both portal frames. It can be seen that strain values of the two structures are different and more particularely in segments OP and UV of the optical fiber. Indeed, as shown in Figure 2.7 while the maximum strain is similar in both structures, the gradient of deformation is more important in the endogenous portal frame than in the non-endogenous portal frame. It implies that the non-endogenous portal frame is more damaged than the endogenous one due to early age drying shrinkage. In fact, the integral of strain at a particular time step (for example $150 \mathrm{~h}$ ) giving the displacement of the segments OP and UV is more important in the non-endogenous portal frame than in the endogenous one. 


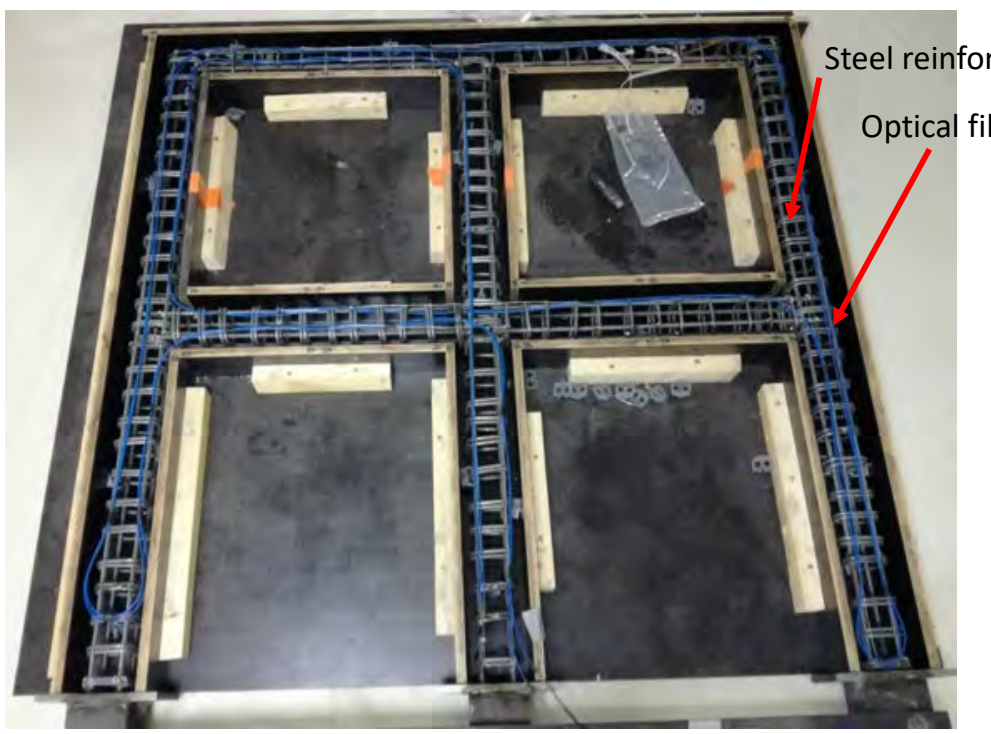

rcements

(a)

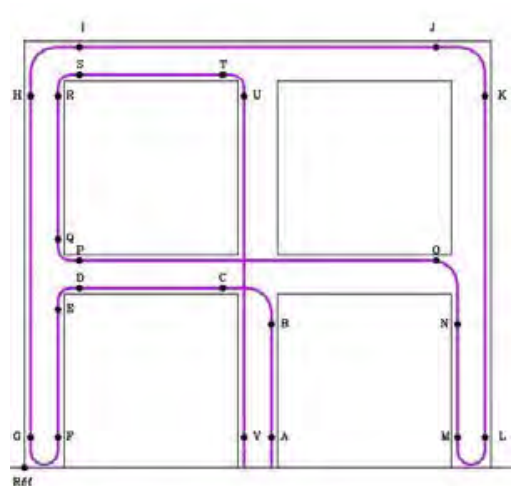

(b)

Figure 2.5: (a) Location of the optical fiber along the reinforcements and (b) mapping of the optical fiber

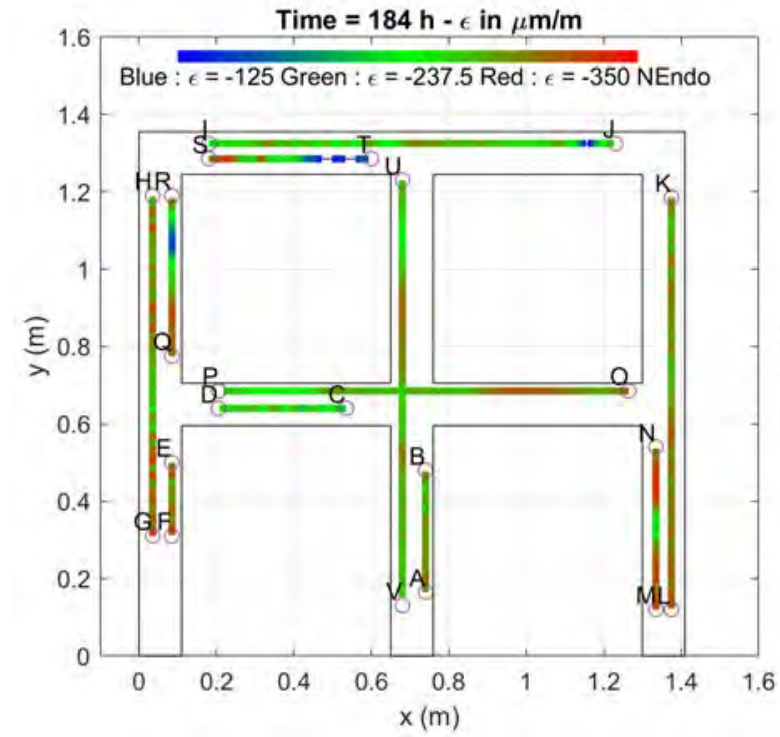

(a)

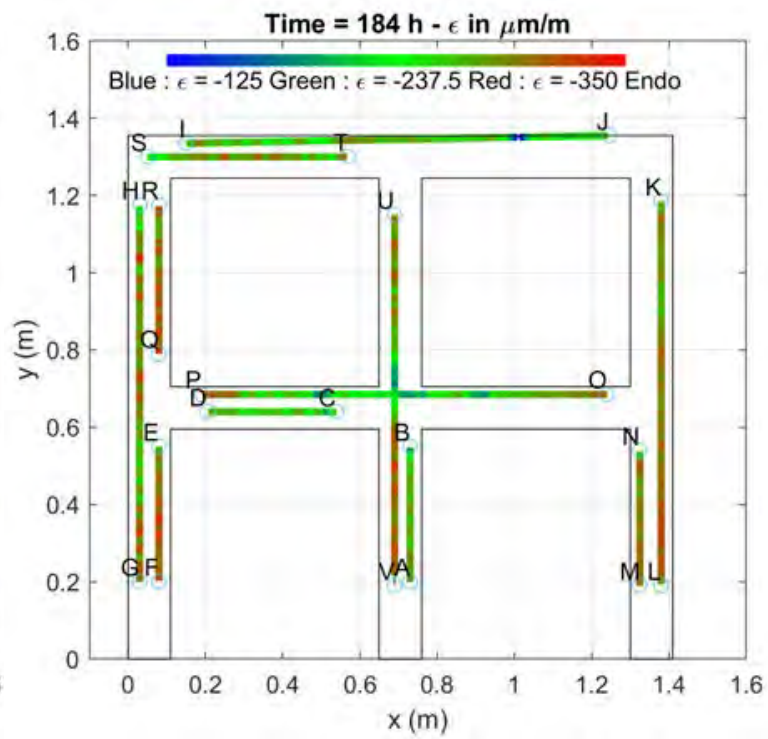

(b)

Figure 2.6: Strain at the end of 8 days (a) Non-Endogenous Frame (b) Endogenous Frame 


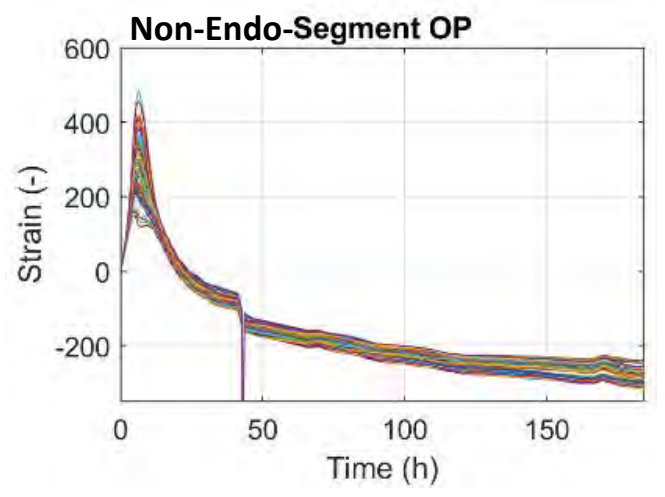

(a)

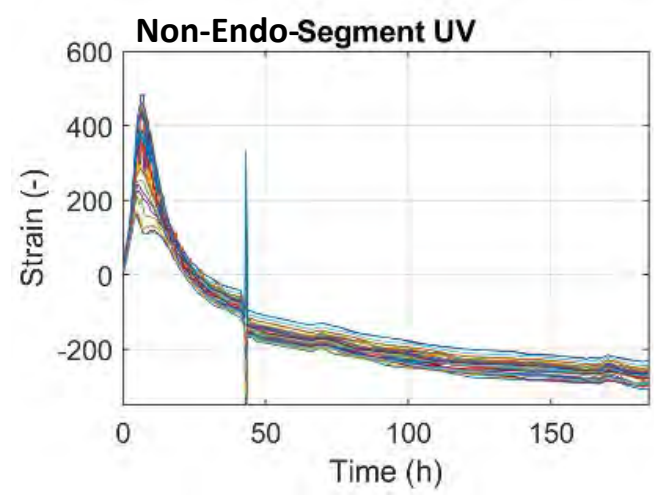

(c)

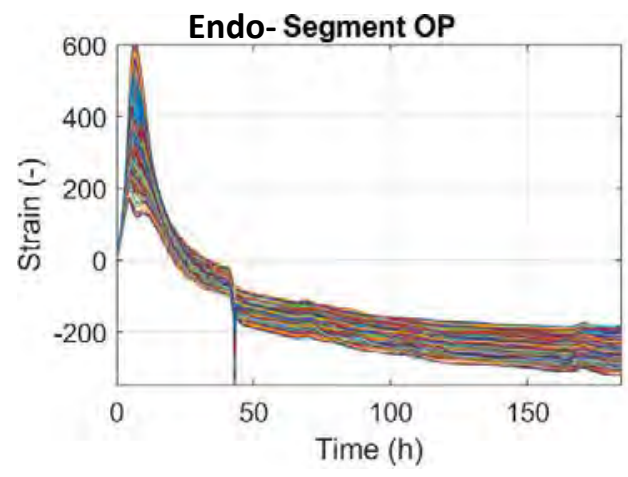

(b)

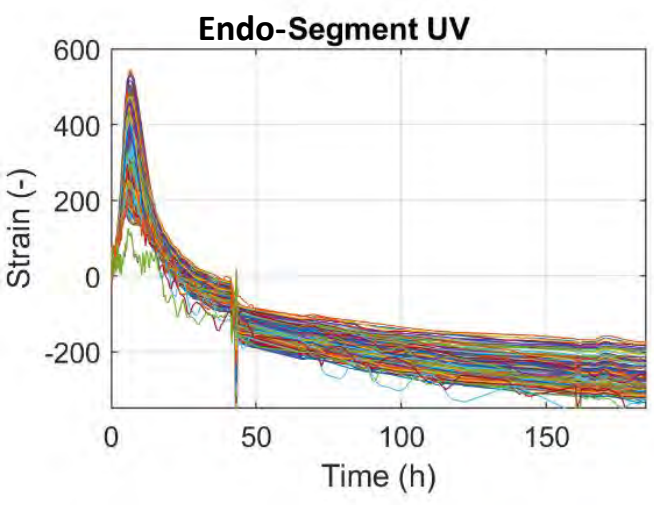

(d)

Figure 2.7: Strain Evolution (a) Non-Endogenous OP Segment (b) Endogenous OP Segment (c) Non-Endogenous UV Segment (D) Endogenous UV Segment 


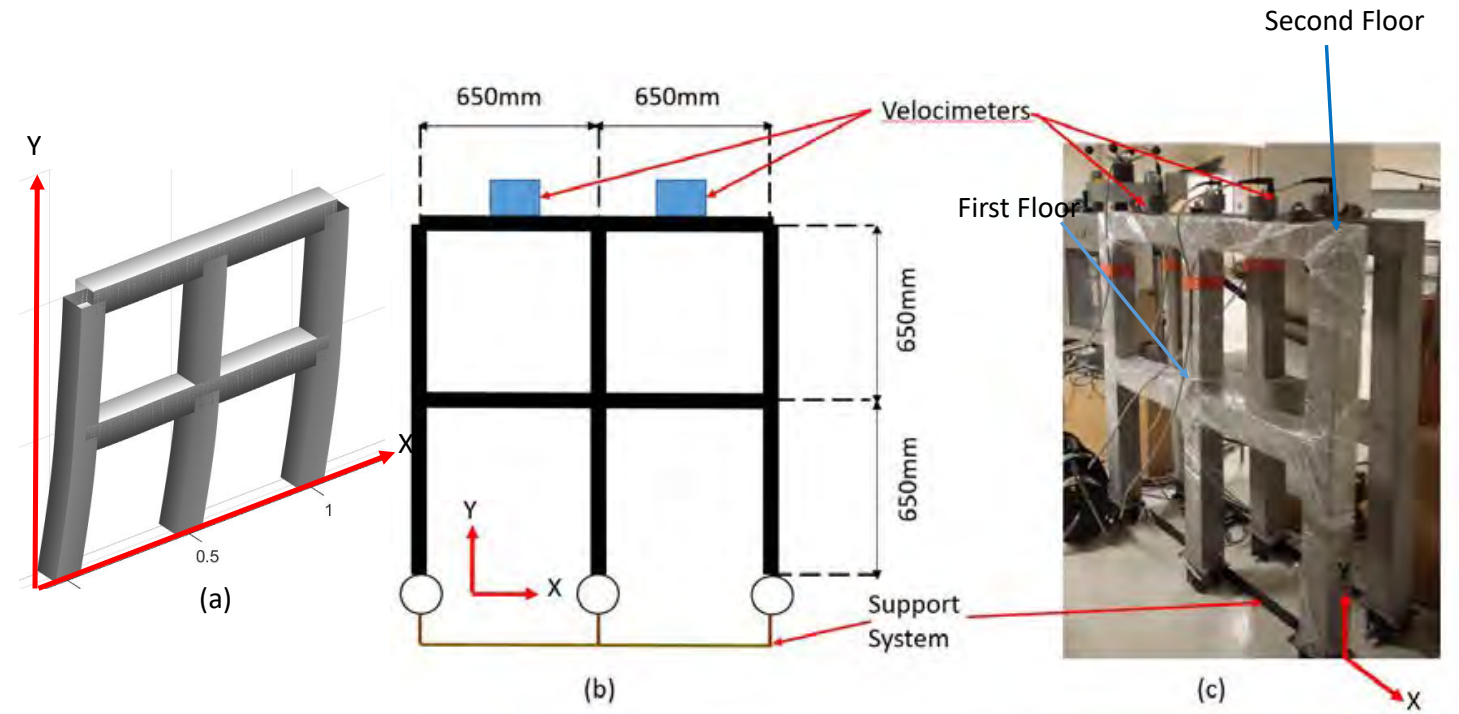

Figure 2.8: (a) First mode of vibration and velocimeters position during early age (a) scheme and (b) Experiment

\subsubsection{Frequency content evolution using ambient vibrations}

Frequency content of the two groups of portal frames was determined using ambient vibrations [15].

For each portal frame group, two velocimeters (LE-3Dlite MkIII brand) were put as shown in Figure 2.8p. Their upper frequency limit is of $100 \mathrm{~Hz}$ and they can be used to perform measurements in three directions. Such devices allowed measuring the velocity evolution following the horizontal direction $((\mathrm{x}, \mathrm{y})$ plane) of the portal frames using the ambient vibration recorder CityShark II [71]. Measurements were performed as follow: 1 measurement at a frequency rate of $600 \mathrm{~Hz}$ during 15 minutes each 2 hours (with a gain factor of 64 for noise removal). Using the Random Decrement Technique (RDT) which is an accurate technique for the determination of the frequency content and damping ratio of structures [74] [75], the first natural frequency evolution of the portal frames following the horizontal direction $((\mathrm{x}, \mathrm{y})$ plane) was determined. Its corresponding mode of vibration is given in Figure 2.8 a. Such deformed shape was validated using 4 velocimeters (2 were put on the first floor of the portal frames and 2 on their second floor (Figure 2.8c)). In order to perform the RDT technique, the velocity measurements were divided into windows having a length of $8 T_{0_{\text {rough }}}$, Where $T_{0_{\text {rough }}}=\frac{1}{f_{0_{\text {rough }}}} \cdot T_{0_{\text {rough }}}$ being the rough first period of the system and $f_{0_{\text {rough }}}$ its rough first natural frequency determined using a Fourier transform as explained in the State of the art of this thesis. When performing the RDT technique, the different windows were average using a trigger value equal to $3 \sigma . \sigma$ being the standard 
deviation of the measured velocities. Once the velocity measurements were performed, the RDT technique was performed using a home made Matlab routine developed by ISTERRE in Grenoble (Institut des Sciences de la Terre). During their early age (EA) period, the portal frames were supported by the system (Table 2.2) presented in Figures $2.8 \mathrm{~b}$ and 2.8c. Ambient vibration measurements that started around 75 hours after portal frames

\begin{tabular}{c|c|c|c}
\hline & AV during EA & SA and PsD & AV during PsD \\
\hline BC & Supporting System & 3 Pinned connections & $\begin{array}{c}\text { 3 Pin ned connections } \\
+ \text { Jack attached on top }\end{array}$ \\
\hline Masses & Self Weight & $M_{1}, M_{2}, M_{3}$ & Self Weight \\
\hline
\end{tabular}

Table 2.2: Boundary conditions and masses: $\mathrm{AV}=$ Ambiant Vibrations, $\mathrm{EA}=$ Early-Age, $\mathrm{SA}=$ Spectral Analysis, $\mathrm{PsD}=$ Pseudo-Dynamic, $\mathrm{BC}=$ Boundary Conditions

were casted and ended around 600 hours after casting (25 th day of the early age period) showed that the initial frequency of the two portal frames is almost identical $(22.7 \mathrm{~Hz}$ for the Non-Endogenous portal frame versus $23.8 \mathrm{~Hz}$ for the Endogenous portal frame) which implies that the two portal frames were constructed in a similar way. 140 hours after the beginning of measurements, the first natural frequency of the NE Portal frame increased by $4 \%$ whereas in the Endogenous portal frame it took 500 hours for it to increase by $3 \%$. Thus, the frequency increase rate was more important in the Non-Endogenous case (where water exchange with the surrounding environment is important) than in the endogenous case (Figure 2.9). During the early age period, it was also observed that the frequency of the portal frames fluctuated every day and reached its pick at midnight. It is due to the fact, that when the temperature is low during the night there is a contraction of the portal frames and a closure of cracks. The amplitude of the daily fluctuations is more important in the NE portal frame in comparison with the Endogenous one. Also such fluctuations became smaller in the endogenous portal frame over time. The difference of the daily fluctuations between the endogenous and non-endogenous portal frames shows that the NE portal frame is more damaged than the Endogenous one.

\subsubsection{Temperature and humidity evolutions at early age}

48 hours after casting, temperature sensors as well as hygrometers were used in order to capture ambient temperature and humidity evolutions (Figure 2.10). The measurements showed that the ambient temperature during early age was on average around $20{ }^{\circ} \mathrm{C}$ and whereas the ambient humidity was on average aroud $50 \%$. Such values will be used in the numerical model of the portal frames presented in Chapter 3. 


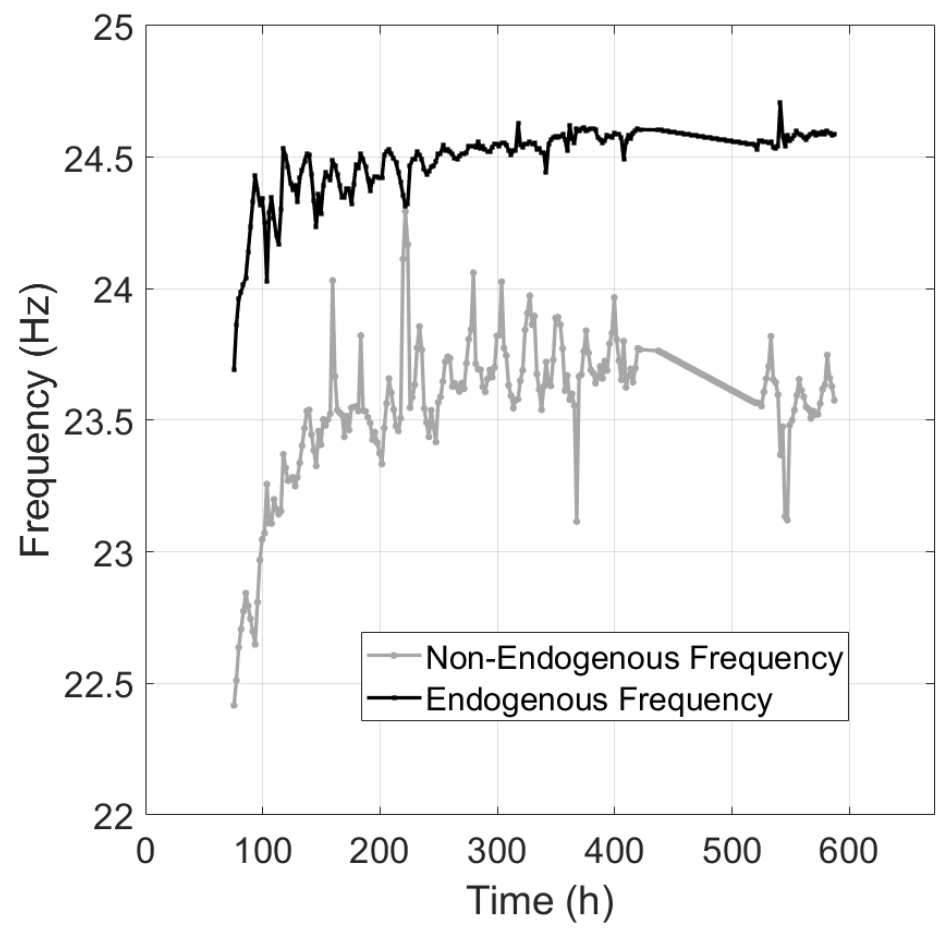

Figure 2.9: First natural frequency evolution in the (xy) plane during the early age period. The period between 437 hours and 521 hours correspond to 'No Data'

\subsection{Static response after early age}

In order to characterize the non-linear static response up to collapse of the portal frames a second group of portal frames was cast in place and kept in the same conditions as the first group (the one monitored during early age and then tested using pseudodynamic tests). Thus, in the second group, one portal frame was kept in endogenous conditions and the other one in non-endogenous conditions. At the end of their early age period, a static cyclic loading was applied to the structures [15]. Figure 2.11 a shows the cyclic displacement imposed on top of the structures using a jack (Figure 2.11b). Two low intensity cycles were performed followed by two cycles of higher intensity in order to characterize the cyclic behavior of the structures. After that, a pushover was applied in order to determine the maximum capacity of the frames. The structures were designed to be pinned at their three ends. They were instrumented using 4 displacement sensors (LVDT1 (measuring range of $\pm 100 \mathrm{~mm}$ ), LVDT2 (measuring range of $\pm 50 \mathrm{~mm}$ ), LVDT3 (measuring range of $\pm 5 \mathrm{~mm}$ ) and LVDT4 (measuring range of $\pm 20 \mathrm{~mm})$ ). LVDT1, LVDT2 and LVDT3 were used to measure in plane horizontal displacements following the $\mathrm{x}$ direction, whereas LVDT4 was used in order to measure any out of plane movement of the portal frames. To avoid the collapse of the portal frames if out of plane movements were to happen, the supporting 


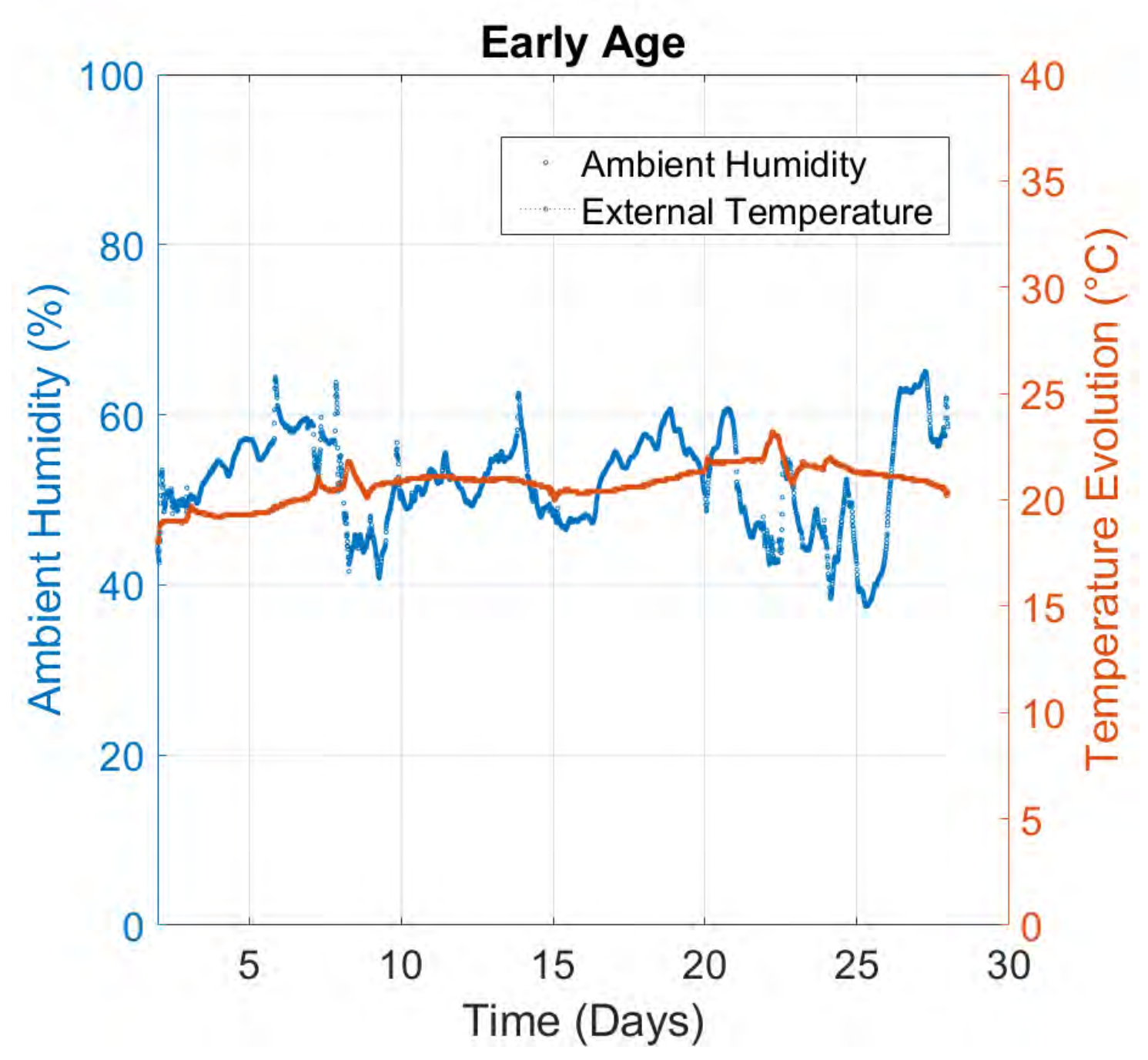

Figure 2.10: External ambient temperature and humidity evolutions during the early age period

system presented in Figure 2.11b was used. The gain ratio of the different displacement sensors is $0.1 \mathrm{~V} / \mathrm{mm}$ whereas the gain ratio of the load sensor used is $0.2 \mathrm{~V} / \mathrm{kN}$.

The response of each structure under the imposed displacement Time History (measured by the LVDT1 displacement sensor and the load sensor of figure 2.11b) is given in figure 2.12. The envelope of the positive increasing cycles is given in figure 2.13. It can be seen that there is a difference between the intial slope of the two portal frames: the endogenous portal frame has an initial slope 4 times higher than the one of the nonendogenous portal frame $\left(72 \times 10^{4} \mathrm{~N} / \mathrm{m}\right.$ versus $\left.31 \times 10^{5} \mathrm{~N} / \mathrm{m}\right)$. Results suggest that the behavior of the two structures if subjected to a moderate intensity earthquake will be 


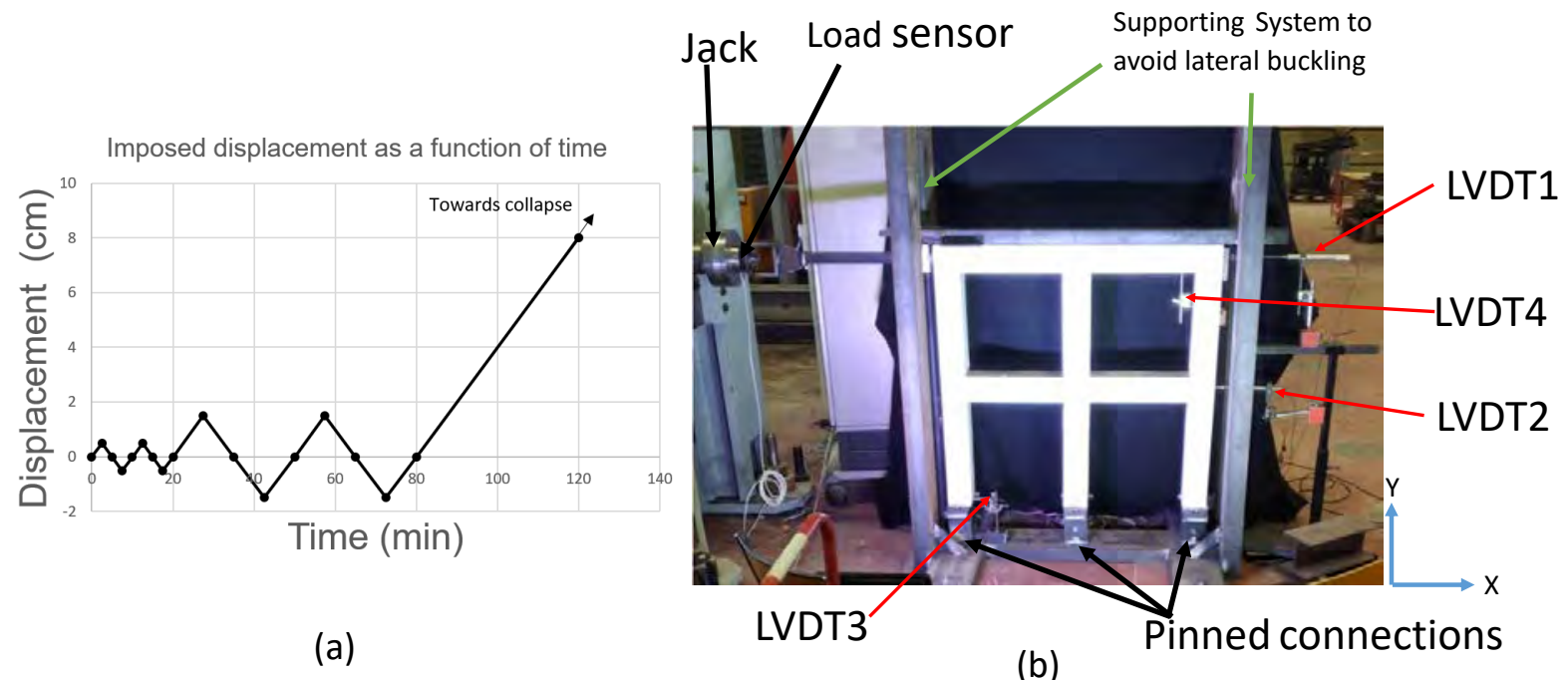

Figure 2.11: (a) Cyclic displacement Time-History and (b) Experimental set-up

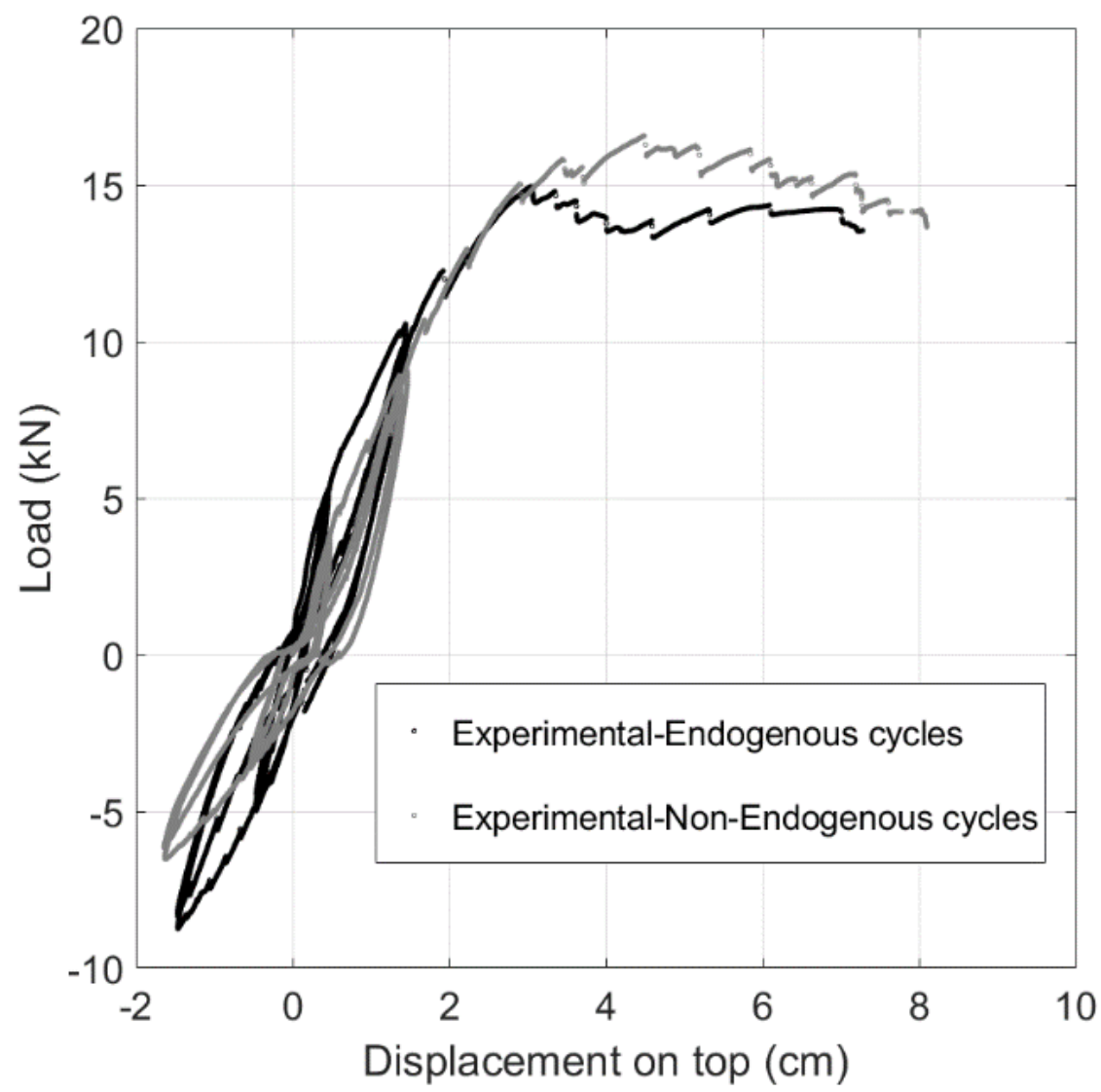

Figure 2.12: Experimental response to the cyclic loading 


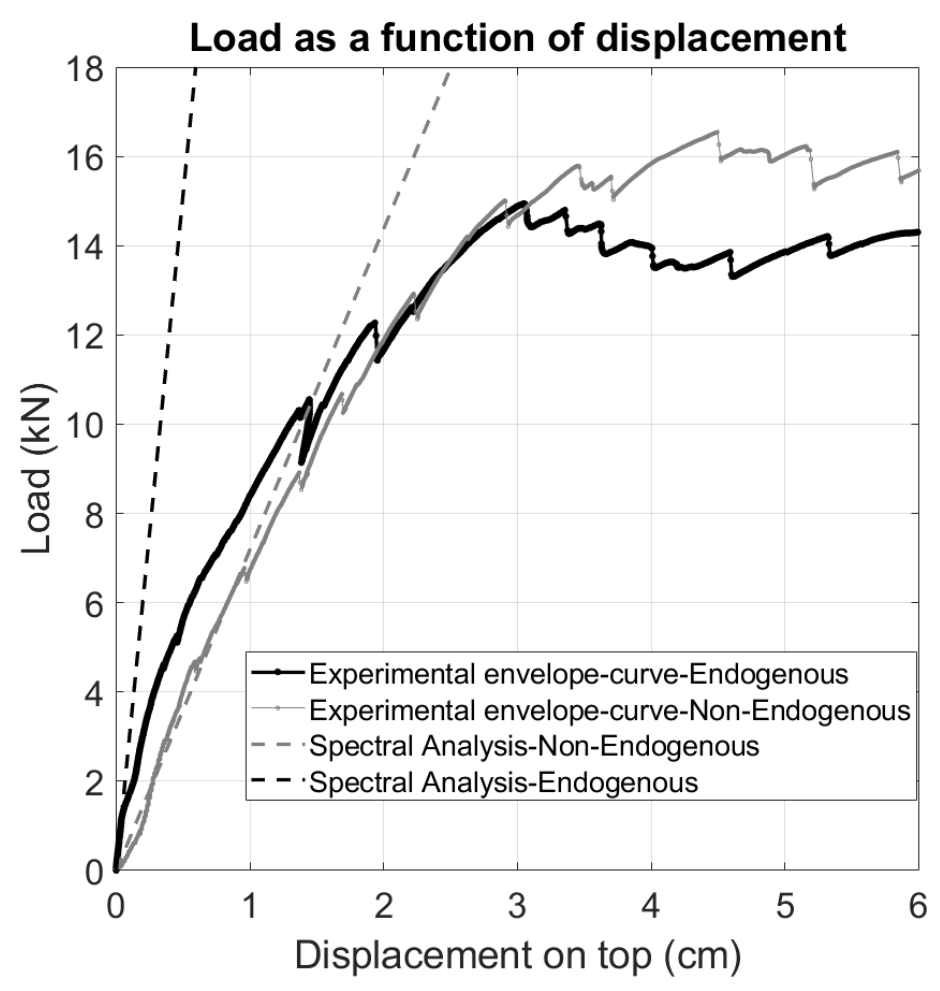

Figure 2.13: Envelope of the experimental response of the portal frames to the cyclic loading and Spectral Analysis curves

different because of their initial stiffness difference. The pushovers performed at the end of the cyclic loadings, showed that there is a difference in maximum capacity between the endogenous and non-endogenous portal frames even if they were casted in place the same day with a similar blend and using similar rebars. The non-endogenous portal frame has a more important capacity $(16.6 \mathrm{kN})$ than the endogenous one $(14.9 \mathrm{kN}$ ) (Group 1 in Table 2.3). To confirm results obtained with the first series of portal frames regarding the ultimate capacity of the structrues, pushovers were performed at the end of the PsD tests on a second series of portal frames as will be presented in 2.5.2.2.

Figure 2.14 gives displacement evolutions measured by the 4 LVDT sensors used on the two portal frames. LVDT1 measures the horizontal displacement imposed on top of the structures, LVDT2 measures the lateral drift of the first floor of the structures whereas LVDT3 was used to measure any lateral displacement at the bottom of the left column of the portal frames. Since the portal frames are supposed to be pinned at their three ends, no lateral movement should be measured by LVDT3 (which is the case here). LVDT4 allowed measuring out of plane movements. It can be seen that the structures underwent in maximum around $5 \mathrm{~mm}$ out of plane displacement. 

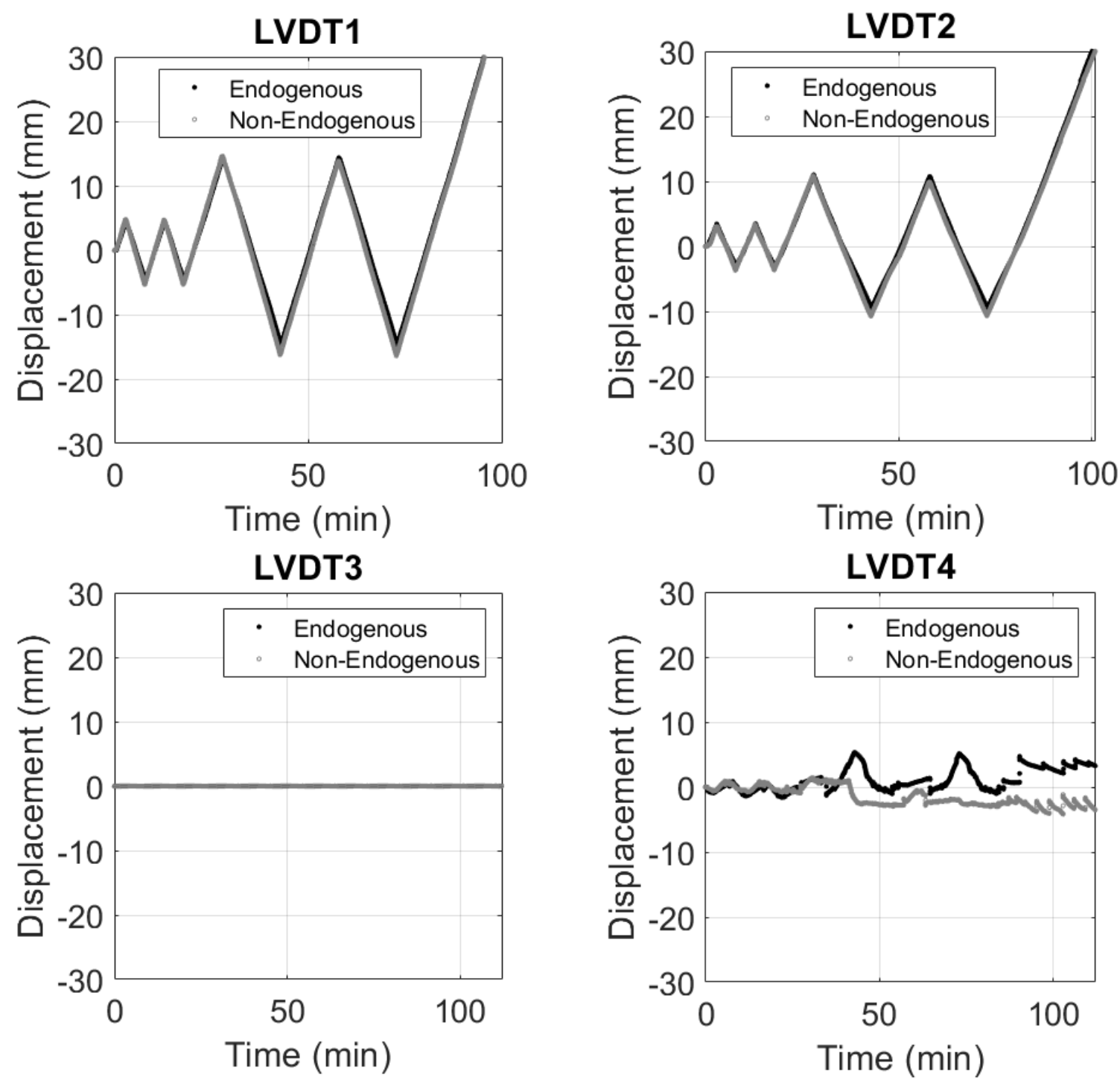

Figure 2.14: Evolution of displacements measured using LVDT1, LVDT2, LVDT3 and LVDT4 during the cyclic displacement static tests performed on the Endogenous and Non-Endogenous portal frames. LVDT sensors were positioned as shown in Figure 2.11b: LVDT1 measured the lateral drift of the second floor of the portal frames, whereas LVDT2 measured the lateral drift of the first floor and LVDT3 the horizontal displacement at the bottom of the left column of the portal frames and LVDT4 measured out of plane movements. 


\begin{tabular}{lcc}
\hline & Endogenous & Non-Endogenous \\
\hline Group1 $(\mathrm{kN})$ & 14.9 & 16.6 \\
Group2 $(\mathrm{kN})$ & 13.8 & 15.6 \\
Group3 $(\mathrm{kN})$ & 18.1 & 19.3 \\
\hline
\end{tabular}

Table 2.3: Maximum capacity detemined by performing pushovers on the tested portal frames: Group 1 corresponds to the portal frames that were tested using static loadings, Group 2 corresponds to the first series of portal frames tested using PsD tests and Group 3 corresponds to the second series of portal frames tested using PsD tests

\subsection{Dynamic response of the portal frames after early age}

A linear spectral analysis was performed in order to assess the linear dynamic response of the portal frames [2] [15]. Then, their non-linear dynamic response was determined using pseudo-dynamic tests. The structures were instrumented using load and displacement sensors and 2D Digital image correlation was performed in order to follow their damage during the pseudo-dynamic tests. Three masses $M_{1}, M_{2}$ and $M_{3}$ (Table 2.2) representing the contribution of upper floors were numerically simulated on top of the portal frames (Figure 2.15a). Each mass equals $1148 \mathrm{~kg}$. Therefore, the total mass imposed to the frame $M_{t o t}$ (self weight is neglected) is equal to $M_{t o t}=M_{1}+M_{2}+M_{3}=3444.4 \mathrm{~kg}$. A moderate intensity $0.3 \mathrm{~g}$ Time History (Figure 2.16) was imposed on the structures using the pseudo-dynamic technique. Such signal was already used to experimentally test a three-pier viaduct made of prestressed concrete in the ELSA laboratory [62].

\subsubsection{Spectral Analysis}

The behavior of the portal frames is mainly dictated by their first mode. Indeed, concentrated masses on top are very important compared to the self-weight of the structures. Thus, they can be assimilated to one degree of freedom systems of stiffness $k$ (Figure $2.15 \mathrm{~b})$. The initial stiffness of the two frames corresponds to the initial slope determined previouslypinned $72 \times 10^{4} \mathrm{~N} / \mathrm{m}$ versus $\left.31 \times 10^{5} \mathrm{~N} / \mathrm{m}\right)$. Frequency of a one degree of freedom system can be determined using equation 2.1 .

$$
f=\frac{1}{2 \pi} \sqrt{\frac{k}{M}}
$$

Where $f$ is the frequency, $k$ the stiffness an $M$ the mass. The first natural frequency of the portal frames was calculated as shown in Table 2.4. 


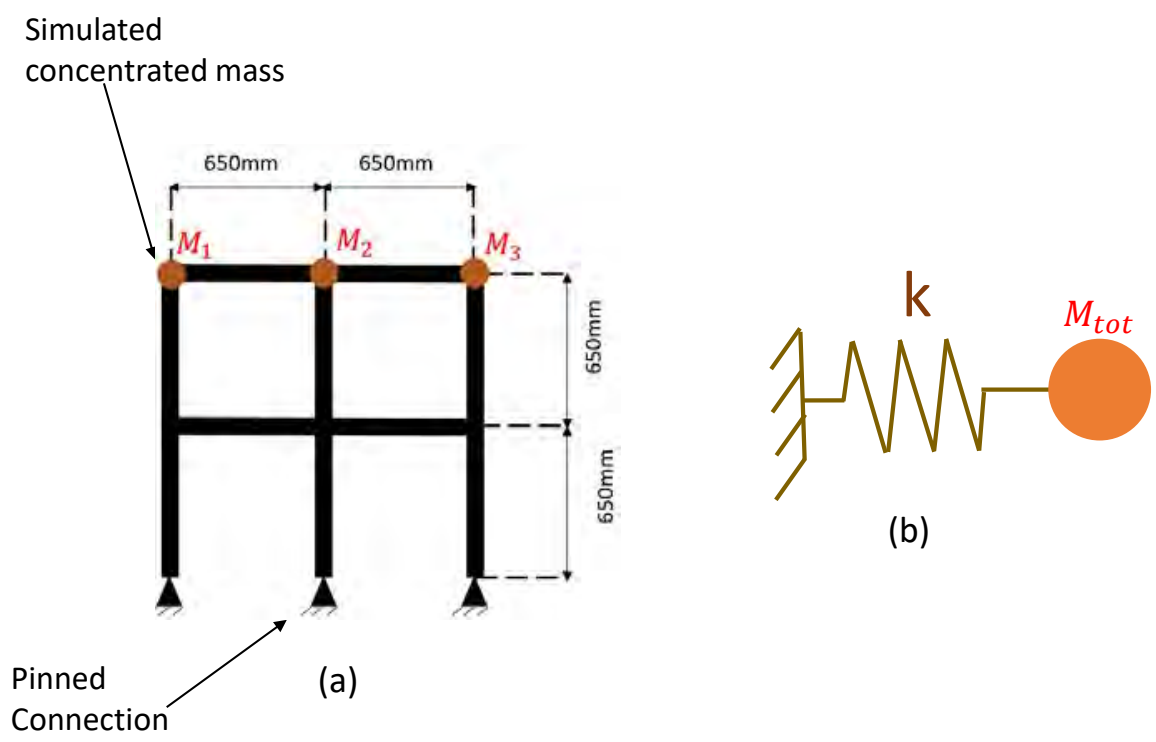

Figure 2.15: (a) Boundary conditions and simulated concentrated masses (b) Equivalent Single Degree of freedom System

\begin{tabular}{cccc}
\hline & Endogenous & Non-Endogenous & \% difference \\
\hline$k(\mathrm{~N} / \mathrm{m})$ & $31 \times 10^{5}$ & $72 \times 10^{4}$ & 77 \\
$f(\mathrm{~Hz})$ & 4.8 & 2.3 & 50 \\
$V(\mathrm{kN})$ & 37 & 26 & 30 \\
\hline
\end{tabular}

Table 2.4: Stiffness $k$, frequency $f$ and maximum base shear $V$ at the end of the early age period

There is a difference in frequency at the end of the early age period between the two types of portal frames $(50 \%)$. Fundamental frequency values of the two structures were used in order to perform a spectral analysis based on the time history of Figure 2.16a. Its corresponding response spectrum is also given in Figure 2.16 b. Spectral Analysis conducted on the two types of portal frames showed (Figure 2.16c) that the maximum base shear in the endogenous case is equal to $26 \mathrm{kN}$ while it is equal to $37 \mathrm{kN}$ in the non-endogenous case (about 30\% difference (Table 2.4)). Spectral Analysis curves were also plotted in Figure 2.13. 


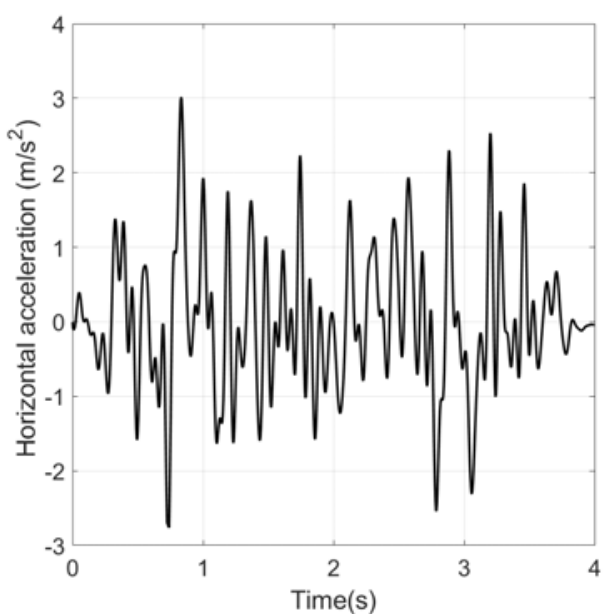

(a)

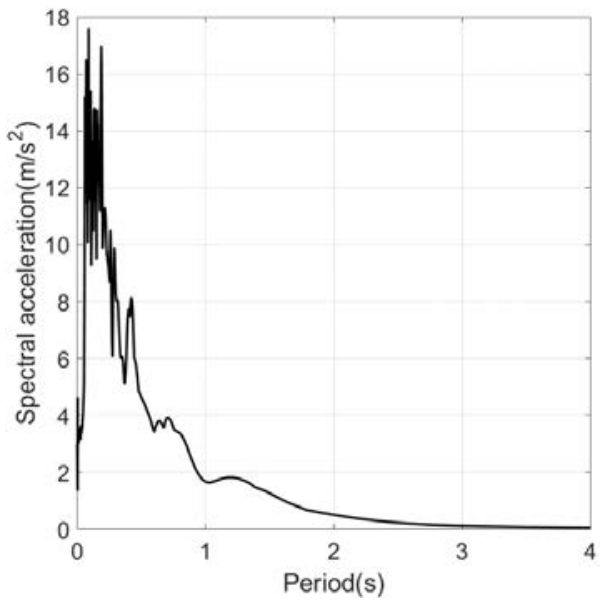

(b)

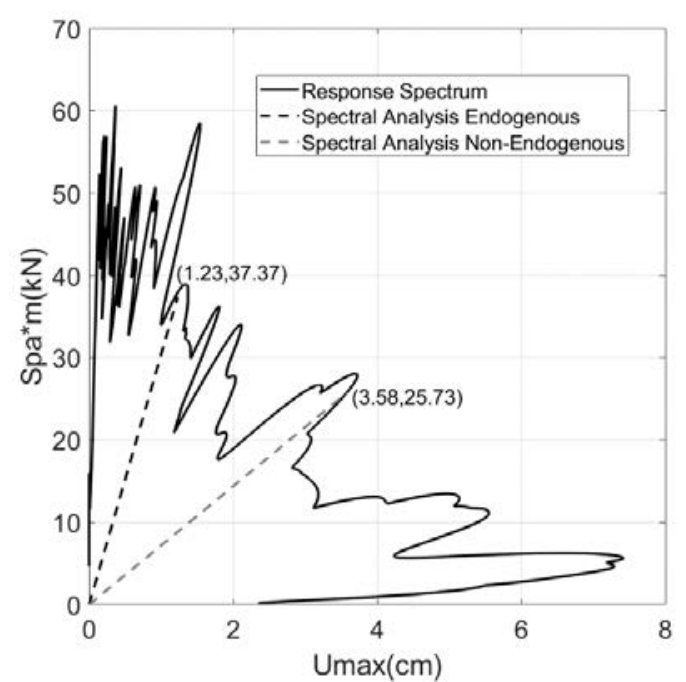

(c)

Figure 2.16: Spectral Analysis (a) 0.3 g Accelerogram, (b) Pseudo-acceleration response spectrum, (c) Spectral analysis results 


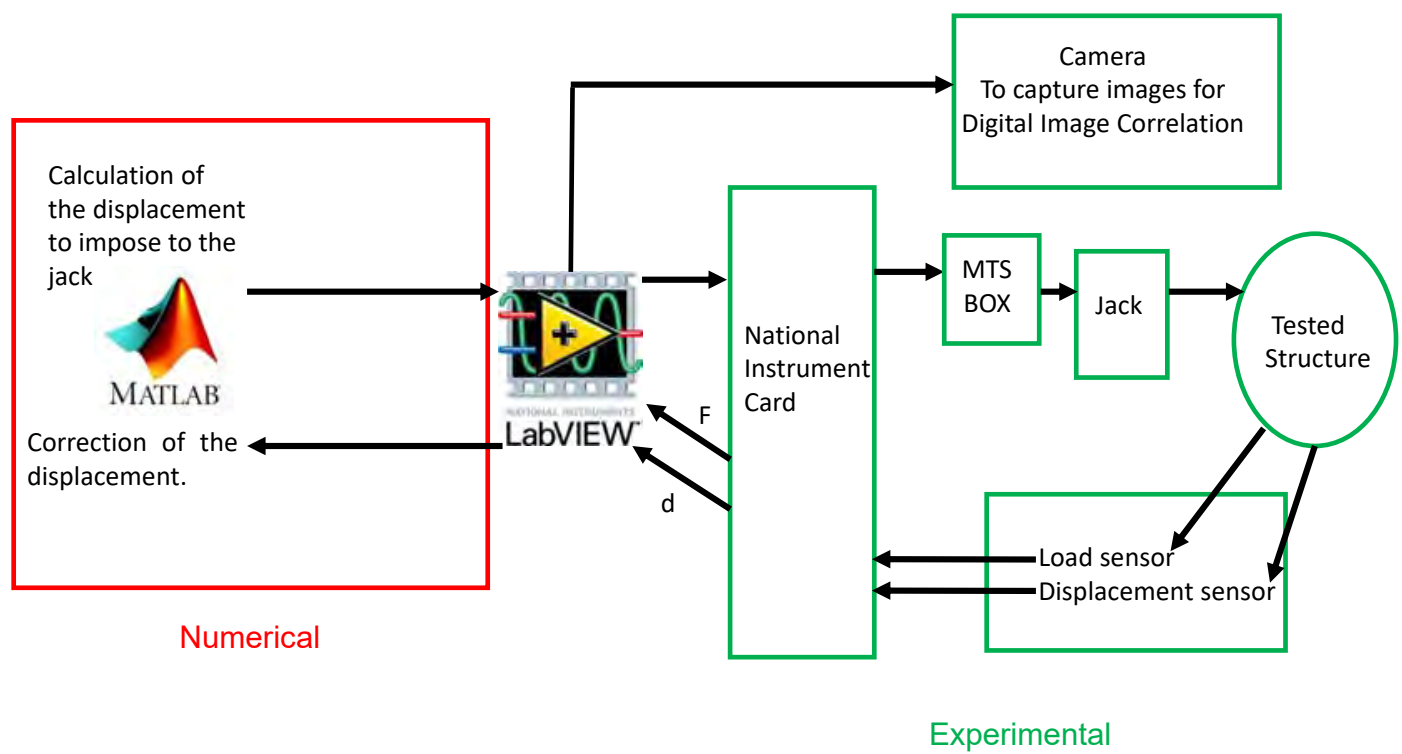

Figure 2.17: Numerical and experimental interaction during the PsD tests. F is the force value and $\mathrm{d}$ the displacement value.

\subsubsection{Pseudo-dynamic tests}

The PsD technique was applied on the reinforced concrete portal frames in order to determine their dynamic behavior under a seismic loading.

\subsubsection{PsD procedure and validation}

Before using the pseudo-dynamic test technique on the portal frames under study, a first step of the work of this thesis consisted in developing and validating such technique in the GEOMAS Lab of INSA Lyon by applying it on a linear steel spring.

2.5.2.1.1 Procedure of resolution In order to perform the PsD tests, a Labview program was developed during this thesis. This program allows to read the displacement value given by the displacement sensor and the force value given by the load sensor as well. It also allows to treat the data and perform the required corrections before calculating (using a MATLAB Loop within the Labview program) the displacement to be imposed in the following step and to monitor the jack so that it performs the required displacement based on the Alpha Operator Splitting Algorithm [4].

The computer that contains the Labview program was connected to a National Instrument Card itself connected to the displacement sensor, the load sensor and the jack via an MTS 
box (Figure 2.17).

It should also be pointed out that the Labview program was developed in a way to also control a camera so that it takes a photo of the studied structures at the end of each PsD test in order to perform Digital Image Correlation or video tracking.

Before using the PsD tests on the portal frames several tests were performed on a steel spring in order to validate the technique.

2.5.2.1.2 PsD application on a linear steel spring The PsD technique was validated using a linear steel spring that was subjected first to a sinusoidal loading and then to an accelerogram. Results obtained using the sinusoidal signal were compared to an analytical solution whereas the response of the linear steel spring under the accelerogram was validated by comparing it to a purely numerical solution. The linear spring under study is presented in Figure 2.18. Such structure can be assimilated to a one degree of freedom system. A laser displacement sensor was used as well as a load sensor to conduct the PsD tests as shown in Figure 2.18. In order to perform the pseudo-dynamic test, a

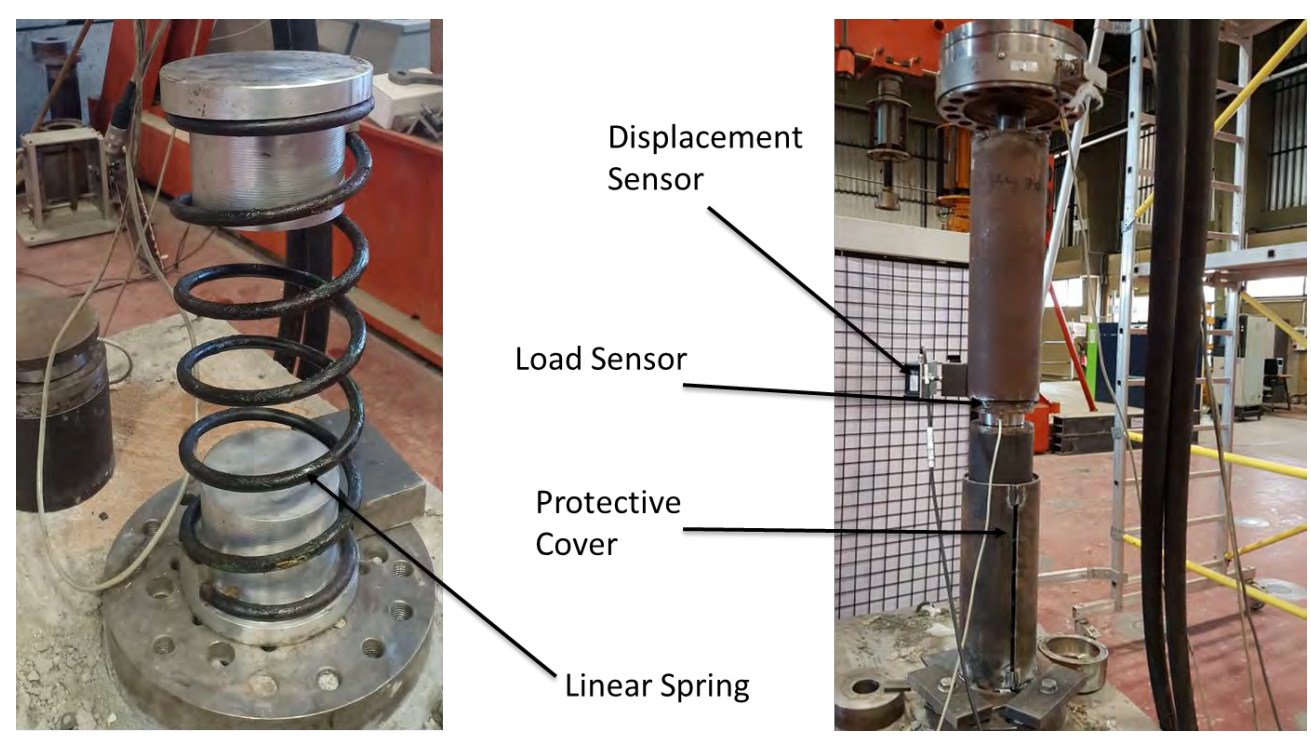

Figure 2.18: Psd test experimental set up used to test a linear steel spring

simulated mass $M=358.4 \mathrm{~kg}$ was considered (numerically simulated), a damping ratio $\xi=0.05$ (typical damping ratio value for steel structures) was also numerically simulated. The corresponding damping coefficient $C$ was calculated starting from the damping ratio using following expression: $C=2 \xi \sqrt{M K}$ whereas a stiffness $K=14431.2 \frac{\mathrm{N}}{\mathrm{m}}$ was used. 
Stiffness value was detemined experimentally by imposing small amplitude cycles (loading and unloading) to the linear spring. Stiffness value was used in the analytical solution also.

The steel spring was first subjected to a sinusoidal signal: $F_{\text {ext }}=30 \sin (2 \pi t)$ in Newtons. Results obtained using the pseudo-dynamic technique were compared to the analytical solution. Indeed, since such structure behaves linearly, its restoring force can be written as: $P(U)=K U$ where $K$ the stiffness and $U$ the displacement. Since the applied load is sinusoidal, the equation of motion $M \ddot{U}+C \dot{U}+K U=F_{\text {ext }}=30 \sin (2 \pi t)$ becomes a second order differential equation that can be solved analytically.

$$
M \ddot{U}+C \dot{U}+P(U)=\overbrace{\text { ext }}^{\text {Sinusoidal signal }}
$$
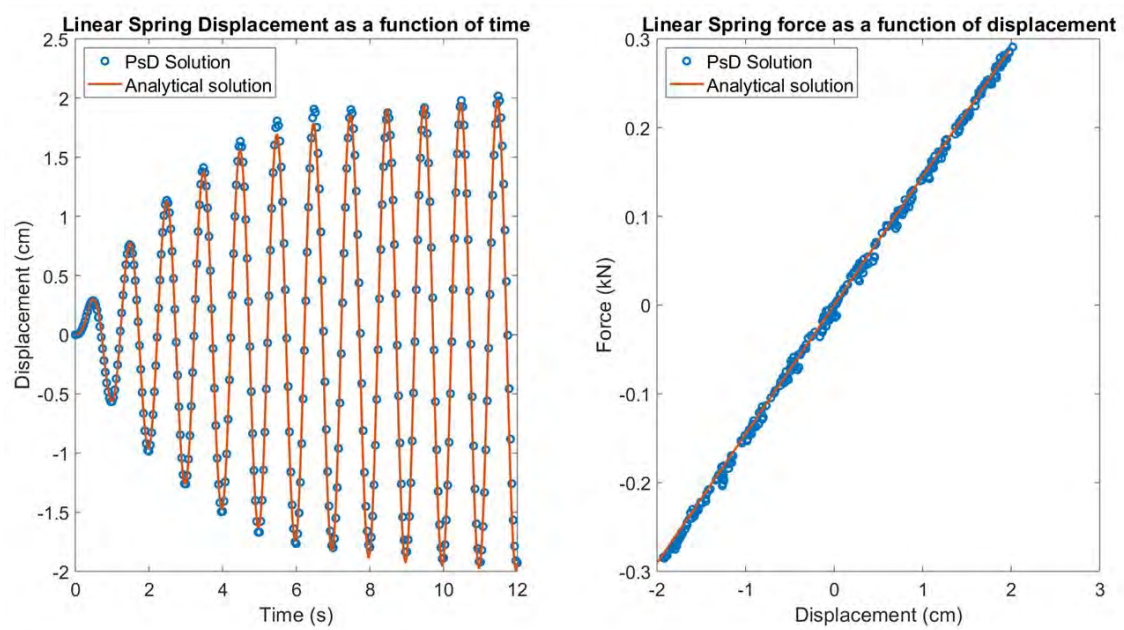

Figure 2.19: Linear steel spring under a sinusoidal signal

Results obtained using the PsD technique and the analytical solution are given in Figure 2.19. A very good matching is observed.

Then, the spring was subjected to a Eurocode [2] (French annex) accelerogram (Figure 2.20a . Its corresponding response spectrum is given in Figure 2.20b. The acceleration imposed to the steel spring induces an external force: $F_{e x t}=-M \frac{A c c S e i s m e E C 8}{3}$. Where, AccSeismeEC8 is the acceleration time history (Figure 2.20a). The acceleration AccSeismeEC8 was devided by 3 in a way that the spring displacement doesn't exceed 3 $\mathrm{cm}$ due to experimental limitations. Using the pseudo-dynamic method, the response of the steel spring was obtained and then compared to a purely numerical solution. In fact, 


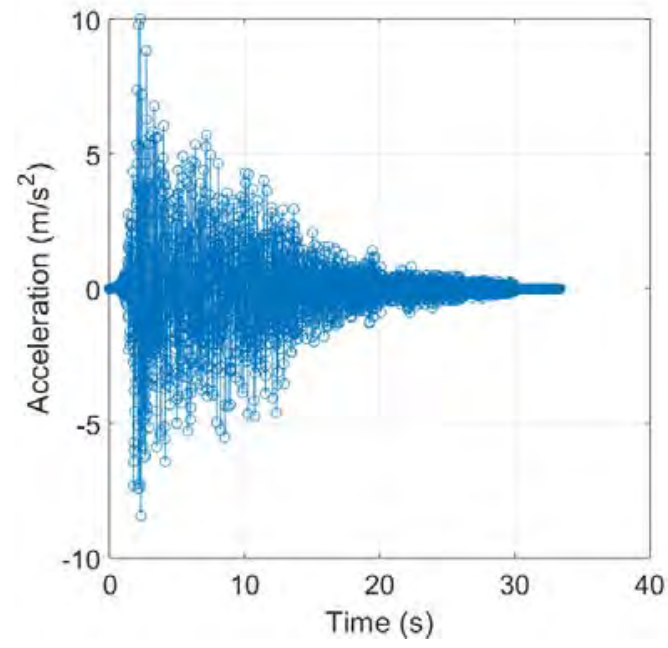

(a) Time History [2]

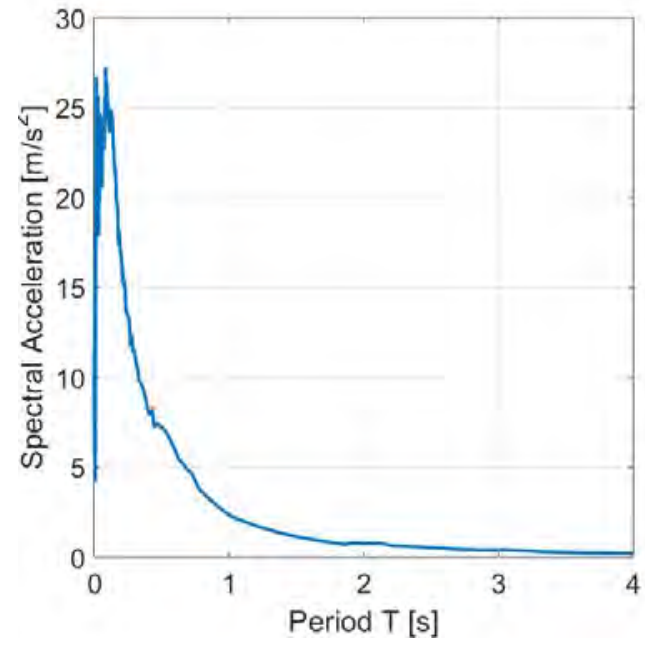

(b) Response Spectrum

Figure 2.20: Eurocode input data for PsD tests on the linear steel spring

since the external force was not a sinusoidal, the equation of motion couldn't be solved analytically.
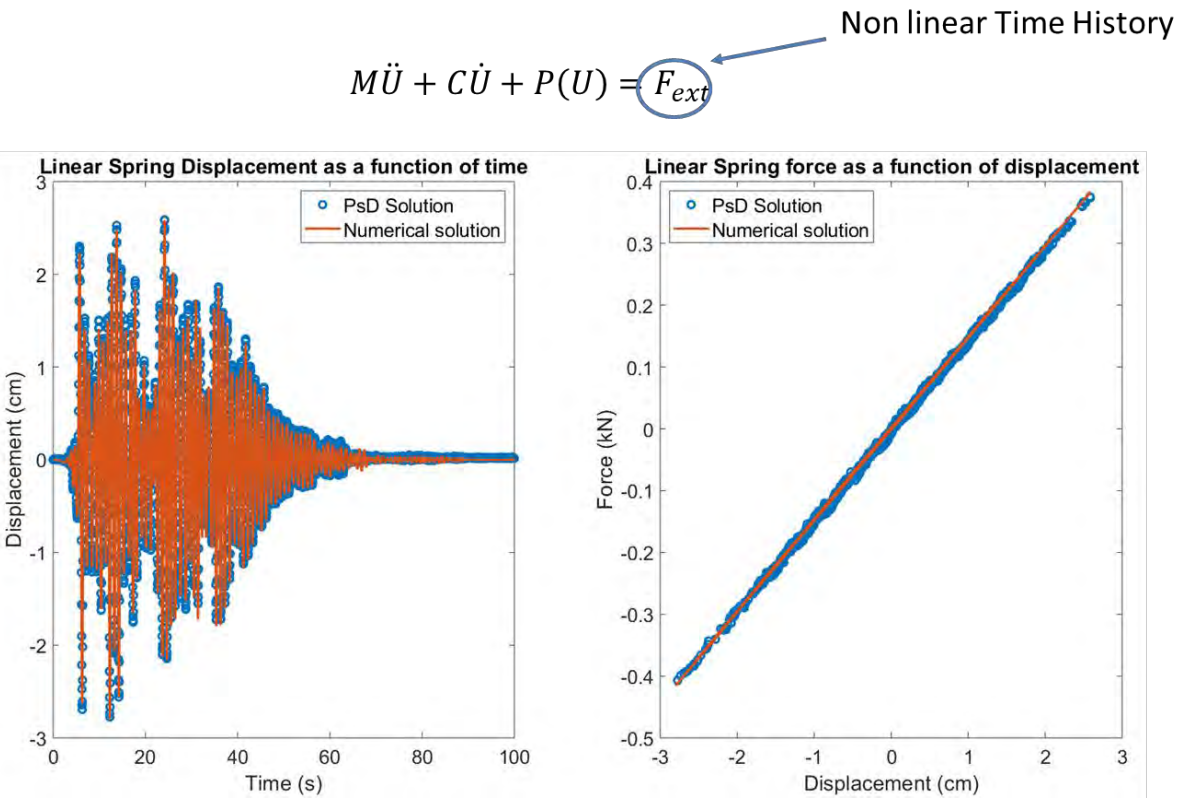

Figure 2.21: Linear Steel Spring under a Non-Linear Time History

There was a need to solve it numerically using a temporal integration scheme (in our 
case Newmark equations with $\alpha=\frac{1}{2}$ and $\beta=\frac{1}{4}$ ) that relates displacement to velocity and acceleration as explained in Chapter 1.

A good matching between the pseudo-dynamic solution and the purely numerical one was obtained as shown in Figure 2.21).

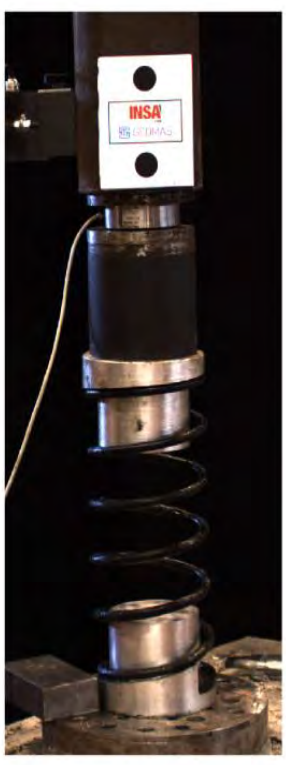

(a)

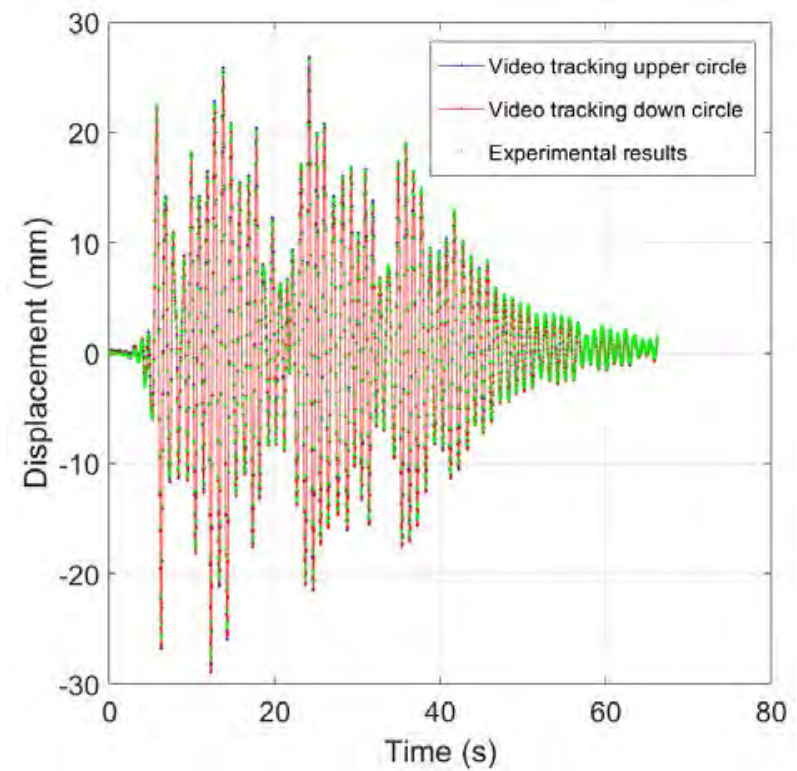

(b)

Figure 2.22: Video Tracking (a) Followed black circles during the video tracking (b) Comparison between the displacement determined using PsD and the measured displacement using video-tracking

In order to confirm results obtained using the displacement laser sensor, a video tracking was performed. Indeed, in civil Engineering it is usually important to use redundant ways of measurements to confirm obtained results. Figure 2.22 a shows the black circles that were followed using a Matlab routine when performing video tracking (photos used for videotracking were taken at the end of each PsD loop with a camera as explained in Figure 2.17).

Results obtained using video tracking match well the ones obtained using the laser sensor (Figure 2.22 b).

\subsubsection{RC portal frames results}

Once the PsD technique was validated using the steel spring, it was used to determine the non-linear dynamic response of the portal frames. The experimental set-up is shown 


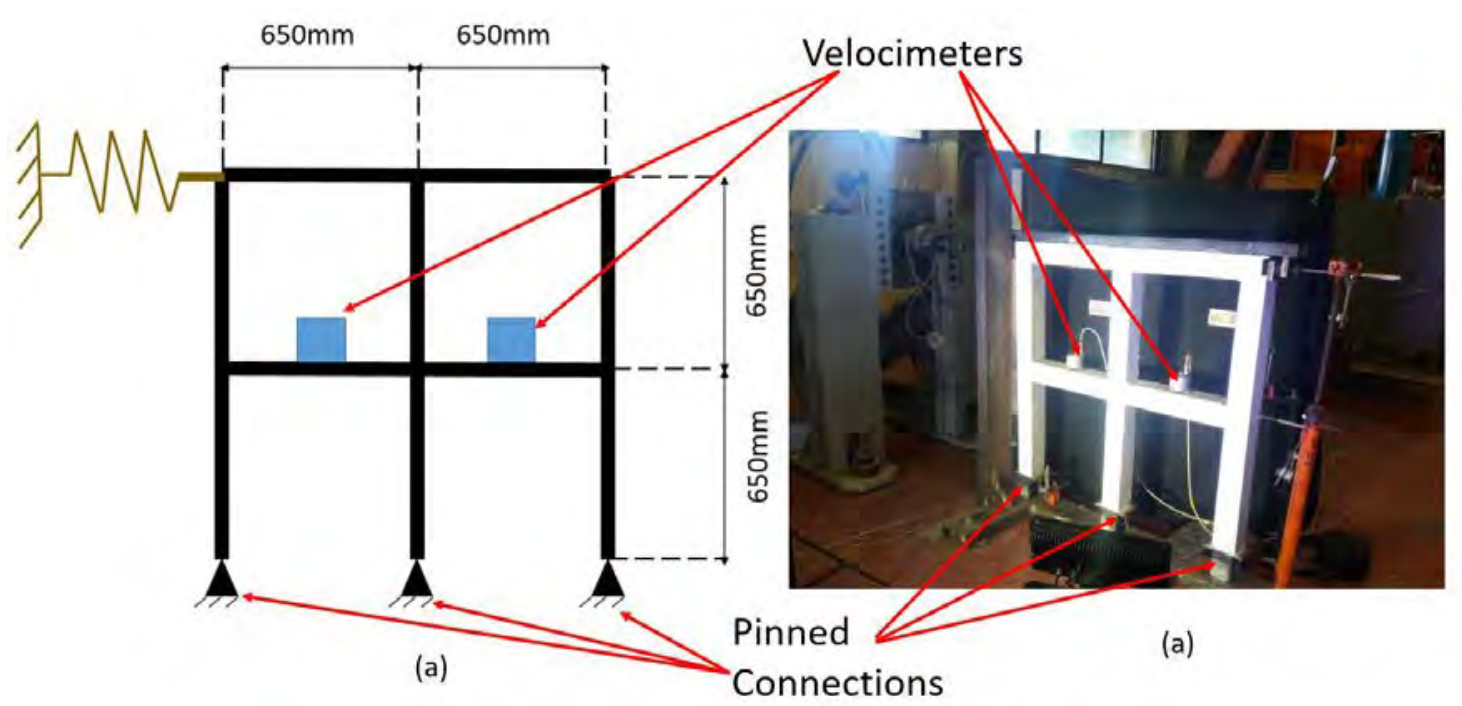

Figure 2.23: Position of Velocimeters during PsD testings (a) Scheme (b) Experiment

in Figure 2.23b. A Rayleigh Damping ratio of $1 \%$ was taken into account in the PsD algorithm (value determined using ambient vibration measurements).

Figure 2.24 shows the mechanical response of the portal frames (Displacement-time and force-displacement evolutions). Displacement was measured using LVDT1 sensor (positioned similarely as in Figure 2.11b). It can be noticed that the maximum displacement (resp. force) in the Non-Endogenous case is 33 \% (resp. $15 \%$ ) higher than in the Endogenous case.

In order to confirm results obtained using LVDT1 sensor, a 2D Digital Image correlation [63] 64 [65] [66] was performed to follow the displacements of the portal frames during the PsD tests. A high resolution camera (Vieworks VN 29M) was used (the resolution of the camera is $29 \mathrm{MPx}$ ) as well as a lens aperture of $\frac{f}{11}$ to capture images of the Region of Interest (ROI) at an interval of 7s. In order to have a diffuse lighting, a white LED and two multicolor LEDS (red, green and blue) were used (figure 2.25;). Image correlation was performed using the UFreckles software [13]. The area to be tracked being the whole portal frame, a grey level speckle pattern was applied on it as shown in Figure 2.25 using a white lime undercoating over which black dots were applied (using a painting). The original image was divided into four-noded quadrilateral finite elements (QUA4) having a size of 20 pixels by 20 pixels in order to interpolate the displacement field (Figure 2.25b). In order to obtain such meshing of the portal frames, a subroutine was developed on Matlab. When running such subroutine, the initial image of the portal frames captured during the PsD test is opened. Then, the user has to click on 16 


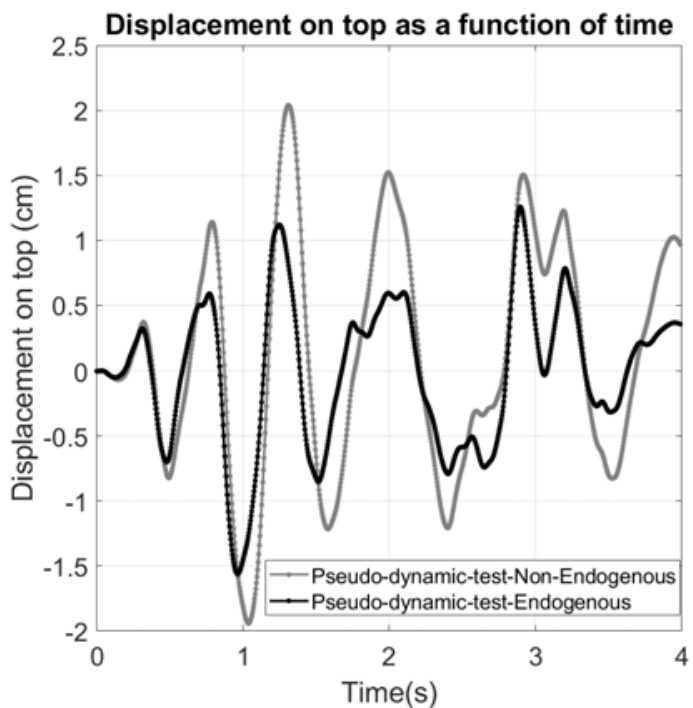

(a)

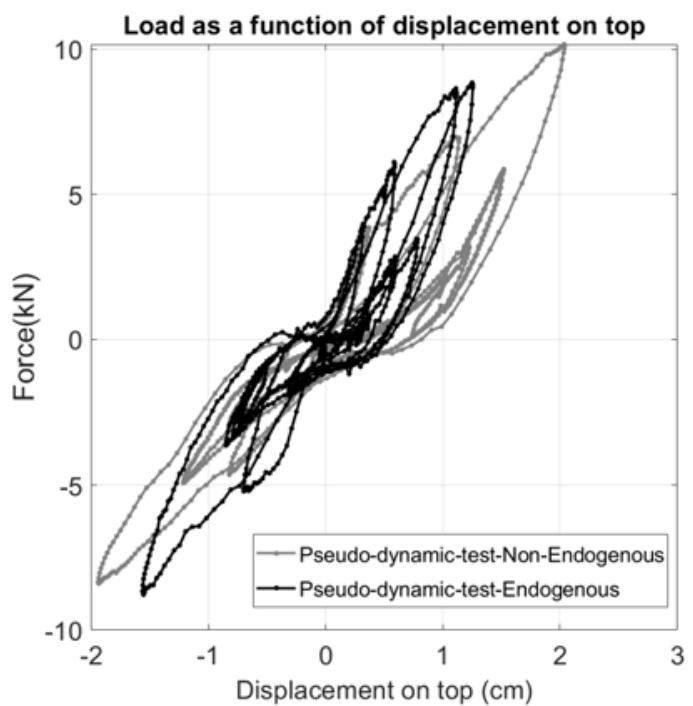

(b)

Figure 2.24: Pseudo-dynamic test results (a) Displacement-time Evolution and (b) ForceDisplacement Evolution

main points as seen in Figure 2.26. From those entry points the Matlab subroutine calls a CAST3M code [76] that allows to mesh the portal frames using QUA4 elements. The obtained mesh is then uploaded on the UFreckles software [13] itself developed on Matlab in order to perform the 2D Digital image correlation. The initial correlation error before loading was on average equal to $0.6 \%$. It corresponds to the noise of the setup.

Figures $2.27 \mathrm{a}$ and $2.27 \mathrm{~b}$, give the evolutions of displacements on top of the two portal frames obtained using Digital Image Correlation that confirm results measured using LVDT1 sensor.

In addition to LVDT1 sensor, LVDT2, LVDT3 and LVDT4 sensors were used during PsD tests (positioned as in Figure 2.11b). Measurement records are given in Figure 2.28 for the two types of portal frames. In addition to the out of plane movement of about 5 $\mathrm{mm}$ that the structures underwent (measured by LVDT4), displacement sensor LVDT3 measured a horizontal displacement at the bottom of the left column for the two types of structures of about $2 \mathrm{~mm}$, wich implies that the pinned boundary conditions were not perfect.

At the end of the PsD tests, a pushover was performed on both frames in order to determine their ultimate capacity. As for the portal frames tested using static cyclic 


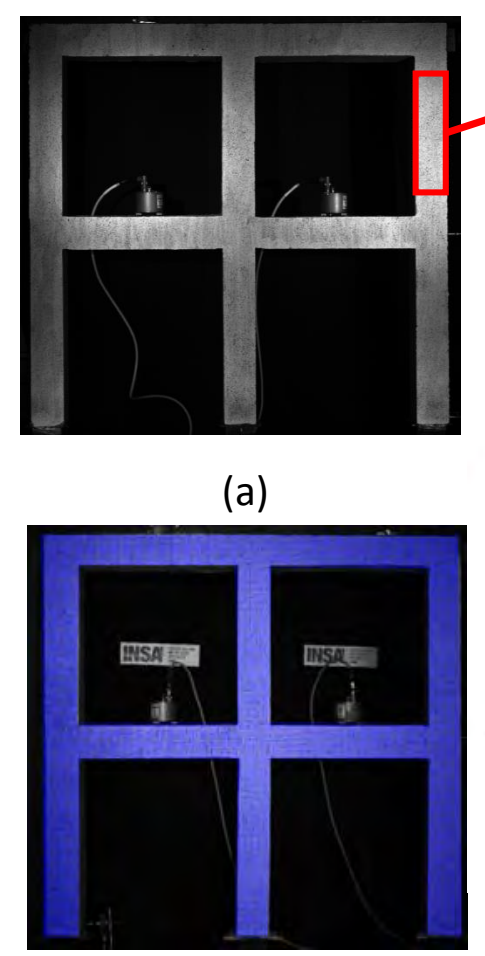

(b)

\section{Speckle}

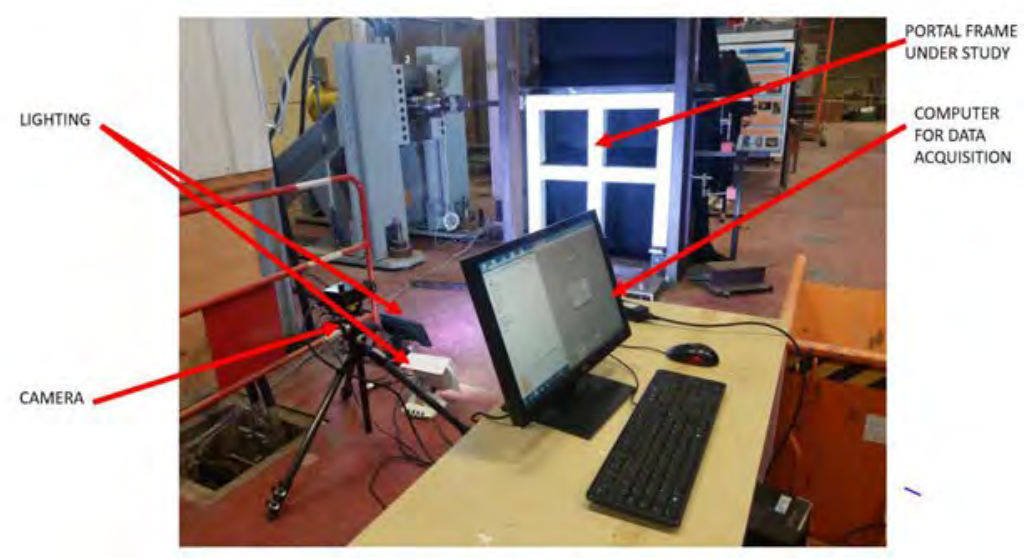

(c)

Figure 2.25: Correlation (a) Speckle (b) grid (c) Experimental set-up

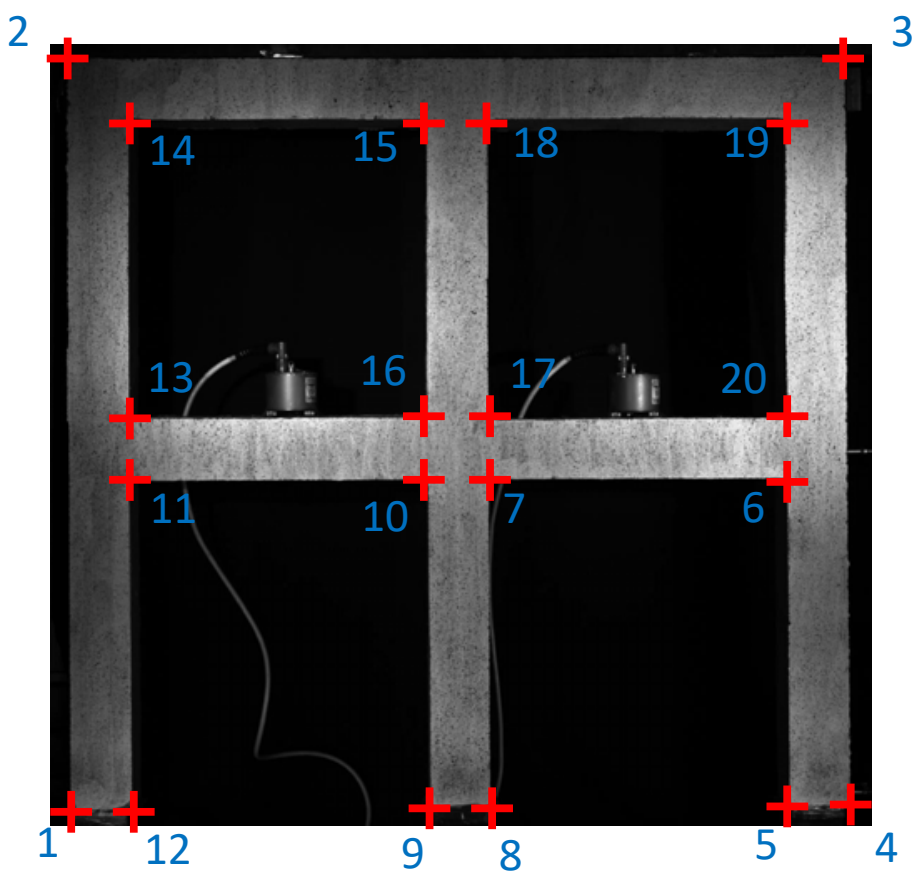

Figure 2.26: Position of points to define by the user in order to generate the meshing of the portal frames 


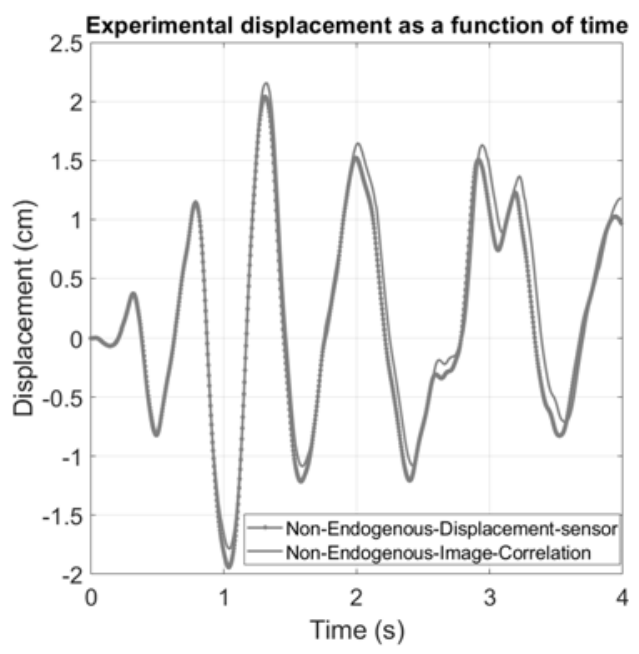

(a)

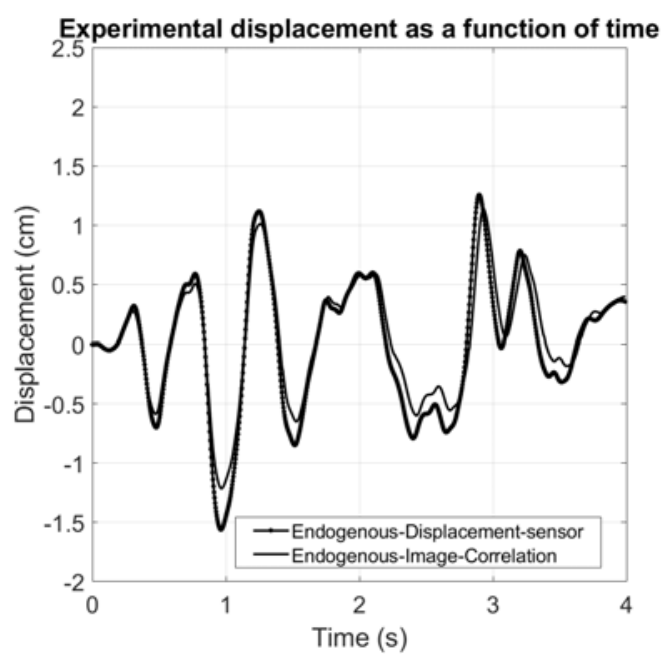

(b)

Figure 2.27: Displacement as a function time results using LVDT1 sensor and digital Image correlation (a) Non-Endogenous portal frame (b) Endogenous portal frame

loading, the two portal frames tested using the PsD technique were casted in place the same day with a similar blend. Similar trends were obtained as for the first pushovers: the non-endogenous structure has a more important capacity $(15.6 \mathrm{kN})$ than the endogenous one $(13.8 \mathrm{kN}$ ) (Group 2 in Table 2.3 . Thus, this difference in ultimate capacity could not be explained only by a variability of material. This point would deserve to be further investigated in future studies.

\subsection{Damage evolution during earthquake}

\subsubsection{Crack pattern evolution over concrete surface}

Based on digital image correlation error, crack apparition was followed during the pseudodynamic tests. The correlation error threshold that was used in order to detect cracks is equal to $20 \%$. Crack patterns were drawn at each displacement pick (numbered from 1 to 11 as shown in Figure 2.29a). Cracks mainly developed in the middle beam and more particularely near the nodes (Figure 2.29b) for both groups of portal frames (figures 2.30 and 2.31 due to the strain increase that occured towards the joints of the structures (strain fields were also determined using Digital Image correlation) during their PsD tests (Figure 2.32 shows how cracks develop in places where strain is important). It should be 

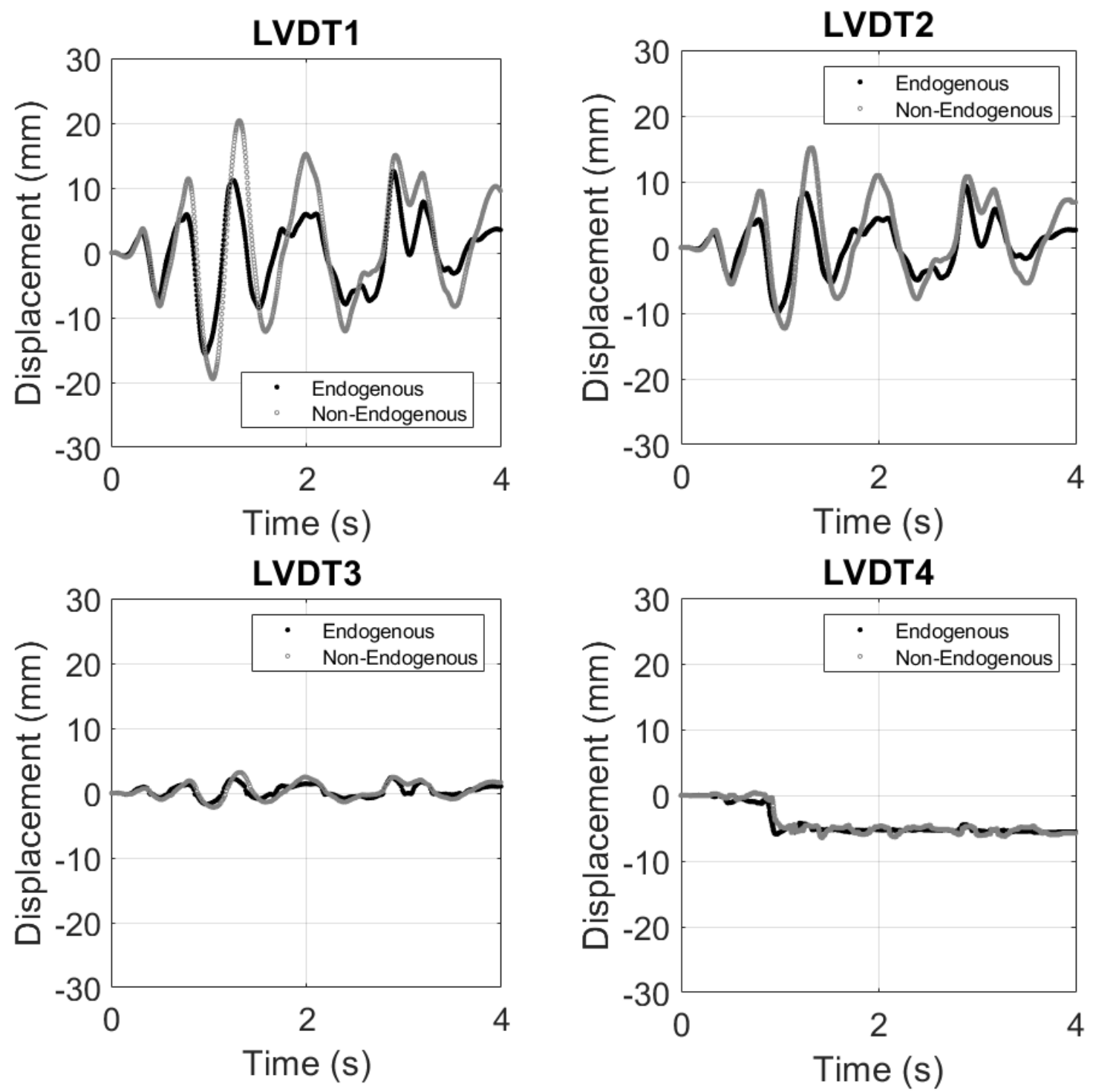

Figure 2.28: Evolution of displacements measured using LVDT1, LVDT2, LVDT3 and LVDT4 during the pseudo-dynamic test performed on the Endogenous and NonEndogenous portal frames. LVDT sensors were positioned as shown in Figure 2.11b: LVDT1 measured the lateral drift of the second floor of the portal frames, whereas LVDT2 measured the lateral drift of the first floor and LVDT3 the horizontal displacement at the bottom of the left column of the portal frames and LVDT4 measured out of plane movements. 

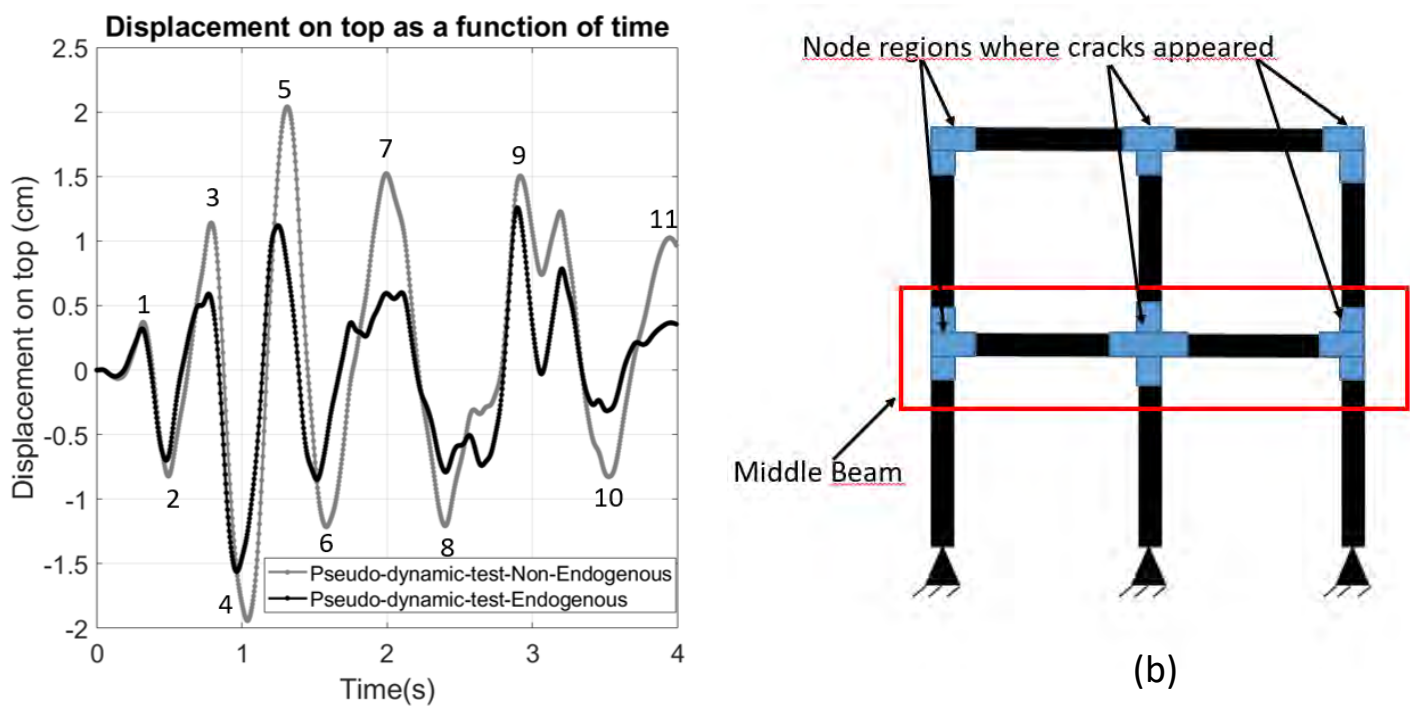

(a)

Figure 2.29: (a) Crack pattern correlation points and (b) Zones of cracks apparition

pointed out that cracks opened and closed back during the loading process (depending on whether the cross-sections were under compression or under traction) as shown in Figures 2.30 and 2.31 .

\subsubsection{Frequency content evolution}

Ambient vibration measurements were performed during the pseudo-dynamic tests (Figure 2.23) in order to follow the frequency evolution of the structures ( $(\mathrm{x}, \mathrm{y})$ plane) under their self weight. As indicated in Table 2.2, the two portal frames were pinned at their three ends and attached on top with the jack system (Figures $2.23 \mathrm{a}$ and $2.23 \mathrm{~b}$ ) during the measurements. The modification of the boundary conditions of the portal frames explains why frequency measured at the end of the early age period is around $23 \mathrm{~Hz}$ with the first supporting system (Figure 2.8) and around $53 \mathrm{~Hz}$ with the second supporting system (Figure 2.23 ). In order to apply the RDT method, windows having a length of $8 T_{0}$ were used as during the early age period as well as a trigger value of $2 \sigma$. One frequency was calculated each 7 seconds (period corresponding to one PsD iteration). During the PsD test, a difference in the frequency content of the two portal frames was detected based on the velocimeters recordings. In fact, it was noticed that the first natural frequency of the portal frame kept at early age in non-endogenous conditions decreased due to the seismic loading from $53 \mathrm{~Hz}$ to $46 \mathrm{~Hz}$ (Figure 2.33b) whereas in the endogenous case it remained constant under the same seismic loading (Figure 2.33 a). Therefore the non-endogenous 


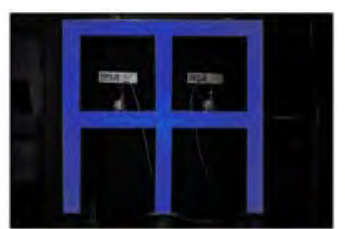

1

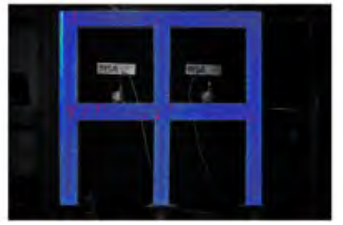

4

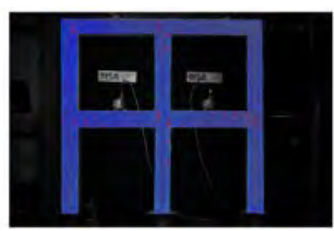

7

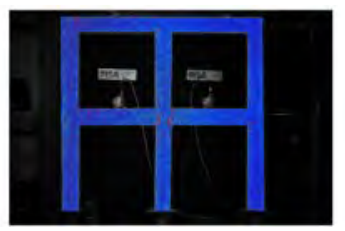

10

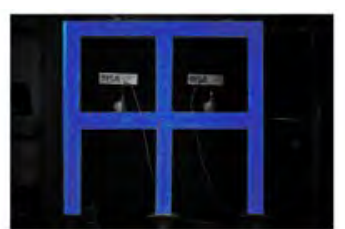

2

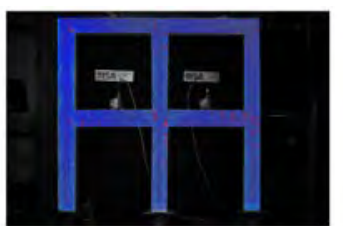

5

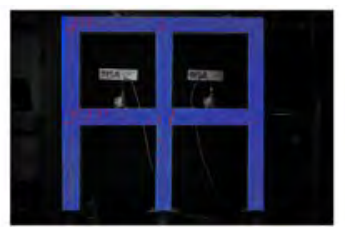

8

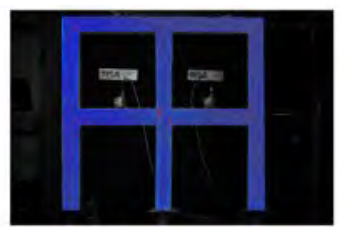

11

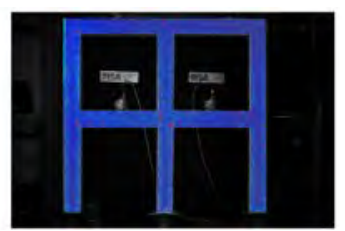

3

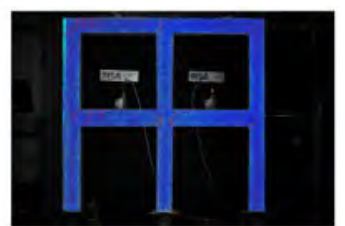

6

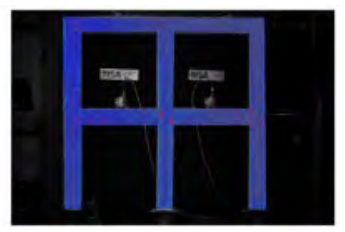

9

Figure 2.30: Non-Endogenous Portal frame crack evolution using Ufreckles [13]

portal frame was more damaged than the endogenous one at the end of the seismic loading.

It should also be pointed out that during the experiment, the frequency of the portal frames decreased punctually when the displacement on top of the portal frames reached its negative peaks and then the frequency increased back (Figures 2.33a and 2.33b) and more particularely in the non-endogenous case. It is due to the fact that during the experiment, the portal frames underwent vertical displacements at the bottom of the three columns when the displacement on top was negative because the boundary conditions were not perfectly well realized (not perfect pinned conditions).

\subsubsection{Discussion}

Under the same accelerogram, the non-endogenous portal frame was more damaged than the endogenous one. In fact, while digital image correlation showed that cracks appeared at the surface (towards the nodes) of both the endogenous and the non-endogenous portal 


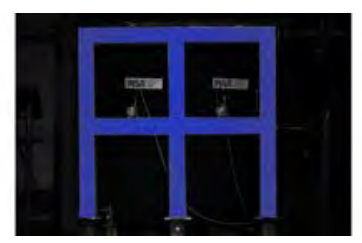

1

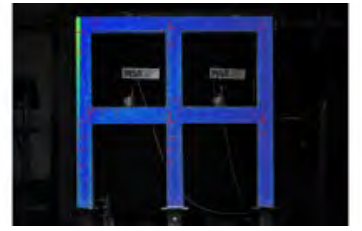

4

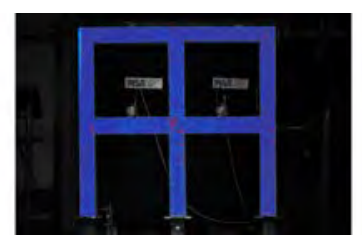

7

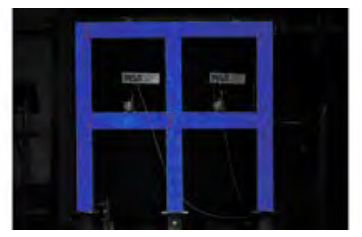

10

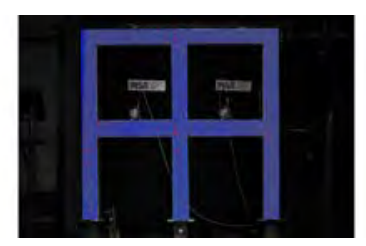

2

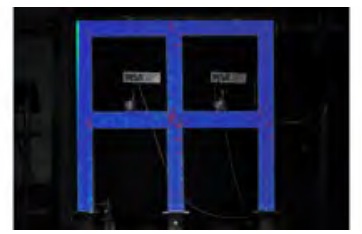

5

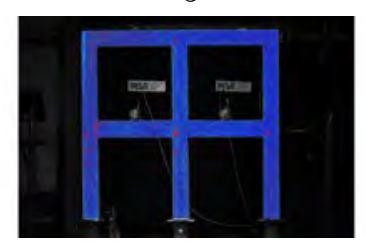

8

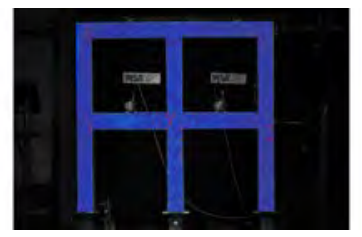

11

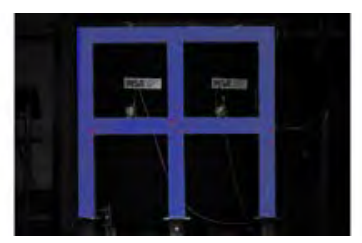

3

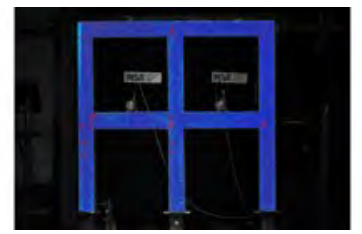

6

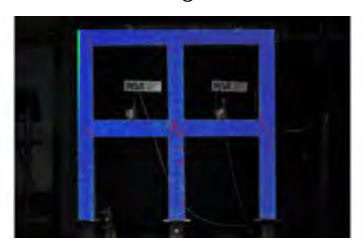

9

Figure 2.31: Endogenous Portal frame crack evolution using Ufreckles [13]

frame, ambient vibration measurements proved that the drop of natural frequency was more important in the NE portal frame during PsD tests. Furthermore, force versus displacement curves of the two structures clearly underlined their different of stiffness.

\subsection{Effect of boundary conditions}

As commonly observed in the practice, it is difficult to build perfect boundary conditions as wanted. The portal frames were initially designed to be pinned at their three ends. During the experiment however, the portal frames underwent vertical displacements at the bottom of the three columns. Such displacements were evaluated using digital image correlation. Figure 2.34 shows the evolution of diplacements following the vertical direction at the three ends. The most important displacement occured at the right column. Its value will be used in order to correct the numerical model developed. It should be pointed out that the originally measured displacement through image correlation had some in- 

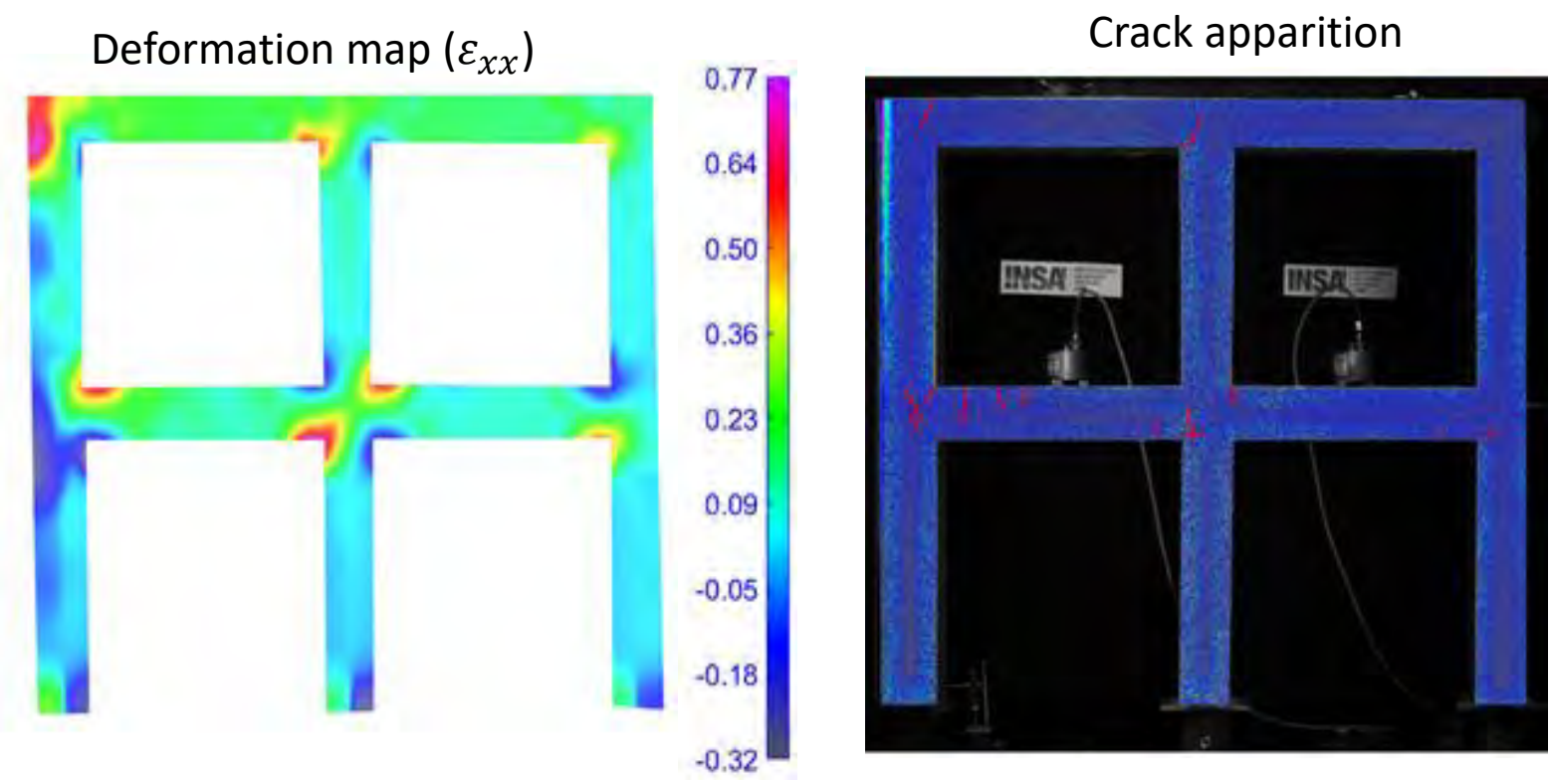

Figure 2.32: Strain increase and cracks apparition using Ufreckles [13]

herent noise, that was filtered in order to obtain a more smooth displacement curve. Using displacement value, corresponding velocities and accelerations were then calculated (Newmark equations) and plotted in Figure 2.35 for the Non-Endogenous portal frame and in Figure 2.36 for the endogenous one. Those values will also be implemented in the numerical model for correction.

A new series of portal frames was built in a way to improve boundary conditions (By Minimizing the vertical displacements). Displacement as a function of time as well as force versus displacement curves obtained using the pseudo-dynamic technique for the second group of portal frames are given in Figure 2.37. It can be noted that the response is different from the one of the first group of portal frames. Also, the difference between the response of the endogenous portal frame and the non-endogenous portal frame is more important in this second case (The maximum displacement on top of the non-endogenous portal frame is $44 \%$ more important than the endogenous portal frame). Which implies that depending on their boundary conditions, the behavior of structures can be different and the impact of early age damage can vary. Again, using image correlation, the real displacement at the end conditions was determined. While being very small in comparison with the first group of portal frames, it is still not equal to zero and was quantified (Figure 2.38). Vertical displacement at the right column given in Figure 2.38 will be taken into account in the numerical model. LVDT sensors measurements given in Figure 2.39 

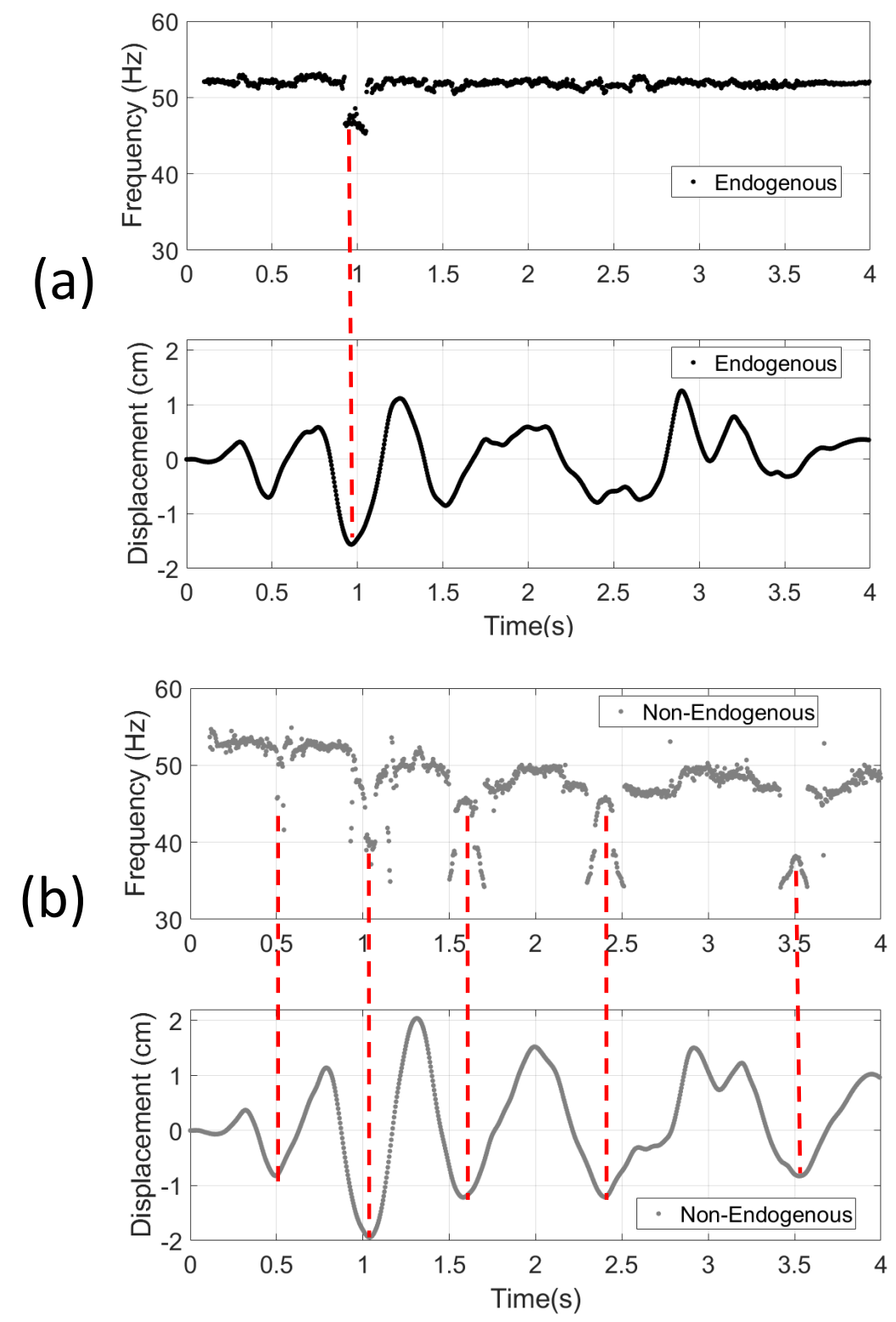

Figure 2.33: Frequency and displacement evolutions during PsD tests: (a) Endogenous and (b) Non-Endogenous. Red dotted lines indicate maximum local negative displacements where a drop of frequency occured 

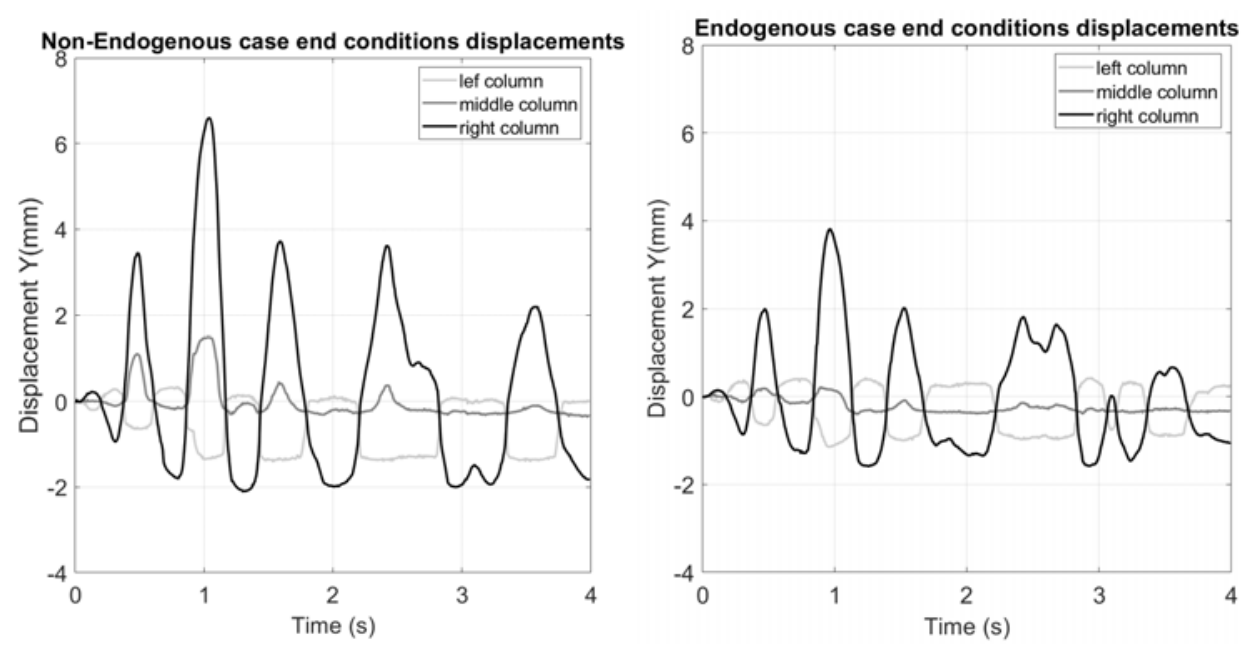

Figure 2.34: Vertical displacements (Y direction) at the bottom of the three columns of the first group of portal fames (endogenous and non-endogenous) tested experimentally with PsD tests
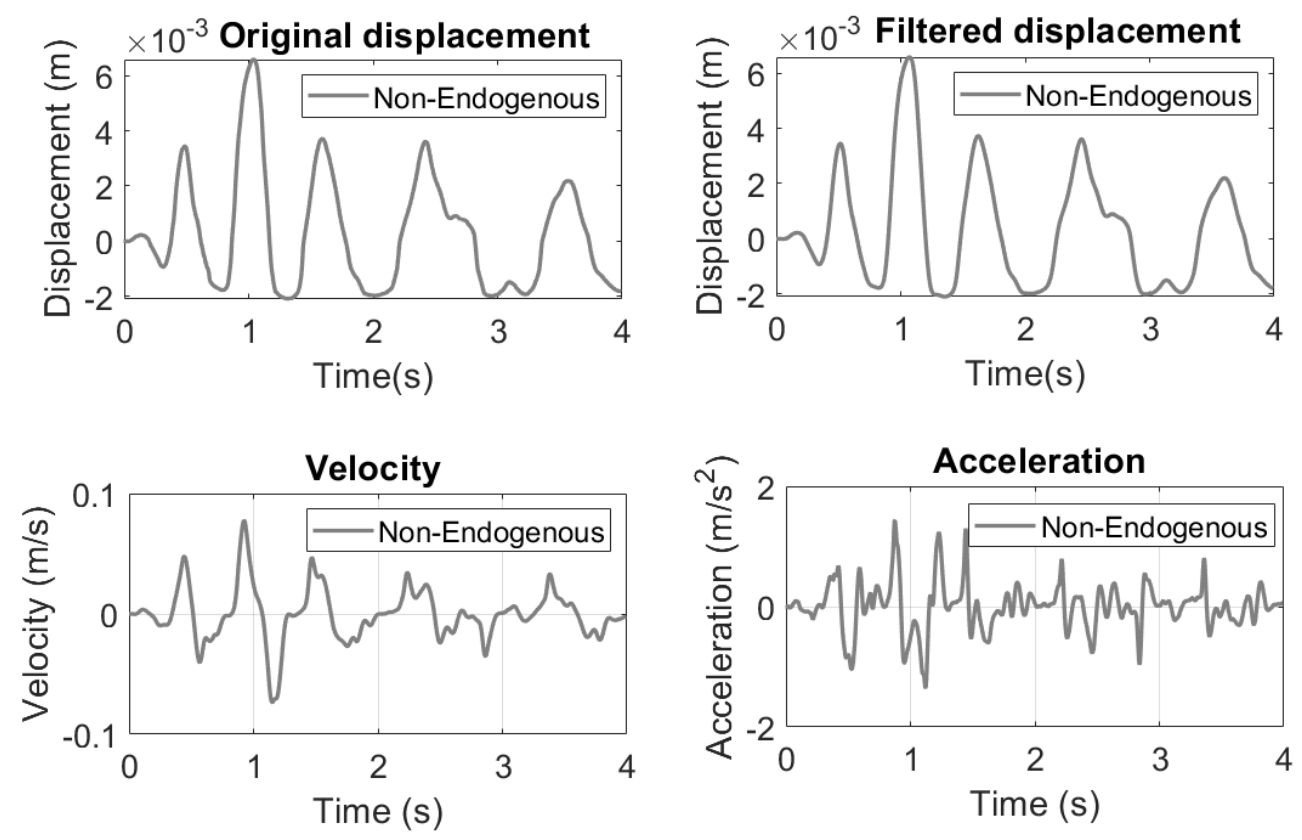

Figure 2.35: Evolutions of vertical displacement (following the Y direction), velocity and acceleration at the bottom of the right column of the NE-portal frame (of the first portal group of portal frames tested with PsD tests) 

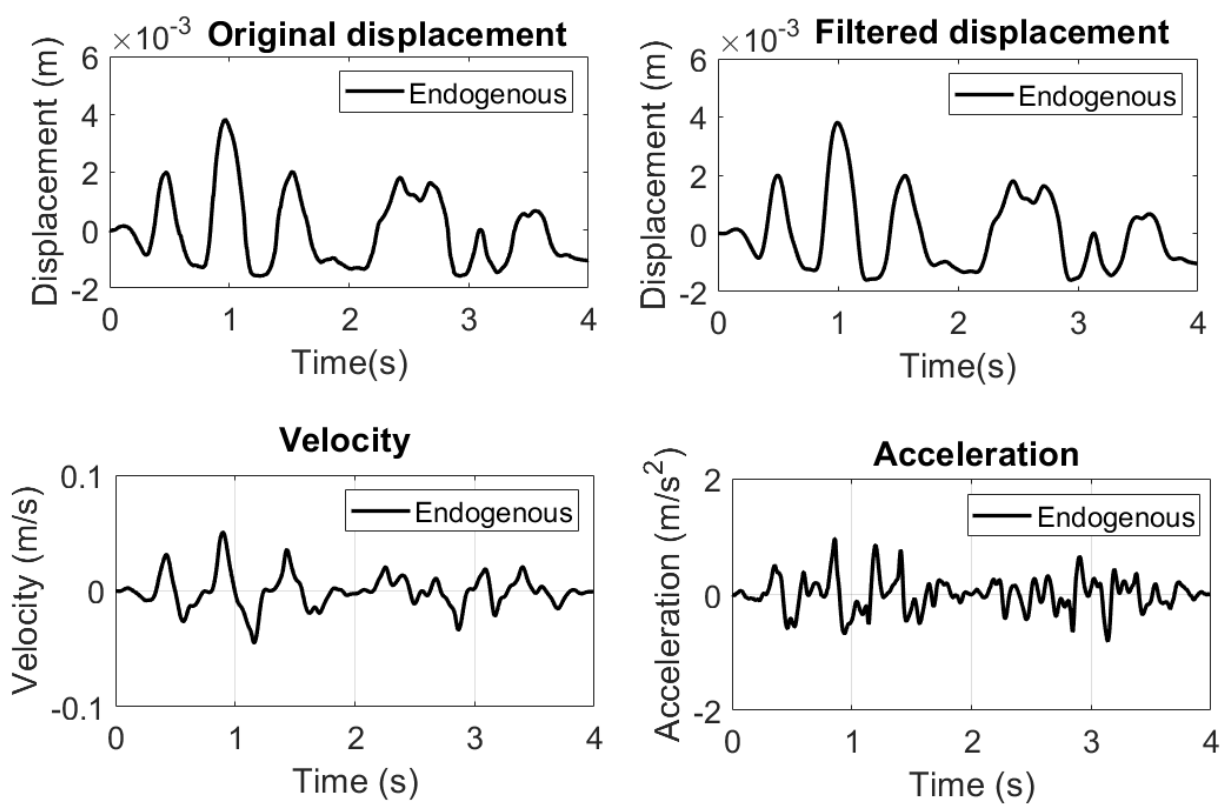

Figure 2.36: Evolutions of vertical displacement (following the Y direction), velocity and acceleration at the bottom of the right column of the E-portal frame (of the first portal group of portal frames tested with PsD tests)
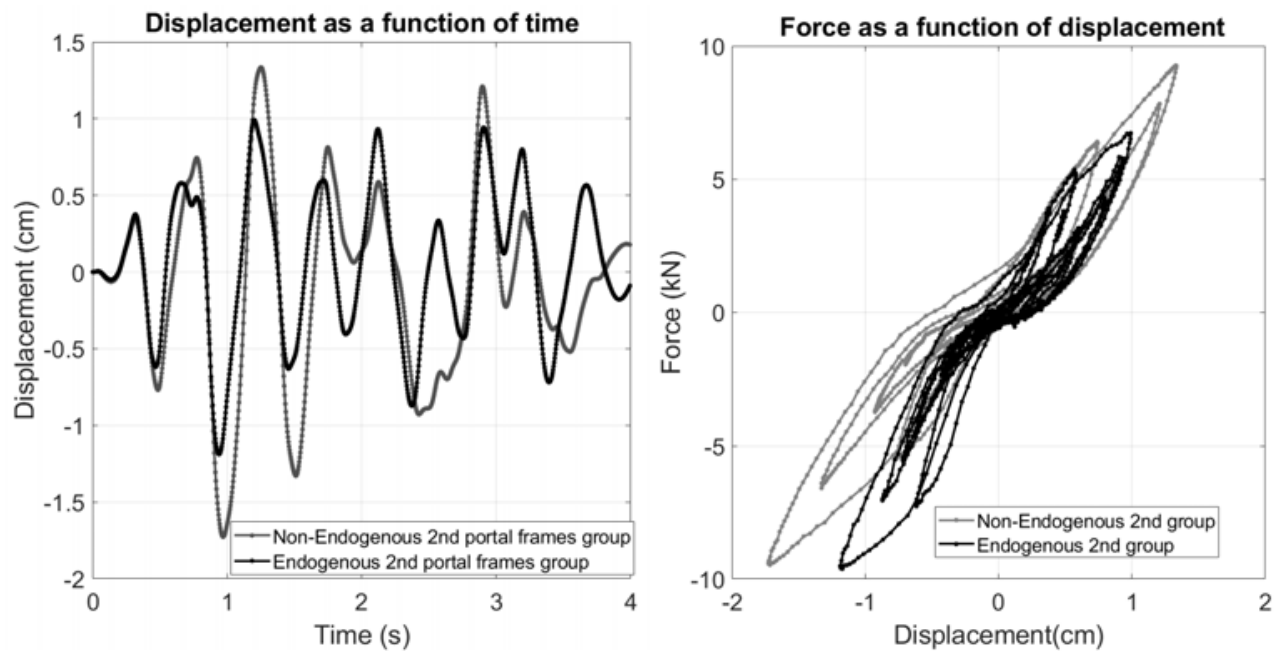

Figure 2.37: Results obtained with the second group of portal frames tested using PsD tests: Displacement as a function time results using LVDT1 sensor and digital image correlation (a) Non-Endogenous portal frame (b) Endogenous portal frame 

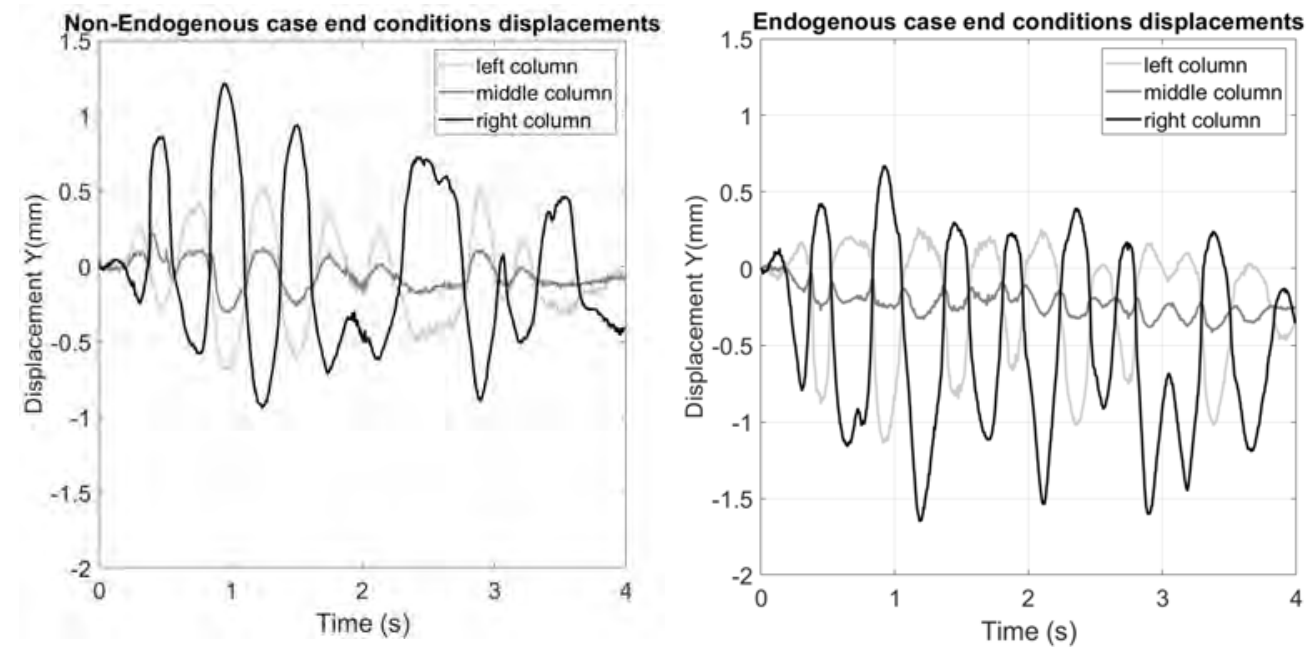

Figure 2.38: Vertical displacements ( $\mathrm{Y}$ direction) at the bottom of the three columns of the second group of portal fames (endogenous and non-endogenous) tested experimentally with PsD tests

confirm that boundary conditions are still not perfect since LVDT3 measures non null displacements. LVDT 4 measured out of plane displacements of the portal frames.

At the end of the PsD tests performed on this series of portal frames, pushovers were performed in order to determine the maximum capacity of the structures. Results are presented in the third line of Table 2.3 (Group 3). Again, it can be observed that the maximum capacity of the non-endogenous portal frame $(19.3 \mathrm{kN})$ is more important than the maximum capacity of the endogenous portal frames $(18.1 \mathrm{kN})$.

\subsection{Conclusions}

The experimental protocol that was conducted allowed showing the effects of early age drying shrinkage on both the static and dynamic behavior of RC portal frames. Through static and pseudo-dynamic tests performed, it was concluded that the fundamental frequency of the structures under study is highly affected by early age damage (50\% loss). Due to the induced frequency reduction, the linear dynamic response of the portal frames obtained by performing a spectral analysis illustrated the effect of damage on base shear reduction.

Non-linear dynamic response obtained using the PsD technique showed the effect of early 
LVDT1
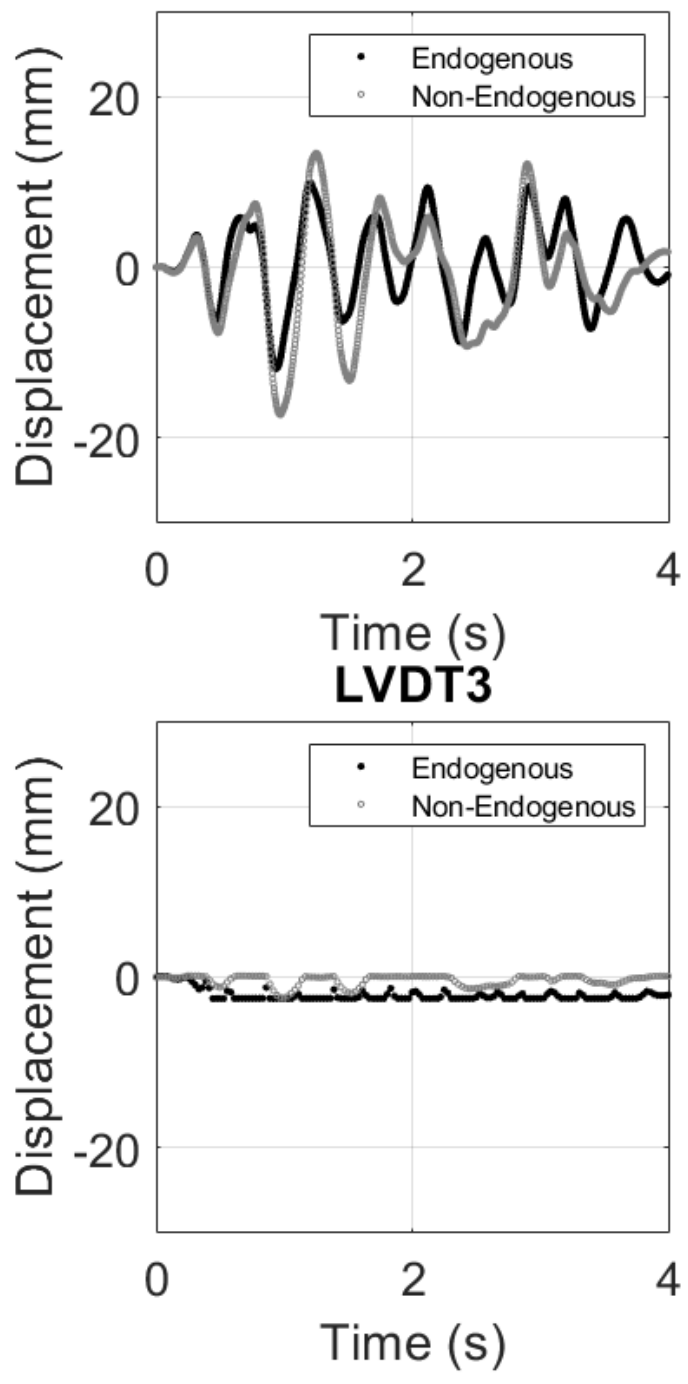

LVDT2
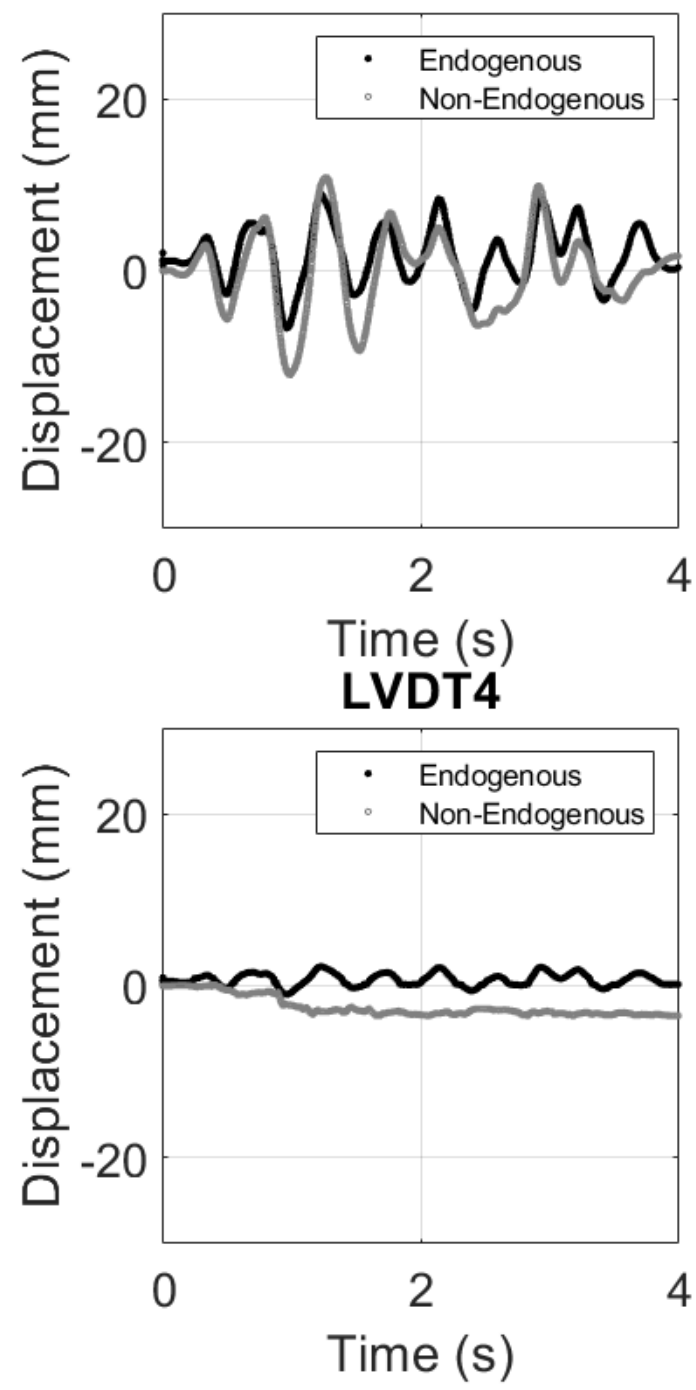

Figure 2.39: Evolution of displacements measured using LVDT1, LVDT2, LVDT3 and LVDT4 during the pseudo-dynamic tests performed on a second group of Endogenous and Non-Endogenous portal frames. LVDT sensors were positioned as shown in Figure 2.11b: LVDT1 measured the lateral drift of the second floor of the portal frames, whereas LVDT2 measured the lateral drift of the first floor and LVDT3 the horizontal displacement at the bottom of the left column of the portal frames and LVDT4 measured out of plane movements. 
age drying shrinkage on the seismic reponse of RC structures (more important drift). For two groups of portal frames, having different boundary conditions, the increase of lateral drift between the endogenous and the non-endogenous portal frame induced by early age drying shrinkage was for the first group of portal frames equal to $33 \%$ and for the second one equal to $44 \%$.

Experimental tests performed and monitoring techniques used (ambient vibration, digital image correlation, optical fiber) showed that early age drying shrinkage can cause an increase of the seismic vulnerability of RC structures. Thus, it can be important to take into account such effects when designing a RC structure.

To help engineers account for early age damage on the static and dynamic behavior of structures, a numerical enhanced multifiber model was developed as will be presented in Chapter 3. By comparing numerical results with experimental ones emphasized in Chapter 2 , the objective will be to validate the numerical model that could be used in the future by practioners to simulate the mechanical behavior of RC structures of different dimensions and boundary conditions while accounting for early age effects. 


\section{Numerical simulation of the early age damage evolution of two RC portal}

\section{frames and its effect on their static and dynamic behavior under a seismic load}

This Chapter presents the numerical model developed for the portal frames experimentally tested in Chapter 2. It is based on the resolution of a Thermo-Hygro-Chemical (THC) model combined with the use of an enhanced finite element multifiber approach and allows to numerically follow their early age damage evolution and to determine their static and dynamic behavior while accounting for their early age damage. Solving the THC problem allows determining the evolutions of shrinkage and internal temperature within the cross-sections of the portal frames during early age. Such values are then taken as inputs of the enhanced multifiber model that calculates the damage evolution of the portal frames before performing either a pushover, a spectral analysis or a transient analysis. Results driven from numerical simulations were compared to experimental ones presented in Chapter 2 to validate the numerical model. This Chapter is composed of 7 main sections. The first section presents briefly the methodology of resolution used in the numerical model. Section 2 deals with the THC model resolution process whereas Section 3 presents the resolution steps of the enhanced multifiber model. Section 4 is on the description of the multifiber model of the portal frames (mesh choice, boundary conditions, calibration coefficients of the constitutive laws, etc.) and Section 5 shows results obtained from the numerical model (early age damage evolution, static non-linear pushover analysis, modal and linear spectral analysis as well as dynamic analysis). Results obtained using the numerical model were compared to experimental ones for validation. Section 6 presents an attempt to extend the work conducted using the multifiber approach to a $2 \mathrm{D}$ model where a $3 \mathrm{D}$ damage law in plane stresses is used. Results obtained with the 2D model were compared to the ones obtained experimentally and using the multifiber approach. Last, conclusions of this Chapter are presented in Section 7. 


\subsection{Methodology of resolution}

The general methodology followed in order to solve the problem is summarized in Figure 3.1. The resolution process is composed of 3 main steps: a first step was conducted using COMSOL while the two following steps were performed on the ATL4S finite element code written in Matlab [51].

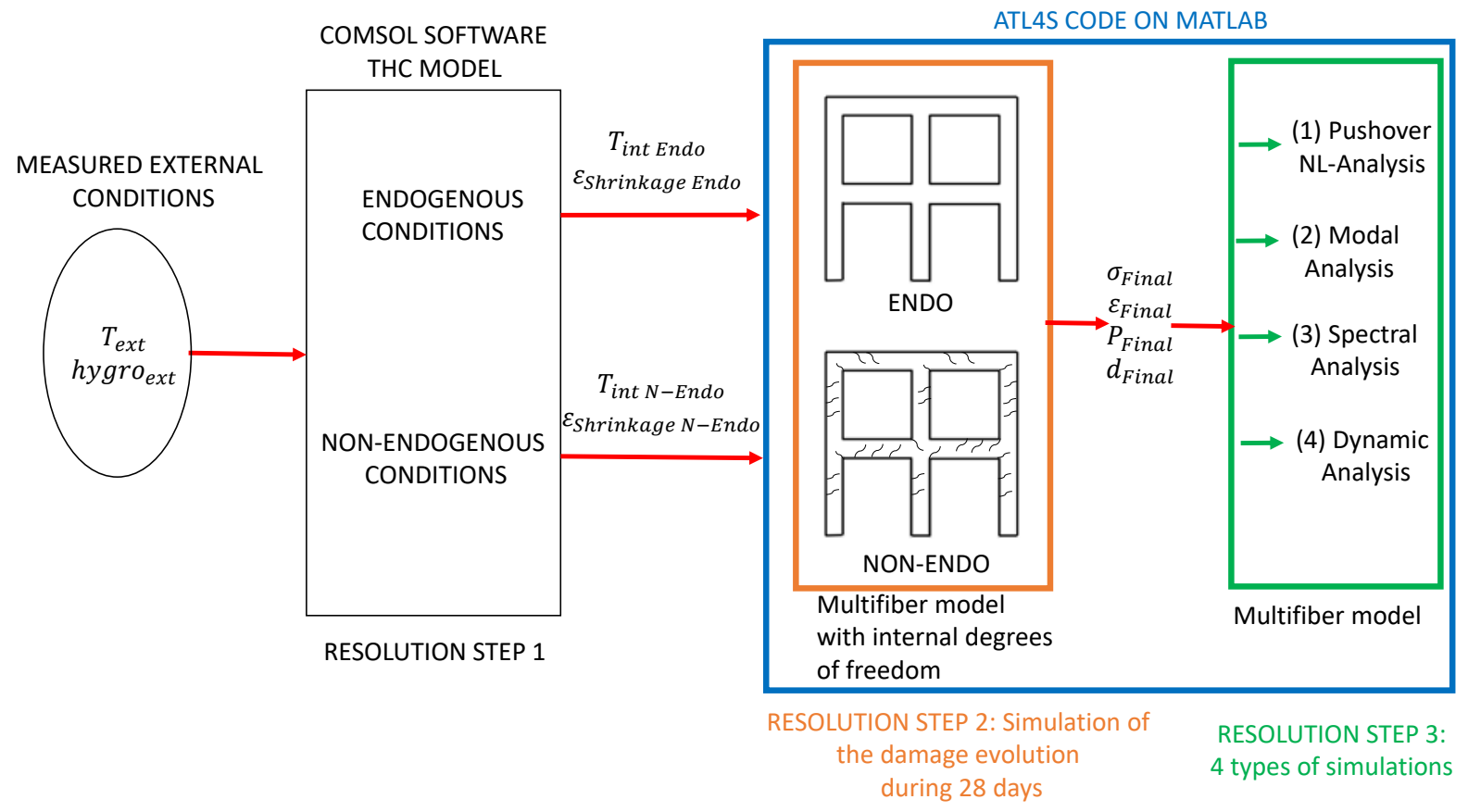

Figure 3.1: Resolution steps and softwares used. Step 1 : Resolution of the THC problem on COMSOL to get the internal temperature and strain shrinkage fields. Step 2: Simulation (ALT4S) of the EA damage by integrating COMSOL outputs (temperature and strain shrinkage fields). Step 3: Simulation of the mechanical response of the structures to an external excitation (pushover or earthquake). $T_{\text {ext }}$ and hygro ${ }_{\text {ext }}$ are the external temperature and humidity measured during the early age period using sensors. $T_{\text {int }}$ and $\epsilon_{\text {shrinkage }}$ are the temperature and shrinkage evolutions within the cross-sections of the portal frames calculated using COMSOL. $\sigma_{\text {Final }}, \epsilon_{\text {Final }}, P_{\text {Final }}$ and $d_{\text {Final }}$ are stress, strain, internal force and displacement values of the different fibers of the model at the end of resolution step 2

\subsubsection{Step 1 : Shrinkage and temperature time evolutions (THC 3D model)}

The first step consisted in using COMSOL in order to simulate the THC reponse of the portal frames. The THC model used is based on 21 equations and unkowns and al- 
lows calculating shrinkage and internal temperature evolutions of the two types of portal frames during their early age period. Before simulating the response of the portal frames on COMSOL, a sub-step consisted in choosing the calibration coefficients of the model. Some of the coefficients were taken from literature references, while others were determined using calibration tests. Once calibration was done, the second sub-step consisted in modeling the portal frames on COMSOL, in order to determine shrinkage and tempertaure evolutions within their cross sections during the early age period knowing as inputs external temperature and humidity evolutions that were measured experimentally using sensors as shown in Chapter 2 (Figure 2.10).

\subsubsection{Step 2 : Early age damage evolution (multifiber beam model coupling creep and damage constitutive laws)}

The outputs of the THC model (which are shrinkage and internal temperature evolutions) were then implemented as inputs of the multifiber numerical model.

Through interpolation, shrinkage and temperature evolutions were determined at the Gauss points of the multifiber model cross-sections.

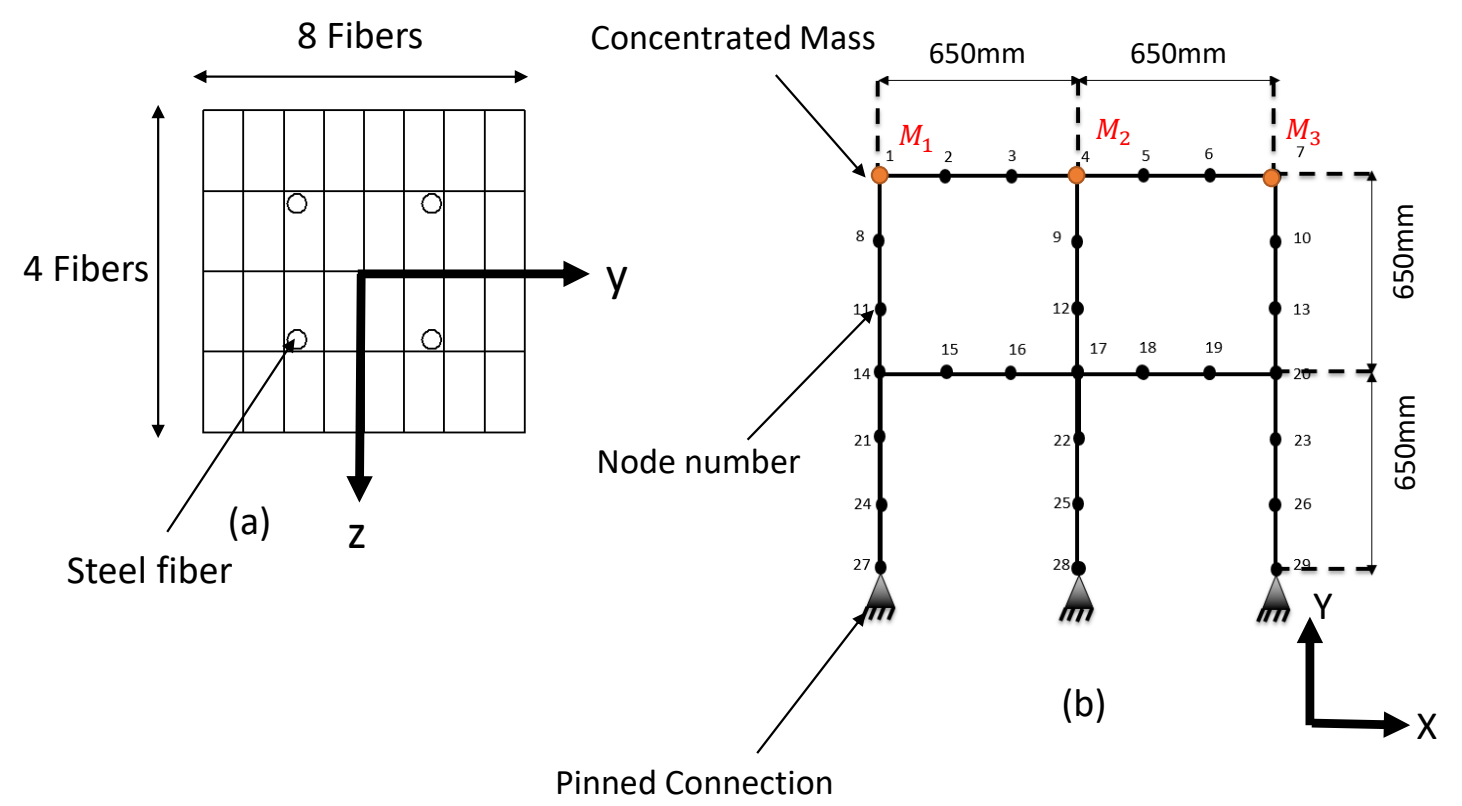

Figure 3.2: (a) Multifiber cross-section and (b) Finite element mesh and concentrated masses 


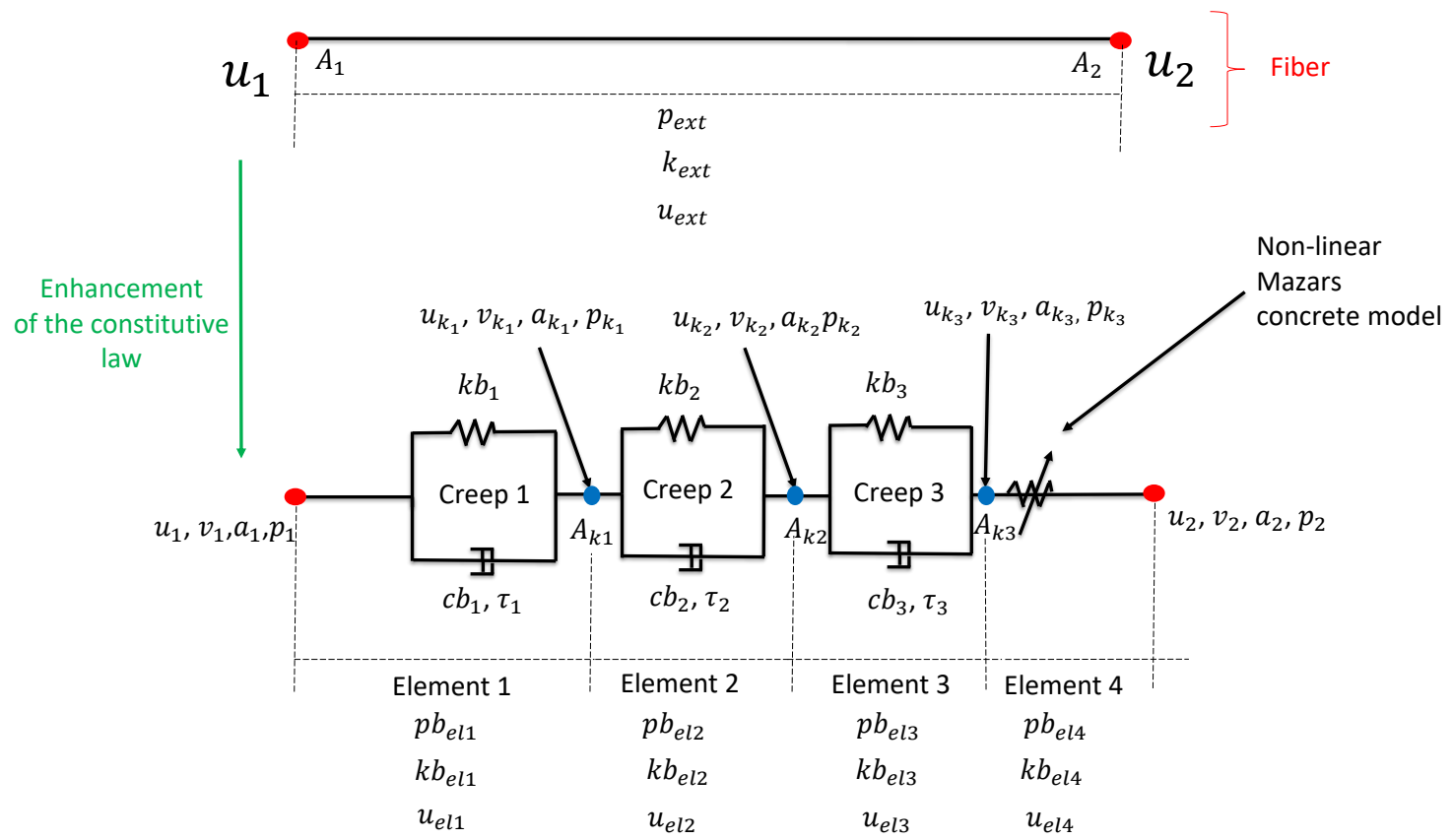

Figure 3.3: Enhanced multifiber beam element with internal degrees of freedom. $u_{k_{i}}$ are deformations, $v_{k_{i}}$ are derivatives of deformations and $a_{k_{i}}$ are second derivatives of deformations and $p_{k_{i}}$ are stresses.

In this second step of resolution, the portal frames were modeled using the multifiber approach, which means that the structures were divided into 3D Timoshenko multifiber beam elements (Figure $3.2 \mathrm{~b}$ ). Only in plane displacements were considered which means that the displacement $U_{z}$ following the $z$ direction and the rotations $\theta_{x}$ and $\theta_{y}$ were considered equal to zero at all the nodes of the portal frames. In order to simulate their early age behavior, the multifiber model was enhanced using a constitutive law with internal degrees of freedom to account for shrinkage, creep, thermal deformations and mechanical deformations (Figure 3.3). In total 3 internal nodes were added $A_{k 1}, A_{k 2}$ and $A_{k 3}$. In the multifiber approach each fiber returns a stress contribution (used in order to calculate the section restoring force vector) and a stiffness contribution (used in order to calculate the section stiffness matrix). From those values it is possible to determine the element stiffness matrix and nodal forces that are used to solve the global finite element problem. Practically speaking, if we compare the resolution methodology followed to the one presented in Chapter 1, the difference when considering a multifiber model with enhanced constitutive law is in the way stiffness and stress values of each fiber are calculated.

Using such enhanced model, damage evolution was followed for the two types of portal 
frames during their early age period.

\subsubsection{Step 3: Static and dynamic response}

At the end of the second step, strains, stresses, displacements, nodal forces and internal variables of the different fibers were kept in memory as initial values of the following resolution step (Figure 3.1). During this third step, different simulations were performed. First of all, a pushover analysis was launched for the endogenous portal frame. Capacity curve obtained as a result was compared to the envelope of the static cyclic test conducted experimentally (Chapter 2) in a way to calibrate material properties of the model. The same parameters were used when performing a pushover calculation on the non-endogenous portal frame at the end of its early age period. The purpose of such simulations is to show the difference in static response between the two structures.

A modal analysis of both groups was performed at the end of the second resolution step in order to evaluate their difference in frequency content. Based on the results of the modal analysis, a spectral analysis was conducted.

Last, a non-linear dynamic analysis simulation was launched for both portal frames. To achieve that, the same accelerometer as the one used in the PsD tests was taken as an input.

Furthermore, since image correlation revealed in Chapter 2 that the portal frames were not perfectly pinned, real boundary conditions determined using image correlation were accounted for in the numerical model. All simulations performed during resolution Step 3 were done using a multifiber beam approach (Figure 3.1).

\section{$3.2 \quad$ THC Model}

This section describes how the THC problem was solved on COMSOL. Tests performed in order to calibrate the THC model are also presented. Pr. Jean Francois Georgin calibrated the model developed on COMSOl in [5] to determine the evolutions of shrinkage and temperature of the portal frames under consideration that were used as inputs of the multifiber model.

\subsubsection{Resolution process on COMSOL}

Equations involved in the THC model were given in Chapter 1. In order to solve the problem using COMSOL, the different equations were combined and divided into 5 groups. 
For each group, dependent variables (which are the main unknowns) were defined in the software, as well as the source terms which are the differential equations to be solved, the boundary conditions (in terms of fluxes) and the initial conditions. The other variables of the problem were then deduced once the main variables were determined. On COMSOL, the portal frames were modeled using 3D tetraedral elements through a discretization of degree two (Lagrange quadratic discretization) and a BDF (backward differentiation formulas) integration scheme of second order was used.

\subsubsection{Hydration}

The first group of differential equation defined in the software is related to the hydration reaction. In such reaction, the main variable (unknown) is $\alpha$ which is the degree of hydration, whereas the source equation (differential equation to be solved) is given by:

$$
\dot{\alpha}=k \pi A e^{-\frac{-E_{a}}{T}}
$$

Where: $A$ is the coefficient of Chemical activity, $T$ the temperature, $E_{a}$ is the activation energy $\left(E_{a}=44665 \frac{\mathrm{J}}{\mathrm{mol}}\right)$ and $R$ is the universal gas constant $\left(R=8.3144621 \frac{\mathrm{J}}{\mathrm{Kmol}}\right) . \pi$ is the coefficient of accessibility to water (calculated knowing calibration constants: $B, n$ and $r_{k}$ as explained in Chapter 1) and $k$ is a calibration constant. Such constants were determined using calorimetric test results.

When defining the hydration reaction equation on COMSOL, no fluxes were imposed and in order to initiate calculations an initial value $\alpha_{0}$ of the degree of hydration was used $\alpha_{0}=0.01$.

\subsubsection{Porosity}

The second group of differential equation defined in the software governs the evolution of porosity.

In this equation, the main variable (unknown) is $\phi$ which is the porosity, whereas the source term is given in equation 3.2 .

$$
\dot{\phi}=\dot{\alpha}\left[1-\beta_{\text {chat }}\left(1+\gamma \frac{d_{c}}{d_{e}}\right)\right] \frac{m_{c}}{d_{c}}
$$

Where $\phi$ is the porosity of the paste, $\alpha$ the degree of hydration, $d_{c}$ the density of cement $\left(d_{c}=3140 \frac{\mathrm{kg}}{\mathrm{m}^{3}}\right)$ and $d_{e}$ the density of water, $\beta_{c h a t}$ the parameter accounting for the contraction of le Chatelier $\left(\beta_{\text {chat }}=0.9007\right), \gamma$ the stoichiometric ratio of the hydration reaction of cement $(\gamma=0.37)$ and $m_{c}$ the initial mass of anhydrous cement. Again, no 
fluxes were imposed when defining this second differential equation. The initial value of porosity $\left(\phi_{0}=0.4\right)$ needed to initiate calculations was automatically calculted by the software knowing the initial mix proportions (water, cement, sand, etc.)

\subsubsection{Mass transfer of liquid water and water vapor}

The third group of differential equations defined governs the mass transfer of liquid water and water vapor. Two main variables (unknowns) are involved: $S$ which is the degree of saturation and $h$ which is the humidity as well as two source equations. The first differential equation (equation 3.3) controls liquid water transfer whereas the second one (equation 3.8) governs vapor water transfer.

$$
\rho_{l} \phi \frac{\partial S}{\partial t}+\operatorname{div}\left(K_{l h} \nabla h_{e q}+K_{l g} \nabla p_{g}+K_{l T} \nabla T\right)=-\frac{\partial m_{l \rightarrow v}}{\partial t}-\frac{\partial m_{l \rightarrow \xi}}{\partial t}-\rho_{l} S \frac{\partial \phi}{\partial t}
$$

Where:

$$
\begin{aligned}
& K_{l h}=-\rho_{l}^{2} \frac{K_{e f f}}{\eta_{l}} \frac{R T}{h M_{e}} \\
& K_{l g}=-\rho_{l} \frac{K_{e f f}}{\eta_{l}} \\
& K_{l T}=-\rho_{l}^{2} \frac{K_{e f f}}{\eta_{l}} \frac{R}{M_{e}} \ln \left(h_{e q}\right) \\
& S(\alpha, T, h)=\left(1-\exp \left[-m \frac{2 \gamma M_{e}^{n \alpha}}{\rho_{l} R T \ln (h)}\right]\right)^{p} \\
& \phi(1-S) \frac{M_{e p} p_{v s}}{R T} \frac{\partial h}{\partial t}-\rho_{v} \phi \frac{\partial S}{\partial t}+\operatorname{div}\left(K_{v h} \nabla h+K_{v g} \nabla p_{g}+K_{v T} \nabla T\right)=\frac{\partial m_{l \rightarrow v}}{\partial t}-\rho_{v}(1-S) \frac{\partial \phi}{\partial t}-\rho_{v} \phi(1-S)\left(\frac{1}{p_{v s}} \frac{\partial p_{v s}}{\partial T}-\frac{1}{T}\right)
\end{aligned}
$$

Where:

$$
K_{v h}=-\rho_{v} \frac{D_{e f f}}{h}
$$




$$
\begin{gathered}
K_{v g}=-\rho_{v} \frac{K_{e f f}}{\eta_{g}} \\
\left.K_{v T}=-\rho_{v} D_{e f f}\left(\frac{1}{p_{v s}}\right) \frac{\partial p_{v s}}{\partial T}-\frac{1}{T}\right)
\end{gathered}
$$

In the previous equations, $\rho_{l}$ is the density of liquid water, $\phi$ is the porosity of the paste, $S$ is the degree of saturation of the cement based material, $K_{\text {eff }}$ is the is the effective permeability relative of the air in the porous medium, $\eta_{l}$ is the viscosity of liquid $\left(\eta_{l}=1 \times 10^{-3}\right.$ Pa.s at $\left.20^{\circ} \mathrm{C}\right), R$ is the universal gas constant $\left(R=8.3144621 \frac{\mathrm{J}}{\mathrm{Kmol}}\right), \mathrm{T}$ the internal temperature, $h$ the internal humidity, $M_{e}$ is the molar mass of water $\left(M_{e}=18\right.$ $\left.\frac{g}{m o l}\right), h_{e q}$ is the equivalent humidity, $p_{g}$ is the gas pressure, $m_{l \rightarrow v}$ is the mass of liquid water that evaporates during hydration, $m_{l \rightarrow \xi}$ is the mass of liquid water consumed during hydration, $\alpha$ is the degree of hydration, while $m, n$ and $p$ are calibration constants involved in the desorption isotherm. $p_{v s}$ is the saturation vapor pressure, $\rho_{v}$ is the density of vapor water, $D_{\text {eff }}$ is the coefficient of the effective diffusion of water vapor in wet air. It depends as explained in Chapter 1 on $D$ the coefficient of diffusion of water vapor in wet air $\left(D=2.17 \times 10^{-5} \frac{\mathrm{m}^{2}}{\mathrm{~s}} \mathrm{at} 20^{\circ} \mathrm{C}\right.$ and $\left.1 \mathrm{~atm}\right)$ and $\eta_{g}$ is the viscosity of gas $\left(\eta_{g}=1.8\right.$ $\times 10^{-5}$ Pa.s at $\left.20{ }^{\circ} \mathrm{C}\right)$.

In addition, two fluxes: flux $x_{1}$ and flux $_{2}$ were imposed:

$$
\begin{gathered}
f l u x_{1}=-\phi(1-S) E h_{v}\left(h p_{v s}-h_{e x t} p_{v s e x t}\right) \\
f l u x_{2}=-\phi(1-S) E h_{l}\left(p_{v s}-h_{e x t} p_{v s e x t}\right)
\end{gathered}
$$

Where $\phi$ is the porosity of the paste, $S$ is the degree of saturation of the cement based material, $h$ the internal humidity, $p_{v s}$ is the saturation vapor pressure, $h_{e x t}$ is the external humidity, $p_{v s e x t}$ is the external vapor pressure, $E h_{l}$ is the emissivity for liquid $\left(E h_{l}=2.65\right.$ $e-9 \frac{\mathrm{kg}}{\mathrm{m}^{2} . \mathrm{s} . \mathrm{Pa}}$ determined through calibration using the loss of mass curve of the 4X4X16 samples and $E h v$ is the emissivity for vapor $\left(E h_{v}=3.975 e-8 \frac{\mathrm{kg}}{\mathrm{m}^{2} . \mathrm{s} . P a}\right)$ determined also through calibration using the loss of mass curve of the 4X4X16 samples.

To solve the differential equations, the initial saturation was determined using the 
initial mortar proportions whereas the initial humidity was calculated starting from the initial saturation value using the inverse of the desorption isotherm.

\subsubsection{Dry air equilibrium}

Dry air equilibrium depends on 5 variables: the density of air $\rho_{a}$, the porosity $\phi$, the internal Temperature $T$, the humidity $h$ and the saturated vapor pressure $p_{v s}$. Such equilibrium is governed by one differential equation:

$$
-\phi(1-S) \frac{M_{a} p_{v s}}{R T} \frac{\partial h}{\partial t}+\phi(1-S) \frac{M_{a}}{R T} \frac{\partial p_{g}}{\partial t}-\rho_{a} \frac{\partial S}{\partial t}+\operatorname{div}\left(K_{a h} \nabla h+K_{a g} \nabla p_{g}+K_{a T} \nabla T\right)=-\rho_{a}(1-S) \frac{\partial \phi}{\partial t}+\phi(1-S) \frac{M_{a}}{R T} h \frac{\partial p_{v s}}{\partial T}+\left(p_{g}-h p_{v s}\right) \frac{M_{a}}{R T^{2}} \frac{\partial T}{\partial t}(3.1
$$

Where:

$$
\begin{gathered}
K_{a h}=-\rho_{a} \frac{D_{e f f}}{\left(p_{g}-h p_{p v}\right)} p_{v s} \\
K_{a g}=-\rho_{a}\left[\frac{K_{e f f}}{\eta_{g}}+\frac{D_{e f f}}{\left(p_{g}-h p_{v s}\right)}\right] \\
K_{a T}=-\rho_{a} D_{e f f}\left[\frac{h}{\left(p_{g}-h p_{v s}\right)} \frac{\partial p_{v s}}{\partial T}+\frac{1}{T}\right]
\end{gathered}
$$

Where $M_{a}$ is the molar mass for wet air $\left(M_{a}=28.96 \frac{\mathrm{g}}{\mathrm{mol}}\right)$.

To solve the govering differential equation a Dirichlet boundary condition type was used. In fact, the pressure at the outer part of the modeled structure was considered to be equal to the atmospheric pressure (known value).

\subsubsection{Heat transfer}

Heat transfer is dependent on a single variable: the internal temperature $T$. Heat transfer is based on the following equation:

$$
\rho C_{p} \frac{\partial T}{\partial t}+\operatorname{div}\left(-\lambda_{T} \operatorname{grad}(T)\right)=\frac{\partial Q_{1}}{\partial t}+\frac{\partial Q_{2}}{\partial t}
$$

Where $\rho$ is the density of the porous material, $C_{p}$ is the specific heat capacity $\left(C_{p}=900\right.$ $\left.\frac{J}{k g K}\right), T$ is the internal temperature, $\lambda_{T}$ is the coefficient of thermal conductivity $\left(\lambda_{T}=1.8\right.$ $\left.\frac{W}{m K}\right), \frac{\partial Q_{1}}{\partial t}$ the rate of the heat of hydration and $\frac{\partial Q_{2}}{\partial t}$ the rate of the heat of vaporization. 
In order to solve such equation, there is a need to define appropriate boundary conditions. Since the modeled structures evolved in non adiabatic conditions, a Newmann Boundary condition given by equation 3.19 was used:

$$
\text { flux }_{\text {heat }}=H_{T}\left(T_{\text {ext }}-T\right)
$$

Where $H_{T}$ is the heat transfer coefficient, $T_{\text {ext }}$ the external temperature and $T$ the internal temperature. The heat transfer coefficient was determined using the expression $H_{T}=\frac{1}{\overline{H_{\text {rad }}+H_{\text {air }}}}$ provided in $[6]$.

The Newmann boundary condition implies that a heat flux is possible between the structures and the external environment. If the structures were kept in adiabatic conditions, then flux flux heat would have been taken equal to zero.

To initiate calculations, the initial internal temperature was defined (considered to be equal to the external temperature).

\subsubsection{Calibration of the THC model}

Calibration coefficients $k, n, B$ and $r_{k}$ involved in the hydration reaction were determined through calibration using quasi-adiabatic calorimetric tests on $4 \mathrm{~cm}$ by $4 \mathrm{~cm}$ by $16 \mathrm{~cm}$ specimens. Their value is given in Table 3.1 .

In Figure 3.4 temperature evolution of the specimens obtained experimentally using the quasi adiabatic calorimetric test and numerically using the THC model is given. It should be pointed out that in adiabatic conditions, in the heat tranfer part of the THC model, no heat flow occurs and thus a Dirichlet flux type of condition is used. Temperature evolution obtained using the THC model seems to match the one found experimentally.

The initial permeability $K_{0}$, the emissivity of liquid $E h_{l}$ and the emissivity for vapor $E h_{v}$ were determined through calibration using mass loss measurements on $4 \mathrm{~cm}$ by $4 \mathrm{~cm}$ by $16 \mathrm{~cm}$ prismatic specimens that have the same composition as the mortar used in the portal frames (coefficients are given in Table 3.1).

Two groups of prismatic samples were used in order to determine such coefficients. Their manufacturing process is shown in Figure 3.5 a. After casting, both groups were kept during 24 hours in endogenous conditions (coverage using a plastic sheet) in a way to limit plastic shrinkage from occuring as shown in Figure 3.5b. Then, one group was kept in endogenous conditions during the remaining days of the early age period (kept covered as shown in Figure 3.5;) whereas the second group was uncovered thus allowing water 


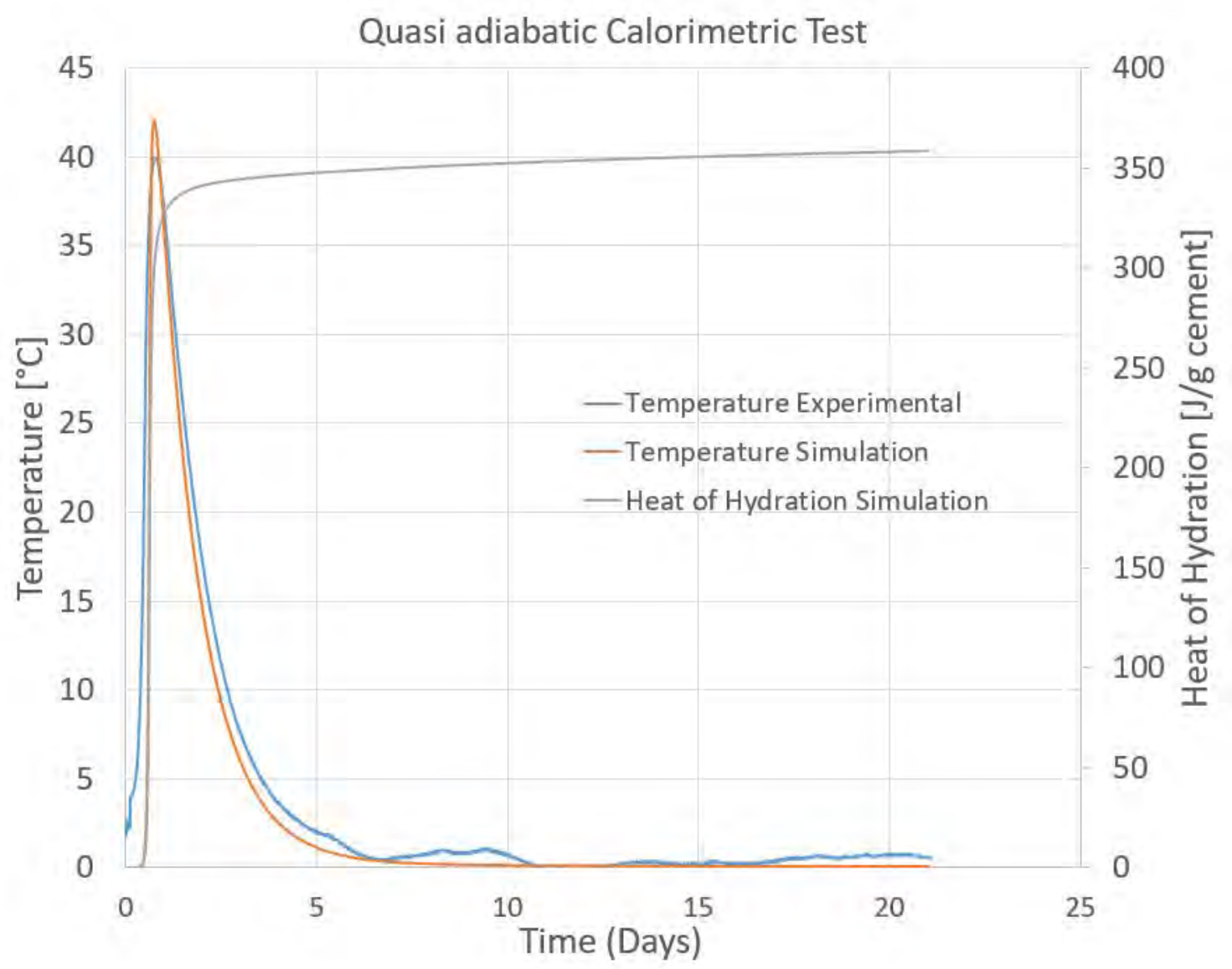

Figure 3.4: Calibration of the THC Model by fitting temperature evolution curve

exchange with the surrounding environment. Both groups were kept in the same room at a temperature of $20{ }^{\circ} \mathrm{C}$ and at a relative humidity of $50 \%$.

The evolution of mass loss and free shrinkage of the specimens kept in endogenous and non-endogenous conditions were measured during the early age period (Figures $3.6 \mathrm{a}$ and 3.6 b). Coefficients $K_{0}, E h_{l}$ and $E h_{v}$ of the THC model were chosen in a way that mass loss curve obtained numerically (using the THC model) match results found experimentally. Experimental free shrinkage curves were compared to numerical shrinkage evolution curves as an additional validation.

On a side note, it can be seen that mass loss of the endogenous specimen is almost equal to zero (result obtained both numerically and experimentally) during the early age period. Such result is logical since no water is supposed to go from the specimens to the surrounding environment in endogenous conditions due to the plastic sheet used to conver them. In practice, a negligeable portion of water is still lost during the hydration process of the specimens due to the fact that the covering sheets used are not waterproof at 100 


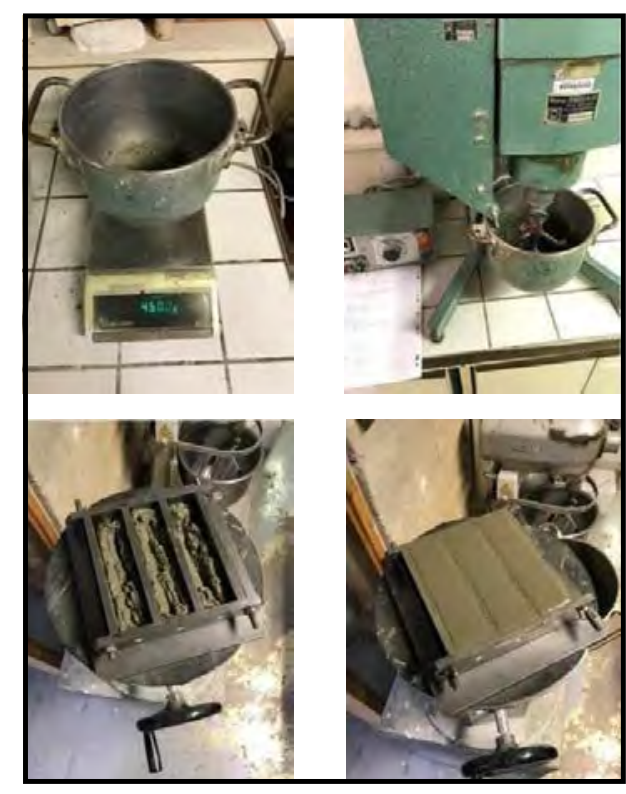

(a)

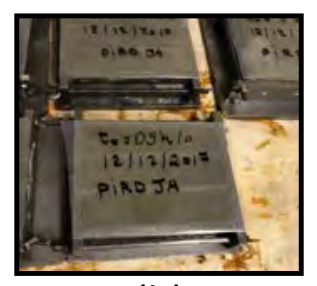

(b)

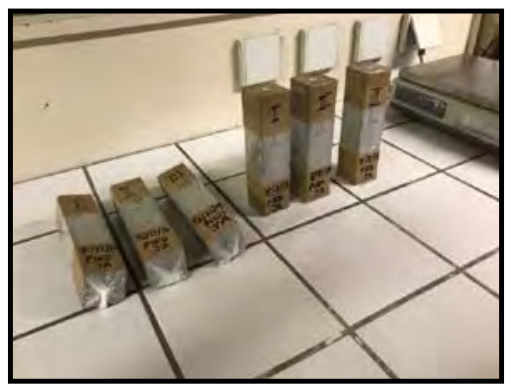

(c)

Figure 3.5: Prismatic beam elements used for the calibration of the THC model (a) Manufacturing process (b) 24 hours coverage using a plastic sheet after casting (c) Endogenous goup conservation conditions

\%. Coefficients $\mathrm{n}, \mathrm{m}$ and $\mathrm{p}$ of the desorption isotherm were taken from literature [77]. The $\mathrm{W} / \mathrm{C}$ (Water to cement ratio) of the reference is indeed equal to 0.5 which corresponds to our mortar. Thus, coefficients $m=4.87 e^{7}, n=2.45$ and $p=0.78$ were chosen (Table 3.1 .

The remaining coefficients used in the THC model were estimated. Values of calibration parameters used in the THC model are given in Table 3.1.

$\hat{\mathrm{A}}$

\subsubsection{Inputs and outputs of the THC model}

The calibrated THC model was used to determine the evolutions of shrinkage and temperature within the cross-sections of the portal frames during early age.

The inputs of the THC model are the external temperature $\left(20^{\circ} \mathrm{C}\right)$ evolution and humidity $(50 \%)$ that were measured experimentally as shown in Chapter 2.

Temperature and shrinkage values were determined at the the different fibers of the multifiber model of the portal frames through interpolation (Figure 3.7). 


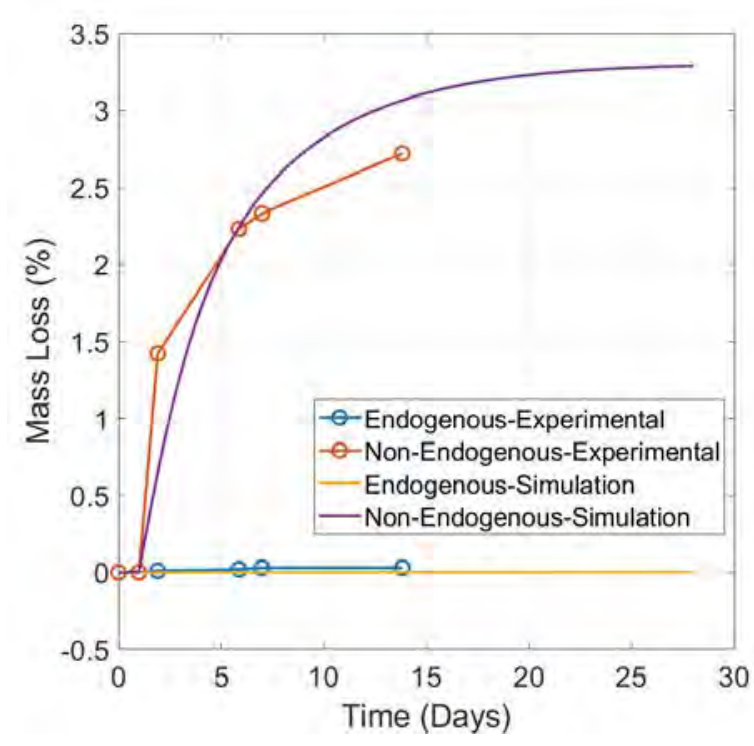

(a)

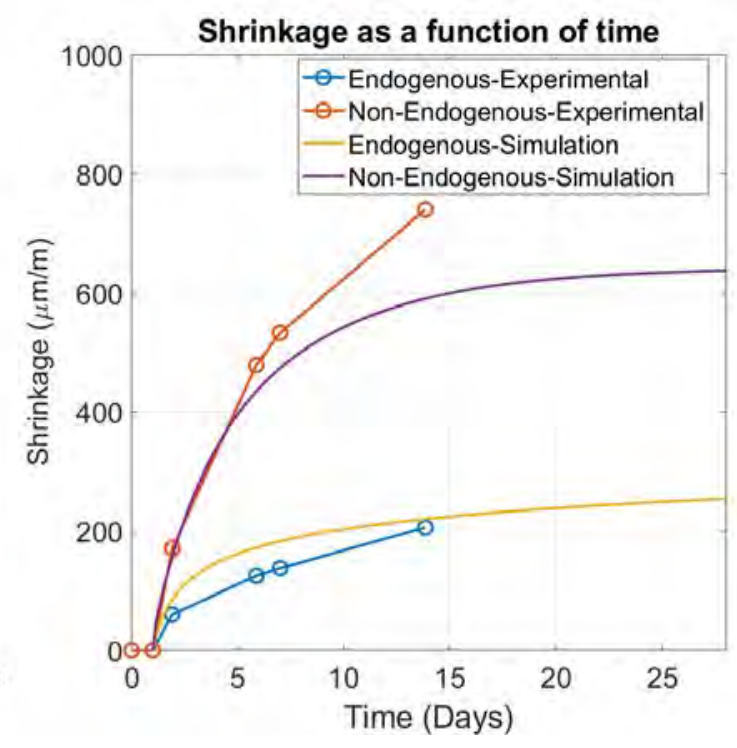

(b)

Figure 3.6: Calibration of the THC Model (a) Percentage of Mass Loss as a function of time (b) Shrinkage as a function of time

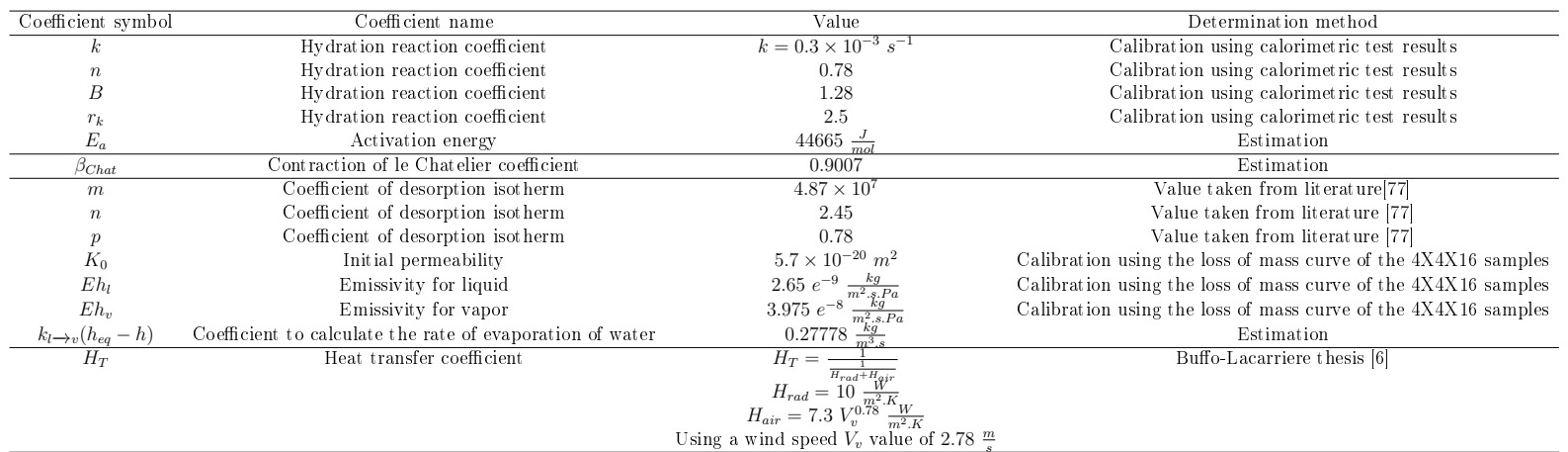

Table 3.1: THC model coefficients and determination method

Next section will explain how the multifiber beam model presented in Chapter 1 was enhanced in a way to take into account shrinkage and temperature evolutions calculated in COMSOL as well as in order to take into account creep and mechanical deformations. Resolution steps of such enhanced multifiber beam model will be given. 


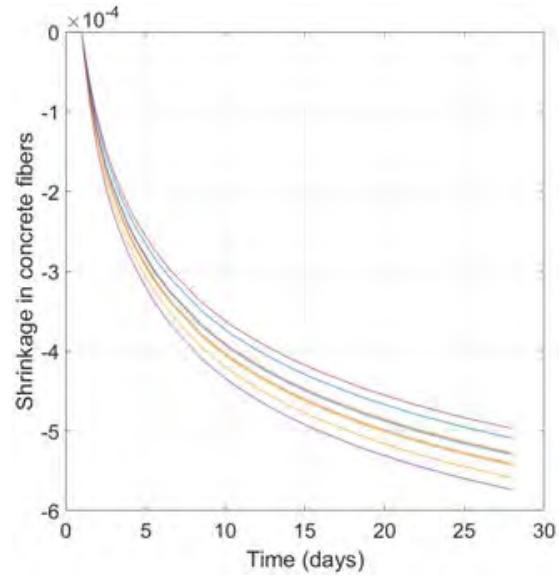

(a) Endogenous case Shrinkage

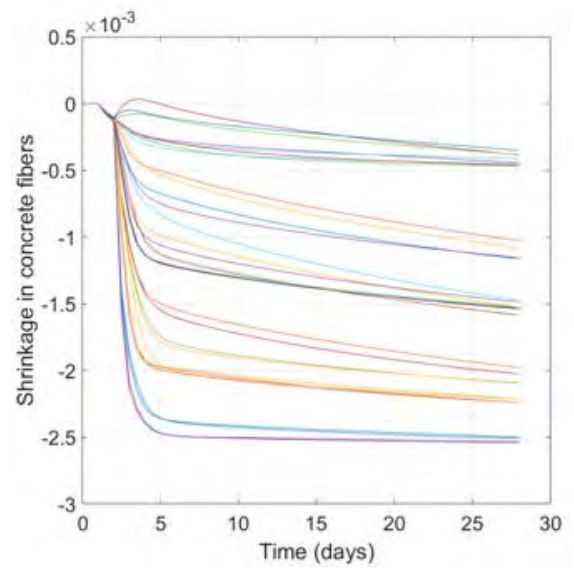

(c) Non-Endogenous case Shrinkage

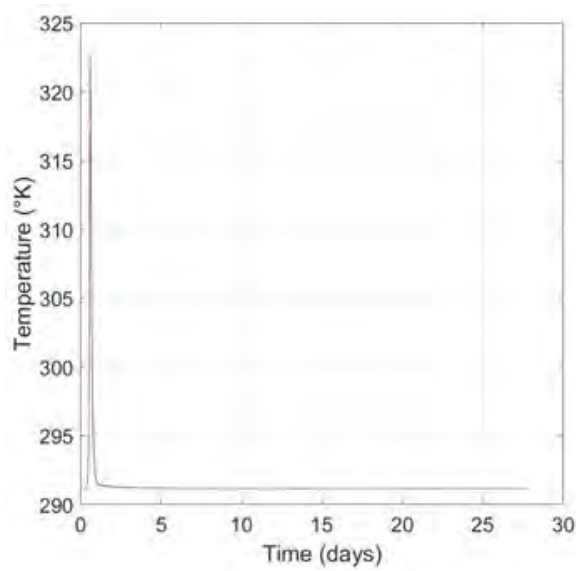

(b) Endogenous case Temperature

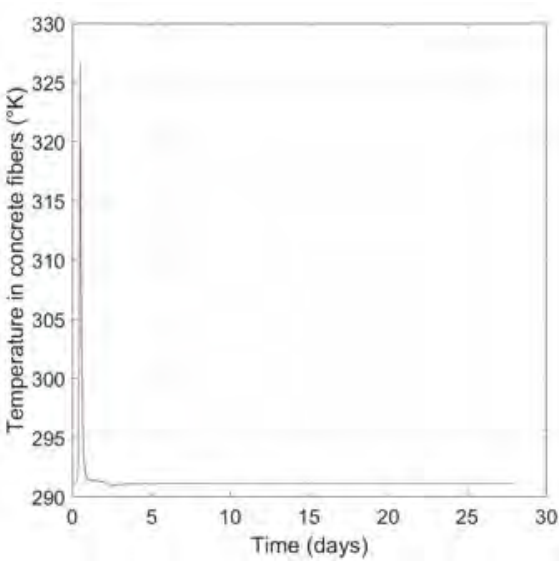

(d) Non-Endogenous case Temperature

Figure 3.7: Shrinkage and temperature evolutions (at the concrete fibers of all the elements of the portal frames) calculated through an interpolation of the data provided by the THC model on COMSOL. The evolutions of temperature of the different fibers are almost similar. The portal frames have a small cross-section, thus the gradient of temperature is negligible.

\subsection{Multifiber beam model with an enhanced constitu- tive law}

\subsubsection{Multifiber approach}

The portal frames were modeled using the multifiber beam approach ([78] [79]). They were divided into 3D Timoshenko beam elements, where each beam element is composed of two nodes (Figure 3.8). At each node there are 6 degrees of freedom: 3 rotations and 3 displacements. Each beam element is composed of 2 Gauss integration points and 
each integration point represents a cross section made of concrete and steel fibers (for the reinforcements). Concrete fibers are located at the section Gauss points. Using shape functions, displacement value can be calculated at any point of the beam element knowing displacement values at the nodes. Timoshenko kinematic then allows determining strain values at the different fibers knowing displacement values. Then, using a non-linear strain to stress relation stress is determined at the different fibers. Through integration over the cross section, force values at the Gauss points are determined. Figure 3.8 summarizes the principle of the multifiber beam approach used for the portal frames ([79] and [78]).

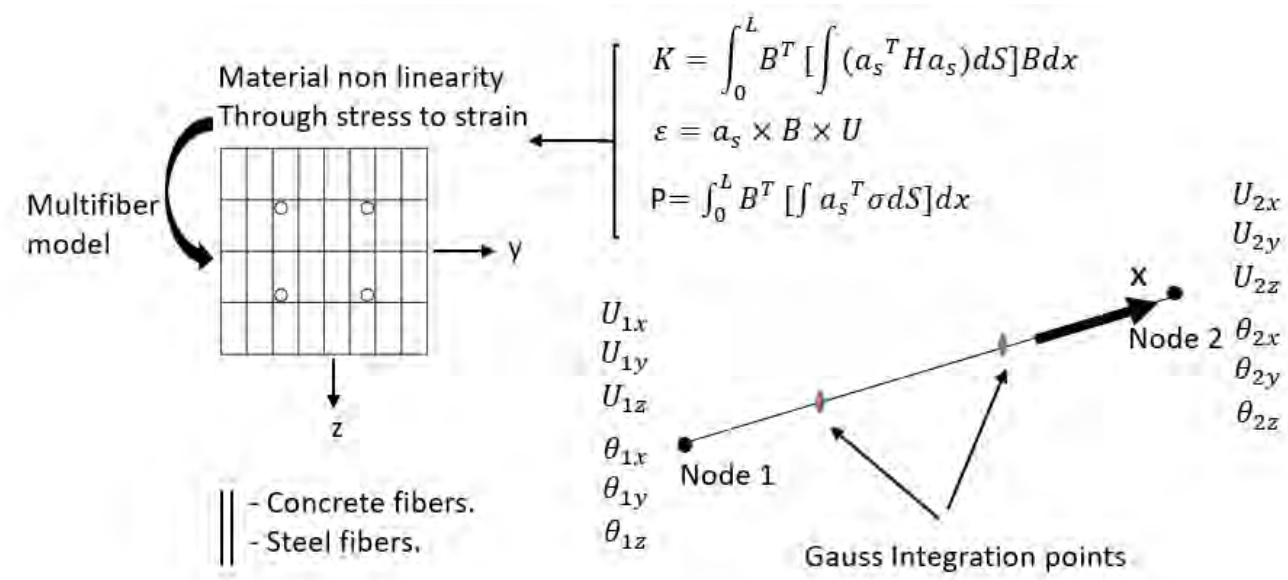

Figure 3.8: Principle of the multifiber beam model ([78 [79]) $K=$ Stiffness Matrix; $a_{s}=$ Section compatibility Matrix; $B=$ Gradient Metric; $L=$ Length of the beam element; $U=$ Nodal displacement; $\sigma=$ Stress Matrix; $P=$ Load Vector, $\epsilon=$ Strain Matrix, $H$ is the damaged Young moduls

In order to account for early age effects, the constitutive laws of concrete and steel fibers were enhanced.

\subsubsection{Concrete fibers enhanced constitutive law}

Deformation at each concrete fiber was calculated in a way to take into account the influence of shrinkage, creep, thermal deformation, and mechanical deformation [80]. The total deformation at a fiber element was considered to be equal to the sum of all 4 contributions (Figure 3.9). Hence:

$$
\epsilon_{\text {tot }}=\epsilon_{\text {shrinkage }}+\epsilon_{\text {thermal }}+\epsilon_{\text {creep }}+\epsilon_{\text {mechanical }}
$$




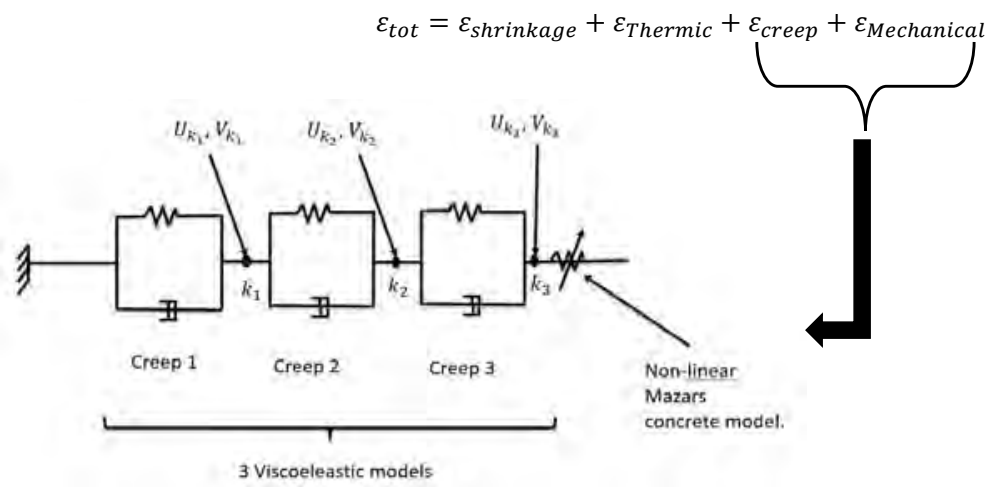

Figure 3.9: Strain calculation within a concrete fiber element [14] [10]

Shrinkage and temperature evolutions were calculated independently using the THC model with COMSOL. In order to account for these values in the multifiber model, at each time step $i$, an internal equilibrium was solved at the concrete fiber level. The constitutive law of each concrete fiber is governed by three viscoelastic elements for creep in series with a Mazars law (Figure 3.3). Each rheological model returns a restoring stress and a stiffness. In order to solve the internal equilibrium, a Newton Raphson algorithm was used. Then, once the internal equilibrium of the fibers was reached, static condensation returned to the global algorithm of resolution stiffness and stress values of each fiber. Such values were then used in order to solve the global Newton Raphson equilibrium.

\subsubsection{Internal elements constitutive laws}

The restoring stress $p b_{e l n}$ and stiffness $k b_{e l n}$ of each internal element (Figure 3.3) is a function of its deformation, derivative of deformation and second derivative of deformation and depends on the law that follows the element.

3.3.2.1.1 Viscoelastic constitutive law Elements 1, 2 and 3 are 1D viscoelastic elements (Figure 3.3). Knowing as inputs their normal deformation $u_{e l n}$ and derivative of normal deformation $v b_{e l n}$, their restoring stress $p b_{e l n}$ and stiffness $k b_{e l n}$ are determined as follow:

$$
p b_{e l n}=k b_{n} \times u_{e l n}+c b_{n} \times v b_{e l n}
$$




$$
k b_{e l n}=k b_{n}+c b_{n} \times \frac{\gamma}{\beta \times \Delta t}
$$

$n$ going from 1 to 3 since there are 3 viscoleastic elements: to model creep 1, creep 2 and creep 3. $\gamma$ and $\beta$ parameters are Newmark parameters used in the temportal integration scheme of the concrete fiber $\left(\gamma=\frac{1}{2}\right.$ and $\left.\beta=\frac{1}{4}\right) . k b_{n}$ is a function of the hydration coefficient $\xi$ :

$$
k b_{n}=k_{b n \infty} \frac{0.473}{2.081-1.608 \xi} \xi^{0.62}
$$

In the previous equation, the final stiffness $k_{b n \infty}$ is a constant determined through calibration, while $\xi$ is the hydration coefficient. Its ultimate value at the end of hydration is equal to 0.84 . In order to determine the hydration coefficient evolution during early age, an Arrehnius differential equation [14] was solved on Matlab:

$$
\dot{\xi}=A(\xi) e^{\frac{-E_{a}}{R T}}
$$

Where $E_{a}$ is the activation energy, $R$ is the ideal gas constant and $A(\xi)$ the chemical affinity. The damping values $c b_{n}$ of the viscoelastic elements were determined as follow:

$$
c b_{n}=k_{0 n} \times \tau_{n}
$$

$n$ going from 1 to 3 while $k_{0 n}$ and $\tau_{n}$ of each viscoelastic element are constants determined through calibration.

3.3.2.1.2 Mazars Concrete law Element 4 follows a 1.5 D non-linear Mazars concrete law. In the $1.5 \mathrm{D}$ version of the $\mu$ Mazars law, permanent strains are taken into account [11]. Such model also includes a hysteretic loop [81].

The inputs of the law are the strains $\epsilon_{x x}, \epsilon_{x y}$ and $\epsilon_{x z}$ and the outputs are the stresses $\sigma_{x x}$, $\sigma_{x y}$ and $\sigma_{x z}$ as well as the tangent stiffness (damaged Young Modulus). Knowing values of $\epsilon_{t 0}$ and $\epsilon_{f c}$ (constants that depend on the concrete used), it is possible to determine the value of the initial damage thresholds for traction and compression respectively $Y_{t 0}$ and $Y_{c 0}$ :

$$
Y_{t 0}=-\epsilon_{t 0}+\frac{f_{t}}{E}
$$




$$
Y_{c 0}=-\epsilon_{t 0}+\frac{f_{c}}{E}
$$

Where $f_{t}$ is the law parameter accounting for tensile strength and $f_{c}$ the law parameter accounting for compression strength. Their ultimate value at 28 days is known as it depends on the mechanical properties of the concrete used.

Using equation 3.28 , it is possible to determine the value of $\epsilon_{t}$ which is the strain threshold. Initially $D_{c}$ and $D_{t}$ that are the damage parameters for concrete cracking and crushing are equal to zero. Then, depending on the state of the material their value evolves. Which allows determinig the value of the strain threshold $\epsilon_{t}$ as follow:

$$
\epsilon_{t}=\frac{\epsilon_{t 0}}{1-D_{c}}-\frac{\epsilon_{f c} \cdot D_{c}}{1-D_{c}}
$$

Then, the parameter $\epsilon_{d}$ that accounts for the damage state of the concrete material can be calculated using equation 3.29 . Its value depends on the strain state $\epsilon$ and on the strain threshold $\epsilon_{t}$.

$$
\epsilon_{d}=\epsilon-\epsilon_{t}
$$

In $1.5 \mathrm{D}$, a concrete fiber will be either under traction or under compression. Its behavior can not be mixed. If the fiber is under traction, the loading surface $f_{t}$ in traction can be determined as well as the damaged stress $\sigma_{d}$ as follow [82]:

$$
\begin{gathered}
f_{t}=\epsilon_{d}-Y_{t} \\
\sigma_{d}=\left(1-D_{t}\right) \cdot E \cdot \epsilon_{d}
\end{gathered}
$$

and $Y_{t}$ and $D_{t}$ for next steps are updated as follow:

$$
\begin{gathered}
Y_{t}=\epsilon_{d} \\
D_{t}=1-\frac{Y_{t 0} \cdot\left(1-A_{t}\right)}{Y_{t}}-A_{t} \cdot e^{\left(-B_{t} \cdot\left(Y_{t}-Y_{t 0}\right)\right)}
\end{gathered}
$$

If the fiber in under compression, $f_{c}$ which is the loading surface in compression can be calculated as follow:

$$
f_{c}=\epsilon_{d}-Y_{c}
$$


and $\sigma_{d}$ is updated using $D_{c}$ :

$$
\sigma_{d}=\left(1-D_{c}\right) \cdot E \cdot \epsilon_{d}
$$

Then, $Y_{c}$ and $D_{c}$ are updated as follow:

$$
\begin{gathered}
Y_{c}=\epsilon_{d} \\
D_{c}=1-\frac{Y_{c 0} \cdot\left(1-A_{c}\right)}{Y_{c}}-A_{c} \cdot e^{\left(-B_{c} \cdot\left(Y_{c 0}-Y_{c}\right)\right)}
\end{gathered}
$$

Using previous equations, it is possible to deduce the value of the normal stress $\sigma_{x x}$. Indeed, such value is equal to the sum of $\sigma_{d}$ and the hysteretic stress (known as the dampping stress [82]). The damping stress is in our case is equal to zero since $\beta_{1}$ and $\beta_{2}$ which are the damping parameters are taken equal to zero. As for stresses $\sigma_{x y}$ and $\sigma_{x z}$ they are determined using shear modulus $G$ value. Its value depends on the Young modulus $E$ and the poisson ratio $\nu=0.2$ as follow:

$$
\begin{gathered}
G=\frac{E}{2(1+\nu)} \\
\sigma_{x y}=G \cdot \epsilon_{x y} \\
\sigma_{x z}=G \cdot \epsilon_{x z}
\end{gathered}
$$

Strains $\epsilon_{x y}$ and $\epsilon_{x z}$ do not need to be corrected by thermal and shrinkage deformations that only act following the $x x$ (normal) direction.

On a side note, it should be pointed out that during the early age period simulated, the tensile and compressive strength $\left(R_{t}\right.$ and $\left.R_{c}\right)$ as well as the Young modulus $E$ of the portal frames increase to become equal at the end of the hydration process to their value at 28 days. In the $\mu$ damage model used to simulate concrete behavior, $f_{t}$ is the parameter accounting for concrete tensile strength, whereas $f_{c}$ is the parameter accounting for concrete compressive strength. Such material parameters were updated at each time step as follow [14]:

$$
f_{t}=f_{t_{\text {final }}}\left(\frac{\xi}{\xi_{\text {asympt }}}\right)^{0.45}
$$




$$
\begin{aligned}
& f_{c}=f_{c_{\text {final }}}\left(\frac{\xi}{\xi_{\text {asympt }}}\right)^{0.45} \\
& E=E_{\text {final }}\left(\frac{\xi}{\xi_{\text {asympt }}}\right)^{0.45}
\end{aligned}
$$

Where $\xi_{\text {asympt }}=0.84$ is the degree of hydration at the maturation of concrete. $f_{t_{\text {final }}}$ and $f_{c_{\text {final }}}$ are the values of the parameters of the $\mu$ damage law accounting for concrete tensile and compressive strengh at the end of 28 days, whereas $E_{\text {final }}$ is the Young modulus of concrete at the end of the early age period.

\subsubsection{Internal equilibrium}

Solving the internal equilibrium of a concrete fiber allows getting deformation, derivative of deformation and second derivative of deformation values at the internal nodes $A_{k 1}, A_{k 2}$ and $A_{k 3}$ knowing deformation values at the external nodes $A_{1}$ and $A_{2}$ that are provided by the global algorithm of resolution (Figure 3.3.

The unknown deformations were determined using a Newton Raphson loop. The main steps of resolution are the following:

(1) First, from the global algorithm of resolution, nodal strain vector $u_{e x t}$, nodal strain velocity vector $v_{\text {ext }}$ and nodal strain acceleration vector $a_{e x t}$ of the fiber (Figure 3.3) are extracted.

$$
\begin{aligned}
& u_{e x t}=\left[u_{1} ; u_{2}\right] \\
& v_{e x t}=\left[\dot{u}_{1} ; \dot{u}_{2}\right] \\
& a_{\text {ext }}=\left[\ddot{u}_{1} ; \ddot{u}_{2}\right]
\end{aligned}
$$

(2) In order to take into account shrinkage and thermal deformation values within a fiber, the external nodal normal deformation $u_{2}$ given by the global problem as equal to $\epsilon_{x x}$ (normal strain) is corrected as follow:

$$
u_{2}=\epsilon_{x x}-\alpha_{T}\left(T-T_{0}\right)-\epsilon_{\text {shrinkage }}
$$

The previous equation shows that thermal deformation $\alpha_{T}\left(T-T_{0}\right)$ is calculated within 
concrete fibers using the thermal expansion coefficient of concrete $\alpha_{T}$ and knowing the evolution of temperature of the fiber $T$ determined using COMSOL. $T_{0}$ being the initial temperature (constant), whereas $\epsilon_{\text {shrinkage }}$ is the shrinkage value calculated using COMSOL.

(3) Then, there is a need to extract the internal kinematic of the internal elements $u_{k}$, $v_{k}$ and $a_{k}$. To start the Newton loop, the internal nodal unknown deformations $u_{k 1}, u_{k 2}$ and $u_{k 3}$, derivative of deformations $v_{k 1}, v_{k 2}$ and $v_{k 3}$ and second derivative of deformations $a_{k 1}, a_{k 2}$ and $a_{k 3}$ are first assumed to be equal to the ones determined at the previous time step of resolution. $k$ is set equal to 1 for this first Newton iteration.

$$
\left\{\begin{array}{l}
u_{k}=\left[u_{k 1} ; u_{k 2} ; u_{k 3}\right] \\
v_{k}=\left[v_{k 1} ; v_{k 2} ; v_{k 3}\right] \\
a_{k}=\left[a_{k 1} ; a_{k 2} ; a_{k 3}\right]
\end{array}\right.
$$

(4) From those internal deformation values, derivative of deformations and second derivative of deformations are calculated using Newmark equations:

$$
\begin{gathered}
v_{k}=v_{i}+(1-\gamma) \Delta t a_{i}+\frac{\gamma}{\beta \Delta t}\left[u_{k}-u_{i}-\Delta t v_{i}-\left(\frac{1}{2}-\beta\right)(\Delta t)^{2} a_{i}\right] \\
a_{k}=\frac{1}{\beta(\Delta t)^{2}}\left[u_{k}-u_{i}-\Delta t v_{i}-\left(\frac{1}{2}-\beta\right) \Delta t^{2} a_{i}\right]
\end{gathered}
$$

(5) Once the internal deformations are determined, for each element we affect a deformation, a derivative of deformation and second derivative of deformation vector (using $\left.(a b)^{t}=[-1 ; 1]\right)$ as follow:

For element 1:

$$
\left\{\begin{array}{l}
u_{e l 1}=(a b)^{t}\left[u_{e x t}(1) ; u_{k}(1)\right] \\
v_{e l 1}=(a b)^{t}\left[v_{e x t}(1) ; v_{k}(1)\right] \\
a_{e l 1}=(a b)^{t}\left[a_{e x t}(1) ; a_{k}(1)\right]
\end{array}\right.
$$

For element 2: 


$$
\left\{\begin{array}{l}
u_{e l 2}=(a b)^{t}\left[u_{k}(1) ; u_{k}(2)\right] \\
v_{e l 2}=(a b)^{t}\left[v_{k}(1) ; v_{k}(2)\right] \\
a_{e l 2}=(a b)^{t}\left[a_{k}(1) ; a_{k}(2)\right]
\end{array}\right.
$$

For element 3:

$$
\left\{\begin{array}{l}
u_{e l 3}=(a b)^{t}\left[u_{k}(2) ; u_{k}(3)\right] \\
v_{e l 3}=(a b)^{t}\left[v_{k}(2) ; v_{k}(3)\right] \\
a_{e l 3}=(a b)^{t}\left[a_{k}(2) ; a_{k}(3)\right]
\end{array}\right.
$$

For element 4:

$$
\left\{\begin{aligned}
u_{e l 4} & =(a b)^{t}\left[u_{k}(3) ; u_{e x t}(2)\right] \\
v_{e l 4} & =(a b)^{t}\left[v_{k}(3) ; v_{e x t}(2)\right] \\
a_{e l 4} & =(a b)^{t}\left[a_{k}(3) ; a_{e x t}(2)\right]
\end{aligned}\right.
$$

(6) Next, there is a need to calculate the restoring stress $p b_{e l n}$ and stiffness $k b_{e l n}$ of each internal element: The restoring stress of each element is a function of its deformation, derivative of deformation and second derivative of deformation and depends on the law that follows the element. $n$ goes from 1 to 4 . Elements 1, 2 and 3 are 1D viscoelastic elements whereas Element 4 follows a Non-linear 1.5D $\mu$ Mazars law.

(7) It is then possible to construct the vectors $p_{e f}$ and $k_{e f}$ giving the enhanced fiber nodal restoring stresses and stiffnesses. $p_{e f}$ is a vector made of 5 terms deduced by assembling vectors $p b_{e l 1}, p b_{e l 2}, p b_{e l 3}$ and $p b_{e l 4}$, whereas $k_{e f}$ is a 5 by 5 matrix determined by assembling $k b_{e l 1}, k b_{e l 2}, k b_{e l 3}$; and $k b_{e l 4}$.

$$
p_{e f}=\left[p_{1} ; p b_{k 1} ; p b_{k 2} ; p b_{k 3} ; p_{2}\right]
$$

(8) Calculation of the nodal stress vector $p_{e}$ and stiffness matrix $k_{e}$ of the internal nodes of the concrete fiber knowing $p_{e f}$ and $k_{e f}$. Terms 1 and 5 of the $p_{e f}$ vector give stresses at the external nodes of the fiber element (such values are known external imposed boundary conditions) whereas terms 2, 3 and 4 give stress values of the internal nodes of the fiber (unknown degrees of freedom of the system). Similarely, in $k_{e f}$ columns and lines 1 and 5 are for external nodes whiles columns and lines 2, 3 and 4 are for internal nodes. By using index $b$ for the external nodes and $r$ for the internal nodes: $k_{e f}(2: 4,2: 4)=k_{r r}$ and $p_{e f}(2: 4)=p_{r}$. 
Thus:

$$
\begin{gathered}
k_{e}=k_{r r} \\
p_{e}=p_{r}
\end{gathered}
$$

The internal equilibrium of a concrete fiber is reached once the nodal stress of the internal nodes $p_{e}$ is equal to zero. Newton loop allows reaching such equilibrium.

(9) Newton loop:

(9.1) Calculation of the residual parameter $R$ that needs to be minimized in the Newton loop, which is $R=-p_{e}$. If its value is bigger than a given chosen threshold value, the Newton loop continues and $k$ is set equal to $k+1$. If else, the Newton loop stops here.

(9.2) An incremental deformation $\Delta u_{k}$ is added to the deformations of the internal nodes in order to achieve an equilibrium state. It is calculated as follow:

$$
\frac{d R}{d U}=-k_{e}
$$

Then:

$$
\Delta u_{k}=-\frac{d R}{d U}
$$

(9.3) From the new deformation vector, using Newton equations velocity and acceleration vectors are determined (same equations as step 4).

(9.4) Deformation, derivative of deformation and second derivative of deformation vectors are calculated (same equations as step 5).

(9.5) The constitutive law of the internal elements is called and their restoring stress and stiffness are calculated (same as step 6).

(9.6) $p_{f}$ and $k_{f}$ are calculated (same as step 7).

(9.7) $p_{e}$ and $k_{e}$ are calculated (same as step 8).

At the end of the Newton loop the internal deformations that best satisfy the internal equilibrium of concrete fibers are obtained. From these deformations and knowing the constitutive law of the internal elements, their corresponding stiffness and nodal stresses are also calculated. Those values can then be used to determine the external stresses and stiffnesses that the fiber will return to the global problem. 


\subsubsection{Static condensation}

When the internal equilibrium of a fiber is reached, stresses at nodes $A_{1}$ and $A_{2}$ of the fiber are determined.

$$
p_{\text {ext }}=\left[p_{1} ; p_{2}\right]
$$

Then, stiffness values at nodes $A_{1}$ and $A_{2}$ that compose the $k_{\text {ext }}$ matrix of the fiber are calculated using static condensation ([14] [51]): By using index $b$ for the external nodes and $r$ for the internal nodes, the stiffness terms that allow determining the external stiffness matrix $k_{e x t}$ of the fiber can be written as: $k e f([1,5],[1,5])=k_{b b}$, kef $(2: 4,[1,5])=k_{r b}$, $k e f([1,5], 2: 4)=k_{b r}$ and $k e f(2: 4,2: 4)=k_{r r}$. Which allows writing a simplified expression of the external stiffness matrix $k_{\text {ext }}$ which is actually equal to the tangent operator.

$$
k_{e x t}=k_{b b}-k_{b r} \times k_{r r}^{-1} \times k_{r b}
$$

\subsubsection{Global Newton-Raphson Algorithm}

Each concrete fiber returns its restoring stress and stiffness that are used for the determination of the sectional stiffness and sectional internal force (from which the stiffness and force of the beam elements are determined). Which allows by combining the different contributions to solve the global Newton Raphson algorithm on the global coordinate system presented in Chapter 1 (subsection 1.2.1). At each resolution step of the global Newton-Raphson loop there is a need to repeat the internal resolution steps that allow reaching the equilibrium of the fibers.

The resolution numerical time step used is 3600 seconds which means 1 hour. This time step allowed having a good convergence of results and enabled us to accuratey follow the evolution of damage of the portal frames.

\subsubsection{Steel fibers enhanced constitutive law}

For steel reinforcements, a non-linear 1D Menegotto cyclic model with strain hardening [39] was used. During the early age period, the steel model was enhanced to take into account the thermal deformation of steel rebars (steel reinforcements are not subjected to shrinkage or creep as concrete fibers). Thus, to the normal strain $\epsilon_{x x}$ at the steel fibers determined using the Timoshenko kinematic as presented in Chapter 1, was substracted 
the thermal deformation as follow:

$$
\epsilon_{x x}=\epsilon_{x x}-\alpha_{T}\left(T-T_{0}\right)
$$

Where $\alpha_{T}$ is the thermal expansion coefficient. $\alpha_{T}=12 e^{-6}, T$ the temperature of the steel fiber and $T_{0}$ the initial temperature of the steel fiber. Knowing $\epsilon_{x x}$, the Menegotto law then allowed to determine the normal stress $\sigma_{x x}$ along the steel fiber axis. During the third step of simulations (Figure 3.1), the Menegotto Pinto law with strain hardening was used without taking into account the thermal deformation of the steel rebars (negligible).

\subsection{Description of the numerical model of the portal frames}

This section describes the meshing chosen and the coefficients that were used in the constitutive laws of the numerical model.

\subsubsection{Mesh and boundary conditions}

Figure $3.2 \mathrm{~b}$ gives the node numbers that were used in the numerical model of the portal frames. In order to show that such meshing is appropriate to use when conducting a dynamic analyis of the structures, a mesh sensitivity analysis was perfomed. It will be presented in subsection 3.5.2.

The cross section of the portal frames was devided into 4 concrete fibers in the $\mathrm{z}$ direction and 8 fibers in the y direction in addition to 4 steel fibers to model longitudinal reinforcements (Figure $3.2 \mathrm{a}$ ). The minimum number of concrete fibers that allows to interpolate well temperature and shrinkage fields over the cross section determined using COMSOL was chosen. Figure 3.10 shows the shrinkage field (non-Endogenous Portal frame) at 28 days interpolated by a multifiber cross section composed of 8 fibers in the y direction and 4 fibers in the $\mathrm{z}$ direction. It was assumed that at each time step all cross-sections of the portal frames have the same shrinkage field.

In the numerical model, 3 concentrated masses $\left(M_{1}, M_{2}\right.$ and $\left.M_{3}\right)$ (orange circles) representing the contribution of upper floors were defined on top of the structures (Figure 3.2p). $M_{1}=M_{2}=M_{3}=1148 \mathrm{~kg}$. Therefore, $M_{t o t}=M_{1}+M_{2}+M_{3}=3444.4 \mathrm{~kg}$. Where $M_{t o t}$ is the total mass of the frame (self weight is neglected). The same concentrated masses were simulated numerically when conducting the PsD tests (Chapter 2). 


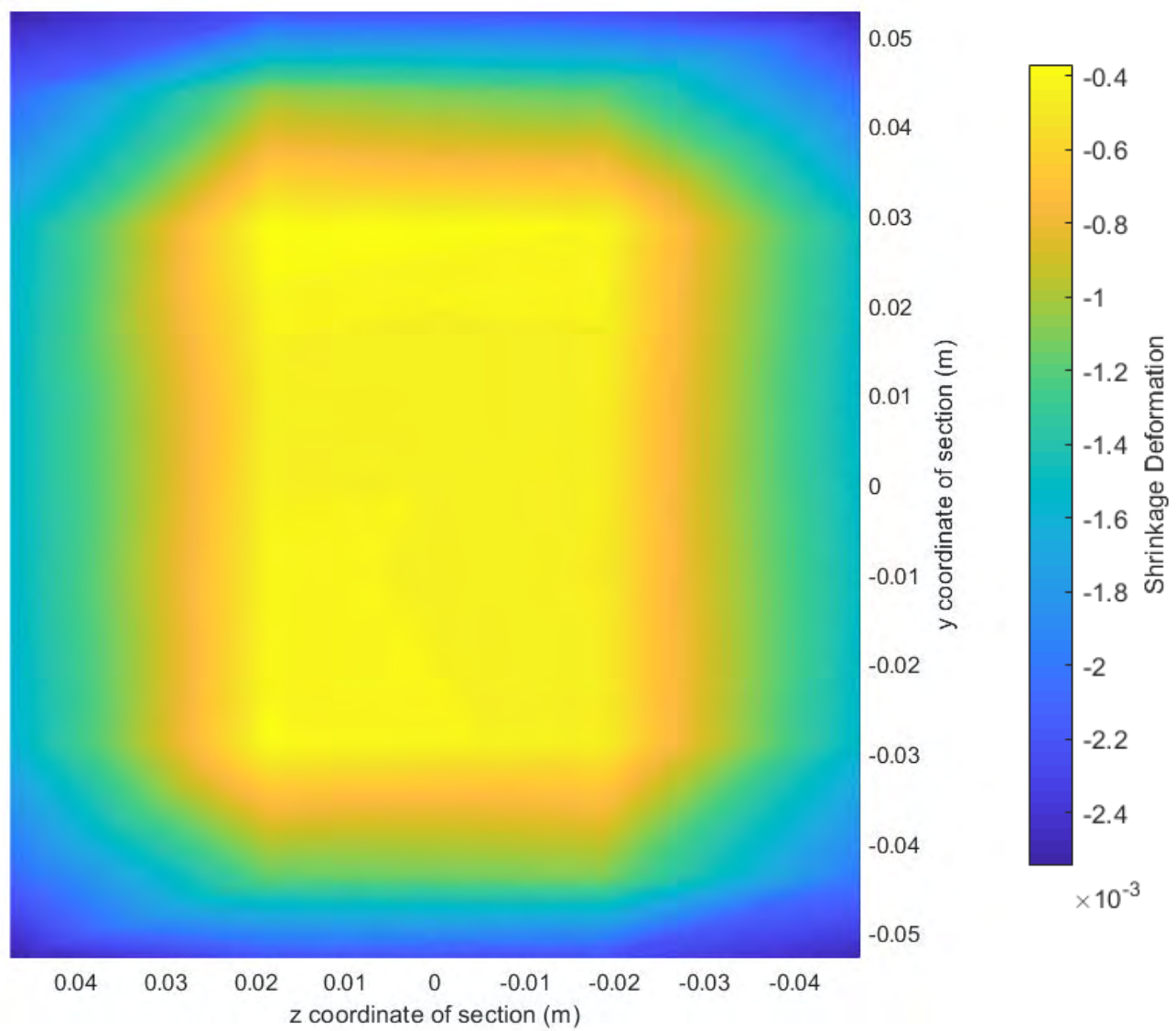

Figure 3.10: Shrinkage evolution at an intermediate cross section of the portal frames interpolated at the Gauss points of a multifiber cross-section at 28 days (Non-Endogenous Case). Since all cross sections of the portal frames except for the sections located at the joints are subjected to similar temperature and humidiy outside conditions, their shrinkage and temperature evolutions are similar. The additional shrinkage occuring at the corners of the joints was not accounted for in the multifiber model.

Structures were initially designed to be perfectly pinned at their three ends as shown in Figure $3.2 \mathrm{~b}$. In the practice, during PsD tests, the right column of the structures underwent a vertical displacement that was measured using Digital Image Correlation (Chapter 2). Such displacement was implemented in the numerical model when running the non-linear dynamic analysis (Figure 3.11).

Furthermore, pins were not in the reality poisitioned at the bottom of the portal frames as depicted in Figure $3.2 \mathrm{~b}$, there was rather an excentricity between the bottom of the portal frames and the pins. Indeed, here is how pinned connection were realized: Plates (including a pin) were welded to the end of the longitudinal rebars of the portal frames. 
After casting, the welded plates were themselves welded to a supporting beam itself fixed to the testing slab using anchors. Thus, between the pins and the bottom of the RC columns there was an excentricity due to the plates containing the pins (Figure 3.11 a). To account for such excentricity in the multifiber model, 3 rigid elements having a length of $13 \mathrm{~cm}$ were added at the bottom of the three columns of the model (Figure $3.11 \mathrm{~b}$ ).

\subsubsection{Material parameters}

In Chapter 2, it was explained that concrete cylindrical samples made of the same material as the portal frames have a compressive strength of $56 \mathrm{MPa}$ and a tensile strength of 3 $\mathrm{MPa}$, whereas their Young modulus is equal on average to $27 \mathrm{GPa}$. Due to scale effects, compressive strength, tensile strength and Young Modulus values of concrete used in the portal frames are different from the ones of the cylindrical samples tested. In fact, according to the Weibull law [14] [36]:

$$
R_{t}(\text { portalframe })=R_{t}(\text { cylinder })\left(\frac{V R G}{V C}\right)^{1 / m}
$$

and

$$
R_{c}(\text { portalframe })=R_{c}(\text { cylinder })\left(\frac{V R G}{V C}\right)^{1 / m}
$$

Where: $R_{t}$ (portalframe) and $R_{c}$ (portalframe) are the tensile strength and compressive strength of the portal frames, $V R G$ is the volume in compression or in traction of the structures. The portal frames being almost under pure flexion, their volume under compression equals their volume under tension. $V C$ is the volume of cylinder under traction (in the Splitting test) or under compression (in the compression test).

$$
\left.V R G=\left(1.355 \times 3 \times 11 \times 11 \times 10^{-2} \times 10^{-2}\right)+\left(0.54 \times 11 \times 11 \times 10^{-2} \times 10^{-2}\right) \times 4\right) / 2=0.037 m^{3}
$$

$$
\left.V C=\pi \times\left(11 \times 10^{-2}\right)\right)^{2 / 4} \times 22 \times 10^{-2}=0.002 m^{3}
$$

The $m$ parameter to use in the Weibull law is taken equal to 10 ([14] [36]).

Thus, $R_{c}($ portalframe $)=42 M P a$ and $R_{t}($ portalframe $)=2.3 M P a$

In order to determine material properties of concrete used in the portal frames, the $\mu$ Mazars concrete numerical model was calibrated in a way to fit the static behavior 

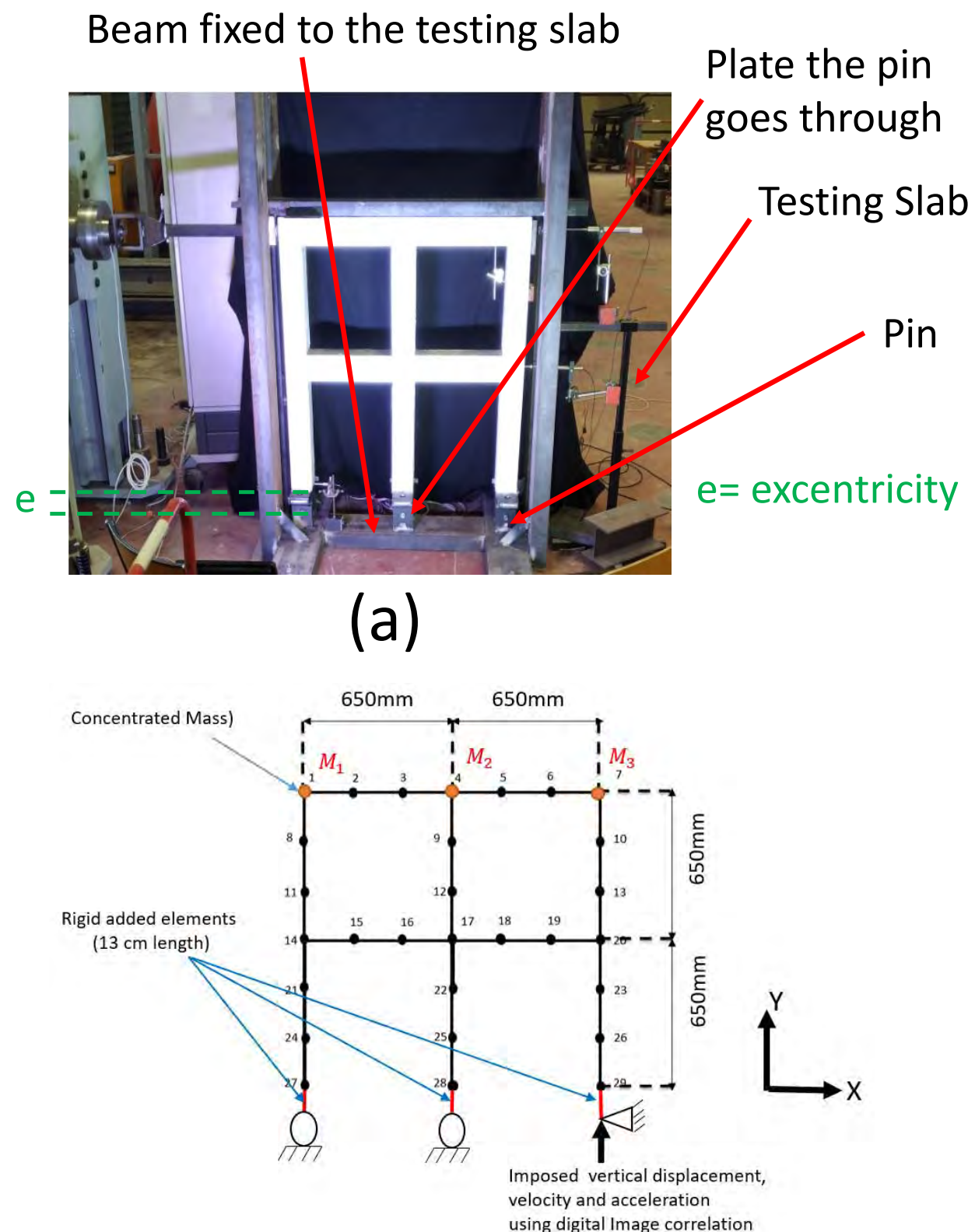

(b)

Figure 3.11: (a) Pinned connection realization process and (b) Corrections applied to the numerical model based on experimental observations: (1) Excentricity of the pinned connections accounted for by adding rigid elements at the bottom of the portal frames and (2) Vertical displacement, velocity and acceleration determined using Digital Image correlation at the bottom of the right column implemented into the model when conducting the dynamic analysis.

found experimentally (Chapter 2). Concrete strength values that best approximated the 
static behavior of the portal frames correspond to a compressive strength of $35 \mathrm{MPa}$, a tensile strength of 2.5 MPa and a Young modulus of 24.1 GPa. Steel reinforcements yield stress used in the numerical model was taken equal to $500 \mathrm{MPa}$ since such value is not dependent on scale effects. This calibration step was performed on the endogenous portal frame and the same material parameters determined for that portal frame were used when simulating the behavior of the non-endogenous portal frame.

Variability of young modulus, tensile and compressive strength was taken into account in the multifiber model. A variability of $5 \%$ was used for Young modulus values affected to the different concrete fibers (random normal distribution with a mean value of $E_{0}=24.1$ GPa and a standard deviation of $\left.E_{0} \frac{5}{100}\right)$.

Initial concrete parameters ( $\mu$ model [14]) $f_{t_{i}}$ and $f_{c_{i}}$ of the different fibers were then determined starting from their respective Young modulus value $E_{i} . f_{t_{i}}=\epsilon_{t 0} \frac{E_{i}}{E_{0}}$ and $f_{c_{i}}=\epsilon_{c 0} \frac{E_{i}}{E_{0}}$. $\epsilon_{t 0}$ being the mean of $f_{t_{i}}$ values and $\epsilon_{c 0}$ the mean of $f_{c_{i}}$ values. In our case, $\epsilon_{c 0}=-4 M P a$ and $\epsilon_{t 0}=2.5 M P a(\mu$ model [14]).

Furthermore, it was observed experimentally that the longitudinal rebars were not in the reality positioned at their designed position. An excentricity of the rebars of $27 \%$ was thus imposed in the numerical model of the first group of portal frames tested using PsD tests whereas no excentricity was accounted for in the numerical model of the second group since rebars were better produced.

\subsubsection{Constitutive laws parameters}

Table 3.2 gives concrete and steel parameters used in the numerical model of the portal frames.

Strain to stress relationship of concrete fibers was determined using a non-linear Mazars $\mu$ model [11] (1.5D model). The cyclic strain to stress relation used at each concrete fiber is shown in Figure 3.12a, where $\sigma_{x x}$ stands for normal stress along the concrete fiber axis. For steel reinforcements, a non-linear 1D Menegotto cyclic model with strain hardening [39] was used as presented in Figure $3.12 \mathrm{~b}, \sigma_{x x}$ stands for normal stress along the steel fiber axis.

Creep was modeled using three Kelvin Voigt models in series (Figure 3.9) as explained in Chapter 1. The calibration parameters for the creep model were taken from [14]. $\tau_{1}=$ 0.1 day $; \tau_{2}=1$ day; $\tau_{3}=10$ days and $k_{1 \infty}=3 \times 10^{11}\left(\frac{\mu m}{m}\right) ; k_{2 \infty}=9 \times 10^{10}\left(\frac{\mu m}{m}\right) ;$ $k_{3 \infty}=2.5 \times 10^{10}\left(\frac{\mu m}{m}\right)$. Those values were determined through calibration tests [14]. 


\begin{tabular}{cc}
\hline Concrete parameters & Steel parameters \\
\hline$E=24.1 \mathrm{GPa}$ & $E=210 \mathrm{GPa}$ \\
$\nu=0.2$ & $F_{y}=500 \mathrm{MPa}$ \\
$A_{t}=0.8$ & \\
$A_{c}=1.2$ & $b=\frac{\left(710 e^{6}-500 e^{6}\right)}{(0.11-0.0023) 210 e^{9}}$ \\
$B_{t}=8000$ & $a_{1}=0$ \\
$B_{c}=320$ & $a_{2}=55$ \\
$f_{t}=2.5 \mathrm{MPa}$ & $a_{3}=0$ \\
$f_{c}=-4 \mathrm{MPa}$ & $R_{0}=18.5$ \\
$\beta_{1}=0 \mathrm{MPa}$ & $c_{R 1}=0.925$ \\
$\beta_{2}=0 \mathrm{MPa}$ & $c_{R 2}=0.15$ \\
\hline
\end{tabular}

Table 3.2: Concrete and steel reinforcements model parameters. $E=$ Elastic modulus; $\nu=$ Poisson ratio; $f_{t}$ is the law parameter accounting for tensile strength; $f_{c}$ is the law parameter accounting for compressive strength; $A_{t}=1$ st parameter govering the evolution of damage (traction); $A_{c}=1$ st parameter govering the evolution of damage (compression); $B_{t}=2$ nd parameter governing the evolution of damge (traction); $B_{c}=2$ nd parameter governing the evolution of damage (compression); $\beta_{1}$ and $\beta_{2}$ are related to damping, respectively with and without damage and $F_{y}=$ Steel yield stress.

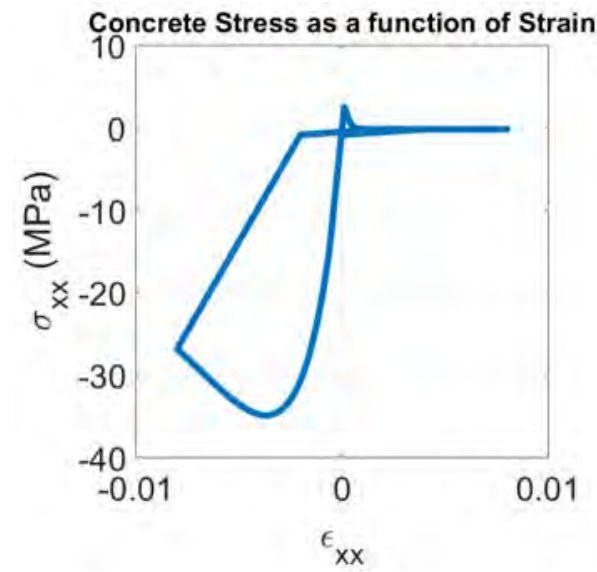

(a) Concrete Cyclic $\mu$ model 11

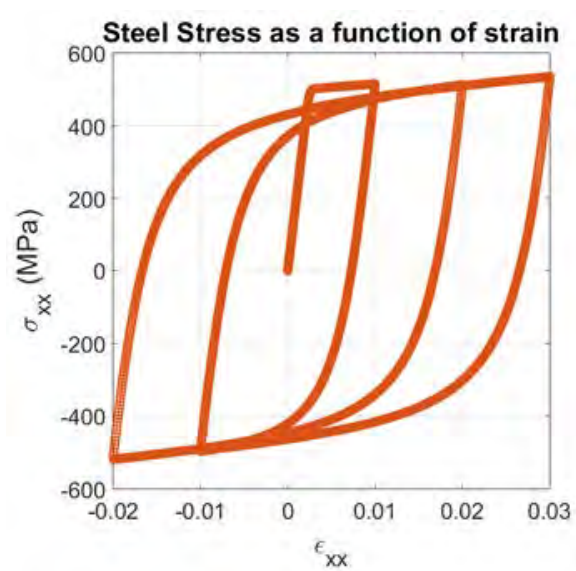

(b) Steel Cyclic model 39

Figure 3.12: Material constitutive laws

\subsubsection{Inputs data from THC model}

Shrinkage and temperature evolutions calculated using COMSOL were implemented into the multifiber model by interpolation. Figure 3.7 gives shrinkage and temperature evolutions used as input data of the numerical model (values at the concrete fibers). 


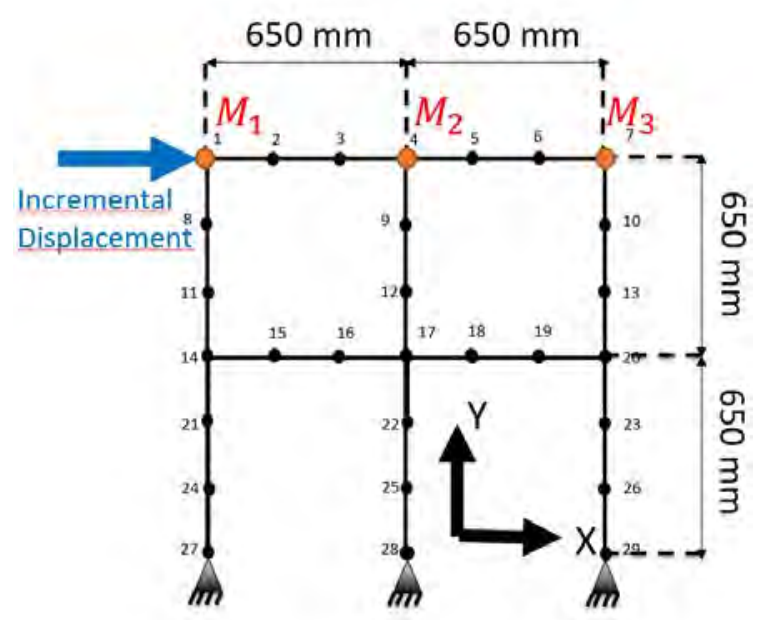

(a) Position of the imposed incremental displacement during the Pushover analysis

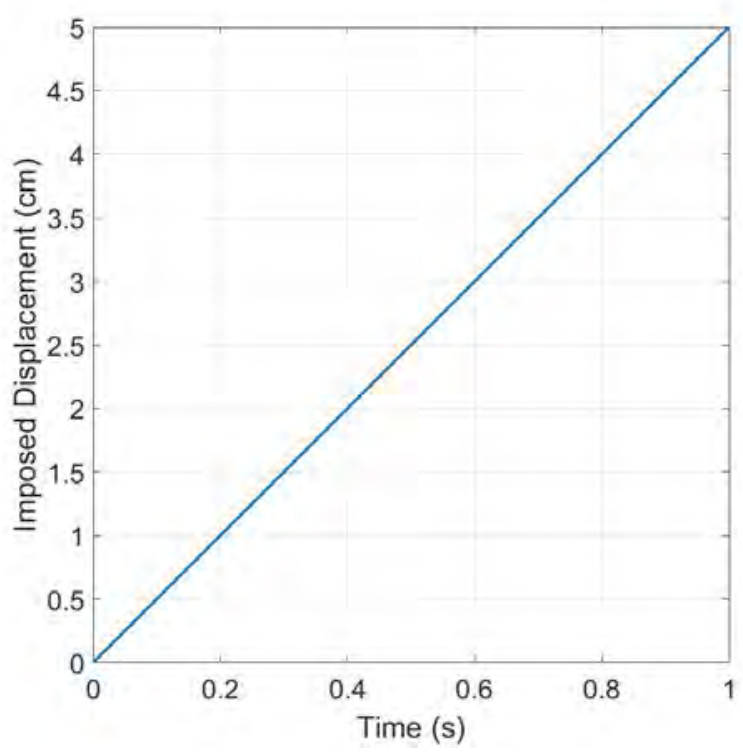

(b) Displacement Time History

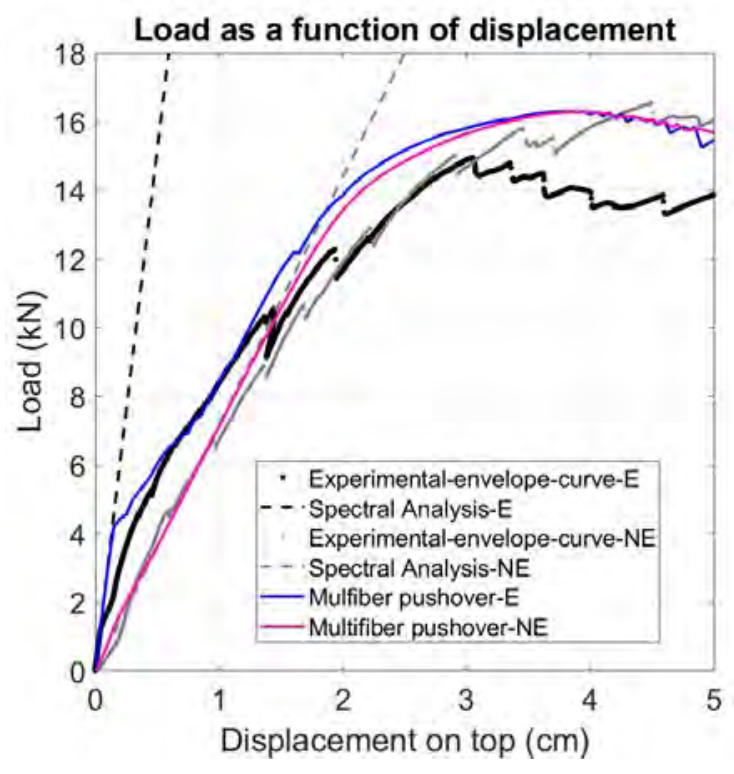

(c) Pushover, Spectral and PsD curves

Figure 3.13: Numerical pushover analysis using the multifiber beam model: Position of the imposed displacement (3.13a), displacement time history (Figure 3.13b and multifiber beam model pushover results and comparison with experimental pushovers (positive envelope of cylic test results) and spectral analysis (Figure 3.13c for Endogenous (E) and Non-Endogenous (NE) portal frames

\subsection{Results}

With the enhanced multifiber beam model, concrete damage was followed during the 28 first days of the life time of the two portal frame groups. A modal analysis and spectral 


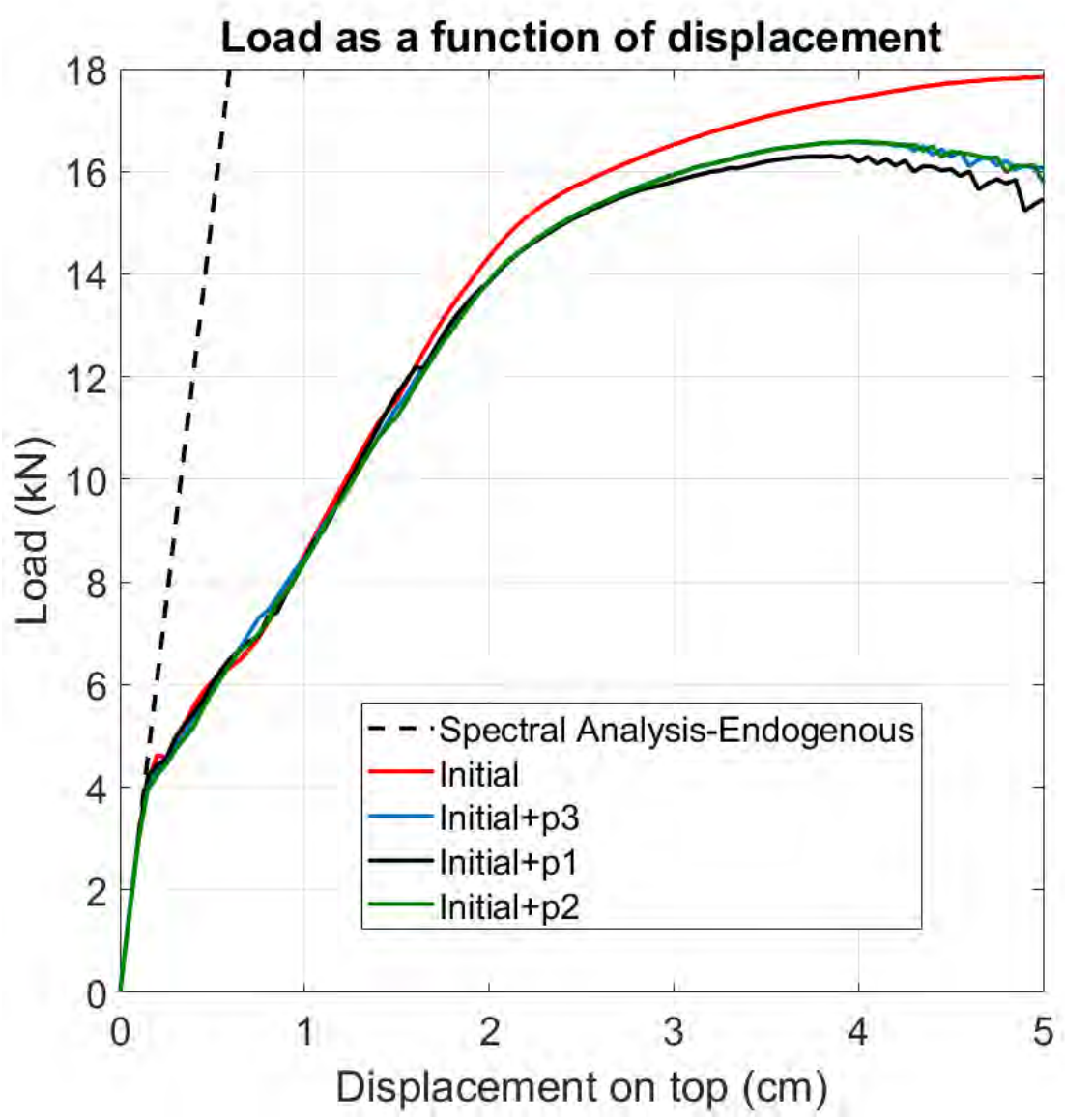

Figure 3.14: Pushover curves obtained for different discretizations to study mesh sensibility. "Initial" corresponds to the initial meshing given in Figure 3.15, while "Initial $+\mathrm{p} 1$ " is the refined mesh presented in Figure 3.16, "Initial + p2" corresponds to the discretization of Figure 3.17 and "Initial + p3" to the discretization of Figure 3.18 .

analysis were performed in order to quantify the difference in response of both structures after their early age period. A static pushover and a non-linear dynamic analysis were also numerically conducted. Results of those simulations are presented in this section as well as their comparison with experimental results.

\subsubsection{Early Age Damage Evolution}

Damage evolution due to shrinkage, creep and thermal deformations of the endogenous and non-endogenous portal frames was followed during their early age period (0-28 days). Time needed to run step $2(3.1)$ is equal to $1 \mathrm{~h} 13 \mathrm{~min}$ (with a time step of 1 hour). Damage at the different concrete fibers remained equal to 0 in the portal frame kept in endogenous conditions as shown in Figure $3.19 \mathrm{a}$ since stress values remained below the 


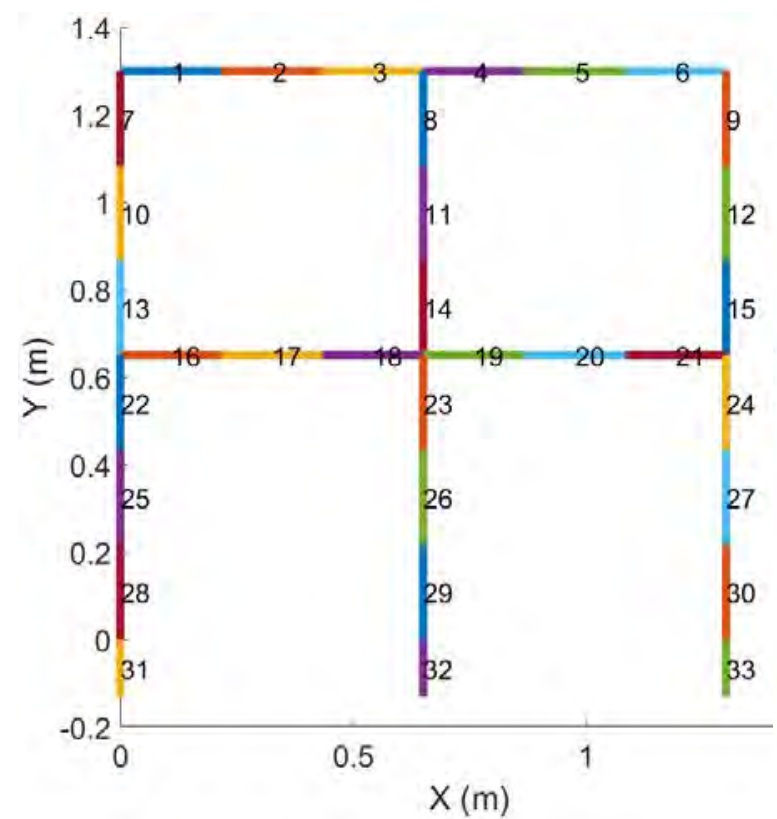

(a)

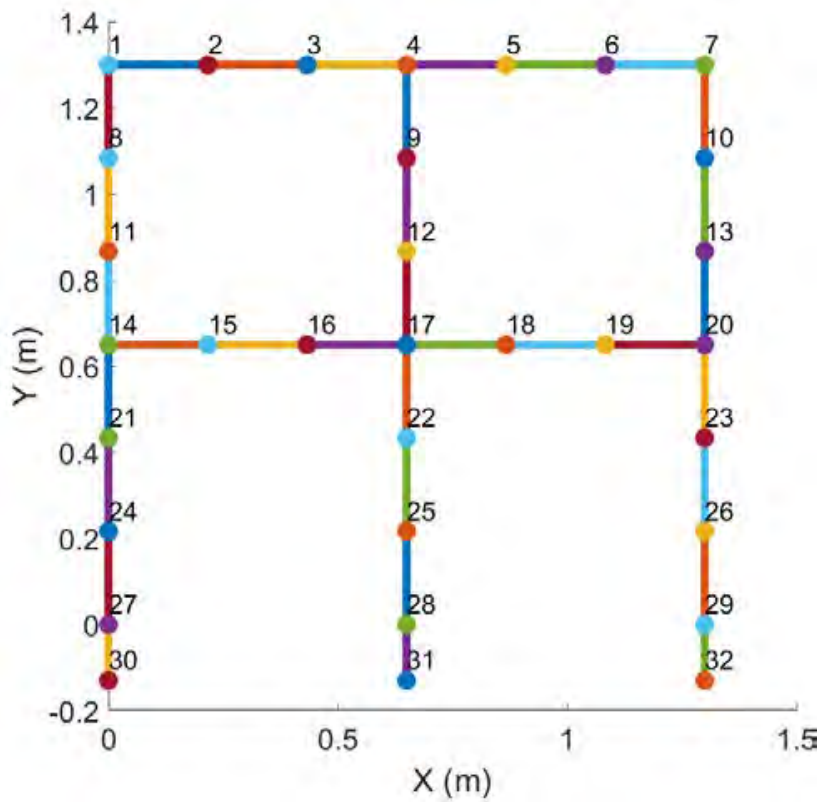

(b)

Figure 3.15: Initial Mesh "Initial" (a) Elements numbers (b) Node numbers

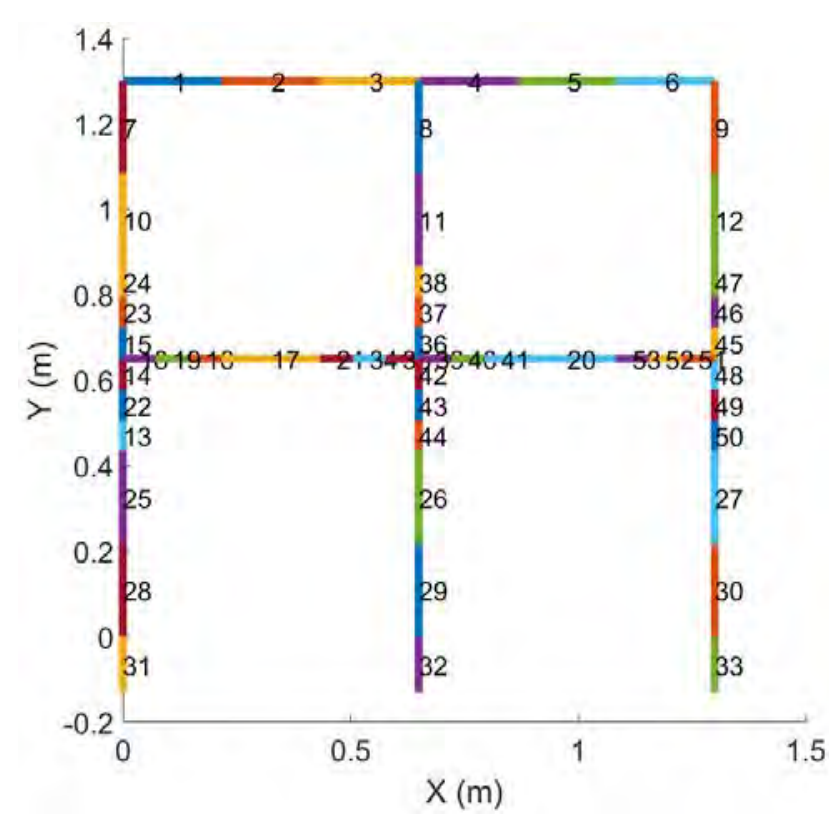

(a)

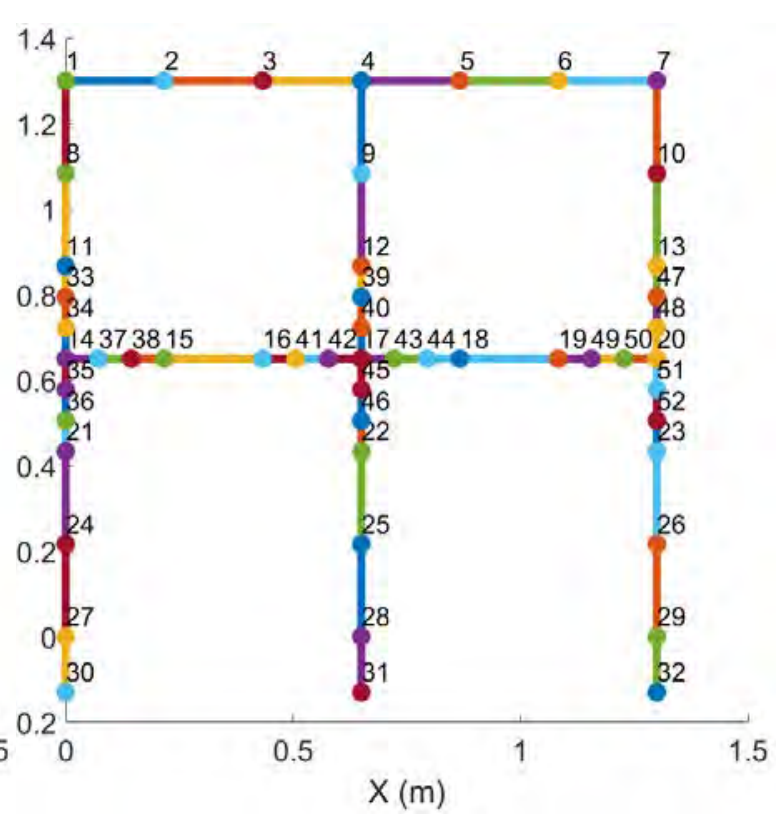

(b)

Figure 3.16: First refinement of the initial mesh by adding elements around the joints of the beam of the first floor "Initial + p1" (a) Elements numbers (b) Node numbers 


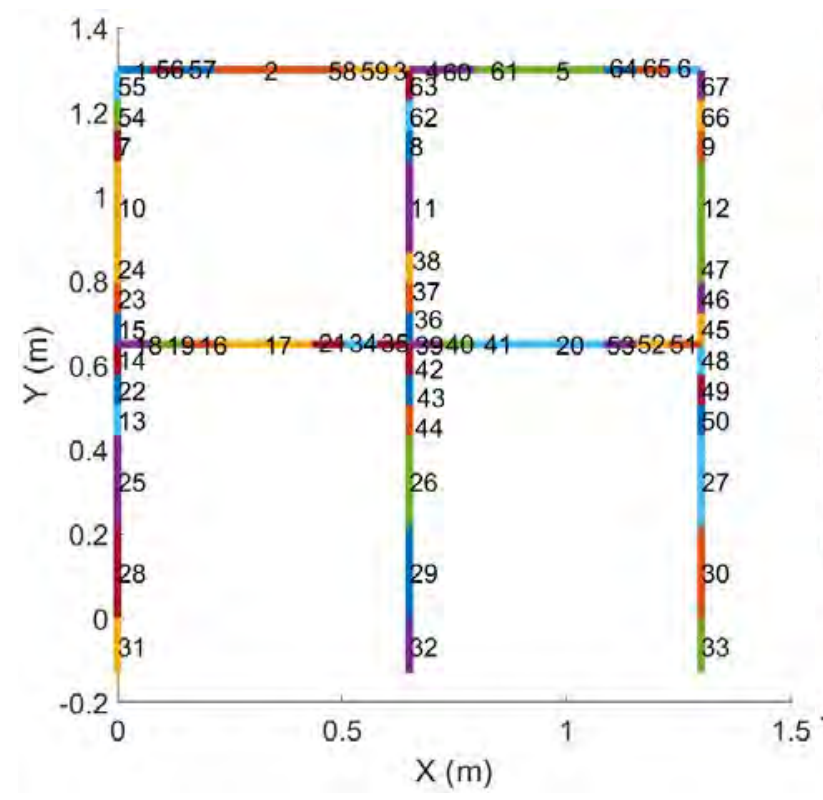

(a)

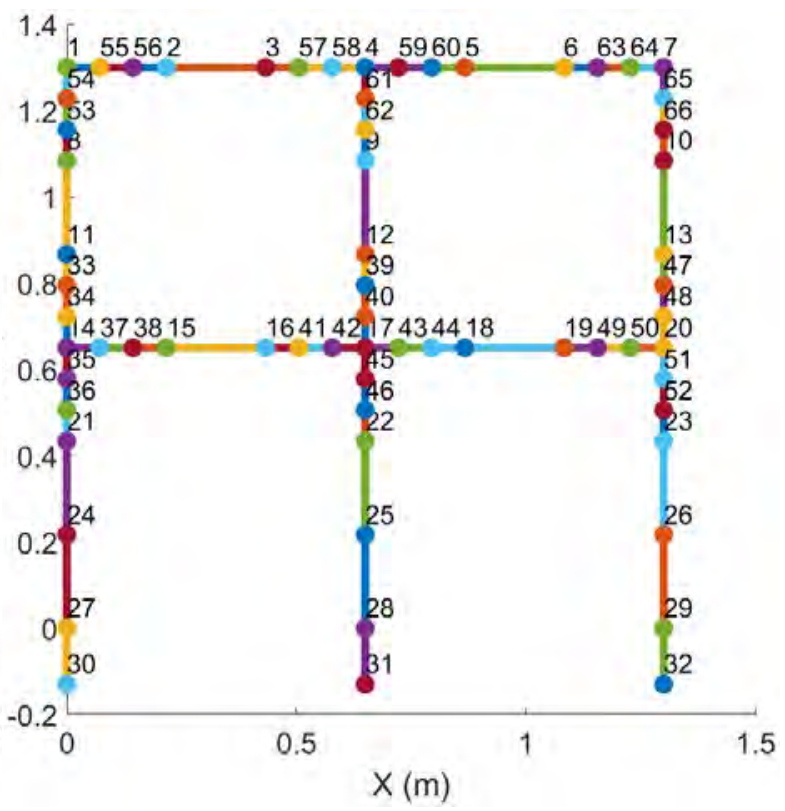

(b)

Figure 3.17: Second refinement of the initial mesh by adding elements around the joints of the beams of the first and second floor "Initial + p2" (a) Elements numbers (b) Node numbers

maximum allowable concrete tensile stress (Figure 3.19b). In the portal frame kept in non-endogenous conditions, damage increased during the early age period at the different concrete fibers (Figure 3.19c) since stress reached its maximum allowable value $R_{t}$ (Figure $3.19 \mathrm{~d}$ ). Concrete damage during the early age period is thus more important in the nonendogenous case than in the endogenous case because of drying shrinkage. Figure 3.20 shows damage maps of the different layers of the multifiber Non-Endogenous portal frame (4 layers since there are 4 fibers following the $\mathrm{z}$ direction) at the end of the early age period. Damage is important at the external layers (1 and 4) of the portal frame. Such result is compatible with what was observed experimentally (cracks on the surface of the non-endogenous portal frames at the end of the early age period).

It should be pointed out that during the early age period, the tensile strength increases with the increase of the hydration coefficient $\xi$ (Figure 3.21 a) and reaches its maximum value $R_{t_{\text {final }}}$ (Figure $3.21 \mathrm{~b}$ ) at the end of the early age period (when $\xi=0.85$ as shown in Figure 3.21 f). This is why some concrete fibers get cracked during the early age period even if their tensile stress is below the final value of $R_{t_{\text {final }}}$ as long as it is below $R_{t}$ at a given time of the early age period.

Figure $3.21 \mathrm{~b}$ shows the evolution of the mean tensile strength of concrete fibers $\bar{R}_{t_{\text {final }}}=$ 


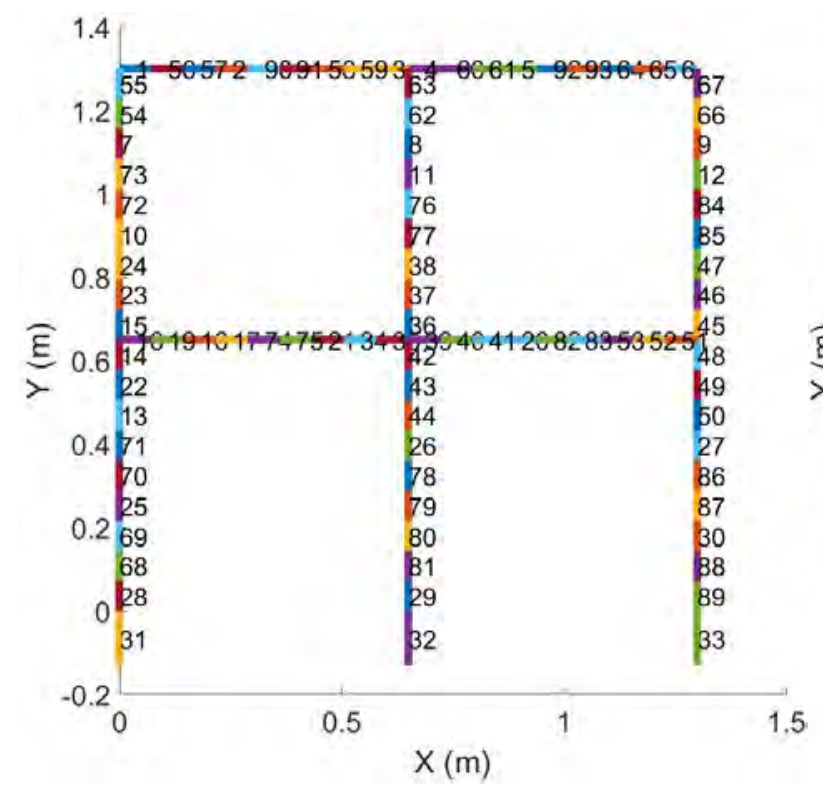

(a)

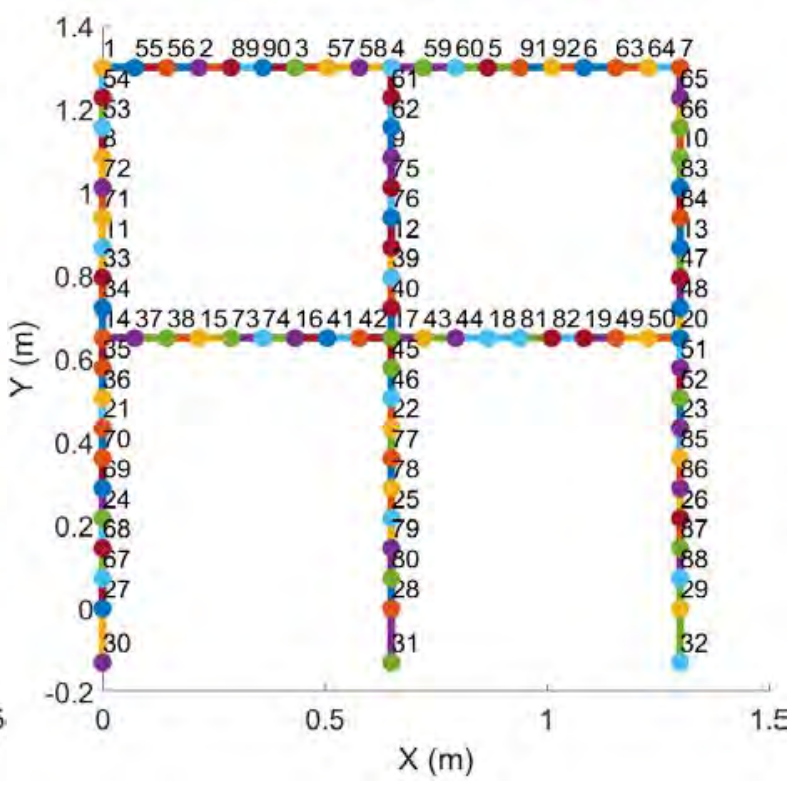

(b)

Figure 3.18: Third refinement consisting in dividing the initial mesh by 3 "Initial + p3" (a) Elements numbers (b) Node numbers

2.5MPa. Since the model takes into account Young modulus, tensile and compressive strength variability as stated earlier, the final tensile strenght $R_{t_{i_{\text {final }}}}$ of the different fibers is not the same and varies from 2.07 to $2.88 \mathrm{MPa}$. The evolution of $R_{t i}$ over time of the different fibers is shown in Figure $3.22 \mathrm{a}$ whereas the evolution of $R_{t i}$ as a function of the hydration coefficient $\xi$ is given in Figure $3.22 \mathrm{~b}$.

\subsubsection{Static Pushover}

Several pushover analysis were performed on an undamaged portal frame (modeled using a classical multifiber beam model without early age damage) for a mesh sensitivity study before performing a pushover analysis on the Endogenous and Non-Endogenous portal frames (using the enhanced multifiber model) to compare their response.

\subsubsection{Mesh sensitivity analysis}

In order to perform a numerical puhover analysis of the undamaged portal frame, an incremental horizontal displacement (Figure 3.13b was imposed at node 1 (Figure 3.13a) until reaching the maximum capacity of the structure. The initial mesh discretization (shown in Figure 3.15) was gradually refined (Figures 3.16 where additional nodes were 


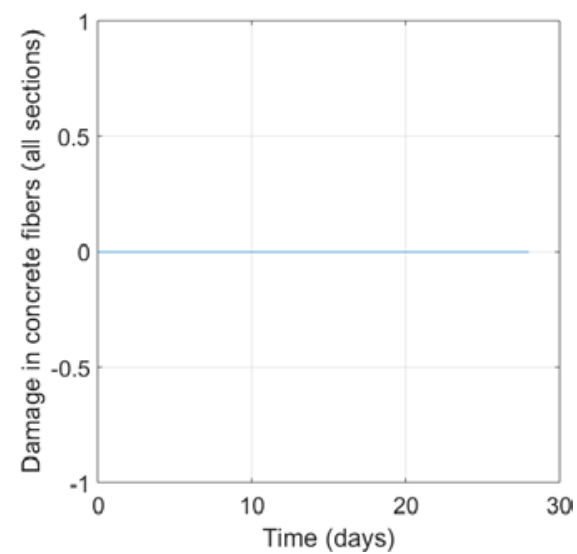

(a) Endogenous portal frame Damage

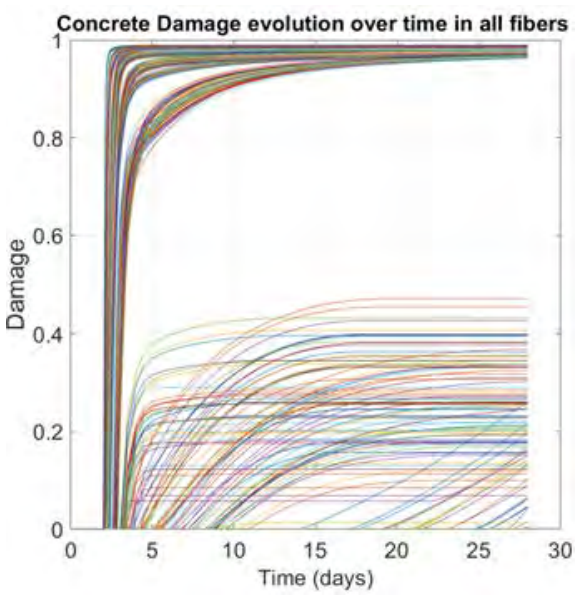

(c) Non-Endogenous portal frame Damage

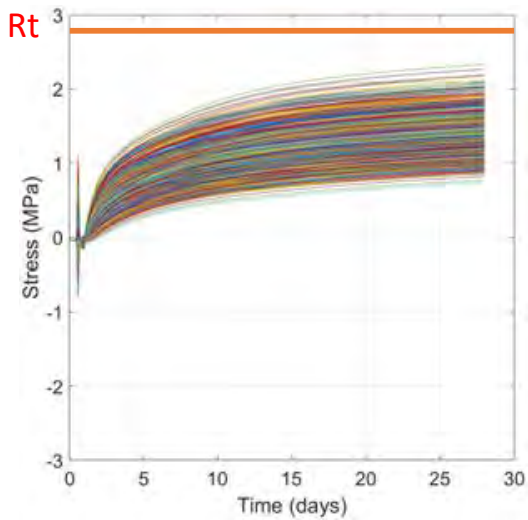

Rt=Concrete Tensile Strength=2.9 MPa

(b) Endogenous portal frame Stress

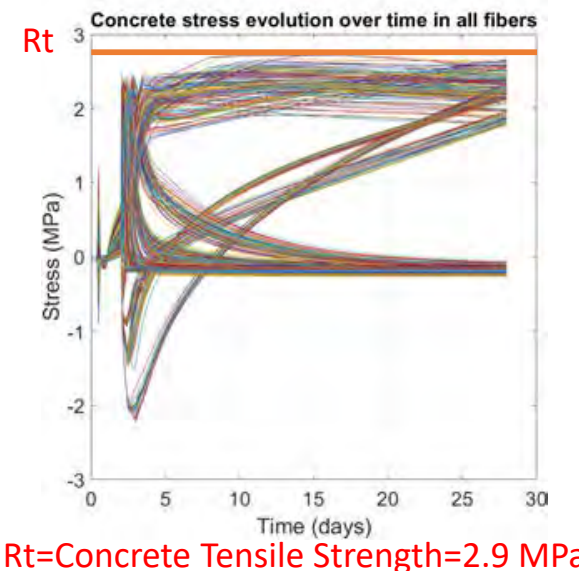

(d) Non-Endogenous portal frame Stress

Figure 3.19: Damage and normal stress $\left(\sigma_{x x}\right)$ evolutions at early age in all portal frame concrete fibers (many fibers get damaged at early age in the non-endogenous portal frame)

added towards the joints of the beam of the first floor, Figure 3.17 where additional nodes were added towards the joints of the beam of the first and second floor and Figure 3.18 where the initial mesh was devided by 3 ). For each mesh the same pushover analysis was performed. Time required to perform the different pushovers is given in Table 3.3 . Results of the different pushovers are given in Figure 3.14. Adding additional elements towards the joints of the first floor reduced the maximum capacity of the portal frame obtained numerically. Joints of the first floor play an important role in the response of the structure. In fact, as observed even experimentally most of the damage during mechanical testing occurs towards the joints of this beam. Meshings "Initial + p1" (Figure 3.16) and "Initial + p2" (Figure 3.17) gave very close pushover results and meshing "Initial + p3" (Figure 3.18) pushover curve is similar to meshing "Initial + p2" (Figure 3.17) 

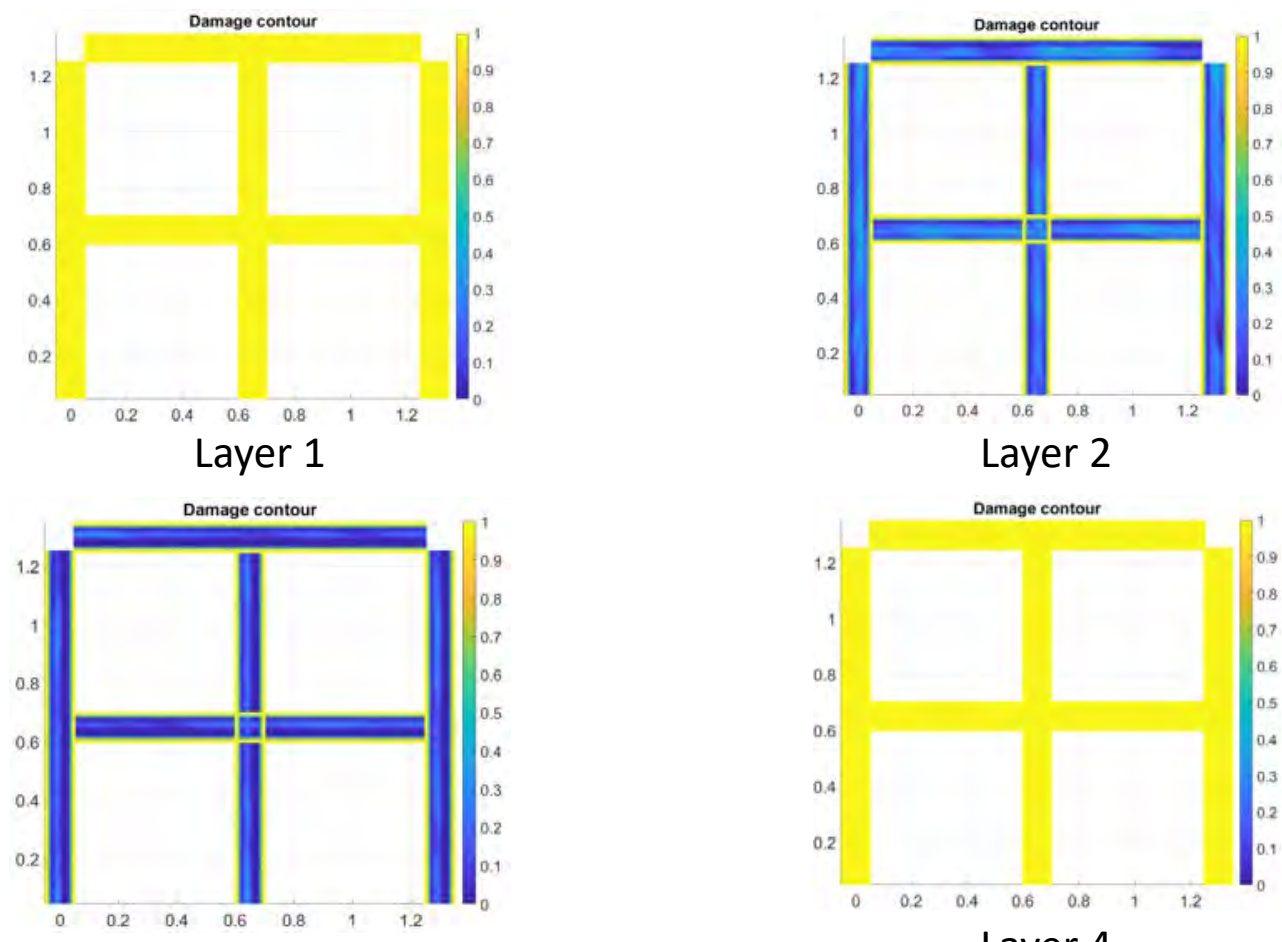

Layer 3

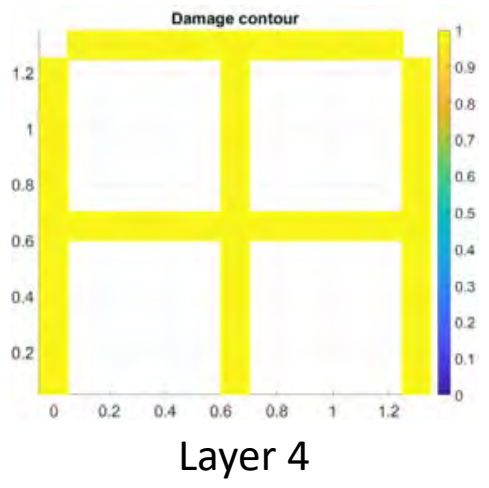

Figure 3.20: Non-Endogenous Portal frame: Damage layers at the end of the early age period

(convergence of results).

Meshing "Initial+p1" (Figure 3.16) was used to perform numerical pushovers of the endogenous and non-endogenous portal frames. A more precise calculation of the mesh size to use would have been required to study the post-peak behavior of the structures.

For the non-linear dynamic analysis, discretization "Initial" (Figure 3.15) was used. Indeed, as seen in Chapter 2, the maximum loading to which structures where subjected to during PsD tests is equal to $10 \mathrm{kN}$ and for such loading, results provided by the numerical model using mesh discretizations "Initial", "Initial + p1", "Initial + p2" and "Initial $+\mathrm{p} 3 "$ are similar (Figure 3.14).

\subsubsection{Pushover results}

After their early age period, a pushover analysis was performed on the Endogenous and Non-Endogenous portal frames. Pushover curves obtained using the numerical model were plotted in Figure $3.13 \mathrm{c}$. 
(a)

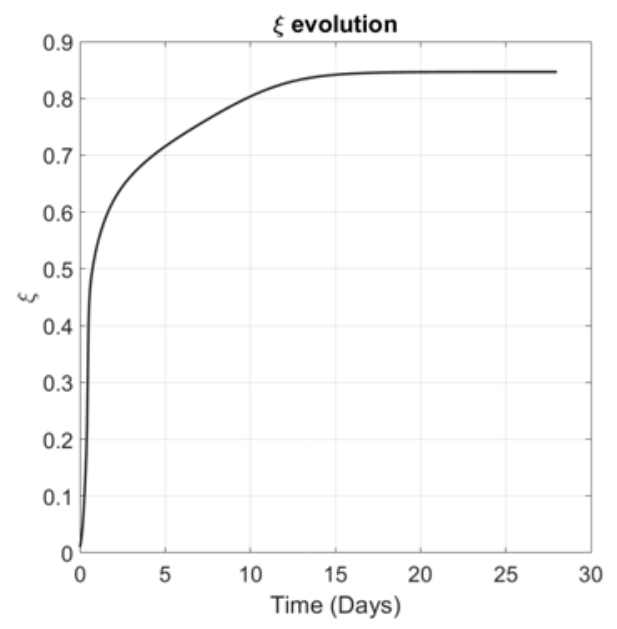

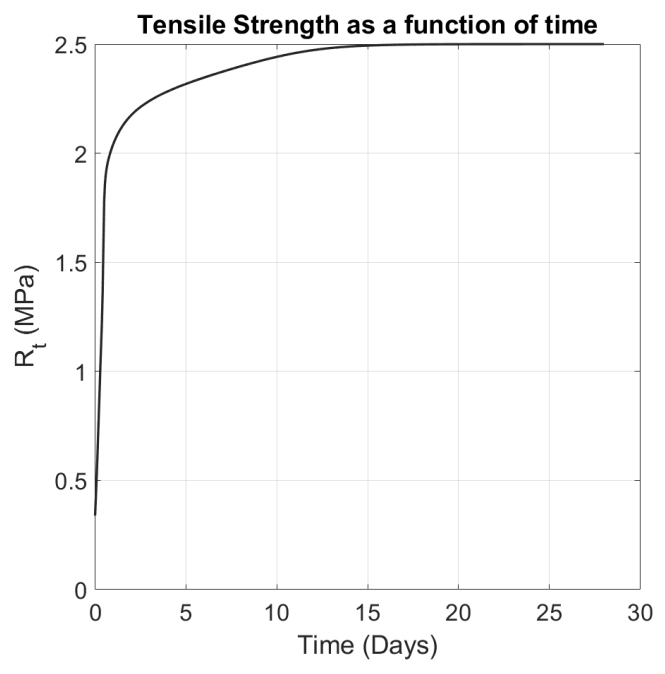

(b)

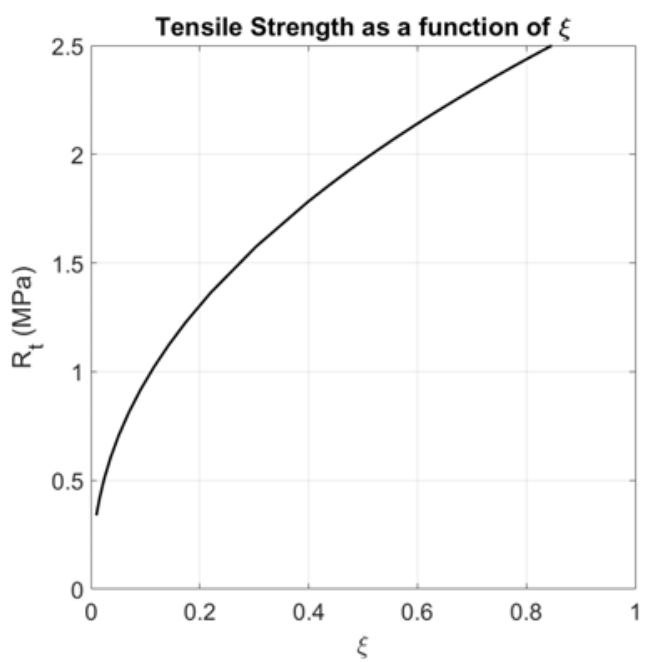

(c)

Figure 3.21: Non-Endogenous portal frame evolving parameters during early age: (a) Evolution of the hydration coefficient $\xi$ (b) Evolution tensile Strength $R_{t}$ and (c) Evolution of tensile strength as a function of $\xi$

It can be seen that the numerical pushover curves match well with the experimental envelope curves. Numerical pushover results also confirm the difference in behavior observed experimentally between the two portal frames (difference in initial slope).

\subsubsection{Modal Analysis}

At the end of resolution step 2 (Figure 3.1) (end of the early age period), a modal analysis was performed for both groups in order to determine the natural frequencies of the portal frames as well as their mode shapes while taking into account their early age damage. 


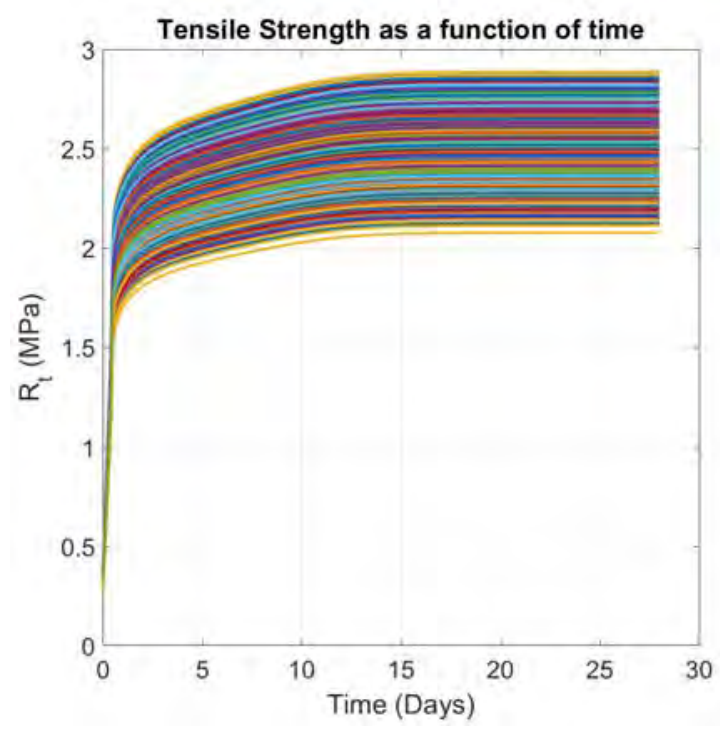

(a)

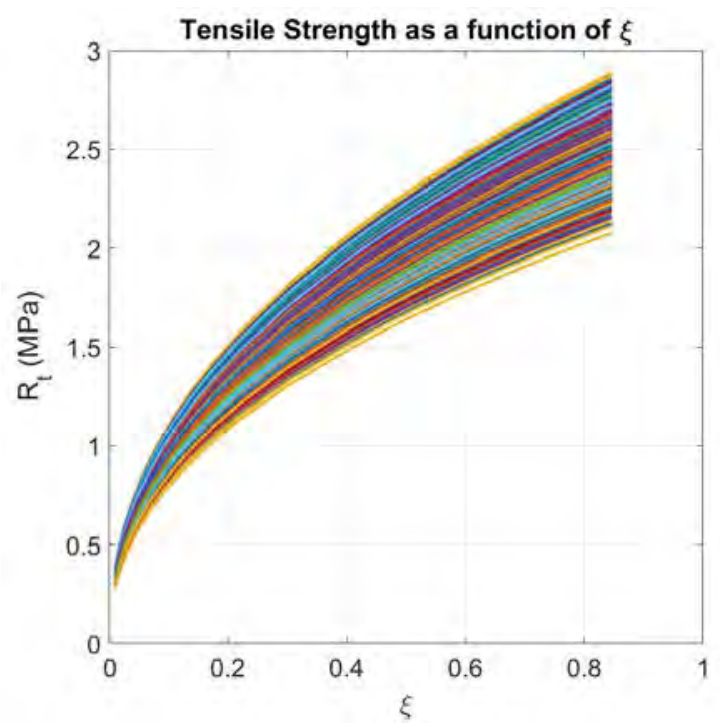

(b)

Figure 3.22: Variability of tensile strength in the numerical model: (a) Evolution tensile Strength $R_{t_{i}}$ of the different fibers and (c) Evolution of tensile strength $R_{t_{i}}$ as a function of $\xi$ (degree of hydration)

The Young modulus of each fiber was multiplied by the damage parameter in traction $D_{t_{i}}$ (of the $\mu$ model [11]) of the last iteration of resolution step 2.

$$
E_{i}=E_{i 0}\left(1-D_{t_{i}}\right)
$$

Where $E_{i}$ is the fiber young modulus to use when performing the modal analysis, $E_{i 0}$ the Young modulus of that fiber if no damage happened and $D_{t_{i}}$ the damage scalar parameter of the fiber at the end of resolution step 2 . The young modulus value $E_{i}$ of each fiber allows as explained in the state of the art of this thesis to determine the sectional stiffness of the multifiber beam elements, from which the stiffness of each beam element is determined. By assembling the contribution of the different elements the stiffness of the whole portal frame can be determined (FEM approach). Knowing the stiffness matrix of the portal frames, it is possible to perform a modal analysis by solving the eigen value problem. The 3 mode shapes of the portal frames obtained after performing modal analysis calculations are presented in Table 3.4. Natural frequencies were calculated after early age for both groups as shown in Table 3.5. Where $f_{1}=$ First Natural frequency; $f_{2}=$ Second Natural frequency and $f_{3}=$ Third Natural frequency. The modal analysis performed showed that the first natural frequency $f_{1}$ of the endogenous portal frame is $50 \%$ higher than the 


\begin{tabular}{cc}
\hline Mesh & Time (minutes) \\
\hline Initial & 11.45 \\
Initial + p1 & 22.6 \\
Initial + p2 & 27 \\
Initial + p3 & 40.5 \\
\hline
\end{tabular}

Table 3.3: Time required to conduct a pushover analysis of the not initially damaged portal frame using different meshes

natural frequency of the non-endogenous portal frame $(4.8 \mathrm{~Hz}$ versus $2.3 \mathrm{~Hz}$ as shown in Table 3.4). Such result can be explained by the fact that in the endogenous portal frame, almost no damage happened during early age whereas an important damage occured during the early age period in the non-endogenous portal frame due to drying shrinkage and as a consequence many concrete fibers reached their maximum allowable tensile stress. Similar observation was made experimentally.

\begin{tabular}{ccc}
\hline Mode 1 & Mode 2 & Mode 3 \\
\hline & & \\
$f_{1}$ & $f_{2}$ & $f_{3}$ \\
\hline
\end{tabular}

Table 3.4: Portal frame mode shapes

\begin{tabular}{ccc}
\hline & Endogenous & Non-Endogenous \\
\hline$f_{1}(\mathrm{~Hz})$ & 4.8 & 2.3 \\
$f_{2}(\mathrm{~Hz})$ & 107 & 69.5 \\
$f_{3}(\mathrm{~Hz})$ & 184.7 & 120 \\
\hline
\end{tabular}

Table 3.5: Natural frequency values at the end of 28 days

It should be noted that the behaviour of the portal frames is mainly dictated by mode 1. Indeed, concentrated masses on top are very important compared to the self weight of the portal frames. In order to prove that, effective modal mass participation was calculated, which showed that the total mass $M_{t o t}$ of the structures is almost equal to the effective modal mass participation of mode 1 . Effective modal mass participation 
$m_{e f f_{i}}$ of mode $i$ is calculated as follows:

$$
m_{e f f_{i}}=\frac{\left(\phi_{i}^{T} M \delta\right)^{2}}{\phi_{i}^{T} M \phi_{i}}
$$

Where: $\phi_{i}$ is the mode shape value at mode $i ; M$ is the structure mass matrix and $\delta$ is the projection vector. For instance the endogenous case gives the following results: $M_{t o t}=m_{e f f_{1}}+m_{e f f_{2}}+m_{e f f_{3}} \approx m_{e f f_{1}}=3444.4 \mathrm{~kg}$. Thus, the structure behaves as a one degree of freedom system of mass $M_{t o t}$.

The natural frequencies determined using the numerical model correspond to the ones found experimentally (starting from stiffness values experimentally determined using cyclic tests and by considering a virtual mass equal to $\left.M_{t o t}\right)$ (Chapter2).

However, as observed even experimentally, such values are different from the ones found using ambient vibration measurements. This difference is due to the fact that ambient vibration measurements do not take into account the simulated masses in the PsD tests and numerically. Only the weight of the structures is accounted for. During early age, the natural frequency of the structures measured using ambient vibrations was around $24 \mathrm{~Hz}$. By performing a numerical modal analysis using the multifiber beam model of the portal frames while considering only their weight without additional masses and using boundary conditions of the portal frames during early age (simply supported), a natural frequency of $25 \mathrm{~Hz}$ was found. During PsD tests, ambient vibrations showed that the natural frequency of the portal frames was around $53.5 \mathrm{~Hz}$, because their boundary conditions were different from the ones at early age (pinned and attached on top with the jack system). Numerically, the portal frames were modeled while accounting only for their self weight. They were pinned and in order to account for the jack system, a spring having a stiffness of $1.56 \times 10^{7} \frac{\mathrm{N}}{\mathrm{m}}$ was used. A modal analysis performed on such structure allowed getting a natural frequency of $53.5 \mathrm{~Hz}$.

\subsubsection{Spectral Analysis}

Modal analysis showed that there is a difference in behaviour between the portal frame that was kept in endogenous conditions and the one that was kept in non-endogenous conditions (change in frequency content as observed experimentally). This difference can be further illustrated if we perform a spectral analysis on the portal frames using the same moderate intensity non-linear Time History as the one presented in Chapter 2 of this thesis (Figure 2.16a). Its corresponding response spectrum is also given in Figure 2.16 b. Spectral Analysis conducted on the two types of portal frames showed (Figure 
2.16 ) that the maximum base shear in the endogenous case is equal to $26 \mathrm{kN}$ while it is equal to $37 \mathrm{kN}$ in the non-endogenous case (about 30\% difference (Table 2.4)). Spectral Analysis curves were also plotted in Figure 3.13c. Maximum Base shear is calculated by summing up base shear values $F_{i}^{\max }$ at each mode $i$.

$$
F_{i}^{\max }=\frac{S_{p a} \times \phi_{i}^{T} M \delta}{\phi_{i}^{T} M \phi_{i}} M \phi_{i}
$$

Where: $S_{p a}$ is the spectral acceleration of mode $i ; \phi_{i}$ is the mode shape value at mode $i$; $M$ is the structure mass Matrix and $\delta$ is the projection vector.

\subsubsection{Dynamic Analysis}

The same moderate intensity $0.3 \mathrm{~g}$ synthetic accelerogram used in the PsD tests was applied numerically on the portal frames (Figure 2.16a). Because the portal frames were not perfectly pinned and their three ends during the tests, real boundary conditions were measured using 2D Digital Image correlation. The most important vertical displacement was observed at the bottom of the right column of the portal frames and was measured using 2D Digital image correlation then filtred for noise removal. Its value was implemented as an input into the numerical model as well as its corresponding velocity and acceleration (Figure 3.11). Time needed to run a dynamic analysis of the portal frames using the multifiber model is 41 minutes.

Results are given in Figures 3.23 and 3.24 for the first group of portal frames and in Figures 3.25 and 3.26 for the second group tested using PsD tests. Numerical results show that there is a significant difference in the dynamic behavior of the endogenous and nonendogenous portal frames. The same observations were made experimentally. Numerical results match very well with the ones obtained using the PsD tests, which allows validating the numerical model.

\subsection{Comparison between multifiber model and 2D model results}

In addition to the multifiber model presented, a 2D finite element model was developed for the portal frames using ATL4S [51]. On a similar way as for the multifiber model, two main steps of resolution were conducted: a first step consisted in following the early age damage evolution of the portal frames and a second step consisted in modeling the behavior of the portal frames under a pushover or a seismic loading. Shrinkage and thermal 


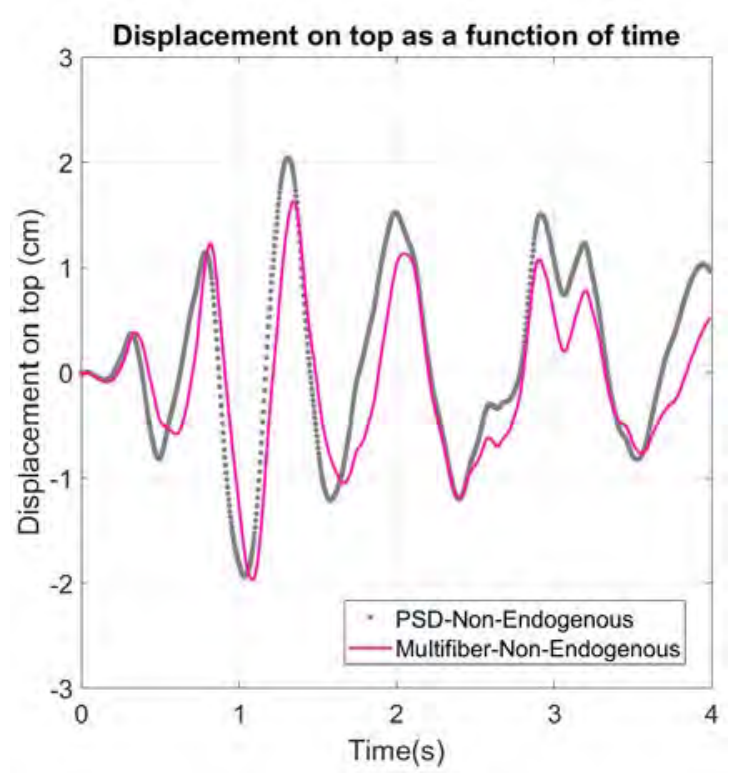

(a)

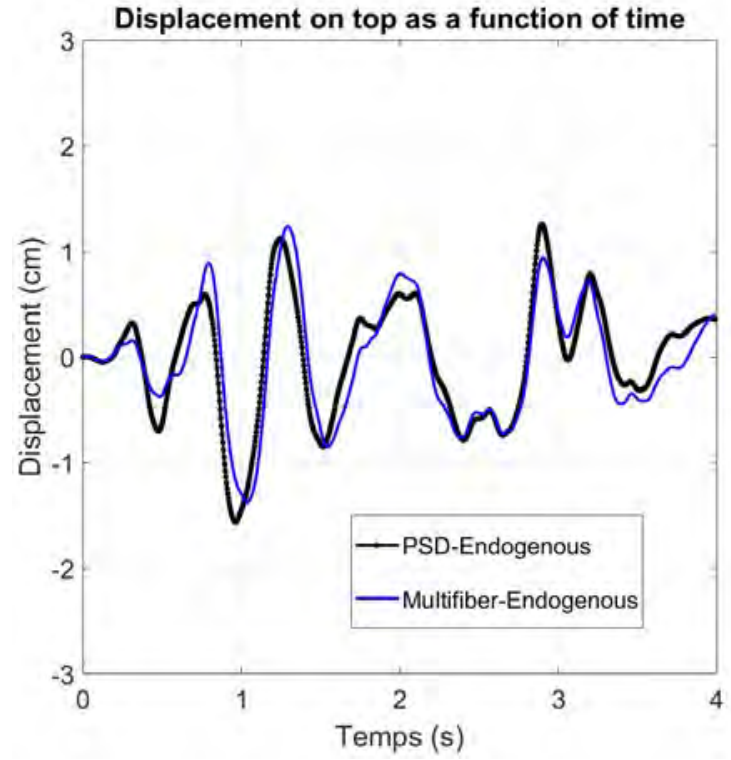

(b)

Figure 3.23: Displacements as a function of time comparison between PsD results and multifiber model in the first group (a) Non-Endogenous (b) Endogenous

deformations determined using COMSOL were implemented into the 2D finite element model as for the multifiber model. The objective of building a 2D model was to determine the damage pattern of the portal frames numerically during their early age period and to show that it reproduces well the pattern observed experimentally. The $2 \mathrm{D}$ model presents the advantage of taking into account the kinematic of the joints that can not be reproduced using the multifiber approach. By comparing results obtained using this $2 \mathrm{D}$ model with the ones of the multifiber model, the objective is also to prove that the proposed enhanced constitutive law can be easily implemented in different types of finite element models $(2 \mathrm{D}, 3 \mathrm{D}$, etc.) in order to simulate the early age behavior of RC concrete structures. Such comparison also allows showing that the multifiber approach is accurate while being less time costly than 2D or 3D finite element models.

\subsubsection{Mesh discretization}

The portal frames were modeled using QUA4 finite elements (with 1 integration Gauss point) for concrete [83] and 1D Navier Bernoulli beam elements for the reinforcements. Both transverse and longitudinal reinforcements were taken into account. The mesh (made 


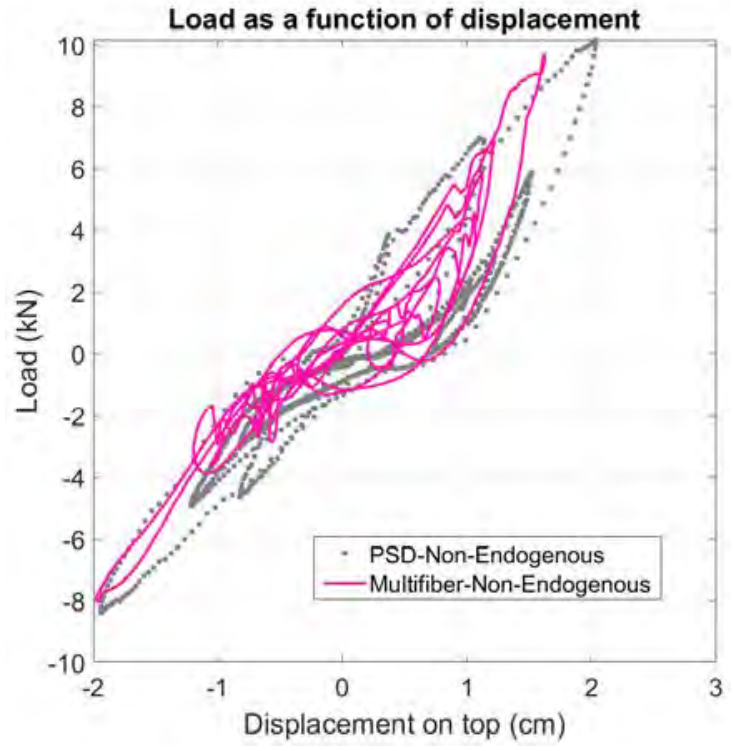

(a)

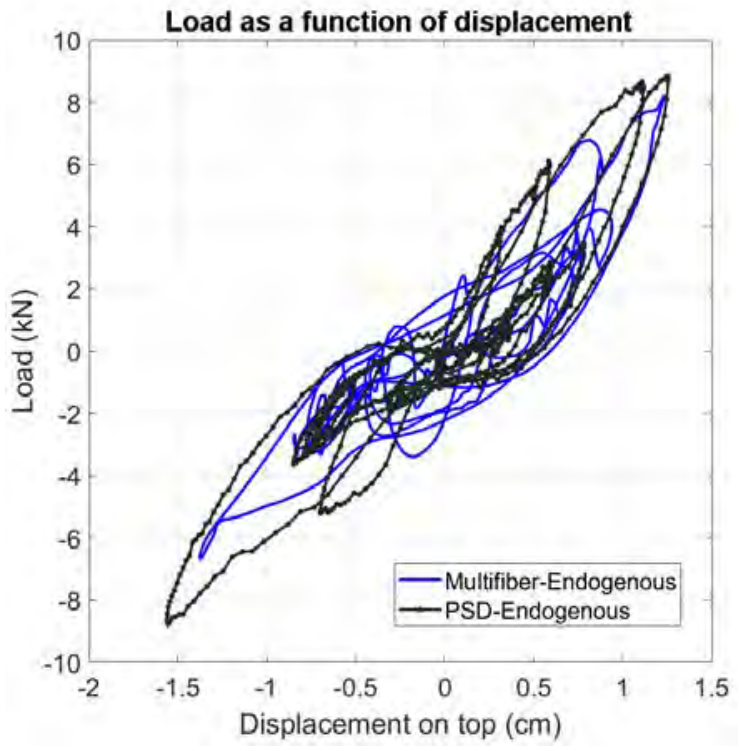

(b)

Figure 3.24: Force as a function of displacement comparison between PsD results and multifiber model in the first group (a) Non-Endogenous (b) Endogenous

of concrete elements and longitudinal rebars) was first defined on the finite element software CAST3M (Figure 3.27), then it was exported to the ATL4S code on Matlab where transverse reinforcements were added (Figure 3.28 gives the mesh discretization used in order to simulate the portal frames).

Transverse rebars were implemented in the numerical model between concrete nodes. Due to the simplified meshing used for transverse rebars, their cross-sectional area was chosen in a way to make sure to have the same density of rebars in the numerical model and in the real structures. The sectional area of transverse rebars was calculated as follow [53]:

$$
A_{\text {transverse }}^{\text {numerical }}=\frac{A_{\text {transverse }}^{\text {real }} \times l_{\text {element }}}{n_{\text {section }} \times s}
$$

Where: $A_{\text {transverse }}^{\text {numerical }}$ is the sectional area of transverse rebars in the $2 \mathrm{D}$ numerical model, $A_{\text {transverse }}^{\text {real }}$ is the area of transverse rebars in built structures, $l_{\text {element }}$ is the length of a beam element in the numerical model, $n_{\text {section }}$ is the number of transvere rebars in the numerical element of lengh $l_{\text {element }}$ and $s$ is the spacing between transverse rebars in the designed portal frames. Therefore, a section of $4.52 \mathrm{~mm}$ was used in the 2D numerical 


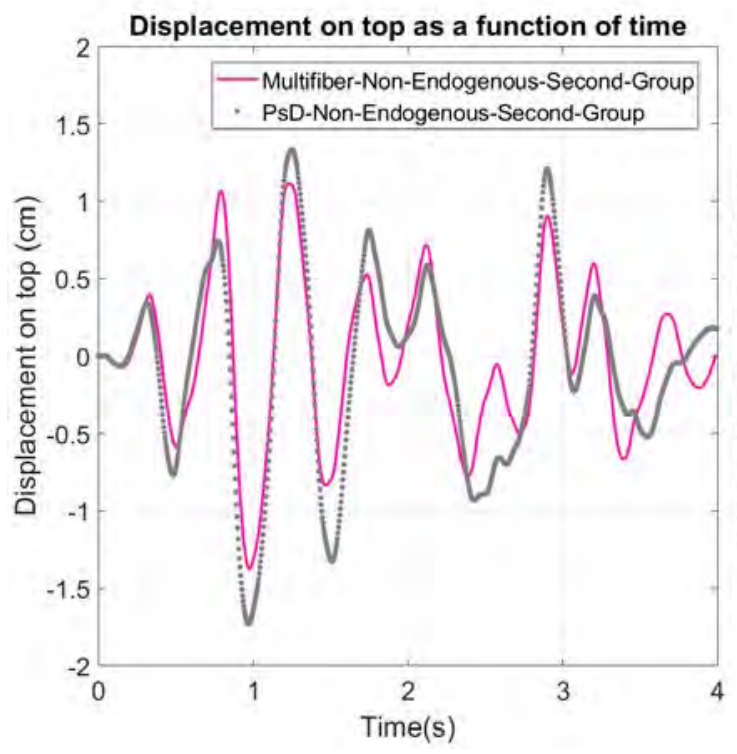

(a)

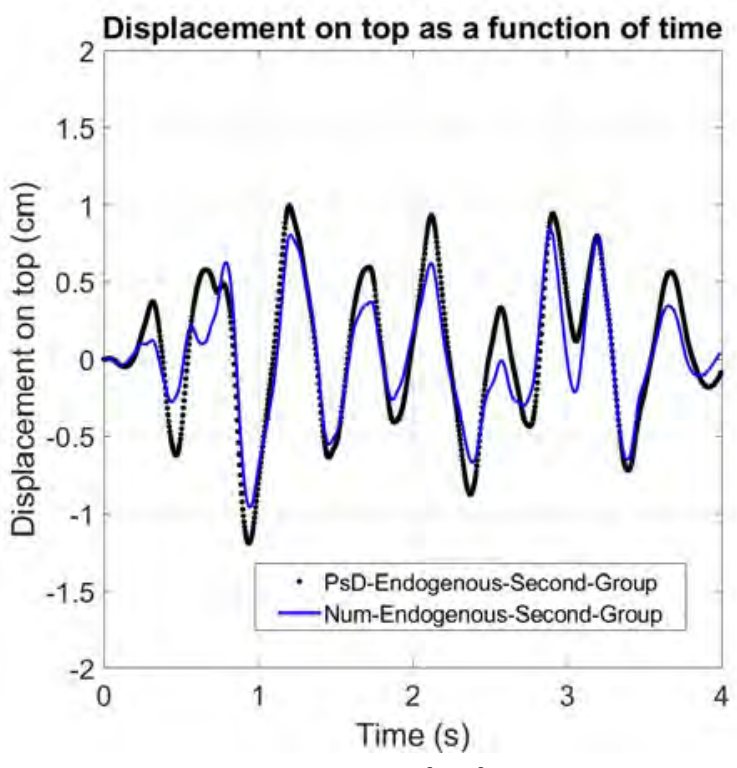

(b)

Figure 3.25: Displacements as a function of time comparison between PsD results and multifiber model in the second group (a) Non-Endogenous (b) Endogenous

model for transverse rebars.

Excentricity of pinned boundary conditions was taken into account by imposing kinematic relations instead of adding rigid elements as in the multifiber model.

\subsubsection{Constitutive laws}

The $\mu$ damage model was used in its 3D formulation [11] (with a plane stress configuration). Thus, in comparison with the multifiber model, $\sigma_{y y}$ was taken into account.

Figure 3.29 shows normal stress versus normal strain curve of concrete used in the 2D model and Table 3.6 gives $\mu$ model parameters used (determined by calibration in order to best feet experimental pushover curves). Tensile and compressive strength of concrete used in the 2D model are slightly heigher than the ones used in the multifiber model (4 MPa versus 2.5 MPa for tensile strength and $38 \mathrm{MPa}$ versus $35 \mathrm{MPa}$ for compressive strength). Such parameters were obtained by calibrating the numerical 2D pushover with experimental curves. The difference between concrete parameters in the 2D model and in the multifiber model could be due to the fact damage is not calculated on a similar way at the joints. The same variability of materials law used in the multifiber model was used in 


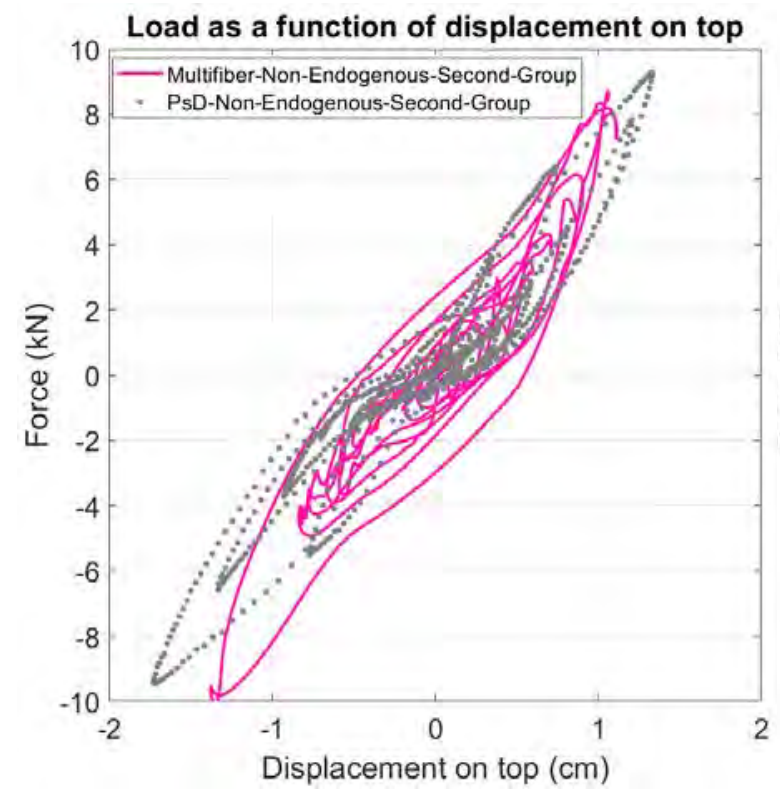

(a)

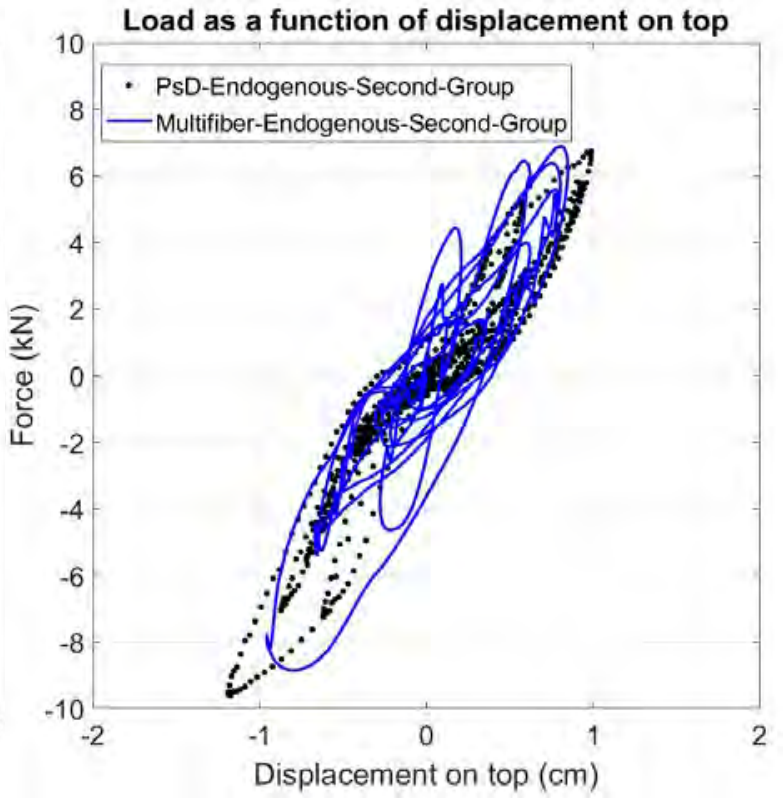

(b)

Figure 3.26: Force as a function of displacement comparison between PsD results and multifiber model in the second group (a) Non-Endogenous (b) Endogenous

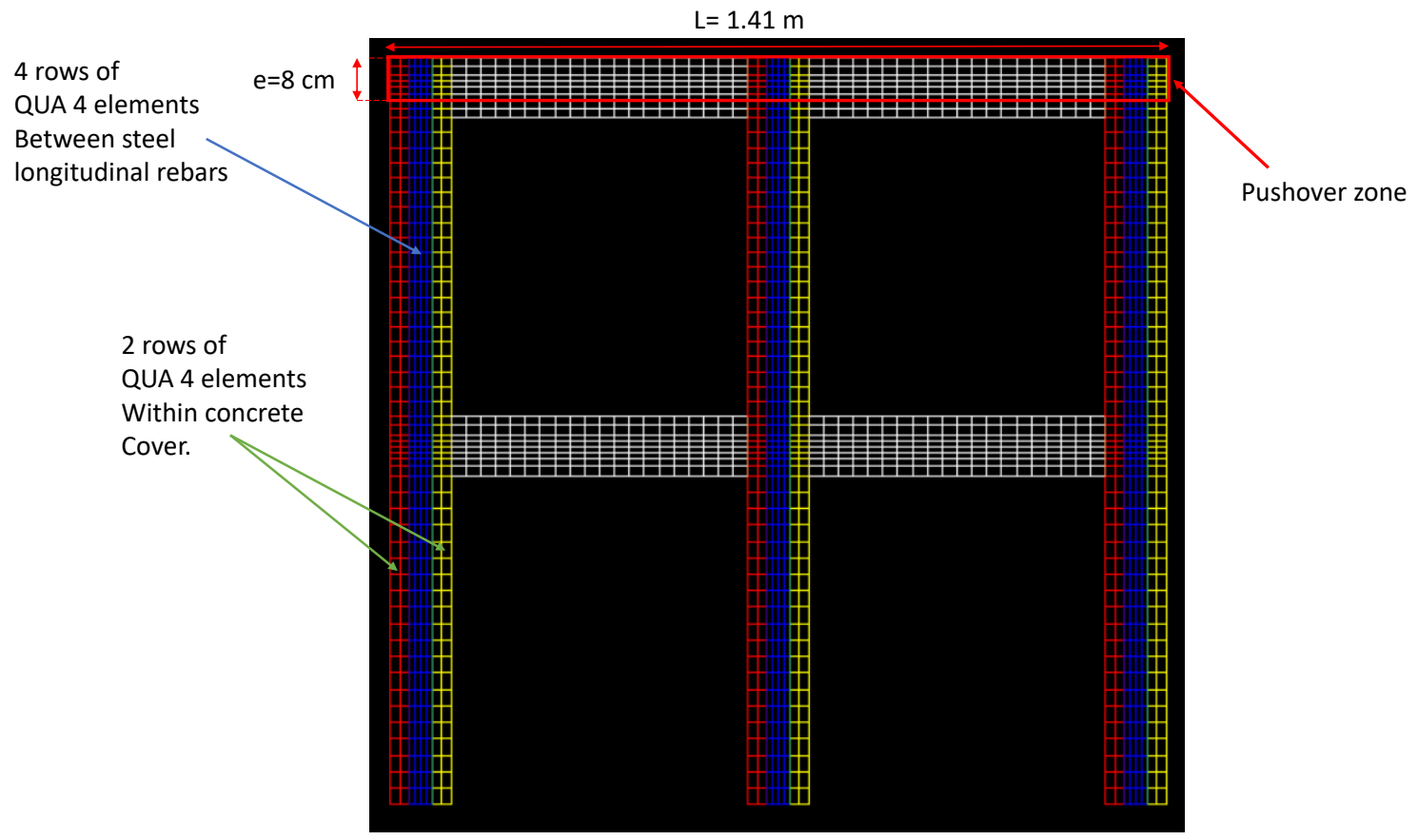

Figure 3.27: 2D Mesh on CAST3M 


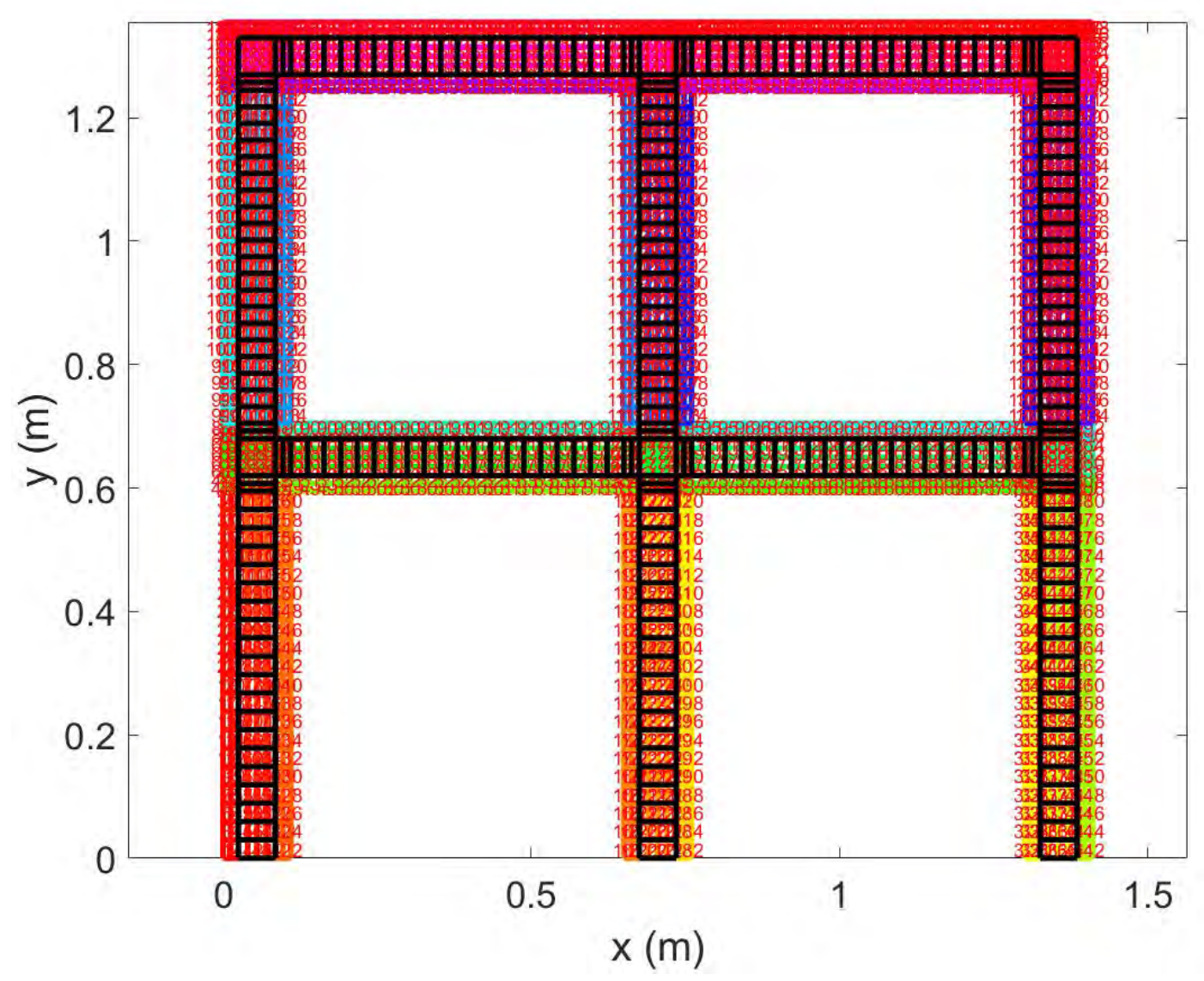

Figure 3.28: 2D Mesh discretization

the $2 \mathrm{D}$ one ( $5 \%$ variability on Young modulus value of the different concrete elements). The constitutive law used for steel is the same Menegetto law with strain hardening used in the multifiber model.

\subsubsection{Early age damage}

Damage evolution of the portal frames was followed during their early age period using the 2D model by imposing as inputs shrinkage and temperature evolutions obtained with COMSOL. Time required to run the early age period of the portal frames using the 2D model is of about 5 hours (with a time step of 2 hours). Due to the geometry of the structures, restrained shrinkage occured in the non-endogenous portal frame towards the joints (which explains cracks observed experimentally at the end of the early age period). In order to account for that in the 2D numerical model, displacements were restrained towards the joints of the non-endogenous portal frame. 


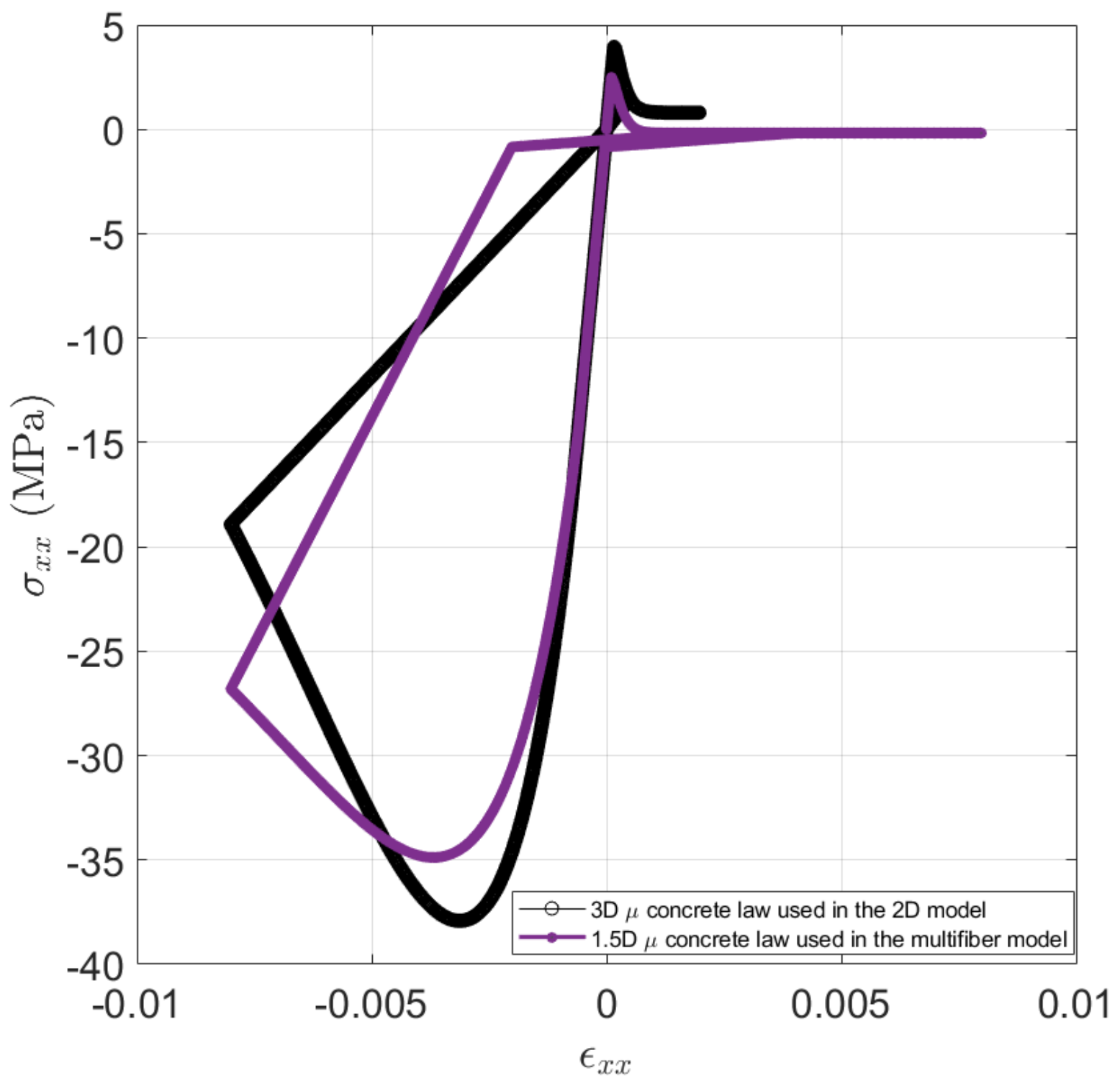

Figure 3.29: Concrete laws used in the 2D model and in the multifiber model. Tensile and compressive strength of concrete used in the 2D model are slightly heigher than the ones used in the multifiber model (4 MPa versus $2.5 \mathrm{MPa}$ for tensile strength and $38 \mathrm{MPa}$ versus $35 \mathrm{MPa}$ for compressive strength)

Damage patterns of the structures at the end of the early age period determined using the 2D model are shown in Figure 3.30. It can be seen that the non-endogenous portal frame got damaged whereas almost no damage was detected numerically in the endogenous portal frame. In the NE portal frame, damage mainly occured at the surface 


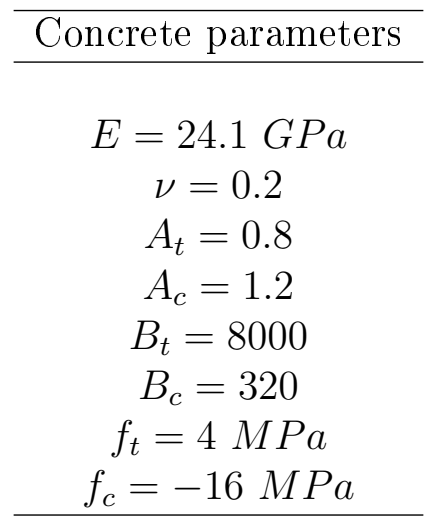

Table 3.6: Concrete parameters used in the 2D model. $E=$ Elastic modulus; $\nu=$ Poisson ratio; $f_{t}$ is the law parameter accounting for tensile strength; $f_{c}$ is the law parameter accounting for compressive strength; $A_{t}=1$ st parameter govering the evolution of damage (traction); $A_{c}=1$ st parameter govering the evolution of damage (compression); $B_{t}=2 \mathrm{nd}$ parameter governing the evolution of damge (traction); $B_{c}=2$ nd parameter governing the evolution of damage (compression)

of the structure and towards the retrained joints. Similarely, the multifiber model also showed damage at the external layers of the NE portal frame.

\subsubsection{Modal Analysis}

A modal analysis was performed using the $2 \mathrm{D}$ model. The 3 mode shapes that were obtained are given in Figure 3.31. They are similar to the ones obtained using the multifiber model.

The first natural frequency of the endogenous portal frame at the end of the early age period calculated with the $2 \mathrm{D}$ model is equal to $5.24 \mathrm{~Hz}$ which is higher than the value obtained experimentally and using the multifiber model $(4.8 \mathrm{~Hz})$. The 2D model is globally stiffer than the multifiber beam model (Table 3.7). It is partially due to the meshing used in the 2D model. In order to obtain better results, it would have been necessary to refine the meshing used. For instance with the meshing presented in Figure 3.32 , the first natural frequency of the endogenous portal frame equals $5.1 \mathrm{~Hz}$. However, due to time and memory issues when performing calculations with a refined mesh, the discretization that was used to launch simulations is the one presented in Figure 3.28 even if it gives a more stiff portal frame. At the end of the early age period, the non-endogenous portal frame first natural frequency obtained using the 2D model was about $2.54 \mathrm{~Hz}$. Again, such frequency is more important than the one obtained both experimentally and using the multifiber approach. However, the difference in frequency between the endogenous and the non-endogenous 
portal frame in $2 \mathrm{D}$ is equal to $51 \%$ which is similar to the difference obtained both experimentally and numerically using the multifiber beam approach (Table 3.7). Stiffness and first natural frequency values of the Non-Endogenous and Endogenous portal frames obtained experimentally and using the numerical models (2D and the multifiber) can be found in Table 3.7 .

\begin{tabular}{ccc}
\hline & $2 \mathrm{D}$ & EXPE/Multifiber \\
\hline Stiffness Endo $(\mathrm{N} / \mathrm{m})$ & $37.3 \times 10^{5}$ & $31 \times 10^{5}$ \\
Stiffness Non-Endo (N/m) & $88 \times 10^{4}$ & $72 \times 10^{4}$ \\
$\%$ Difference Stiffness & 76.4 & 76.8 \\
\hline Frequency Endo (Hz) & 5.24 & 4.8 \\
Frequency Non-Endo (Hz) & 2.55 & 2.3 \\
\% Difference Frequency & 51.4 & 52.1 \\
\hline
\end{tabular}

Table 3.7: Comparison of stiffness and natural frequency values at the end of 28 days between the Endogenous and Non-Endogenous Portal frames (results obtained experimentally and numerically using $2 \mathrm{D}$ and multifiber beam simulations)

\subsubsection{Pushover Analysis}

A pushover analysis was performed numerically using the 2D model of the portal frames at the end of the early age period. In order to achieve that, the same incremental displacement time history used in the multifiber model was imposed at the nodes located at the upper zone of the portal frames delimited by the red rectangular shape in Figure 3.28 (their position was first detected numerically). Time needed to run such simulation is of 1 hour 10 minutes.

Results obtained can be found in Figure 3.33. It can be seen, that the pushovers obtained using the multifiber beam model are closer to experimental values than the ones obtained using the 2D model. Stiffness decrease during the loading obtained with the 2D model is less important than the decrease observed experimentally. Also, the ultimate capacity of the $2 \mathrm{D}$ portal frames is less important than the capacity of the experimentally tested structures.

\subsubsection{Dynamic Analysis}

A non-linear dynamic analysis was performed using the $2 \mathrm{D}$ model (with the same accelerometer used for PsD tests 2.16). Real boundary conditions obtained with digital image correlation were implemented in the model. Time needed to run such analysis is 
around 3 hours.

Results obtained using the 2D model were compared to the ones driven from the multifiber simulations and the PsD tests (Figures 3.34 and 3.35). It can be observed that multifiber model gives results (displacement evolutions and force versus displacement curves) that are closer than the 2D model to experimental ones. This difference can be due to the fact that the $2 \mathrm{D}$ model is stiffer than the multifiber model. Also, the two types of models are not based on the same kinematic approach. A beam kinematic approach seems to reproduce better the behavior of the portal frames under study. Further studies might need to be conducted on the $2 \mathrm{D}$ model.

\subsection{Conclusions}

In this Chapter the numerical model developed for the portal frames was explained. First, the resolution process of the THC problem was shown. Then, a detailed explanation was given of the resolution steps involved when running a multifiber numerical model with enhanced constitutive law. Such model allowed characterizing damage evolution of RC structures during early age and determining their mechanical response when subjected to static or dynamic excitations. It also accounted for experimental boundary conditions (displacement measured using Digital Image Correlation), took into account the variability of materials (Young modulus, compressive and tensile strength), as well as the excentricity of rebars observed experimentally. The model was successfully validated by comparing its results to experimental ones. Indeed, modal, spectral, pushover and dynamic analysis results obtained with the model matched very well experimental results. Then, a $2 \mathrm{D}$ model of the portal frames was proposed. The idea was to extend the work done using the multifiber approach to 3D by using a 3D constitutive law in plane stress to account for damage at the joints. The 2D model also accounted for real boundary conditions determined using digital image correlation. It allowed reproducing the difference of frequency content between the endogenous and the non-endogenous portal frames (50\%) observed experimentally at the end of the early age period. The response of the portal frames when subjected to a static and dynamic loading was roughly reproduced by the $2 \mathrm{D}$ model. The multifiber model reproduced better experimental results than the $2 \mathrm{D}$ model. That later deserves further studies. 

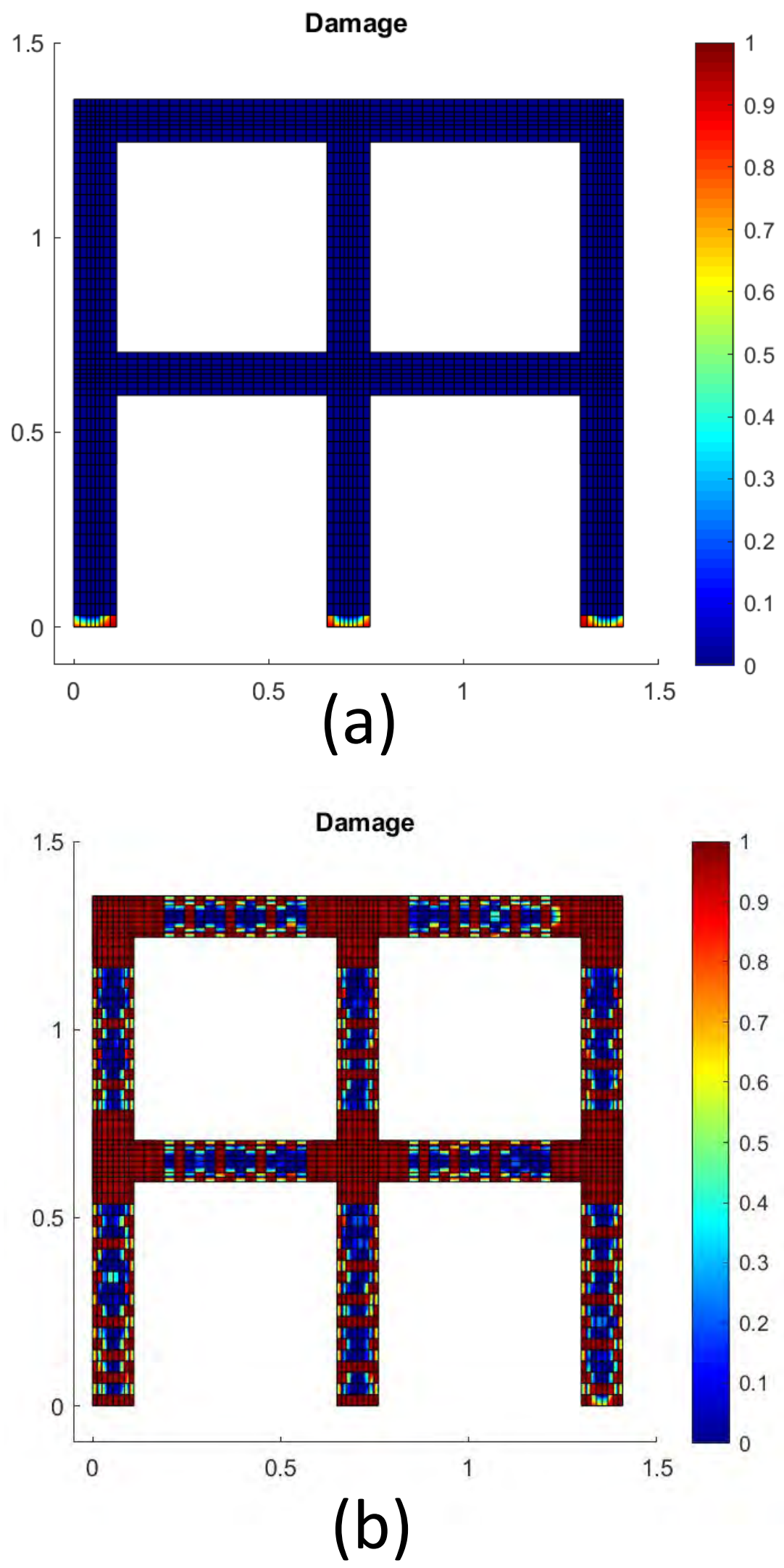

Figure 3.30: 2D damage pattern at the end of the early age period (a) Endogenous (b) Non-Endogenous 138 

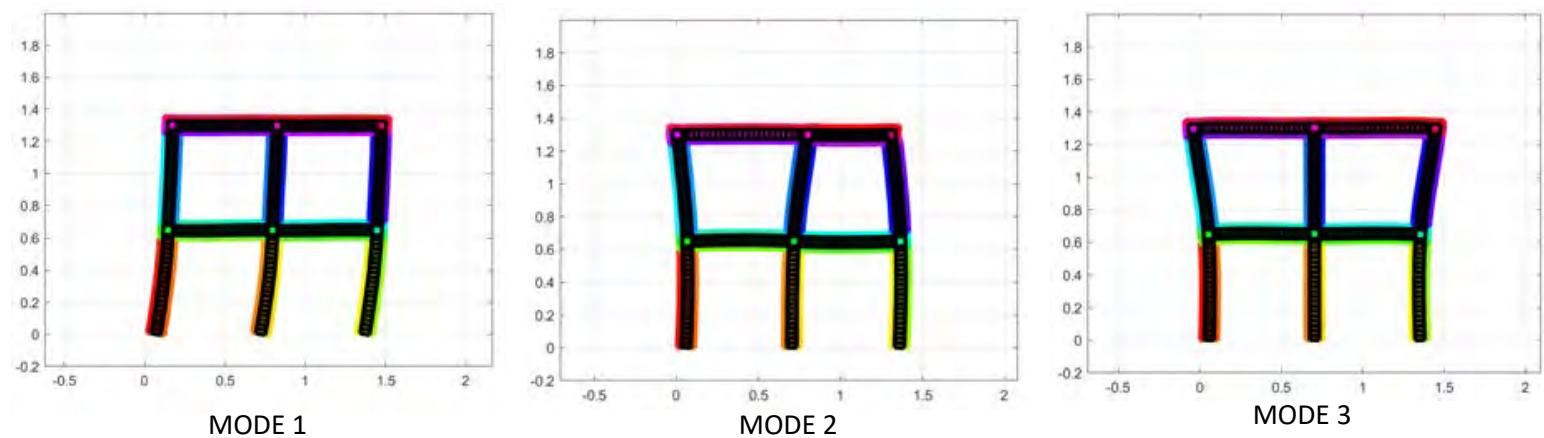

Figure 3.31: 2D mode shapes determined using a modal analysis

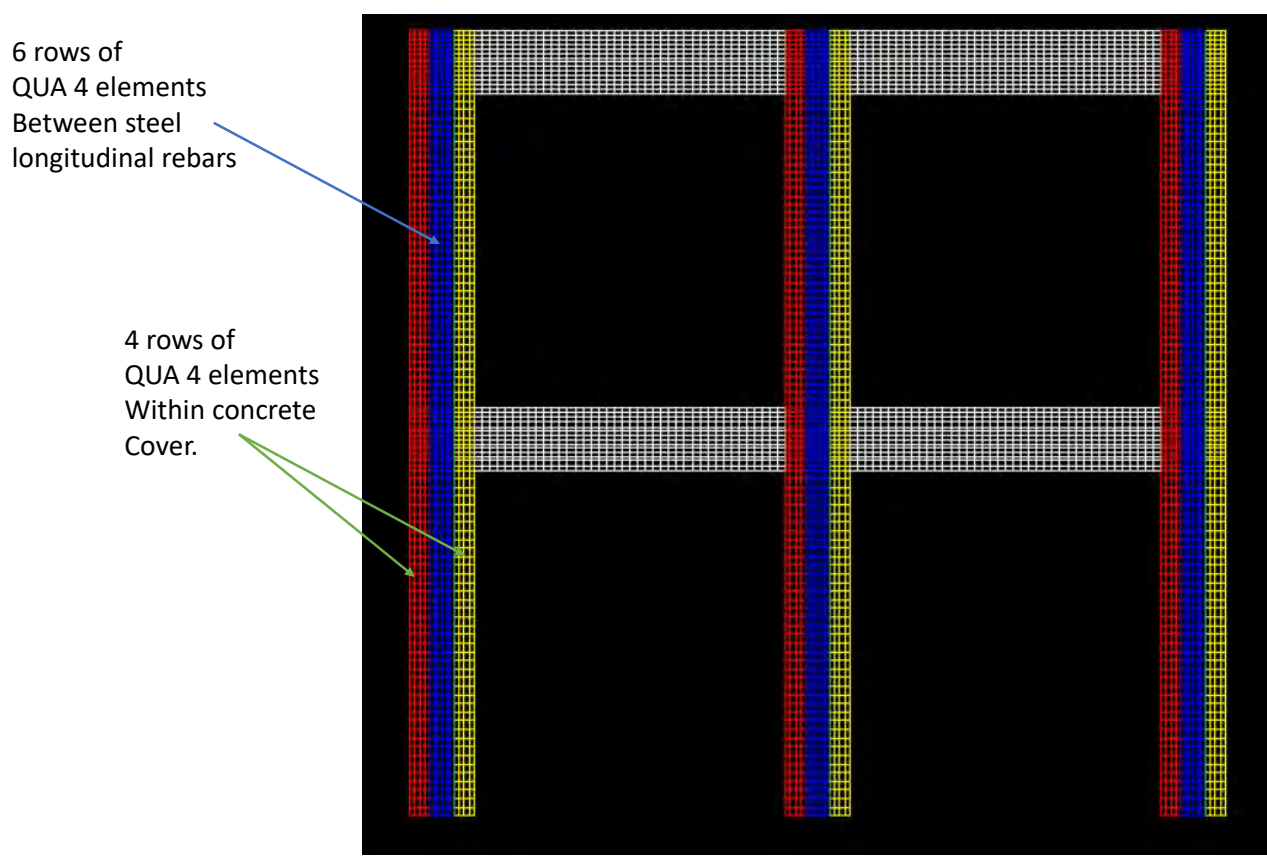

Figure 3.32: 2D more refined mesh 


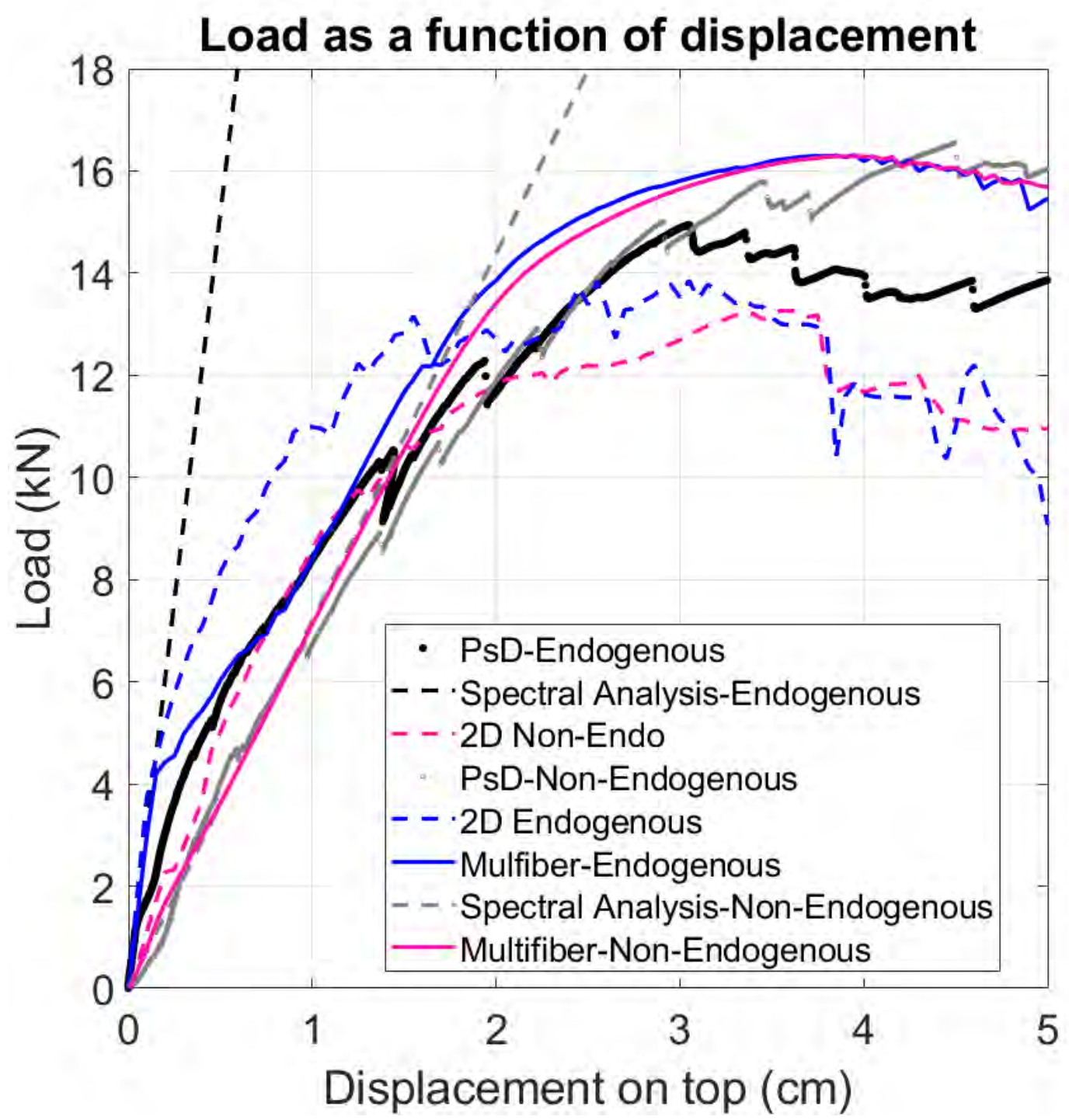

Figure 3.33: Pushover results obtained: experimentally and numerically (using 2D and multifiber models). Spectral analysis curves obtained experimentally are also plotted. 


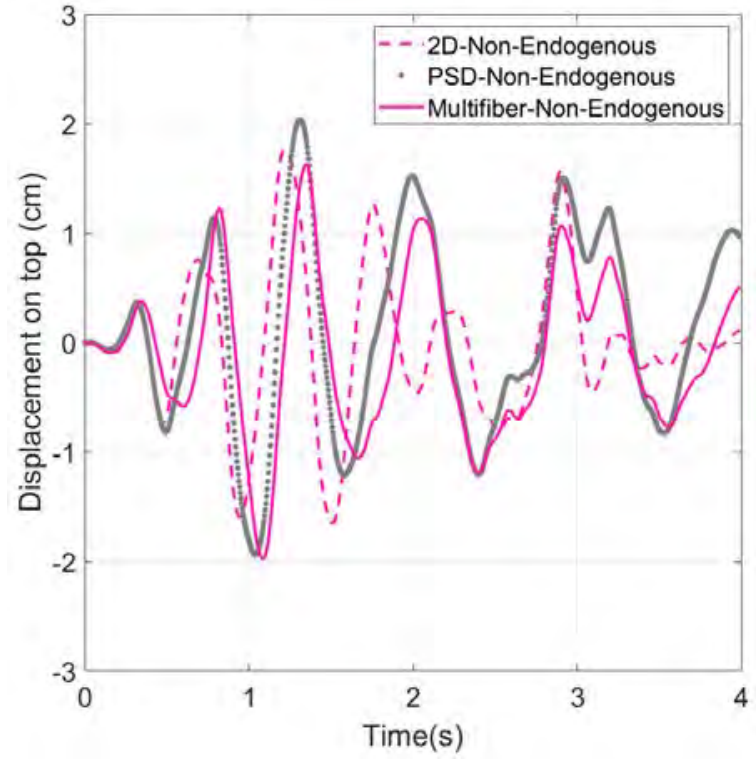

(a)

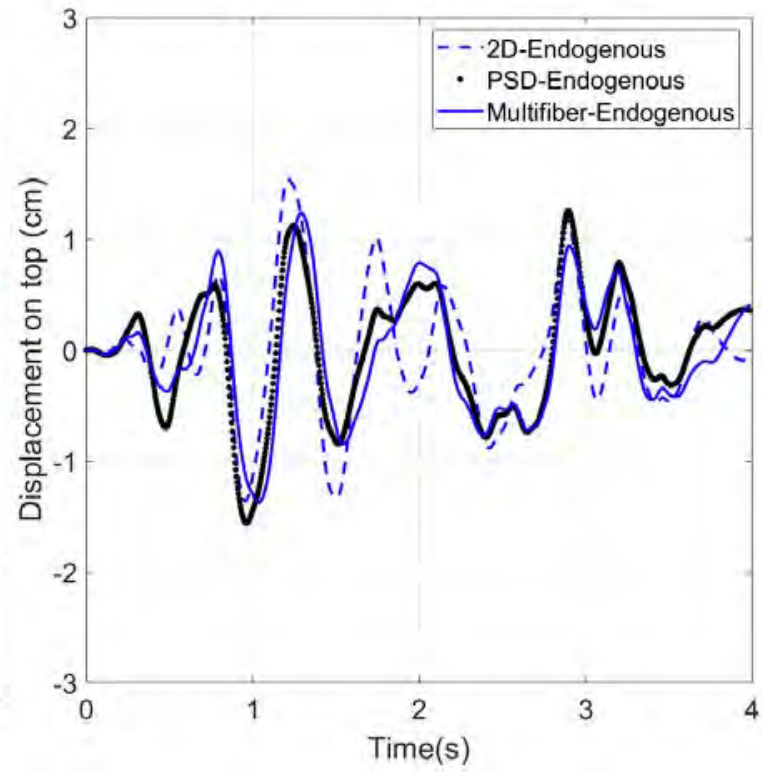

(b)

Figure 3.34: Comparison of the diplacement as a function of time curve obtained using PsD tests, multifiber and 2D simulations (a) Non-Endogenous (b) Endogenous

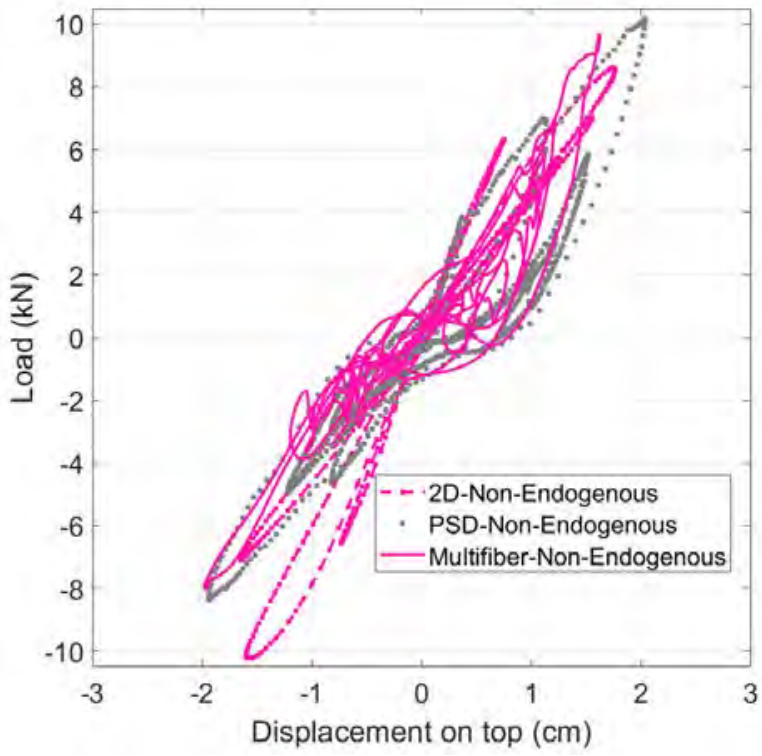

(a)

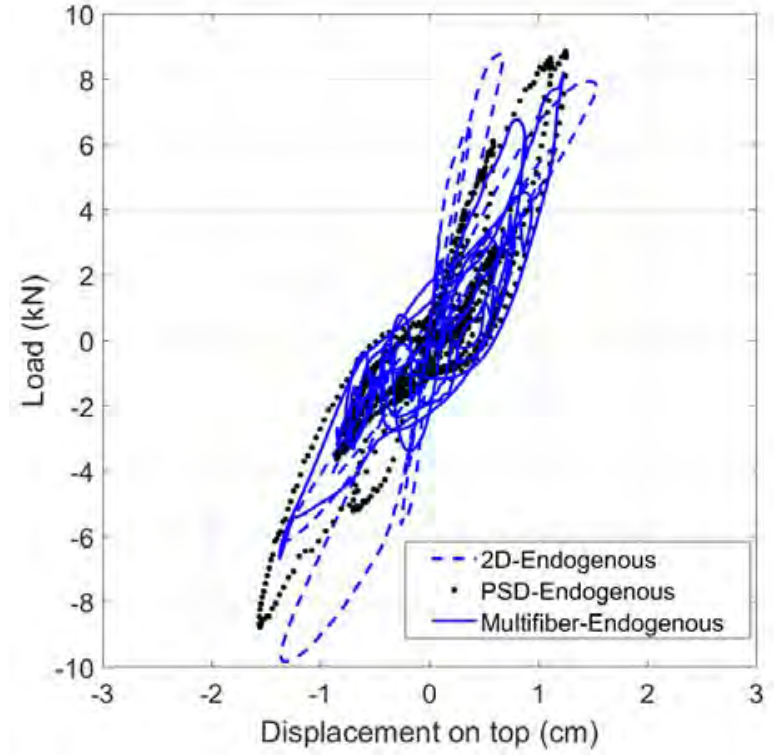

(b)

Figure 3.35: Comparison of the load as a function of diplacement curve obtained using PsD tests, multifiber and 2D simulations (a) Non-Endogenous (b) Endogenous 


\section{General conclusions}

Two types of portal frames that evolved in different conditions during their early age period were constructed in order to evaluate their difference in behavior under seismic loadings. One group was kept at early age in endogenous conditions (to limit drying shrinkage) whereas the second group was kept in non-endogenous conditions. Damage evolution at early age was monitored using optical fiber measurements. Crack openings were more important in the non-endogenous portal frame than in the endogenous one. Then, cyclic and pseudodynamic tests were successfully conducted on the two types of structures at the end of the early age period. Experimentally, a difference in behavior was observed between the two groups for their particular geometry and boundary conditions. Indeed, cyclic test results showed that the force versus displacement curve initial slope of the two portal frames is different (which implies a difference in stiffness and in frequency content). The difference between the curves of the two portal frames also suggested that if they are subjected to a moderate intensity earthquake their behavior will be different. In France, moderate intensity earthquakes are the most commonly occuring type of earthquakes. Therefore, it is important to quantify early age effects when designing structures. Pseudodynamic tests were performed on the two portal frames using a moderate intensity earthquake. A difference in behavior was observed between the two portal frames when drawing their displacement versus time and force versus displacement curves. As a matter of fact, the maximum displacement in the non-endogenous portal frame was $33 \%$ higher than in the endogenous case. Image correlation allowed monitoring crack openings (that occured mainly towards the nodes) during the pseudo-dynamic tests. Then, the enhanced multifiber model that was developped for the portal frames and that allows following their damage during the early age period as well as predicting their dynamic behavior was explained. A comparison between experimental and numerical results were presented and allowed validating the numerical model. The model presented and validated in this thesis can be used in the practice in order to evaluate the impact of early age damage on the seismic behavior of reinforced concrete structures of different geometries, boundary conditions and composition (there is only a need to re-calibrate the THC equations to account for the new concrete composition). 
Studied portal frames are of small scale. Due to their small cross-section, creep and thermal deformations are not important (the gradient of temperature is negligible ). An extension to this work could be studying structures of real size (beams subjected to restrained shrinkage, portal frame joints, etc.) By considering real size structures, it would be possible to experimentally study the effects of creep and thermal deformations at early age on the seismic response of reinforced concrete massive structures where such damage sources are more important. Furthermore, the numerical model that was developed already allows taking into account creep and thermal deformations. Testing structures of real size, will allow to validate or improve the actual model.

In addition, it is possible to further enhance the actual model by taking into account other sources of damage like the effects of corrosion or alkali-granulat reaction. Such sources of damage take place during the aging process of RC structures and can affect considerably their seismic response.

Hydraulic structures such as dams are particularely subjected to alkali granulat and corrosion reactions [84] (example of the hydroelectric complex of Quebec). In fact, as explaned Charlwood [85] in structures where humidity is above $75 \%$ the alkali-granulat reaction is accelerated. Corrosion is also accelerated in environments subjected to agressive agents such as acid or salt [86]. Corrosion and alkali-granulat reactions are the cause of an important decrease of the mechanical strength of RC structures.

By incorporating damage sources such as corrosion or the alkali-granulat reaction in the model, it will be possible to study damage evolution of aging structures and to evaluate their vulnerability when being subjected to hazards such as impacts or earthquakes. Such model will certainly be of great use by ingineers in the context of aging structures.

In order to validate such model it could be possible to compare its results with data provided by site measurements in existing structures.

On a side note, it should be pointed out that so far, the THC model of the portal frames used in order to determine early age shrinkage and temperature evolution was solved using the COMSOL software and then results were incorporated onto a finite element (either multifier or 2D) model in Matlab. It will be interesting to incorporate the THC model directly onto the Matlab plateform to have a more user friendly application. 


\section{Bibliography}

[1] Portland Cement Association. "Types and causes of concrete deterioration." Portland Cement Association: Skokie, IL, USA (2002).

[2] Standard, British. "Eurocode 8: Design of structures for earthquake resistance." Part 1 (2005): 1998-1.

[3] Standard, British. "Eurocode 2: Design of concrete structures?." Part 1-1: General rules and rules for buildings (2004): 230 .

[4] Combescure, Didier, and Pierre Pegon. " $\alpha$-Operator splitting time integration technique for pseudodynamic testing error propagation analysis." Soil Dynamics and Earthquake Engineering 16, no. 7-8 (1997): 427-443.

[5] Nguyen, Hai Trung. "Transfert hydrique dans le milieu poreux réactif: Application à l?étude de séchage d?une pâte pure ettringitique au jeune âge." PhD diss., Université de Lyon, 2018.

[6] Lacarrière, Laurie. "Prévision et évaluation de la fissuration précoce des ouvrages en béton." PhD diss., Toulouse, INSA, 2007.

[7] Mainguy, Marc. "Modèles de diffusion non linéaire en milieux poreux. Applications a la dissolution et au séchage des matériaux cimentaires." PhD diss., 1999.

[8] Coussy, Olivier, Patrick Dangla, Thierry Lassabatère, and Véronique Baroghel-Bouny. "The equivalent pore pressure and the swelling and shrinkage of cement-based materials." Materials and structures 37, no. 1 (2004): $15-20$.

[9] De Schutter, Geert. "Degree of hydration based Kelvin model for the basic creep of early age concrete." Materials and Structures 32, no. 4 (1999): 260.

[10] Briffaut, M., F. Benboudjema, Jean Michel Torrenti, and G. Nahas. "Numerical analysis of the thermal active restrained shrinkage ring test to study the early age behavior of massive concrete structures." Engineering Structures 33, no. 4 (2011): 1390-1401. 
[11] Mazars, Jacky, François Hamon, and Stéphane Grange. "A new 3D damage model for concrete under monotonic, cyclic and dynamic loadings." Materials and Structures 48, no. 11 (2015): 3779-3793..

[12] Réthoré, Julien, François Hild, and Stéphane Roux. "Extended digital image correlation with crack shape optimization." International Journal for Numerical Methods in Engineering 73, no. 2 (2008): 248-272.

[13] Réthoré, J. "Ufreckles." (2018).

[14] Mazars, Jacky, Stéphane Grange, and Matthieu Briffaut. "Simplified modeling strategy for the thermomechanical analysis of massive reinforced concrete structures at an early age." Applied Sciences 8, no. 3 (2018): 448.

[15] Jaafari, Chaimaa, David Bertrand, Tina Guillot, Elodie Prudhomme, Nicolas Tardif, Jean-François Georgin, Fabien Delhomme et al. "Effect of early age drying shrinkage on the seismic response of RC structures." Materials and Structures 53, no. 6 (2020): 1-19.

[16] Maruyama, Ippei. "Multi-scale review for possible mechanisms of natural frequency change of reinforced concrete structures under an ordinary drying condition." Journal of Advanced Concrete Technology 14, no. 11 (2016): 691705

[17] Kurihara, Ryota, Nobuhiro Chijiwa, and Koichi Maekawa. "Thermo-hygral analysis on long-term natural frequency of RC buildings with different dimensions." Journal of Advanced Concrete Technology 15, no. 8 (2017): 381-396.

[18] Chijiwa, Nobuhiro, and Koichi Maekawa. "Thermo-hygral case-study on full scale RC building under corrosive environment and seismic actions." Journal of Advanced Concrete Technology 13, no. 10 (2015): 465-478.

[19] Sasano, Hiroshi, Ippei Maruyama, Akihiro Nakamura, Yoshihito Yamamoto, and Masaomi Teshigawara. "Impact of drying on structural performance of reinforced concrete shear walls." Journal of Advanced Concrete Technology 16, no. 5 (2018): 210-232.

[20] Tanimura, Makoto, Ryoichi Sato, and Yoichi Hiramatsu. "Serviceability performance evaluation of RC flexural members improved by using low-shrinkage high-strength concrete." Journal of Advanced Concrete Technology 5, no. 2 (2007): 149-160. 
[21] Sato, Ryoichi, and Hajime Kawakane. "A new concept for the early age shrinkage effect on diagonal cracking strength of reinforced HSC beams." Journal of Advanced Concrete Technology 6, no. 1 (2008): 45-67.

[22] Nakarai, Kenichiro, Shigemitsu Morito, Masaki Ehara, and Shota Matsushita. "Shear strength of reinforced concrete beams: concrete volumetric change effects." Journal of Advanced Concrete Technology 14, no. 5 (2016): 229-244.

[23] Lampropoulos, A. P., and Stephanos E. Dritsos. "Concrete shrinkage effect on the behavior of $\mathrm{RC}$ columns under monotonic and cyclic loading." Construction and Building Materials 25, no. 4 (2011): 1596-1602.

[24] Gribniak, Viktor, Gintaris Kaklauskas, Romualdas Kliukas, and Ronaldas Jakubovskis. "Shrinkage effect on short-term deformation behavior of reinforced concrete?when it should not be neglected." Materials \& Design 51 (2013): 1060-1070.

[25] McCormac, Jack C., and Russell H. Brown. Design of reinforced concrete. John Wiley \& Sons, 2015.

[26] Kosmatka, Steven H., Beatrix Kerkhoff, and William C. Panarese. Design and control of concrete mixtures. Vol. 5420. Skokie, IL: Portland Cement Association, 2002.

[27] Gilbert, R. I. "Shrinkage, cracking and deflection-the serviceability of concrete structures." Electronic Journal of Structural Engineering 1, no. 1 (2001): 2-14.

[28] Topçu, ?lker Bekir, and Veysel Baran Elgün. "Influence of concrete properties on bleeding and evaporation." Cement and concrete research 34, no. 2 (2004): $275-281$.

[29] Li, Jianyong, and Yan Yao. "A study on creep and drying shrinkage of high performance concrete." Cement and Concrete Research 31, no. 8 (2001): 1203-1206.

[30] A. M. Neville, J. J. Brooks.Concrete Technology. Pearson Education, 2010

[31] Gribniak, Viktor, Gintaris Kaklauskas, Siim Idnurm, and Darius Bacinskas. "Finite element mesh size effect on deformation predictions of reinforced 
concrete bridge girder." The Baltic Journal of Road and Bridge Engineering 5, no. 1 (2010): 19-27.

[32] Le-Bihan, Tina, Jean-Francois Georgin, Marie Michel, Jean Ambroise, and Fabrice Morestin. "Measurements and modeling of cement base materials deformation at early age: The case of sulfo-aluminous cement." Cement and concrete research 42, no. 8 (2012): 1055-1065.

[33] Ghodousi, P., M. H. Afshar, H. Ketabchi, and E. Rasa. "Study of early-age creep and shrinkage of concrete containing Iranian pozzolans: an experimental comparative study." (2009): 126-137.

[34] Kovler, K. "Drying creep of concrete in terms of the age-adjusted effective modulus method." Magazine of Concrete Research 49, no. 181 (1997): 345351.

[35] De Schutter, Geert. "Degree of hydration based Kelvin model for the basic creep of early age concrete." Materials and Structures 32, no. 4 (1999): 260.

[36] Mazars, Jacky. "Application de la mécanique de l'endommagement au comportement non linéaire et à la rupture du béton de structure." THESE DE DOCTEUR ES SCIENCES PRESENTEE A L'UNIVERSITE PIERRE ET MARIE CURIE-PARIS 6 (1984).

[37] Pontiroli, Christophe, Alain Rouquand, and Jacky Mazars. "Predicting concrete behaviour from quasi-static loading to hypervelocity impact: an overview of the PRM model." European Journal of Environmental and Civil Engineering 14, no. 6-7 (2010): 703-727.

[38] Berthet-Rambaud, Philippe. "Structures rigides soumises aux avalanches et chutes de blocs: modélisation du comportement mécanique et caractérisation de l'interaction phénomène-ouvrage." PhD diss., Doctorat sciences et geographie, spécialité: mécanique et génie-civil, Université Joseph Fourier Grenoble I, 2004.

[39] Menegotto, M., and P. E. Pinto. "Method of analysis for cyclically loaded reinforced concrete plane force and bending." In Proceedings, IABSE Symposium on Resistance and Ultimate Deformability of Structures Acted on by Well Defined Repeated Loads, Lisbon, pp. 15-22. 1973. 
[40] Filippou, Filip C., Egor Paul Popov, and Vitelmo Victorio Bertero. "Effects of bond deterioration on hysteretic behavior of reinforced concrete joints." (1983): 137-147.

[41] Hughes, Thomas JR. The finite element method: linear static and dynamic finite element analysis. Courier Corporation, 2012.

[42] Zienkiewicz, Olek C., Robert L. Taylor, and Jian Z. Zhu. The finite element method: its basis and fundamentals. Elsevier, 2005.

[43] Chopra, Anil K. Dynamics of structures. Upper Saddle River, NJ: Pearson Education, 2012.

[44] Tso, W. K., and A. S. Moghadam. "Pushover procedure for seismic analysis of buildings." Progress in Structural Engineering and Materials 1, no. 3 (1998): 337-344.

[45] Kotronis, Panagiotis, Luc Davenne, and Jacky Mazars. "Poutre multifibre Timoshenko pour la modélisation de structures en béton armé: Théorie et applications numériques." Revue française de génie civil 8, no. 2-3 (2004): 329-343.

[46] Mazars, Jacky, Panagiotis Kotronis, Frédéric Ragueneau, and Géraldine Casaux. "Using multifiber beams to account for shear and torsion: Applications to concrete structural elements." Computer Methods in Applied Mechanics and Engineering 195, no. 52 (2006): 7264-7281.

[47] Owen, D. R. J., and E. Hinton. "Finite elements in plasticity: theory and practice. 1980." Swansea, UK: Pineridge Press Limited.

[48] Kotronis, Panagiotis. "Cisaillement dynamique de murs en béton armé. Modèles simplifiés 2D et 3D." PhD diss., 2000.

[49] Capdevielle, Sophie, Stéphane Grange, Frédéric Dufour, and Cédric Desprez. "A multifiber beam model coupling torsional warping and damage for reinforced concrete structures." European Journal of Environmental and Civil Engineering 20, no. 8 (2016): 914-935.

[50] Filippou, F. C., and Margarita Constantinides. "FEDEASLab getting started guide and simulation examples." NEESgrid Report 22 (2004): 2004-05. 
[51] Grange, S. "ATL4S a tool and language for simplified structural solution strategy." Internal Report (2016).

[52] Bitar, Ibrahim, Nathan Benkemoun, Panagiotis Kotronis, and Stéphane Grange. "A multifiber Timoshenko beam with embedded discontinuities." Engineering Fracture Mechanics 214 (2019): 339-364.

[53] Khoder, Natalia. "Enhancement of multifiber beam elements in the case of reinforced concrete structures for taking into account the lateral confinement of concrete due to stirrups." PhD diss., 2018.

[54] Caillerie, Denis, Panagiotis Kotronis, and Robert Cybulski. "A Timoshenko finite element straight beam with internal degrees of freedom." International Journal for Numerical and Analytical Methods in Geomechanics 39, no. 16 (2015): 1753-1773.

[55] Williams, M. S., and A. Blakeborough. "Laboratory testing of structures under dynamic loads: an introductory review." Philosophical Transactions of the Royal Society of London. Series A: Mathematical, Physical and Engineering Sciences 359, no. 1786 (2001): 1651-1669.

[56] Takanashi, Koichi, and Masayoshi Nakashima. "Japanese activities on on-line testing." Journal of Engineering Mechanics 113, no. 7 (1987): 1014-1032.

[57] Shing, Pui-Shum, and Stephen A. Mahin. Pseudodynamic test method for seismic performance evaluation: theory and implementation. Verlag nicht ermittelbar, 1984.

[58] Dermitzakis, Stavros N., and Stephen A. Mahin. "Development of substructuring techniques for on-line computer controlled seismic performance testing." PhD diss., University of California, Berkeley, 1985.

[59] Shing, PuiShum B., Mani T. Vannan, and Edward Cater. "Implicit time integration for pseudodynamic tests." Earthquake Engineering \& Structural Dynamics 20, no. 6 (1991): 551-576.

[60] Thewalt, Christopher Robin, and Stephen A. Mahin. "Hybrid solution techniques for generalized pseudodynamic testing." PhD diss., University of California, Berkeley, 1987. 
[61] Nakashima, Masayoshi, Hiroto Kato, and Eiji Takaoka. "Development of real?time pseudo dynamic testing." Earthquake Engineering \& Structural Dynamics 21, no. 1 (1992): 79-92.

[62] Pinto, A. V., G. Verzeletti, G. Magonette, P. Pegon, P. Negro, and J. Guedes. "Pseudo-dynamic testing of large-scale R/C bridges in ELSA." In 11th World Conference on Earthquake Engineering, pp. 23-28. 1996.

[63] Roux, Stéphane, Julien Réthoré, and François Hild. "Digital image correlation and fracture: an advanced technique for estimating stress intensity factors of 2D and 3D cracks." Journal of Physics D: Applied Physics 42, no. 21 (2009): 214004.

[64] Sutton, Michael A., Stephen R. McNeill, Jeffrey D. Helm, and Yuh J. Chao. "Advances in two-dimensional and three-dimensional computer vision." In Photomechanics, pp. 323-372. Springer, Berlin, Heidelberg, 2000.

[65] Sutton, Michael A., W. J. Wolters, W. H. Peters, W. F. Ranson, and S. R. McNeill. "Determination of displacements using an improved digital correlation method." Image and vision computing 1, no. 3 (1983): 133-139.

[66] Chu, T. C., W. F. Ranson, and Michael A. Sutton. "Applications of digitalimage-correlation techniques to experimental mechanics." Experimental mechanics 25, no. 3 (1985): 232-244.

[67] Grégoire, David. "Initiation, propagation, arrêt et redémarrage de fissures sous impact." PhD diss., 2008.

[68] Dunand, François. "Pertinence du bruit de fond sismique pour la caractérisation dynamique et l'aide au diagnostic sismique des structures de génie civil." PhD diss., 2005.

[69] Cole Jr, Henry A. "On-line failure detection and damping measurement of aerospace structures by random decrement signatures." (1973).

[70] Wen, Q., X. G. Hua, Z. Q. Chen, H. W. Niu, and X. Y. Wang. "AMD-based random decrement technique for modal identification of structures with close modes." Journal of Aerospace Engineering 31, no. 5 (2018): 04018057.

[71] Chatelain, Jean-Luc, Philippe Gueguen, Bertrand Guillier, Julien Frechet, Francis Bondoux, Jacques Sarrault, Pascal Sulpice, and Jean-Marc Neuville. 
"CityShark: A user-friendly instrument dedicated to ambient noise (microtremor) recording for site and building response studies." Seismological Research Letters 71, no. 6 (2000): 698-703.

[72] Bado, Mattia Francesco, Joan Ramon Casas, and António Barrias. "Performance of Rayleigh-based distributed optical fiber sensors bonded to reinforcing bars in bending." Sensors 18, no. 9 (2018): 3125.

[73] EarlyQuake Project, internal report, INSA Lyon, 2020

[74] Mikael, Ali, Philippe Gueguen, Pierre-Yves Bard, Philippe Roux, and Mickael Langlais. "The analysis of longterm frequency and damping wandering in buildings using the Random Decrement Technique." Bulletin of the Seismological Society of America 103, no. 1 (2013): 236-246.

[75] Guéguen, Philippe, Paul Johnson, and Philippe Roux. "Nonlinear dynamics induced in a structure by seismic and environmental loading." The Journal of the Acoustical Society of America 140, no. 1 (2016): 582-590.

[76] Cast3M, C. E. A. "Finite Element Software." (2017)

[77] Baroghel-Bouny, Véronique, M. Mainguy, T. Lassabatere, and Olivier Coussy. "Characterization and identification of equilibrium and transfer moisture properties for ordinary and high-performance cementitious materials." Cement and concrete research 29, no. 8 (1999): 1225-1238.

[78] Bitar, Ibrahim, Stéphane Grange, Panagiotis Kotronis, and Nathan Benkemoun. "A comparison of displacement-based Timoshenko multi-fiber beams finite element formulations and elasto-plastic applications." European Journal of Environmental and Civil Engineering 22, no. 4 (2018): 464-490.

[79] P. Kotronis, J. Mazars. Simplified modelling strategies to simulate the dynamic behaviour of R/C walls. J. Earthq. Eng , 9, 285306, 2005.

[80] Jaafari, Chaimaa, Fabien Delhomme, David Bertrand, Jean-François Georgin, and Stéphane Grange. "Impact of early age damage on the seismic response of reinforced concrete structures." COMPDYN 2019

[81] Mazars, Jacky, and Stephane Grange. "Modeling of reinforced concrete structural members for engineering purposes." Computers and Concrete 16, no. 5 (2015): 683-701. 
[82] Mazars, Jacky, and Stephane Grange. "Modeling of reinforced concrete structural members for engineering purposes." Computers and Concrete 16, no. 5 (2015): 683-701.

[83] Batoz, J. L., and Gouri, Dhatt. "Modélisation des structures par éléments finis: Poutres et plaques (Vol. 2)." Hermès (1990).

[84] Léger, P., P. Côté, and R. Tinawi. "Finite element analysis of concrete swelling due to alkali-aggregate reactions in dams." Computers and structures 60, no. 4 (1996): 601-611.

[85] Charlwood, R. G., S. V. Solymar, and D. D. Curtis. "A review of alkali aggregate reactions in hydroelectric plants and dams." In Proceedings of the international conference of alkali-aggregate reactions in hydroelectric plants and dams, vol. 129. (1992).

[86] Chabbi Radhia,Ferhoune Noureddine, BouabdAllah FouziLa. "Corrosion et les ouvrages en béton armé dans les zones humides en Algérie : cas de wilaya d'Annaba", Conference: Séminaire International de Génie Civil sur les Matériaux cimentaires "SIGC2018" - Ecole Nationale Polytechnique Maurice Audin d'Oran, Algérie (2018) 


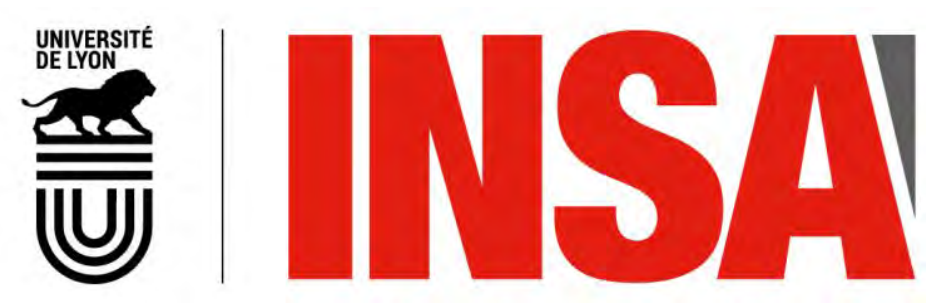

\section{FOLIO ADMINISTRATIF}

\section{THESE DE L'UNIVERSITE DE LYON OPEREE AU SEIN DE L'INSA LYONN}

NOM : JAAFARI

DATE de SOUTENANCE : 27/11/2020

Prénoms : Chaimaa

TITRE : Effect of early age drying shrinkage on the seismic response of RC Structures

NATURE : Doctorat

Numéro d'ordre : 2020LYSEI 113

Ecole doctorale : MEGA

Spécialité : Génie Civil

RESUME : Les structures en béton armé s'endommagent au cours de leur vie à cause de plusieurs facteurs : thermiques, chimiques, retrait, fluage, carbonatation, corrosion. Ces processus débutent dès les premiers jours de la vie de l'ouvrage et continuent lors de son vieillissement. Plus particulièrement, l'endommagement au jeune âge (entre 0 et 28j) peut influencer significativement le comportement dynamique des structures. En effet, leur fréquence propre, peut être fortement réduite à cause de cet endommagement. Afin de déterminer l'influence de l'endommagement dû aux effets du jeûne âge sur la réponse sismique d'une structure en béton armé, ce travail de thèse a combiné à la fois modélisations numériques et essais pseudodynamiques sur deux groupes de portique. Le premier groupe a été gardé en conditions endogènes (échanges hydriques avec l'extérieur empêchés) durant le jeune âge afin de limiter les effets du retrait de séchage (fissuration). Le second groupe a quant à lui été gardé en conditions non-endogènes (échange d'eau avec le milieu extérieur possible) similaires aux conditions de chantier, ce qui a induit un endommagement initial (fissurations) dû notamment à un retrait de séchage plus important. Les deux types de portiques ont été soumis à la fin de leur jeune âge au même chargement sismique modéré au moyen d'essais pseudo-dynamiques. Les structures ont été instrumentées en utilisant de la fibre optique, des capteurs de déplacement et de force ainsi que des vélocimètres et de la corrélation d'image. D'autre part, un modèle numérique en poutres multifibres permettant de suivre l'évolution de leur endommagement au jeune âge mais aussi lors de l'accident sismique a été réalisé. Ce modèle numérique intégré a été validé en le comparant avec l'expérience, permettant de calculer l'évolution de fréquences propres des deux types de structures mais aussi leur différence de comportement dans le domaine non-linéaire afin d'en évaluer leur vulnérabilité.

MOTS-CLÉS : Jeûne Age, Retrait de séchage, Essais Pseudo-dynamiques, Béton Armé, Réponse sismique, Modélisation en Eléments Finis Multifibres, Monitoring, Vulnérabilité sismique.

Laboratoire (s) de recherche : GEOMAS

Directeur de thèse: Stéphane Grange

Président de jury : DARQUENNE Aveline

Composition du jury : DAVENE Luc (Rapporteur), CANDIA Gabriel (Rapporteur), RICHARD Benjamin (Examinateur), DARQUENNE Aveline (Examinatrice), DJERAN MAIGRE Irini (Examinatrice), GRANGE Stéphane (Directeur de thèse), BERTRAND David (Encadrant), DELHOMME Fabien (Encadrant). 